Eduardo Anselmo Garcia

\author{
Avaliação da expressão dos membros da família de \\ fatores de crescimento endotelial vascular e seus \\ receptores e da densidade vascular sanguínea e linfática, \\ em lesões malignas e benignas da tireóide
}

Tese apresentada à Faculdade de Medicina da Universidade de São Paulo para obtenção do título de Doutor em Ciências

Programa de: Fisiopatologia Experimental

Orientador: Prof. Dr. Roberto Souza Camargo

São Paulo

2010 


\section{Dados Internacionais de Catalogação na Publicação (CIP)}

Preparada pela Biblioteca da

Faculdade de Medicina da Universidade de São Paulo

Creprodução autorizada pelo autor

Garcia, Eduardo Anselmo

Avaliação da expressão dos membros da família de fatores de crescimento endotelial vascular e seus receptores e da densidade vascular sanguínea e linfática, em lesões malignas e benignas da tireóide / Eduardo Anselmo Garcia. -- São Paulo, 2010.

Tese(doutorado)--Faculdade de Medicina da Universidade de São Paulo. Programa de Fisiopatologia Experimental.

Orientador: Roberto Souza Camargo.

Descritores: 1.Glândula tireóide 2.Neoplasias da glândula tireóide 3.Angiogênese 4.Linfagiogênese 5.Fator de crescimento do endotélio vascular 6.Receptores de fator de crescimento do endotélio vascular

USP/FM/DBD-439/10 


\section{Dedicatória}

A minha esposa Luciana por todo o amor, sabedoria e cumplicidade. Por toda a inspiração e exemplo de vida que me apaixona;

À minha família, em especial a meu pai Edson, minha mãe Solange e minha irmã Daniela pelo eterno apoio e companheirismo de uma verdadeira família; 
Ao Prof. Dr Roberto Souza Camargo, orientador e amigo, por todos os ensinamentos, confiança e exemplo de caráter neste longo tempo de convívio;

Ao Prof. Dr Oswaldo Alves Mora (in memorian) por todos os ensinamentos e eterna inspiração. 


\section{Agradecimentos}

Ao Prof. Dr Adhemar Longatto Filho da Faculdade de Medicina da Universidade de São Paulo (FMUSP) pelo privilégio do convívio, pela sabedoria compartilhada, prontidão de seu auxílio, entusiasmo e amizade. Por todas as inúmeras colaborações, em especial na confecção desta tese.

Ao Dr Kleber Simões da Divisão de Patologia do Hospital das Clínicas da FMUSP pelo inestimável auxílio na leitura das lâminas, análise estatística e amizade.

Ao Laboratório de Investigação Médica 26 (LIM-26) e a todos os amigos do Departamento de Cirurgia da Disciplina de Técnica Cirúrgica da FMUSP em especial ao Prof. Dr Luiz F. Poli de Figueiredo.

Ao Laboratório de Investigação Médica 14 (LIM-14) da FMUSP, em especial a Alda Wakamatsu, Cinthya Cirqueira e Rodrigo Albergaria Ressio pelo apoio na confecção dos TMAs e imuno-histoquímica. Pelo apoio e amizade.

Ao Prof. Dr Venâncio Avancini Ferreira Alves do Departamento de Patologia da FMUSP e Laboratório de Investigação Médica 14 (LIM-14) pelo apoio e colaboração.

Ao Prof. Dr Hélio Bisi (in memorian) do Departamento de Patologia da FMUSP pelos agradáveis momentos e ensinamentos compartilhados.

Ao Dr Celso Di Loreto da Divisão de Patologia do Instituto Adolfo Lutz pelos sábios ensinamentos e contribuições.

A Prof. Dra Elia Tamaso Espin Garcia Caldini do Departamento de Patologia da FMUSP pela sabedoria compartilhada e amizade. Por despertar em mim a paixão pela biologia celular.

A Prof. Dra Olga Maria de Toledo Corrêa do Departamento de Morfologia da Universidade Federal de São Paulo (UNIFESP) pela admirável 
participação em minha formação acadêmica e por todos os ensinamentos que até hoje carrego.

Ao Prof. Dr Paulo Pinto Joazeiro da Universidade Estadual de Campinas (UNICAMP) pela admirável sabedoria compartilhada e amizade.

Aos amigos da Universidade Santa Cecília por todos os anos de convivência e amizade.

Ao Prof. Ms Adriano Mora Veridiano da Universidade Santa Cecília pelos ensinamentos, companheirismo e grande amizade.

Aos amigos Christopher Alexander Roisin e Eduardo Flávio Portela por uma vida de inestimável apoio e companheirismo. Minha eterna gratidão.

A BD por disponibilizar parte do meu tempo para minha dedicação a esta tese.

Ao meu avô Douglas pelo entusiasmos e exemplo de vida.

A meu sogro Paulo pelos momentos de descontração e felicidade em família. 


\section{NORMATIZAÇÃO}

Esta tese segue as seguintes normas em vigor no momento de sua publicação:

Referências: Foi utilizado o modelo do International Committee of Medical Journals Editors (Vancouver) através do gerenciador bibliográfico Endnote@ X3 (Thompson inc@);

Universidade de São Paulo. Faculdade de Medicina. Serviço de Biblioteca e Documentação. Guia de apresentação de dissertações, teses e monografias. Elaborado por Anneliese Carneiro da Cunha, Maria Julia de A. L. Freddi, Maria F. Crestana, Marinalva de Souza Aragão, Suely Campos Cardoso, Valéria Vilhena. 2a ed. São Paulo: Serviço de Biblioteca e Documentação; 2005;

Abreviaturas dos títulos dos periódicos de acordo com List of Journals Indexed in Index Medicus. 


\section{Sumário}

Lista de abreviaturas

Lista de tabelas

Lista de figuras

Resumo

Summary

1 INTRODUÇÃO. 1

1.1 Os fatores de crescimento endotelial vascular - VEGFs (vascular endothelial growth factor) .......................................4

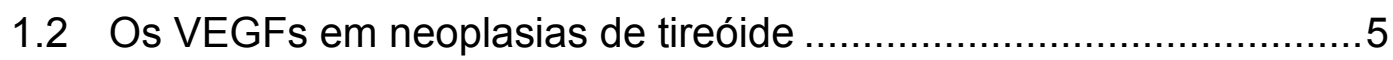

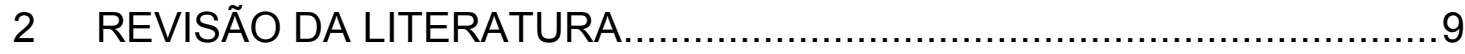

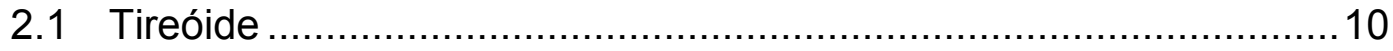

2.1.1 Nódulos Tireoidianos ............................................ 12

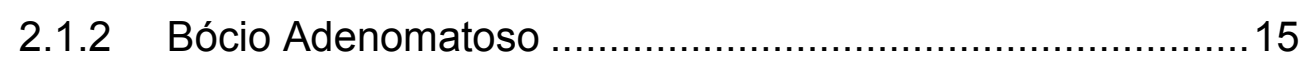

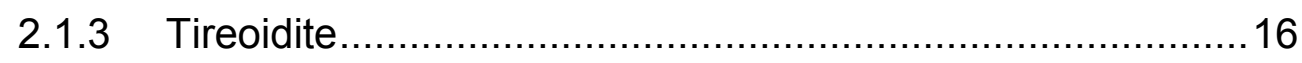

2.1.4 Adenoma .............................................................. 17

2.1.5 Carcinoma Papilífero ................................................ 18

2.1.6 Carcinoma Folicular............................................... 23

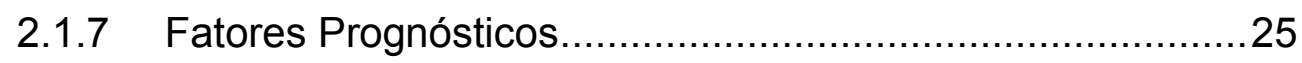

2.2 Angiogênese ..................................................................26

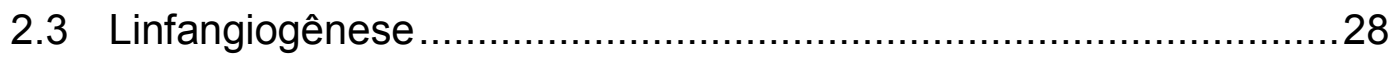

2.4 Os fatores de crescimento endotelial vascular (VEGFs) ................29

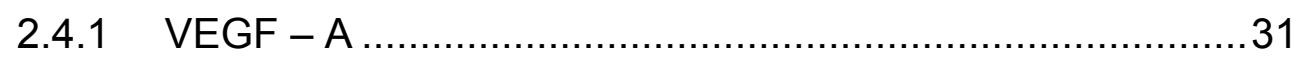

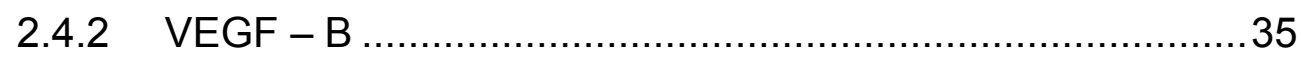

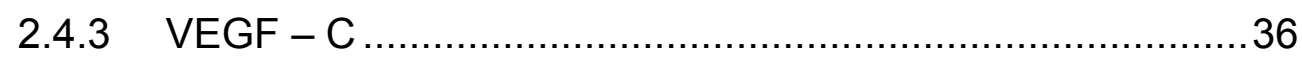

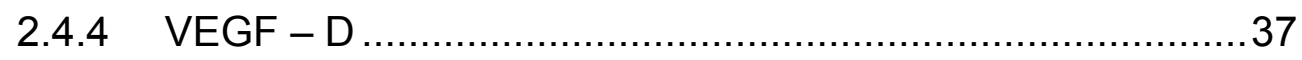

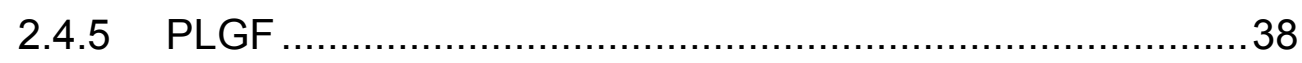

2.5 Os receptores dos fatores de crescimento endotelial vascular (VEGFRs). 
3.1 Objetivos Específicos.

4 MÉTODOS.

4.1 Casuística

4.1.1 Características clínico-patológicas da casuística estudada ...46

4.1.2 Características clínico-patológicas dos Carcinomas Papilíferos estudados

4.1.3 Características clínico-patológicas dos Carcinomas Foliculares estudados

4.1.4 Variáveis idade e sexo nos bócios adenomatosos, tireoidites linfocitárias e adenomas foliculares estudados ......55

4.2 Critérios de exclusão de amostras

4.3 Obtenção de cortes histológicos e método de coloração .................57

4.4 Construção das micromatrizes teciduais (TMA) ..........................59

4.5 Procedimento Imuno-histoquímico ........................................60

4.6 Interpretação das Reações Imuno-histoquímicas das Proteínas da Família VEGF

4.7 Interpretação das Reações Imuno-histoquímicas para avaliação da DVL e DVS

4.8 Aspectos éticos envolvidos

4.9 Análise Estatística

5.1 Expressão imuno-histoquímica dos fatores de crescimento endotelial vascular e de seus receptores nos carcinomas papilíferos estudados

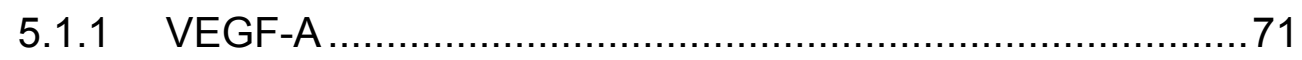

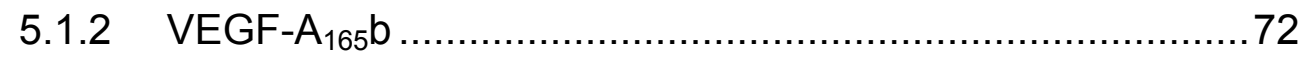

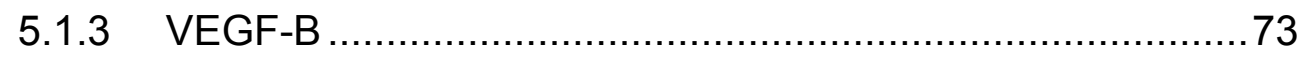

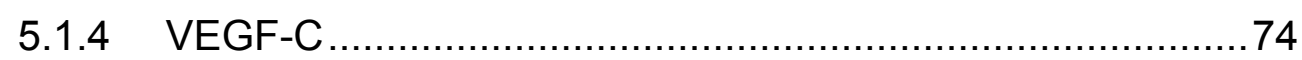

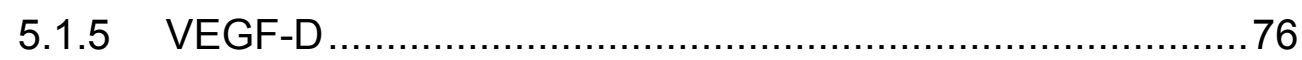

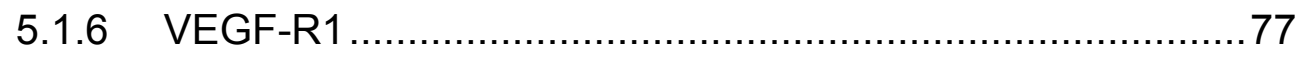

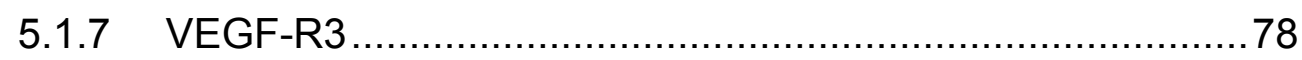


5.2 Expressão imuno-histoquímica, dicotomizada em negativa ou positiva, dos fatores de crescimento endotelial vascular e de seus receptores nos carcinomas papilíferos estudados

5.3 Correlações entre a expressão imuno-histoquímica dos fatores de crescimento endotelial vascular e de seus receptores e as variáveis clínico-patológicas dos carcinomas papilíferos estudados.

5.4 Expressão imuno-histoquímica dos fatores de crescimento endotelial vascular e de seus receptores nos carcinomas foliculares estudados

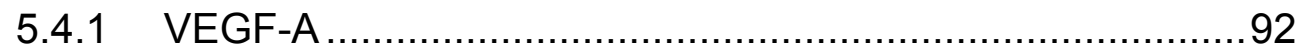

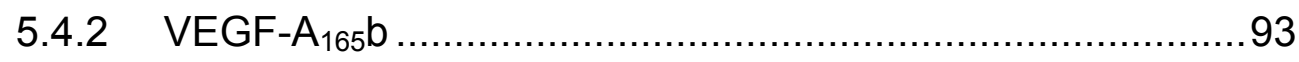

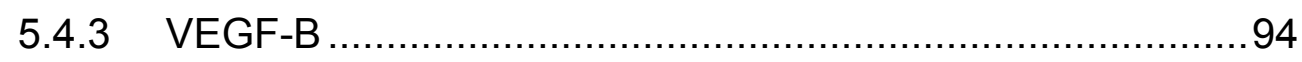

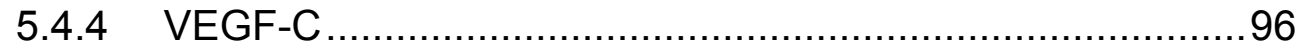

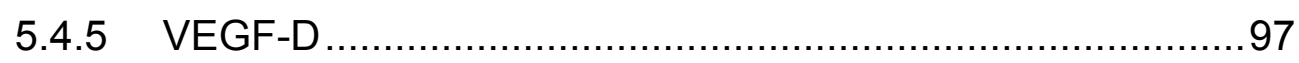

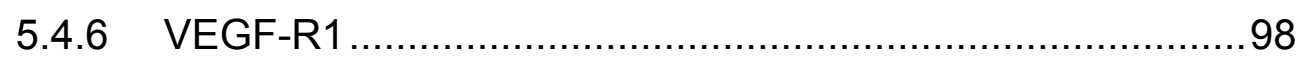

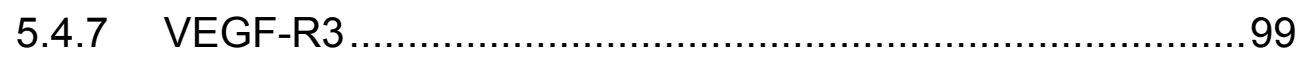

5.5 Expressão imuno-histoquímica, dicotomizada em negativa ou positiva, dos fatores de crescimento endotelial vascular e de seus receptores nos carcinomas foliculares estudados .............................100

5.6 Correlações entre a expressão imuno-histoquímica dos fatores de crescimento endotelial vascular e de seus receptores e as variáveis clínico-patológicas dos carcinomas foliculares estudados .. 104

5.7 Expressão imuno-histoquímica dos fatores de crescimento endotelial vascular e de seus receptores nos bócios adenomatosos, tireoidites linfocitárias e adenomas foliculares estudados

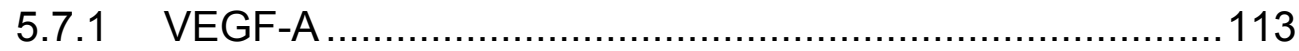

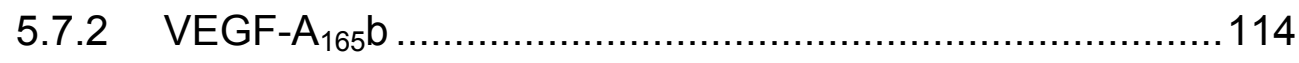

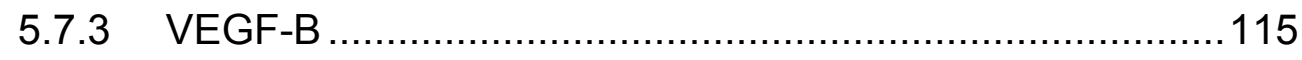

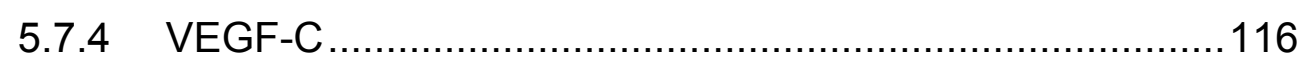

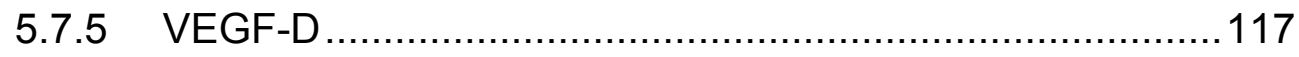

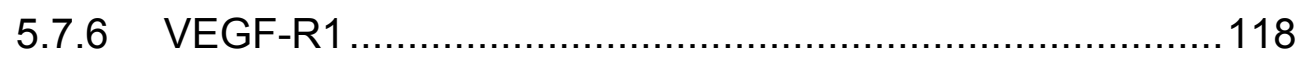

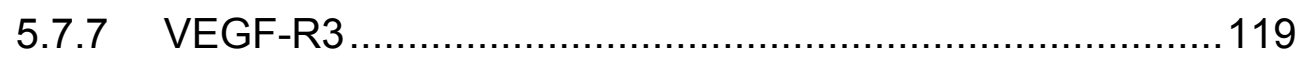


5.8 Expressão imuno-histoquímica, dicotomizada em negativa ou positiva, dos fatores de crescimento endotelial vascular e de seus receptores nos bócios adenomatosos, tireoidites linfocitárias e adenomas foliculares estudados

5.9 Densidades vasculares linfáticas e densidades vasculares sanguíneas dos carcinomas papilíferos, carcinomas foliculares, bócios adenomatosos, tireoidites linfocitárias e adenomas foliculares estudados.

5.9.1 Correlações entre a DVL e DVS total, intra e peritumoral e as variáveis clínico-patológicas dos carcinomas papilíferos estudados

5.9.2 Correlações entre a DVL e DVS total, intra e peritumoral e as variáveis clínico-patológicas dos carcinomas foliculares estudados

5.9.3 Correlações entre a DVL e DVS total, intra e peritumoral $e$ as expressões dos fatores de crescimento endotelial vascular e seus receptores nos carcinomas papilíferos.

5.9.4 Correlações entre a DVL e DVS total, intra e peritumoral $e$ as expressões dos fatores de crescimento endotelial vascular e seus receptores nos carcinomas foliculares

5.9.5 Correlações entre a DVL e DVS total, intra e peritumoral e as expressões dos fatores de crescimento endotelial vascular e seus receptores nos bócios adenomatosos, tireoidites linfocitárias e adenomas foliculares estudados

6.1 Expressão dos VEGFs e VEGFRs nos carcinomas papilíferos e carcinomas foliculares da tireóide.

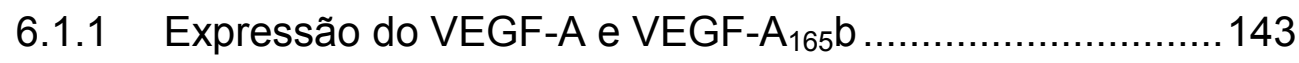

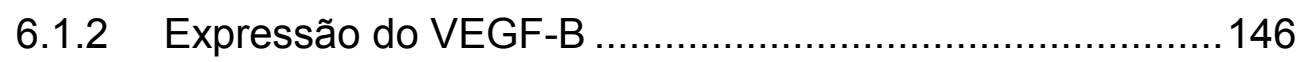

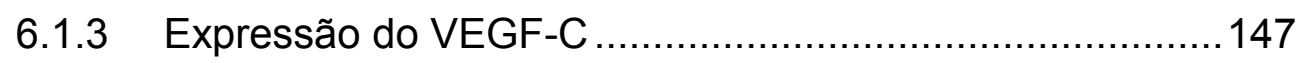

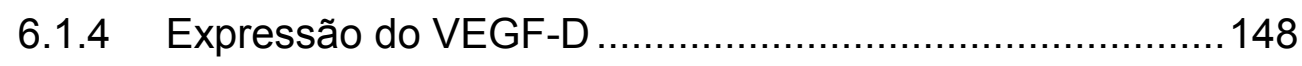

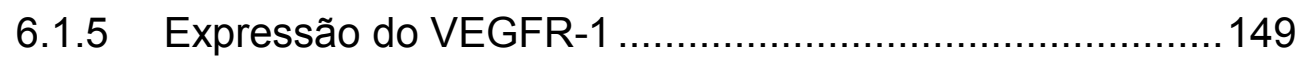

6.1.6 Expressão do VEGFR-3 ..............................................150 
6.2 Valor prognóstico da expressão dos VEGFs e VEGFRs nos carcinomas papilíferos e foliculares da tireóide.

6.3 Expressão dos VEGFs e VEGFRs nos bócios adenomatosos, tireoidites linfocitárias e adenomas foliculares

6.4 A densidade vascular linfática (DVL) e sanguínea (DVS) nos carcinomas papiliferos, carcinomas foliculares, bócios adenomatosos, tireoidites linfocitárias e adenomas foliculares

6.5 Considerações finais

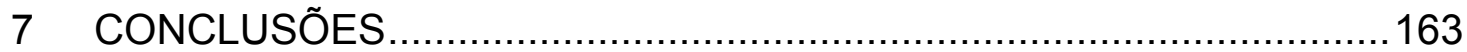

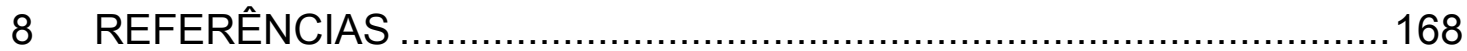

APÊNDICE 


\section{Lista de Abreviaturas}

AGES

AMES

$\mathrm{Bcl} 2$

BRAF

BSA

CAPPesq

cm

DIT

DP

DVL

DVS

F

FDA

H.E

$\mathrm{H}_{2} \mathrm{O}_{2}$

M

MAPK

MEN2A

MEN2B

MIT

mRNA

NP-1

NP-2

p

p53
Age, grade, extracapsular spread, and size

Age, metastasis, extracapsular tumor, and size

B-cell CLL/lymphoma 2

V-raf murine sarcoma viral oncogene homolog B1

Soro albumina bovina

Comissão de ética para análise de projetos de pesquisa

Centímetros

Diiodotironina

Desvio padrão

Densidade vascular linfática

Densidade vascular sanguínea

Feminino

Food Drugs Administration

Hematoxilina eosina

Peróxido de hidrogênio

Masculino

Mitogen activated protein kinase

Multiple endocrine neoplasia $2 A$

Multiple endocrine neoplasia $2 B$

Monoiodotiroxina

Ácido ribonucleico mensageiro

Receptor neuropilin 1

Receptor neuropilin 2

Nível de significância estatística

Tumor protein p53 
PAX8

PBS

PDGF

PLGF

PLGF

PPAR $\gamma$

RET

RTK

SPSS

$\mathbf{T}_{3}$

$\mathrm{T}_{4}$

TMA

TNM

TSH

VEGF-A

VEGF-A $A_{165} b$

VEGF-B

VEGF-C

VEGF-D

VEGF

VEGFR-1 (FIt-1) Receptor de fator de crescimento endotelial vascular 1 (Vascular endothelial growth factor receptor 1)

VEGFR-2 (KDR) Receptor de fator de crescimento endotelial vascular 2 (Vascular endothelial growth factor receptor 2) 
VEGFR-3 (FIt-4) Receptor de fator de crescimento endotelial vascular 3 (Vascular endothelial growth factor receptor 3)

VPF

Fator de permeabilidade vascular

(Vascular permeability factor)

VW

Von Willebrand Factor 


\section{Lista de Tabelas}

Tabela 1 - Causas dos nódulos tireoidianos

Tabela 2 - Sumário da distribuição das variáveis clínico-patológicas registradas

Tabela 3 - Sumário da distribuição das variáveis clínico-patológicas dos carcinomas papilíferos estudados

Tabela 4 - Sumário da distribuição das variáveis clínico-patológicas dos carcinomas foliculares estudados

Tabela 5 - Distribuição das variáveis idade e sexo registradas nos bócios adenomatosos estudados

Tabela 6 - Distribuição das variáveis idade e sexo registradas nas tireoidites linfocitárias estudadas

Tabela 7 - Distribuição das variáveis idade e sexo registradas nos adenomas foliculares estudados

Tabela 8 - Descrição dos anticorpos primários utilizados e suas condições ótimas de trabalho com seus respectivos fabricantes, proteínas alvo, números dos catálogos, clones, métodos utilizados para recuperação antigênica, títulos e kit de revelação

Tabela 9 - Número de amostras avaliadas quanto a expressão imunohistoquímica dos VEGFs e VEGFRs nos carcinomas papilíferos e em suas regiões adjacentes contendo tecido normal, bócio adenomatoso e tireoidite linfocitária

Tabela 10 - Porcentagem de casos com expressão imuno-histoquímica negativa (até 10\%) ou positiva (> do que 10\%) dos VEGFs e VEGFRs nos Carcinomas Papilíferos e suas adjacências apresentando tecido Normal, Bócio Adenomatoso e Tireoidite Linfocitária. 
Tabela 11 - Correlação das variáveis clínico-patológicas e da imunoexpressão do VEGF-A com freqüências absolutas e percentual de casos de acordo com o nível de imunoexpressão nos carcinomas papilíferos

Tabela 12 - Correlação das variáveis clínico-patológicas e da imunoexpressão do VEGF-A $A_{165} \mathrm{~b}$ com freqüências absolutas e percentual de casos de acordo com o nível de imunoexpressão nos carcinomas papilíferos

Tabela 13 - Correlação das variáveis clínico-patológicas e da imunoexpressão do VEGF-B com freqüências absolutas e percentual de casos de acordo com o nível de imunoexpressão nos carcinomas papilíferos

Tabela 14 - Correlação das variáveis clínico-patológicas e da imunoexpressão do VEGF-C com freqüências absolutas e percentual de casos de acordo com o nível de imunoexpressão nos carcinomas papilíferos

Tabela 15 - Correlação das variáveis clínico-patológicas e da imunoexpressão do VEGF-D com freqüências absolutas e percentual de casos de acordo com o nível de imunoexpressão nos carcinomas papilíferos

Tabela 16 - Correlação das variáveis clínico-patológicas e da imunoexpressão do VEGF-R1 com freqüências absolutas e percentual de casos de acordo com o nível de imunoexpressão nos carcinomas papilíferos

Tabela 17 - Correlação das variáveis clínico-patológicas e da imunoexpressão do VEGF-R3 com freqüências absolutas e percentual de casos de acordo com o nível de imunoexpressão nos carcinomas papilíferos

Tabela 18 - Sumário das significâncias das correlações entre a expressão imuno-histoquímica negativa (até 10\%) ou positiva ( $>$ do que 10\%) dos VEGFs e VEGFRs e das variáveis clínico-patológicas dos carcinomas papilíferos estudados 
Tabela 19 - Número de amostras avaliadas quanto a expressão imunohistoquímica dos VEGFs e VEGFRs nos carcinomas foliculares e em suas regiões adjacentes contendo tecido normal, bócio adenomatoso e tireoidite linfocitária

Tabela 20 - Porcentagem de casos com expressão imuno-histoquímica negativa (até $10 \%$ ) ou positiva (> do que $10 \%$ ) dos VEGFs e VEGFRs nos Carcinomas Foliculares e suas adjacências apresentando tecido Normal, Bócio Adenomatoso e Tireoidite Linfocitária

Tabela 21 - Correlação das variáveis clínico-patológicas e da imunoexpressão do VEGF-A com freqüências absolutas e percentual de casos de acordo com o nível de imunoexpressão nos carcinomas foliculares

Tabela 22 - Correlação das variáveis clínico-patológicas e da imunoexpressão do VEGF-A ${ }_{165} b$ com freqüências absolutas e percentual de casos de acordo com o nível de imunoexpressão nos carcinomas foliculares

Tabela 23 - Correlação das variáveis clínico-patológicas e da imunoexpressão do VEGF-B com freqüências absolutas e percentual de casos de acordo com o nível de imunoexpressão nos carcinomas foliculares

Tabela 24 - Correlação das variáveis clínico-patológicas e da imunoexpressão do VEGF-C com freqüências absolutas e percentual de casos de acordo com o nível de imunoexpressão nos carcinomas foliculares

Tabela 25 - Correlação das variáveis clínico-patológicas e da imunoexpressão do VEGF-D com freqüências absolutas e percentual de casos de acordo com o nível de imunoexpressão nos carcinomas foliculares

Tabela 26 - Correlação das variáveis clínico-patológicas e da imunoexpressão do VEGF-R1 com freqüências absolutas e percentual de casos de acordo com o nível de imunoexpressão nos carcinomas foliculares. 
Tabela 27 - Correlação das variáveis clínico-patológicas e da imunoexpressão do VEGF-R3 com freqüências absolutas e percentual de casos de acordo com o nível de imunoexpressão nos carcinomas foliculares

Tabela 28 - Sumário das significâncias das correlações entre a expressão imuno-histoquímica negativa (até 10\%) ou positiva (> do que 10\%) dos VEGFs e VEGFRs e das variáveis clínico-patológicas dos carcinomas foliculares estudados

Tabela 29 - Número de amostras avaliadas quanto a expressão imunohistoquímica dos VEGFs e VEGFRs nos bócios adenomatosos, tireoidites linfocitárias e adenomas foliculares

Tabela 30 - Porcentagem de casos com expressão imuno-histoquímica negativa (até $10 \%$ ) ou positiva (> do que $10 \%$ ) dos VEGFs e VEGFRs nos bócios adenomatosos, tireoidites linfocitárias e adenomas foliculares

Tabela 31 - Freqüência absoluta, média e desvio padrão da DVL e DVS total, intratumoral e peritumoral dos carcinomas papilíferos, carcinomas foliculares e adenomas foliculares e da DVL e DVS total dos bócios adenomatosos e tireoidites linfocitárias.

Tabela 32 - Correlações entre a DVL total, intra e peritumoral e a DVS total intra e peritumoral dos carcinomas papilíferos, carcinomas foliculares e adenomas foliculares estudados .....126

Tabela 33 - Correlações das variáveis clínico-patológicas e da DVL intratumoral, peritumoral e total e da DVS intratumoral, peritumoral e total nos carcinomas papilíferos estudados

Tabela 34 - Correlações das variáveis clínico-patológicas e da DVL intratumoral, peritumoral e total e da DVS intratumoral, peritumoral e total nos carcinomas foliculares estudados

Tabela 35 - Correlação da DVL intratumoral, peritumoral e total e da DVS intratumoral, peritumoral e total com a imunoexpressão dos VEGFs e VEGFRs nos carcinomas papilíferos estudados 
Tabela 36 - Sumário das significâncias das correlações entre a imunoexpressão negativa (até $10 \%$ ) ou positiva (> do que $10 \%$ ) dos VEGFs e VEGFRs e das densidades vasculares linfáticas e sanguíneas dos carcinomas papiliferos estudados

Tabela 37 - Correlação da DVL intratumoral, peritumoral e total e da DVS intratumoral, peritumoral e total com a imunoexpressão dos VEGFs e VEGFRs nos carcinomas foliculares estudados

Tabela 38 - Sumário das significâncias das correlações entre a imunoexpressão negativa (até $10 \%$ ) ou positiva (> do que $10 \%$ ) dos VEGFs e VEGFRs e das densidades vasculares linfáticas e sanguíneas dos carcinomas foliculares estudados

Tabela 39 - Média e desvio padrão da DVL e DVS total dos bócios adenomatosos e tireoidites linfocitárias e DVL e DVS total, intratumoral e peritumoral dos adenomas foliculares estudados

Tabela 40 - Sumário das significâncias das correlações entre a imunoexpressão de 0 a ++++ e negativa (até 10\%) ou positiva ( $>$ do que 10\%) dos VEGFs e VEGFRs e das densidades vasculares linfáticas e sanguíneas nas lesões benignas estudadas. 


\section{Lista de Figuras}

Figura 1. A- Esquema representativo da anatomia básica da glândula tireóide. B- Esquema representativo da morfologia microscópica básica da glândula tireóide. ...............................11

Figura 2. A via de sinalização MAPK é ativada fisiologicamente pela ligação de fatores de crescimento a receptores tirosino quinase (RTKs) como RET, resultando na dimerização do receptor e ativação via autofosforilação dos resíduos de tirosina no domínio intracelular.

Figura 3. Esquema representativo das glicoproteínas da família VEGF, seus receptores e suas interações.

Figura 4. Esquema representativo da estrutura gênica do VEGF-A que apresenta 16.272 pares de bases e fica localizado no cromossomo $6 \mathrm{p} 12$ apresentando oito exons.

Figura 5. Fotomicrografias dos tipos histológicos de lesões tireoidianas estudadas coradas pela Hematoxilina - Eosina. ....49

Figura 6. Expressão imuno-histoquímica do VEGF-A nos Carcinomas Papilíferos e suas adjacências apresentando tecido Normal, Bócio Adenomatoso e Tireoidite Linfocitária

Figura 7. Expressão imuno-histoquímica do VEGF-A $A_{165} \mathrm{~b}$ nos Carcinomas Papilíferos e suas adjacências apresentando tecido Normal, Bócio Adenomatoso e Tireoidite Linfocitária.

Figura 8. Expressão imuno-histoquímica do VEGF-B nos Carcinomas Papilíferos e suas adjacências apresentando tecido Normal, Bócio Adenomatoso e Tireoidite Linfocitária

Figura 9. Expressão imuno-histoquímica do VEGF-C nos Carcinomas Papilíferos e suas adjacências apresentando tecido Normal, Bócio Adenomatoso e Tireoidite Linfocitária

Figura 10. Expressão imuno-histoquímica do VEGF-D nos Carcinomas Papilíferos e suas adjacências apresentando tecido Normal, Bócio Adenomatoso e Tireoidite Linfocitária 
Figura 11. Expressão imuno-histoquímica do VEGF-R1 nos Carcinomas Papilíferos e suas adjacências apresentando tecido Normal, Bócio Adenomatoso e Tireoidite Linfocitária......78

Figura 12. Expressão imuno-histoquímica do VEGF-R3 nos Carcinomas Papilíferos e suas adjacências apresentando tecido Normal, Bócio Adenomatoso e Tireoidite Linfocitária .......79

Figura 13. Fotomicrografias dos padrões de imunoexpressão do VEGF-A, VEGF-A ${ }_{165} b$, VEGF-B, VEGF-C, VEGF-D, VEGF-R1 e VEGF-R3 nos carcinomas papiliferos

Figura 14. Expressão imuno-histoquímica do VEGF-A nos Carcinomas Foliculares e suas adjacências apresentando tecido Normal, Bócio Adenomatoso e Tireoidite Linfocitária

Figura 15. Expressão imuno-histoquímica do VEGF-A ${ }_{165} b$ nos Carcinomas Foliculares e suas adjacências apresentando tecido Normal, Bócio Adenomatoso e Tireoidite Linfocitária......94

Figura 16. Expressão imuno-histoquímica do VEGF-B nos Carcinomas Foliculares e suas adjacências apresentando tecido Normal, Bócio Adenomatoso e Tireoidite Linfocitária

Figura 17. Expressão imuno-histoquímica do VEGF-C nos Carcinomas Foliculares e suas adjacências apresentando tecido Normal, Bócio Adenomatoso e Tireoidite Linfocitária

Figura 18. Expressão imuno-histoquímica do VEGF-D nos Carcinomas Foliculares e suas adjacências apresentando tecido Normal, Bócio Adenomatoso e Tireoidite Linfocitária

Figura 19. Expressão imuno-histoquímica do VEGF-R1 nos Carcinomas Foliculares e suas adjacências apresentando tecido Normal, Bócio Adenomatoso e Tireoidite Linfocitária.

Figura 20. Expressão imuno-histoquímica do VEGF-R3 nos Carcinomas Foliculares e suas adjacências apresentando tecido Normal, Bócio Adenomatoso e Tireoidite Linfocitária ....100

Figura 21. Fotomicrografias dos padrões de imunoexpressão do VEGF-A, VEGF-A 165 b, VEGF-B, VEGF-C, VEGF-D, VEGF-R1 e VEGF-R3 nos carcinomas foliculares 
Figura 22. Expressão imuno-histoquímica do VEGF-A nos Bócios Adenomatosos, Tireoidites Linfocitárias e Adenomas Foliculares

Figura 23. Expressão imuno-histoquímica do VEGF-A $\mathrm{A}_{165} \mathrm{~b}$ nos Bócios Adenomatosos, Tireoidites Linfocitárias e Adenomas Foliculares

Figura 24. Expressão imuno-histoquímica do VEGF-B nos Bócios Adenomatosos, Tireoidites Linfocitárias e Adenomas Foliculares

Figura 25. Expressão imuno-histoquímica do VEGF-C nos Bócios Adenomatosos, Tireoidites Linfocitárias e Adenomas Foliculares

Figura 26. Expressão imuno-histoquímica do VEGF-D nos Bócios Adenomatosos, Tireoidites Linfocitárias e Adenomas Foliculares

Figura 27. Expressão imuno-histoquímica do VEGF-R1 nos Bócios Adenomatosos, Tireoidites Linfocitárias e Adenomas Foliculares

Figura 28. Expressão imuno-histoquímica do VEGF-R3 nos Bócios Adenomatosos, Tireoidites Linfocitárias e Adenomas Foliculares

Figura 29. Fotomicrografias dos padrões de imunoexpressão do VEGF-A, VEGF-A 165 b, VEGF-B, VEGF-C, VEGF-D, VEGF-R1 e VEGF-R3 nos bócios adenomatosos, tireoidites linfocitárias e adenomas foliculares.

Figura 30. Média da DVL e DVS total nos diferentes tipos de lesões tireoidianas estudadas 


\section{Resumo}

Garcia EA. Avaliação da expressão dos membros da família de fatores de crescimento endotelial vascular e seus receptores e da densidade vascular sanguínea e linfática, em lesões malignas e benignas da tireóide [tese]. São Paulo: Faculdade de Medicina, Universidade de São Paulo; 2010. 180p.

As neoplasias tireoidianas são importante causa de morbi-mortalidade. A patogênese da disseminação neoplásica pelo organismo é um complexo e intrigante processo pelo qual grande parte das neoplasias malignas se dissemina, a partir de um sítio de origem, para diferentes partes do organismo, utilizando como vias preferenciais os sistemas vasculares venoso e linfático. A expressão dos fatores de crescimento endotelial vascular e de seus receptores (VEGFs e VEGFRs) estão relacionados à angiogênese e linfangiogênese tumoral participando do diagnóstico, avaliação prognostica e tratamento de neoplasias malignas. O papel da angiogênese e da linfangiogênese na patogênese dos cânceres de tireóide ainda não foi completamente desvendado. Os diferentes padrões de comportamento dos tumores tireoidianos e de suas metástases variam de acordo com o tipo de tumor e ainda não foi completamente explorado se diferenças na expressão dos VEGFs e VEGFRs influenciam a metástase tumoral ou determinam um comportamento mais agressivo. Na presente tese, avaliamos a expressão imuno-histoquímica dos VEGFs e VEGFRs e a densidade vascular sanguínea e linfática nos bócios adenomatosos, tireoidites linfocitárias e adenomas foliculares, bem como nos carcinomas papilíferos e foliculares e suas regiões adjacentes. Posteriormente, correlacionamos nossos achados com os dados clínico-patológicos. Observamos que há um crescimento gradual na intensidade da expressão dos VEGFs e VEGFRs a partir do tecido tireoidiano com fenótipo normal, lesões proliferativas benignas e neoplasias malignas. Nos carcinomas, apesar da profusa expressão dos VEGFs e VEGFRs detectamos correlação estatisticamente significativa apenas do VEGF-D e VEGF-R3 com um pior estadiamento tumoral nos carcinomas papilíferos. A densidade vascular sanguínea foi superior a densidade vascular linfática em todas as lesões estudadas sendo que os carcinomas foliculares apresentaram a maior densidade vascular sanguínea e as tireoidites linfocitárias a maior densidade vascular linfática. Nos carcinomas papilíferos uma menor densidade vascular sanguínea está associada a invasão vascular e a diferença de perfil linfangiogênico entre adenomas foliculares e carcinomas foliculares pode ser uma nova ferramenta na diferenciação destas categorias diagnósticas.

Descritores: 1.Angiogênese 2.Linfagiogênese 3.Glândula tireóide 4.Neoplasias da glândula tireóide 5.Fator de crescimento do endotélio vascular 6.Receptores de fator de crescimento do endotélio vascular 


\section{Summary}

Garcia EA. Evaluation of the family members of vascular endothelial growth factors and their receptors and blood and lymphatic vascular density in malignant and benign thyroid lesions [thesis]. São Paulo: "Faculdade de Medicina, Universidade de São Paulo"; 2010. 180p.

The thyroid neoplasms are important causes of morbi-mortality. The pathogenesis of the neoplastic dissemination through the organism is a complex and intriguing process by which many malignancies spreads from a site of origin to different parts of the body, using as preferential routes the venous and lymphatic vascular systems. The expression of vascular endothelial growth factors and their receptors (VEGFs and VEGFRs) are related to tumor angiogenesis and lymphangiogenesis participating in the diagnosis, prognostic evaluation and treatment of malignant neoplasms. The role of angiogenesis and lymphangiogenesis in the pathogenesis of thyroid cancers has not been completely elucidated. The different patterns of behavior of thyroid tumors and their metastases vary with the tumoral type and have not yet been fully explored whether differences in the expression of VEGFs and VEGFRs influence tumor metastasis or determine a more aggressive behavior. In this thesis, we evaluated the immunohistochemical expression of VEGFs and VEGFRs and the blood and lymphatic vascular density in goiter, thyroiditis and follicular adenomas and in papillary and follicular carcinomas and their adjacent regions. Afterward, we correlated our findings with the clinical pathological data. We observe that there is a gradual increase in intensity of expression of VEGFs and VEGFRs from normal thyroid tissue, proliferative lesions, benign and malignant neoplasms. In carcinomas, despite the profuse expression of VEGFs and VEGFRs we detected only statistically significant correlation of VEGF-D and VEGF-R3 with a worse tumor staging in papillary carcinomas. The blood vessel density was higher than lymphatic vascular density in all lesions studied. The follicular carcinomas showed the highest blood vessel density and thyroiditis the largest lymphatic vascular density. In the papillary carcinomas a lower blood vessel density was associated with vascular invasion and the different lymphangiogenic profiles between follicular adenomas and follicular carcinomas may be a new tool in differentiating these diagnostic categories.

Descriptors: 1.Angiogenesis 2.Lymphagiogenesis 3.Thyroid gland 4.Thyroid neoplasms 5.Vascular endothelial growth factor 6.Receptors, vascular endothelial growth factor 
A patogênese da disseminação neoplásica é um tema que tem atraído a atenção de pesquisadores por quase um século (1) A metástase é um complexo e intrigante processo pelo qual grande parte das neoplasias malignas se dissemina, a partir de um sítio de origem, para diferentes partes do organismo, utilizando como vias preferenciais os sistemas vasculares venoso e linfático.

Essa característica é a principal causa de mortalidade por câncer, posto que o potencial de disseminação condiciona o prognóstico e a sobrevida dos pacientes (2).

A partir dos anos setenta, os postulados de Folkman (3) mostraram que a angiogênese é um processo crucial no entendimento da biologia do câncer, primeiro por seu papel essencial à proliferação neoplásica para suprir a demanda de energia necessária ao crescimento tumoral, e por apresentar-se como importante alvo terapêutico. Em decorrência dessas observações, o estudo da angiogênese apresentou um rápido e consistente desenvolvimento. As células requerem oxigênio e nutrientes para sobreviverem e o limite de difusão está ao redor de 100 a $200 \mu \mathrm{m}$ dos vasos sangüíneos. Para as células neoplásicas crescerem, além disso, é necessário a neoformação vascular. Em condições neoplásicas, esses novos vasos podem crescer a partir de células endoteliais pré-existentes ou pelo recrutamento de células precursoras da medula óssea, e fornecem o 
substrato necessário para o crescimento e disseminação das células neoplásicas (4).

As neoplasias humanas podem, no entanto permanecer quiescentes por anos devido ao balanço entre ativadores e inibidores da angiogênese, permitindo o estabelecimento de um equilíbrio entre proliferação e apoptose celular. Por terem uma meia-vida muito longa, os inibidores de angiogênese podem exceder aos estimuladores e assim inibir o crescimento metastático em órgãos distantes do tumor primário. Esta premissa norteou a hipótese de alvos terapêuticos baseados na inibição específica da angiogênese, como por exemplo, as angiostatinas e as endostatinas $(5,6)$.

Um dos primeiros fármacos utilizado como inibidor da angiogênese aprovado pelo Food Drugs Administration (FDA) foi o anticorpo monoclonal Avastin (bevacizumabe), que inibe a atividade de um dos principais ativadores da angiogênese, o vascular endothelial growth factor (VEGF). Este inibidor é atualmente utilizado para tratamento de primeira linha de câncer colo-retal metastático (7). Vários outros agentes anti-angiogênicos já foram aprovados pelo FDA ou encontram-se em clinical trials (8).

As regulações da vasculogênese, hematopoiese, angiogênese, linfangiogênese e permeabilidade vascular são muito complexas. Diversas moléculas, como as da família dos VEGFs e dos fatores de crescimento têm sido descritas como importante reguladores da angiogênese e linfangiogênese tumoral, sendo assim considerados importantes alvos terapêuticos $(9,10)$. 


\subsection{Os fatores de crescimento endotelial vascular - VEGFs (vascular endothelial growth factor)}

A família dos fatores de crescimento endotelial vascular (VEGFs) é composta por um grupo de fatores altamente conservados que regulam a vasculogênese, a hematopoiese, a angiogênese, a linfangiogênese e a permeabilidade vascular $(11,12)$.

O VEGF foi originalmente descrito como uma proteína de 34,000 a 42,000 daltons que aumenta a permeabilidade vascular. Foi identificado através de purificação parcial de fluido ascítico de sobrenadantes de cultura células de hepatocarcinoma de cobaias, sendo denominado fator de permeabilidade vascular (VPF - vascular permeability factor) (13). Em 1989 Ferrara e Henzel (14) identificaram um fator de crescimento para células endoteliais em células pituitárias foliculares de bovinos que denominaram VEGF. Posteriormente, VPF e VEGF foram seqüenciados constatando-se que são idênticos (15).

Os membros da família VEGF em mamíferos são: o VEGF-A, VEGF-B, VEGF-C, VEGF-D e fator de crescimento placentário (PLGF). Estas glicoproteínas pertencem a uma superfamília que incluem os fatores de crescimento derivados das plaquetas (PDGF). Há também três receptores que pertencem à família dos receptores tirosina-quinase (RTK): VEGFR-1 (Flt-1), VEGFR-2 (KDR) e VEGFR-3 (FIt-4). O VEGFR-1 (vascular endothelial growth factor receptor) se liga aos VEGF-A e -B; o VEGFR-2 se 
liga aos VEGF-A, -C, e -D e o VEGFR-3 se liga aos VEGF-C e -D $(12,16)$. Os receptores neuropilin - 1 (NP-1) e neuropilin - 2 (NP-2) são coreceptores para algumas isoformas e subtipos de VEGF (16).

O VEGF-A está relacionado principalmente a angiogênese enquanto que o VEGF-C e VEGF-D estão envolvidos na linfangiogênese (15). Pouco se sabe a respeito do significado da expressão do VEGF-B em tumores (11).

Os VEGFs são importantes peptídeos que têm sido amplamente investigados em diversas condições, tanto fisiológicas, a exemplo do crescimento do endométrio e desenvolvimento embrionário, como em condições patológicas, como no crescimento tumoral e metástase $(9,15,17)$.

\subsection{Os VEGFs em neoplasias de tireóide}

As neoplasias endócrinas são importantes causas de morbimortalidade. Adicionalmente, essas neoplasias podem oferecer variados graus de dificuldade diagnóstica, devido à grande variedade de apresentações fenotípicas, e por apresentarem particularidades entre comportamento biológico e apresentação morfológica (18).

Além das inúmeras funções atribuídas aos membros da família do VEGF (para revisão consultar; $(9,10,15-17)$ estas proteínas cumprem um importante papel na angiogênese e linfangiogênese tumoral $(10,19)$. 
O aumento da expressão de VEGF em neoplasias tem sido relacionado a um pobre prognóstico ou maior risco de recorrência ou metástase em diversos tipos de cânceres (20).

A participação da angiogênese e da linfangiogênese na patogênese dos carcinomas de tireóide ainda não foi elucidada. Os padrões de comportamento tumoral e metástase variam de acordo com o tipo de tumor e ainda não foi completamente explorado se as diferenças nos fenótipos angiogênico e linfangiogênico determinam um comportamento mais agressivo e influenciam a metástase tumoral (21).

Garcia et al. (21) demonstraram diferentes padrões angiogênicos e linfangiogênicos entre carcinomas, lesões proliferativas benignas e tecido tireoidiano normal. A imuno-expressão de VEGF-A foi maior em carcinomas da tireóide (papilífero, folicular e medular). Em lesões proliferativas benignas e micro-carcinomas papilíferos a intensidade da reação foi intermediária, e os menores níveis foram observados nas amostras normais.

Tanaka et al. (22) investigaram a expressão do mRNA de VEGF-A, VEGF-B, VEGF-C e VEGF-D em tecido tireoidiano humano hiperplásico e neoplásico. A expressão de mRNA de VEGF-A e VEGF-B foi encontrada em todos os casos analisados. Não houve expressão de VEGF-C em apenas dois carcinomas papilíferos e em uma doença de Graves, enquanto que a de VEGF-D foi encontrada em aproximadamente metade dos casos.

Os pacientes com linfonodos comprometidos mostraram um aumento significativo da expressão de VEGF-C em relação aos pacientes sem 
comprometimento dos linfonodos. Além disso, o número de linfonodos com metástases, correlacionou-se positivamente com a expressão de mRNA de VEGF-C no tumor primário (22).

O fator-C de crescimento endotelial vascular (VEGF-C), aumentado em neoplasias malignas primárias, correlaciona-se com um aumento da disseminação de células neoplásicas malignas para os linfonodos regionais em vários carcinomas (23). Para algumas neoplasias, como os melanomas (24), carcinomas de mama (25), carcinomas colorretais $(26,27)$ e carcinomas gástricos (28), as metástases precoces em linfonodos são um achado clínico importante por serem bastante comuns e freqüentemente relacionados com mau prognóstico (29).

O papel dos ligandos VEGF-C e VEGF-D parece estar consistentemente relacionado não só com a linfangiogênese propriamente dita, mas também com a invasão dos linfáticos e metástase para linfonodos (30). Em carcinoma papilífero da tireóide, essa correlação também parece existir quando se compara a expressão de VEGF-C ao tecido normal, mas não com outros carcinomas tireoidianos. Por isso, o papel do VEGF-C não parece tão claro, o que sugere a participação de outras moléculas no aumento da densidade vascular linfática (31). Similarmente, o VEGF-D apresenta-se como um poderoso indutor de neovascularização linfática em carcinomas papilíferos da tireóide, constituindo-se em importante parâmetro prognóstico para a disseminação neoplásica (32). 
Os membros da família do VEGF têm se mostrado atraentes moléculas para utilização em terapias anti-câncer. O bloqueio destes fatores tem sido considerado um importante recurso para a inibição da angiogênese e melhora da resposta às quimioterapias e radioterapias (15).

O estudo da família VEGF e seus receptores, em séries bem documentadas de carcinomas tireoidianos, com adequado seguimento dos pacientes, incluindo tempo de sobrevida, e uma consistente variedade dos tipos tumorais, são necessários para um melhor entendimento dos processos que envolvem a expressão e regulação dessas moléculas, e a progressão das neoplasias primárias da tireóide, contribuindo para a melhoria das opções diagnósticas, avaliação prognóstica e possibilidades terapêuticas. 
2 REVISÃo DA LITERATURA 


\subsection{Tireóide}

O termo tireóide se originou a partir das palavras gregas thyreos e udos que significam respectivamente escudo oblongo e forma. Esta glândula recebeu este nome por apresentar conformação semelhante a um determinado tipo de escudo $(33,34)$.

A tireóide está localizada na porção anterior e inferior do pescoço e é nossa maior glândula endócrina, em indivíduos adultos normais, pesa entre 25 e $30 \mathrm{~g}(33,35)$, é constituída por dois lobos que se unem por um istmo $(33,34)$. O istmo está localizado sobre o segundo e terceiro anéis de cartilagem da traquéia, enquanto que, os lobos laterais estendem-se desde a parte média da cartilagem da tireóide, superiormente, até o sexto anel traqueal, inferiormente. Um terceiro lóbulo de formato cônico pode existir, denominado lobo piramidal ou pirâmide de Lalouette, este lobo surge da borda superior do istmo, mais freqüentemente de seu lado esquerdo $(33,35)$ (Figura $1 \mathrm{~A})$.

Estruturas esféricas denominadas folículos, amplamente inervadas e recobertas por uma extensa rede de capilares e vasos linfáticos, constituem os lobos tireoidianos. Os folículos são as unidades morfofuncionais da glândula tireóide e nos seus interiores ficam armazenados os produtos de secreção desta glândula, o colóide (33) (Figura 1 B). Pelo menos quatro tipos celulares distintos podem ser encontrados na tireóide: células 
endoteliais ( 20\%), células C ou parafoliculares ( 0,1\%), fibroblastos $(\sim 10 \%)$ e as células foliculares ( $70 \%)$, que compõem propriamente os folículos e que são o tipo celular predominante (34).
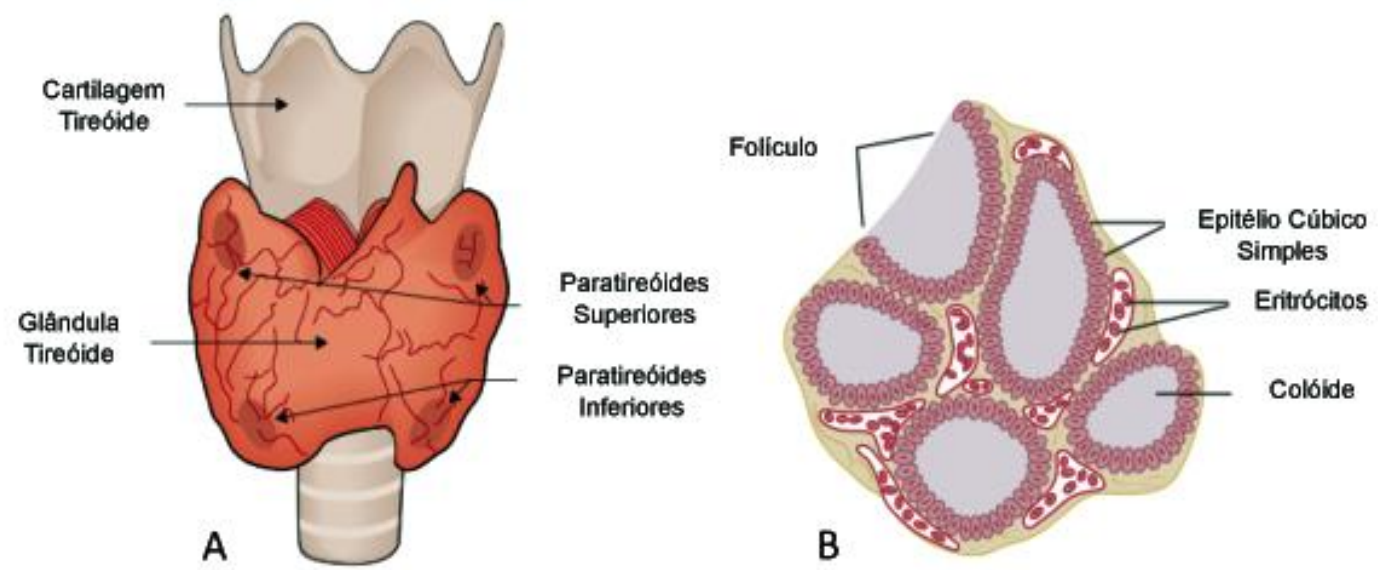

Figura 1. A- Esquema representativo da anatomia básica da glândula tireóide. B- Esquema representativo da morfologia microscópica básica da glândula tireóide (A - Adaptado de Sherman (36) / B - Adaptado de Guyton (37) ).

A glândula tireóide tem como principal função a produção e secreção dos hormônios tireoidianos. As células foliculares produzem tiroxina $\left(T_{4}\right)$ e triiodotironina $\left(T_{3}\right)$ e as células $C$ produzem e secretam o hormônio calcitonina $(33,34)$. Os hormônios da tireóide desempenham papeis críticos na diferenciação, no crescimento, metabolismo e nas funções fisiológicas de praticamente todos os tecidos. Estes hormônios se ligam a receptores nucleares regulando a transcrição gênica (38).

Para que ocorra a produção dos hormônios tireoidianos é necessário uma fonte de iodo e a integridade do eixo hipotálamo-hipófise-tireóide (33, 38), que é regulado por um sistema de feedback negativo (38). A principal fonte de iodo é a alimentação, o iodo da dieta é absorvido pelo trato gastrointestinal transformando-se em iodeto no líqüido extracelular. Parte do 
iodo é proveniente do metabolismo periférico dos hormônios e do iodo liberado pela glândula, sendo que, o iodo não utilizado na síntese dos hormônios é rapidamente eliminado pelos rins e os resíduos, pelas fezes. No lúmen do folículo, o iodeto é oxidado a iodo pela ação da enzima peroxidase que se liga à tirosina, um resíduo da glicoproteína tiroglobulina. Irá ocorrer, no colóide folicular, a formação de monoiodotiroxina (MIT) ou diiodotironina (DIT). A peroxidase facilitará a transformação de duas moléculas de DIT em $\mathrm{T}_{4}$ (tiroxina ou tetraiodotironina), ou a união de uma molécula de MIT com uma de DIT que formará o $T_{3}$ (triiodotironina). Ambos hormônios, $\mathrm{T}_{3}$ e $\mathrm{T}_{4}$, permanecem ligados a tireoglobulina (colóide) sob forma inativa . Para que os hormônios sejam liberados na circulação irá ocorrer pinocitose ou difusão através da ação de enzimas proteolíticas (33).

\subsubsection{Nódulos Tireoidianos}

Muitas doenças malignas ou benignas podem ser causadas por nódulos tireoidianos (39) (Tabela 1), que é um achado clínico comum sendo freqüentemente benignos $(39,40)$. Estudos epidemiológicos demonstraram que a prevalência de detecção por palpação é de aproximadamente $5 \%$ em mulheres e $1 \%$ em homens que vivem em regiões do mundo iodo suficientes $(40,41)$. Com o uso corrente da ultrasonografia de alta definição, eles são encontrados com freqüência ainda maior (42). 
Tabela 1 - Causas dos nódulos tireoidianos (Adaptado de McHenry et al., (39)).

\begin{tabular}{ll}
\hline & Causas de Nódulos Tireoidianos \\
\hline Benignas & Malignas \\
\hline Bócio Multinodular & Carcinoma Papilífero \\
Tireoidite de Hashimoto & Carcinoma Folicular \\
Cisto Simples ou Hemorrágico & Carcinoma de Células de Hürthle \\
Adenomas Foliculares & Carcinoma Medular \\
Tireoidite Subaguda & Carcinoma Anaplásico \\
& Linfoma Primário da Tireóide \\
& Lesão Maligna Metastática \\
\hline
\end{tabular}

Atualmente, estima-se que cerca de $20-76 \%$ da população apresenta nódulos tireoidianos solitários ou múltiplos $(39,40)$ com altas freqüências em mulheres e idosos. A importância clínica dos nódulos tireoidianos, além dos infreqüentes casos aonde ocorrem sintomas compressivos locais ou hiperfunção tireoidiana, é primariamente a necessidade de se excluir a presença de uma lesão tireoidiana maligna, que correspondem por cerca de $5 \%$ de todos os nódulos tireoidianos, dependendo da idade, sexo, histórico de exposição à radiação, histórico familiar, entre outros fatores. Dada a enorme prevalência das doenças nodulares tireoidianas não é necessário, nem economicamente viável, que todos os nódulos sejam submetidos a um completo exame para se determinar sua estrutura e função. No entanto, é essencial que sejam desenvolvidas estratégias custo efetivas para o diagnóstico e tratamento dos nódulos tireoidianos (39). 
O câncer da tireóide é a neoplasia endócrina maligna mais comum $(36,39,43)$, representa cerca de $1 \%$ de todos os novos diagnósticos de câncer (43), estima-se que 37.200 novos casos sejam diagnosticados e que 1.630 homens e mulheres morram em virtude desta malignidade no ano de 2009 (44).

A classificação dos tumores tireoidianos é baseada em sua célula de origem. As neoplasias tireoidianas mais comuns, benignas e malignas, se originam das células epiteliais foliculares da tireóide e incluem os adenomas foliculares, carcinomas foliculares e os carcinomas papilíferos da tireóide e suas respectivas variantes. A maioria das neoplasias malignas, derivadas das células epiteliais tireoidianas, são carcinomas diferenciados. No entanto, as células do epitélio folicular da tireóide, originam carcinomas tireoidianos menos diferenciados incluindo o carcinoma anaplásico e os carcinomas pouco diferenciados da tireóide. Menos freqüentemente ocorrem as neoplasias originadas a partir das células C (carcinoma medular da tireóide), células linfóides (linfomas malignos) e células mesenquimais (sarcomas) (45). Os cânceres tireoidianos diferenciados que inclui o carcinoma papilífero e folicular da tireóide compreendem a vasta maioria $(90 \%)$ de todas as neoplasias malignas da tireóide $(39,43,46,47)$; sendo o carcinoma papilífero da tireóide o mais freqüente, com cerca de $80 \%$ de todos os casos (43). Os adenomas e carcinomas de Hürthle, também de origem folicular, representam formas variantes de neoplasia (48).

Com o decorrer dos anos, diversos fenômenos têm mantido vivo o interesse nas neoplasias malignas da tireóide. Um aumento estatisticamente 
significativo da incidência em mulheres e homens tem sido observado, no entanto, as taxas de mortalidade estão diminuindo. Historicamente, a descoberta de inúmeros oncogenes nos carcinomas tireoidianos, estimulou uma grande quantidade de estudos, iniciados com o propósito de se encontrar alterações no genoma celular que afetassem a expressão ou o funcionamento de genes que controlam o crescimento celular e diferenciação. O comportamento biológico das neoplasias malignas da tireóide nem sempre correspondem aos padrões morfológicos, dificultando tanto o diagnóstico como a avaliação prognóstica destas lesões (18).

\subsubsection{Bócio Adenomatoso}

O bócio, ou aumento do tamanho da tireóide, é a patologia tireoidiana decorrente de alteração no metabolismo mais comum. Na maioria das vezes surge a partir de alterações na síntese dos hormônios tireoidianos, hormonogênese, por deficiência de iodo na dieta. Um aumento compensatório nos níveis séricos de TSH (Thyroid-Stimulating Hormone), causado pela diminuição na síntese hormonal, leva a hipertrofia e hiperplasia das células foliculares tireoidianas e conseqüentemente a um aumento no tamanho da glândula. Pode ocorrer também pelo estímulo contínuo da tireóide pelo TSH, não alterando, necessariamente, a função tireoidiana. Há, ainda, a variedade idiopática por alterações discretas no eixo hipotálamo-hipófise. O aumento compensatório da massa funcional da glândula permite a superação da deficiência hormonal dos pacientes gerando, na grande maioria das vezes, 
um estado metabólico eutireóideo; no entanto, em alguns casos pode ocorrer moderado hipotireoidismo $(33,49)$.

\subsubsection{Tireoidite}

A inflamação da tireóide, tireoidite, abrange inúmeras desordens que promovem a inflamação desta glândula. Podem ocorrer desde inflamações agudas intensas até inflamações brandas aonde normalmente a manifestação da doença irá ocorrer primariamente pela disfunção glandular. Este grupo de doenças tem como características mais proeminentes a inflamação, fibrose ou infiltrado linfocitário $(49,50)$.

Na tireoidite infecciosa pode ocorrer a infecção da tireóide pela ação de microorganismos por colonização direta ou disseminação hematogênica. Nestes casos, em geral, a função tireoidiana não é comprometida gravemente (49).

A condição inflamatória mais comum da glândula tireóide é a tireoidite linfocitária crônica, também chamada de tireoidite de Hashimoto (33). Esta patologia auto-imune é a causa mais comum de hipotireoidismo em regiões com níveis adequados de iodo (49). Foi descrita inicialmente por um médico Japonês, Hashimoto, em 1912 e se caracteriza por altos níveis de anticorpos anti-peroxidase e tireoglobulina circulantes. Os portadores eurotiroideos desenvolvem hipotireoidismo a uma taxa de cinco por cento ao ano. Noventa e cinco por cento dos casos ocorrem em mulheres entre 30 e 
50 anos de idade. A incidência desta patologia tem aumentado exponencialmente durante as últimas décadas, provavelmente por maior disponibilidade de iodo na dieta (50). Estudos epidemiológicos têm demonstrado um importante componente genético associado à tireoidite de Hashimoto; no entanto, como na maioria das doenças auto-imunes o padrão de herança não é mendeliano, há, provavelmente, sutis variações nas funções de inúmeros genes (49). A tireoidite de Hashimoto está relacionada a outras doenças auto-imunes incluindo lúpus eritromatoso, artrite reumatóide, diabetes mellitus entre outras. Normalmente, é assintomática sendo que no momento do diagnóstico o hipotireoidismo pode estar presente em apenas $20 \%$ dos pacientes (50).

\subsubsection{Adenoma}

Os adenomas, em geral, se manifestam como formações bem definidas e solitárias, que apresentam cápsula (33, 49). Podem ser denominados adenomas foliculares, uma vez que apenas raramente não são originados a partir das células foliculares da tireóide (49).

Clinicamente, a distinção dos adenomas foliculares, nódulos hiperplásicos foliculares e de carcinomas foliculares é difícil (49) sendo a diferença entre carcinoma e adenoma estritamente anatomopatológica. Diferentemente do carcinoma, no adenoma folicular não há invasão de cápsula e de vasos (33). Admite-se que os adenomas foliculares não malignizam, havendo apenas raras exceções descritas. A vasta maioria dos 
casos é indolor, porém, tumores maiores podem provocar sintomas localizados (49).

\subsubsection{Carcinoma Papilífero}

Apesar da alta freqüência dos nódulos tireoidianos, os carcinomas diferenciados da tireóide são relativamente raros. Os casos clinicamente detectados correspondem a menos de $1 \%$ de todos os cânceres humanos (51); entretanto, as neoplasias malignas da tireóide são as mais comuns do sistema endócrino $(36,39,43)$. A média de idade no momento do diagnóstico é de 45 a 50 anos e os carcinomas tireoidianos são de duas a quatro vezes mais freqüentes nas mulheres do que nos homens $(36,51)$.

O carcinoma papilífero da tireóide é o mais freqüente; pelo menos $80 \%$ de todos os casos $(39,43,46,47)$ podem ocorrer em qualquer idade, sendo as maiores taxas observadas dos 20 aos 40 anos. Os carcinomas tireoidianos são os mais relacionados a exposição prévia a radiação ionizante. Podem se apresentar como lesões solitárias ou multifocais localizadas em qualquer região da glândula e ocasionalmente podem ser encapsulados $(49,52)$. Um pior prognóstico é observado em homens idosos (52). Entre as principais características dos carcinomas papilíferos estão: a possibilidade de formação de papilas, cromatina nuclear finamente dispersa, resultando em um aspecto de "vidro fosco", invaginações 
citoplasmáticas aparentando inclusões celulares e calcificações concêntricas denominadas corpos psamomatosos. O carcinoma papilífero da tireóide apresenta ainda algumas variantes como a encapsulada, de células altas e foliculares (49).

Mutações e rearranjos gênicos específicos dos carcinomas papilíferos já foram descritas (53). Estas alterações podem levar a ativação da via de sinalização da proteína quinase ativadora de mitose (MAPK: mitogen activated protein kinase). As alterações mais comuns dos carcinomas papilíferos são as mutações pontuais dos genes BRAF e RAS e o rearranjo RET/PTC $(43,48)$.

O BRAF é uma serina-treonina quinase pertencente à família das proteínas RAF, que são as efetoras intracelulares da cascata de sinalização de MAPK. Após sua ativação, desencadeada pela ligação de RAS, esta quinase fosforila e ativa MEK que irá ativar ERK e os efetores seguintes da cascata de MAPK (Figura 2). Mutações pontuais do gene BRAF são encontradas em aproximadamente $45 \%$ dos carcinomas papilíferos da tireóide, com uma alta prevalência nos carcinomas papilíferos de histologia clássica e na variante de células altas, sendo rara na variante folicular. Diversos estudos têm correlacionado a presença da mutação de BRAF com características mais agressivas do tumor como extensão extra-tireoideana, recorrência, metástases em linfonodos e metástases distantes (43).

O proto-oncogene RAS e suas isoformas H-RAS, K-RAS, N-RAS são importantes proteínas da superfície interna das membranas celulares, 
apresentam papel central na transdução de sinais intracelulares e tem reconhecida participação na tumorigênese e na progressão tumoral de uma grande variedade de tecidos incluindo a tireóide. A proteína RAS ativada desencadeia vias importantes de sinalização como a de $\operatorname{MAPK}(43,48)$. Mutações de RAS promovem sua ativação constitutiva e a amplificação do gene ocasiona instabilidade genômica, o que promove o aparecimento de novas mutações que favorecem à progressão da transformação neoplásica. Cerca de $18 \%$ dos carcinomas papilíferos apresentam mutações de RAS. Esta mutação é considerada um evento inicial da tumorigênese tireoidiana uma vez que foi observada em lesões benignas da tireóide (48). Na maioria dos casos, os carcinomas papilíferos que apresentam mutações de RAS, fazem parte, histologicamente, da variante folicular. Esta mutação também se correlaciona com características nucleares menos proeminentes, tumores encapsulados e menores taxas de metástases para linfonodos; porém, alguns estudos relatam uma associação entre a mutação de RAS e um comportamento mais agressivo dos carcinomas papilíferos da tireóide com uma maior freqüência de metástases distantes (43). 


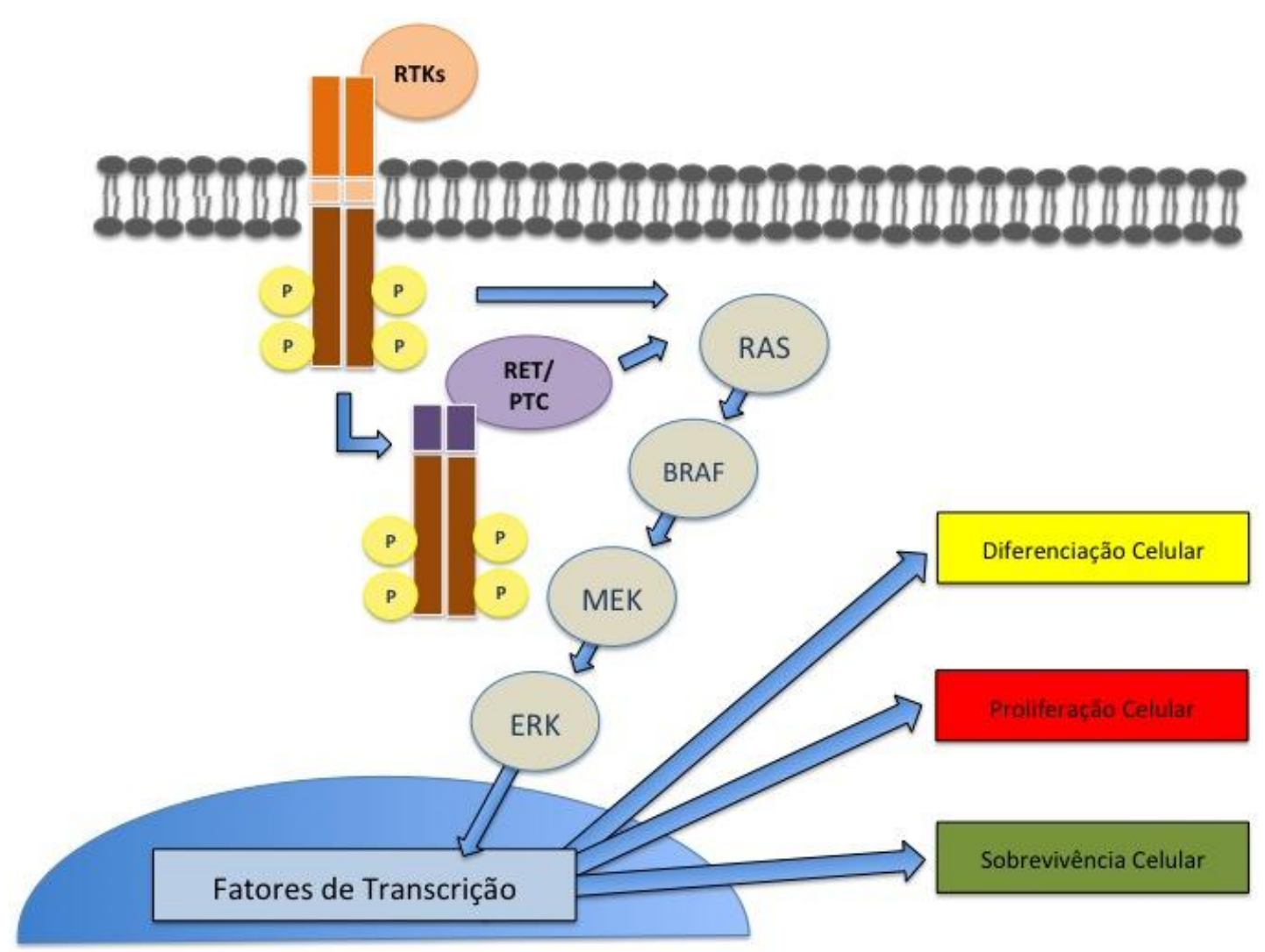

Figura 2. A via de sinalização MAPK é ativada fisiologicamente pela ligação de fatores de crescimento a receptores tirosino quinase (RTKs) como RET, resultando na dimerização do receptor e ativação via autofosforilação dos resíduos de tirosina no domínio intracelular. O receptor ativado por meio de uma série de proteínas adaptadoras leva a ativação de RAS que está localizada na face interna da membrana celular. A proteína RAS ativada se liga e recruta proteínas RAF, principalmente BRAF nas células foliculares tireoidianas. BRAF ativada fosforila e ativa MAPK/ERK quinase (MEK) que por sua vez ativa e fosforila a quinase regulada por sinal extracelular (ERK). A proteína ERK ativada transloca-se para o núcleo aonde ela regulará a transcrição de genes envolvidos na diferenciação, sobrevivência e proliferação celular. As alterações desta via de sinalização no câncer da tireóide ocorrem em diferentes níveis como resultado de mutações pontuais ou rearranjos envolvendo os genes RET, RAS e BRAF (Adaptado de Nikiforov et al., 2008 (43)) 
O proto-oncogene RET codifica um receptor de membrana tirosino quinase que é normalmente expresso nas células parafoliculares (células C) e não nas células foliculares da tireóide normal, aonde pode ser ativado pelo rearranjo cromossômico conhecido como rearranjo RET/PTC $(43,48)$. Este receptor está envolvido na transdução de sinais para a proliferação, diferenciação e migração no desenvolvimento de células da crista neural. Rearranjos de RET estão presentes em cerca de $20-25 \%$ dos carcinomas papilíferos de tiróide (48). No rearranjo RET/PTC a porção 3' do gene RET se funde a porção 5' de vários genes. Pelo menos 11 tipos de rearranjos RET/PTC já foram relatados, sendo sempre formados pela fusão de RET com algum outro gene. O rearranjo de RET/PTC mais comumente encontrado no carcinoma papilífero da tireóide é o RET/PTC1 que é formado pela fusão de RET com o gene H4 (D10S170). Após a fusão, o domínio tirosino quinase do receptor RET permanece intacto, permitindo que a oncoproteína RET/PTC ative a cascata de sinalização de RAS-RAF-MAPK. Carcinomas papilíferos com o rearranjo RET/PTC tipicamente se apresentam em idade menos avançada, tem taxas de metástase para linfonodos mais elevada, e geralmente com padrão histológico clássico de carcinoma papilífero. Casos com rearranjo do tipo RET/PTC1 apresentam prognóstico mais favorável (43). Crianças expostas à radiação da usina de Chernobyl em 1996, com carcinoma papilífero da tireóide, apresentaram a maior freqüência de ativação do rearranjo RET/PTC (48).

Clinicamente, a maioria dos carcinomas papilíferos se apresenta como nódulos indolores e assintomáticos; entretanto, a primeira 
manifestação pode ser a observação de adenomegalia. O carcinoma papilífero da tireóide, em geral, apresenta excelente prognóstico com taxa de sobrevida em 10 anos maior do que $95 \%(49,52)$.

\subsubsection{Carcinoma Folicular}

O carcinoma folicular da tireóide é caracterizado por sua diferenciação folicular sem a presença de alterações nucleares características do carcinoma papilífero $(45,51)$. Representa a segunda forma mais comum de neoplasia maligna tireoidiana, compreendendo aproximadamente de $10-30 \%$ dos tumores tireoidianos malignos, e ocorre com uma maior incidência no sexo feminino, principalmente na faixa etária acima dos 40 anos. Regiões do mundo que são deficientes de iodo apresentam maior incidência desta patologia $(49,52)$. A diferenciação entre lesão benigna, adenoma folicular, da maligna, carcinoma folicular, é estritamente anatomopatológica, sendo feita por observação microscópica que analisa a existência de invasão da cápsula e vasos $(33,51)$. Lesões foliculares que apresentarem alterações nucleares típicas do carcinoma papilífero devem ser tratadas como papilíferas (49). Duas formas do carcinoma folicular da tireóide são reconhecidas de acordo com o padrão de invasão, o minimamente invasivo e o extensamente invasivo, sendo a segunda menos freqüente $(45,51)$. A distinção entre adenomas foliculares e o carcinoma folicular minimamente invasivo pode ser difícil. Nos carcinomas 
foliculares a disseminação linfática é rara (49) ocorrendo preferencialmente pelos vasos sanguíneos. Eventualmente, os carcinomas foliculares se apresentam com células de citoplasma abundante, eosinofílico e granuloso. Estas células são denominadas células de Hürthle, também conhecidas como oxifílicas ou oncocíticas, e compõem o carcinoma de células de Hürthle, uma variante citológica do carcinoma folicular $(49,51)$.

As alterações moleculares mais freqüentemente encontradas nos carcinomas foliculares são mutações da RAS e o rearranjo PAX8-PPAR $\gamma$. Mutação da RAS é encontrada em cerca de 40 - 50\% dos tumores e pode estar relacionada a desdiferenciação tumoral e a um pior prognóstico (43). O rearranjo PAX8-PPAR $\gamma$ resulta de uma translocação que promove a fusão do gene PAX8, um fator de transcrição, ao gene PPAR $\gamma$, receptor ativador da proliferação de peroxissomos (peroxisome proliferator activated receptor) $(43,48)$. O produto deste rearranjo é a proteína quimérica PAX8-PPAR $\gamma$ que apresenta atividade oncogênica (48). Aproximadamente $35 \%$ dos carcinomas foliculares apresentam este rearranjo, sendo que uma menor prevalência é observada nos carcinomas de células de Hürthle. Tumores com o rearranjo PAX8-PPAR $\gamma$ tendem a se apresentar em indivíduos mais jovens, com menor tamanho e apresentam, mais freqüentemente, invasão vascular (43).

Geralmente, os carcinomas foliculares se apresentam como nódulos indolores e de crescimento lento. A invasão por via linfática é rara e na disseminação vascular sanguínea os principais tecidos acometidos são 
ossos, pulmões e fígado. O prognóstico é altamente dependente da extensão da invasão encontrada, sendo que nos minimamente invasivos, a taxa de sobrevida em 10 anos é maior do que $90 \%$ e nos extensamente invasivos cerca de metade dos pacientes morre em 10 anos $(49,52)$.

\subsubsection{Fatores Prognósticos}

Os carcinomas tireoidianos diferenciados, como o carcinoma papilífero e o folicular, de maneira geral, apresentam excelente prognóstico $(54,55)$. Inúmeros estudos têm buscado identificar fatores prognósticos que permitam classificar os portadores destas patologias em indivíduos de baixo e alto risco na tentativa de se aperfeiçoar a abordagem cirúrgica e o seguimento dos pacientes. Diversas classificações, baseadas principalmente na idade e características anatomopatológicas, como o AGES (Age, Grade, Extracapsular spread, and Size) e o AMES (Age, Metastasis, Extracapsular tumor, and Size) já foram propostas (54).

Os fatores prognósticos mais importantes para as neoplasias tireoidianas diferenciadas são: a idade no momento do diagnóstico inicial, o sexo do paciente, tamanho do tumor, tipo histológico da neoplasia, presença de invasão extra tireoidiana e metástases distantes (56), sendo que, idade acima dos 45 anos, sexo masculino, tumores com mais de 4 centímetros de diâmetro, variantes histológicas como as de células altas, Hürthle, colunar e insular, invasão vascular, comprometimento de linfonodos e presença de metástases distantes estão relacionadas a um pior prognóstico (54). 


\subsection{Angiogênese}

O sistema circulatório é essencial para o transporte de oxigênio, nutrientes e moléculas sinalizadoras, e para a remoção de dióxido de carbono, metabólitos e de produtos celulares e teciduais. A neovascularização, formação de novos vasos sangüíneos, é subdividida em vasculogênese e angiogênese (57).

$\mathrm{Na}$ vasculogênese ocorre diferenciação in situ de angioblastos, com o aparecimento de células endoteliais precursoras, hemangioblastos, derivadas do mesoderme $(9,16)$. No embrião, os primeiros vasos sangüíneos se desenvolvem a partir de agregados de angioblastos que formam uma rede primitiva de simples tubos endoteliais (57).

Na angiogênese, a formação de novos vasos sangüíneos ocorre a partir do brotamento de vasos pré-existentes $(8,9,16,57,58)$. A angiogênese tem atraído a atenção e fascinado a mente de estudiosos a séculos. Leonardo Da Vinci especulava que a vasculatura se desenvolvia a partir do coração, como uma árvore da semente, e comparava as raízes espalhadas de uma árvore com uma rede de capilares e o seu tronco com as artérias. O termo angiogênese foi cunhado por John Hunter em 1787 para descrever o crescimento de novos vasos sangüíneos (58). Evidências recentes demonstraram que a incorporação de células progenitoras endoteliais da medula óssea contribuem para o crescimento de vasos sanguíneos, complementando o brotamento ocorrido a partir de células endoteliais pré- 
existentes; contudo, a real contribuição destes elementos, em diversas condições fisiopatológicas, ainda precisa ser melhor explorado $(9,16)$. Estes achados sugerem que a vasculogênese e a angiogênese constituem mecanismos complementares da neovascularização pós natal (57).

Fisiologicamente, a angiogênese está relacionada ao desenvolvimento, reprodução e reparo. A angiogênese patológica ocorre não somente nas neoplasias, mas também em uma gama de doenças como diabetes, artrite reumatóide, psoríase, endometriose, aterosclerose, hiperplasia prostática entre outras (8). Inúmeros fatores pró e antiangiogênicos já foram descritos e um balanço entre estes fatores deve ser mantido para que as células endoteliais se mantenham quiescentes $(5,6)$.

Em 1971, o cirurgião Judah Folkman propôs a hipótese de que o crescimento do tumor é angiogênico dependente. Desde então as publicações relacionadas à angiogênese crescem em escala logarítmica (4). As neoplasias humanas podem permanecer quiescentes por anos devido ao balanço entre ativadores e inibidores da angiogênese. Por terem uma meiavida muito longa, os inibidores de angiogênese podem exceder aos estimuladores e assim inibir o crescimento metastático em órgãos distantes do tumor primário. Esta premissa norteou a hipótese da utilização de inibidores específicos de angiogênese como alvo terapêutico $(5,6)$.

A regulação da vasculogênese e da angiogênese é altamente complexa e envolve uma série de sinalizações moleculares ainda não totalmente compreendidas (59). A família dos fatores de crescimento 
endotelial vascular (VEGFs) tem sido descrita como a mais importantes reguladora da angiogênese e linfangiogênese, tanto em condições fisiológicas como na transformação neoplásica $(9,10,60)$.

\subsection{Linfangiogênese}

Durante o desenvolvimento embrionário, células endoteliais venosas se diferenciam em células endoteliais linfáticas, a partir dos vasos sanguíneos pré existentes, originando os sacos linfáticos primitivos. A vasculatura linfática periférica é formada por brotamento de células endoteliais linfáticas a partir dos sacos linfáticos em um processo conhecido como linfangiogênese (60). Esta hipótese foi inicialmente proposta por Florence Sabin no ano de 1902 (61) e mais recentemente foi corroborada por estudos in vitro que demonstraram que a expressão do gene Prox-1, envolvido no desenvolvimento e diferenciação dos vasos linfáticos, é suficiente para induzir o fenótipo linfático em células endoteliais sangüíneas $(62,63)$. Outra hipótese, demonstrada em aves (64), postula que o surgimento dos vasos linfáticos ocorre a partir de células precursoras independentes dos vasos sanguíneos, os linfangioblastos, e que portanto as conexões com as veias seriam estabelecidas mais tardiamente $(65,66)$. Apesar dos achados mais recentes apoiarem a teoria da linfangiogênese a partir de células endoteliais sanguíneas talvez ambos os mecanismos linfangiogênicos possam coexistir (66). 
Vias de sinalização interconectadas por complexos mecanismos de regulação controlam diretamente a proliferação, brotamento e migração das células endoteliais durante a vasculogênese, angiogênese e linfangiogênese. No centro desta complexa rede de sinalização estão os fatores de crescimento endotelial vascular (VEGFs) e seus receptores (VEGFRs). Estas moléculas são cruciais para estes processos tanto em condições fisiológicas como no desenvolvimento embrionário, e processos de cicatrização como em patologias, a exemplo do câncer e doenças inflamatórias (60).

O sistema linfático compreende uma complexa rede capilar que transporta o fluido drenado dos interstícios teciduais. Além disso, é uma das vias preferenciais das metástases dos carcinomas que inicialmente acometem os linfonodos para depois se disseminarem a órgãos distantes (67). Recentemente, o estudo da linfangiogênese tem atraído a atenção da comunidade científica uma vez que os vasos linfáticos apresentam importante papel na disseminação neoplásica (63). A inibição da linfangiogênese pode evitar a disseminação tumoral, o que poderá representar uma opção terapêutica importante $(29,60)$.

\subsection{Os fatores de crescimento endotelial vascular (VEGFs)}

Os membros da família VEGF em mamíferos são: o VEGF-A, VEGF-B, VEGF-C, VEGF-D e fator de crescimento placentário (PLGF). 
Estas glicoproteínas pertencem a uma superfamília que incluem os fatores de crescimento derivados das plaquetas (PDGF). Os VEGFs se ligam com diferentes especificidades aos seus receptores (60). Três pertencem à família dos receptores tirosina quinase (RTK): VEGFR-1 (FIt-1), VEGFR-2 (KDR) e VEGFR-3 (FIt-4). O VEGFR-1 (vascular endothelial growth factor receptor) se liga aos VEGF-A, -B e PLGF; o VEGFR-2 se liga aos VEGF-A, -C, e -D e o VEGFR-3 se liga aos VEGF-C e -D $(12,16)$. Os receptores neuropilin - 1 (NP-1) e neuropilin - 2 (NP-2) são co-receptores para algumas isoformas e subtipos de VEGF e PLGF (16) (Figura 3).

O VEGF-A está principalmente relacionado à angiogênese enquanto o VEGF-C e VEGF-D estão envolvidos na linfangiogênese (15). Pouco se sabe a respeito do significado da expressão do VEGF-B em tumores (11).

Os VEGFs são importantes peptídeos que têm sido amplamente investigados em diversas condições, tanto fisiológicas, a exemplo do crescimento do endométrio e desenvolvimento embrionário, como em condições patológicas, como no crescimento tumoral e metástase $(9,15,17)$. 


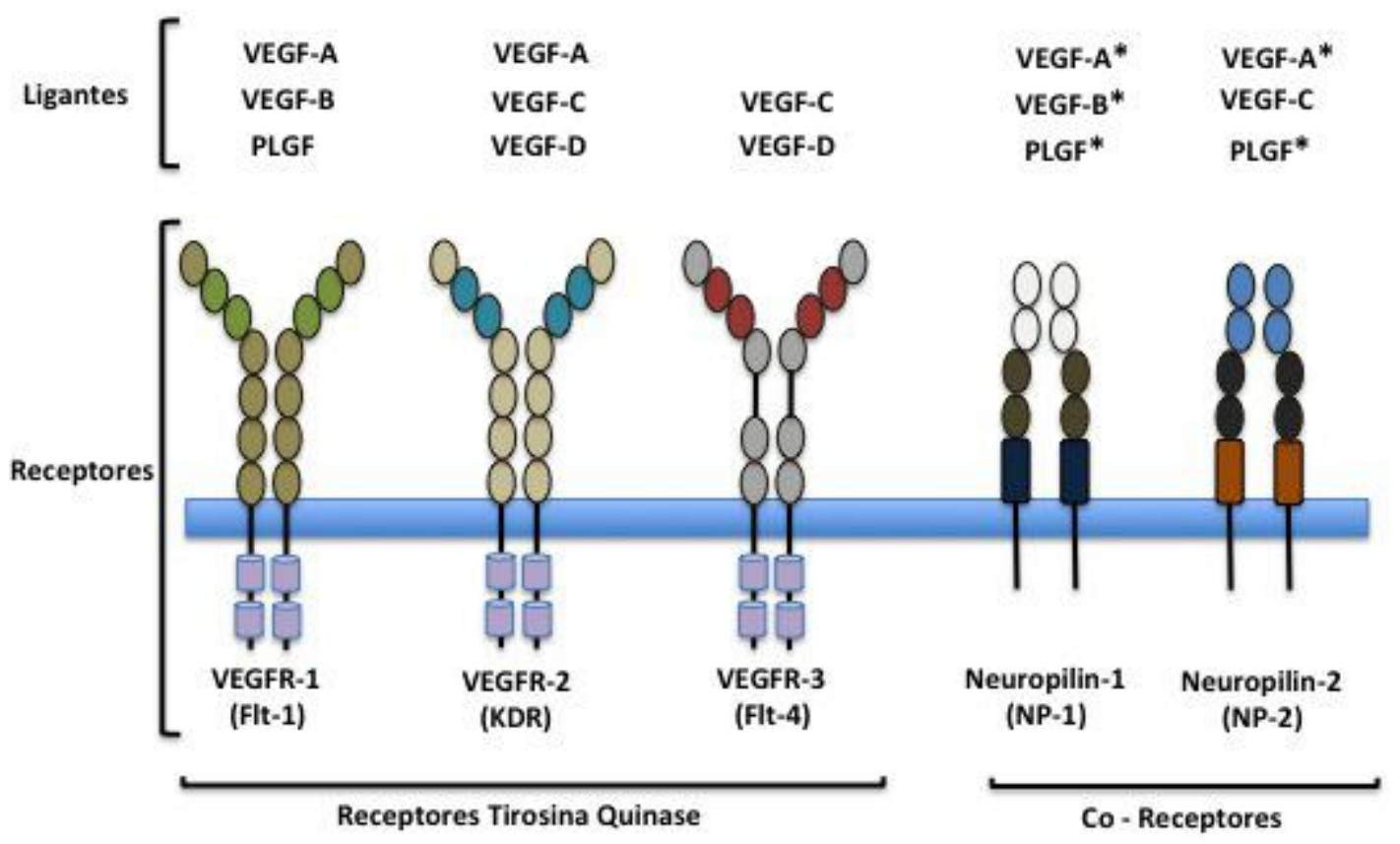

Figura 3. Esquema representativo das glicoproteínas da família VEGF, seus receptores e suas interações. * ligação observada em apenas algumas isoformas (Adaptado de Yamazaki et al., 2006 (16))

\subsubsection{VEGF - A}

O VEGF-A (vascular endothelial growth factor A), também denominado apenas VEGF, foi originalmente descrito como uma proteína de 34,000 a 42,000 daltons com capacidade de aumentar a permeabilidade vascular. Sua identificação ocorreu primeiramente através de purificação parcial de fluido ascítico de sobrenadantes de cultura células de hepatocarcinoma de cobaias. Nesta ocasião foi denominado fator de permeabilidade vascular (VPF - vascular permeability factor) (13), posteriormente, no ano de 1989, Ferrara e Henzel identificaram um fator de crescimento para células endoteliais, em células pituitárias foliculares de 
bovinos, que recebeu o nome de fator de crescimento endotelial vascular (VEGF). Após o seqüenciamento do VPF e do VEGF ficou constatado que ambos os fatores são idênticos $(9,15)$.

O VEGF-A é a principal molécula relacionada à angiogênese. Sua estrutura gênica é composta de 16.272 pares de bases que ficam localizados no cromossomo 6 apresentando 8 exons. Existem múltiplas isoformas geradas por splicing alternativo que apresentam diferentes propriedades e padrões de expressão (68). A primeira isoforma de VEGF-A descrita foi a do VEGF-A ${ }_{165}$, as outras isoformas, VEGF-A ${ }_{121}, V E G F-A_{145}$, VEGF-A 148 , VEGF-A ${ }_{183}$, VEGF-A 189 e VEGF-A 206 (16, 68, 69) foram identificadas entre os anos de 1989 e 2003 sendo geradas por splicing alternativo dos exons 6 e 7 que codificam as regiões que se ligam ao glicosaminoglicano Heparina e moléculas semelhantes. Posteriormente, uma outra isoforma, gerada pelo splicing do sítio de splicing distal do exon 8, VEGF-A ${ }_{165} \mathrm{~b}$ foi identificada. Duas famílias de isoformas de mRNA são produzidas: as isoformas pro-angiogênicas (VEGF-Axxx) e as antiangiogênicas (VEGF-Axxxb), sendo xxx o número de aminoácidos da proteína madura. A estrutura da proteína do VEGF-A contêm os sítios de dimerização e ligação à heparina e sítios de ligação ao VEGFR-1 e -2, que estão presentes em todas as isoformas. Os seis aminoácidos da extremidade carboxi terminal da proteína irão determinar se a isoforma de VEGF em questão é pró-angiogênica ou anti-angiogênica. Esta diferença promove profundas implicações na estrutura, interação com os receptores e função (68) (Figura 4). O VEGF 165 b se liga com afinidade equivalente ao 
VEGF $_{165}$ no receptor VEGFR-2; no entanto, não promove a sua ativação ou estímulo das vias de sinalização subseqüentes (69).

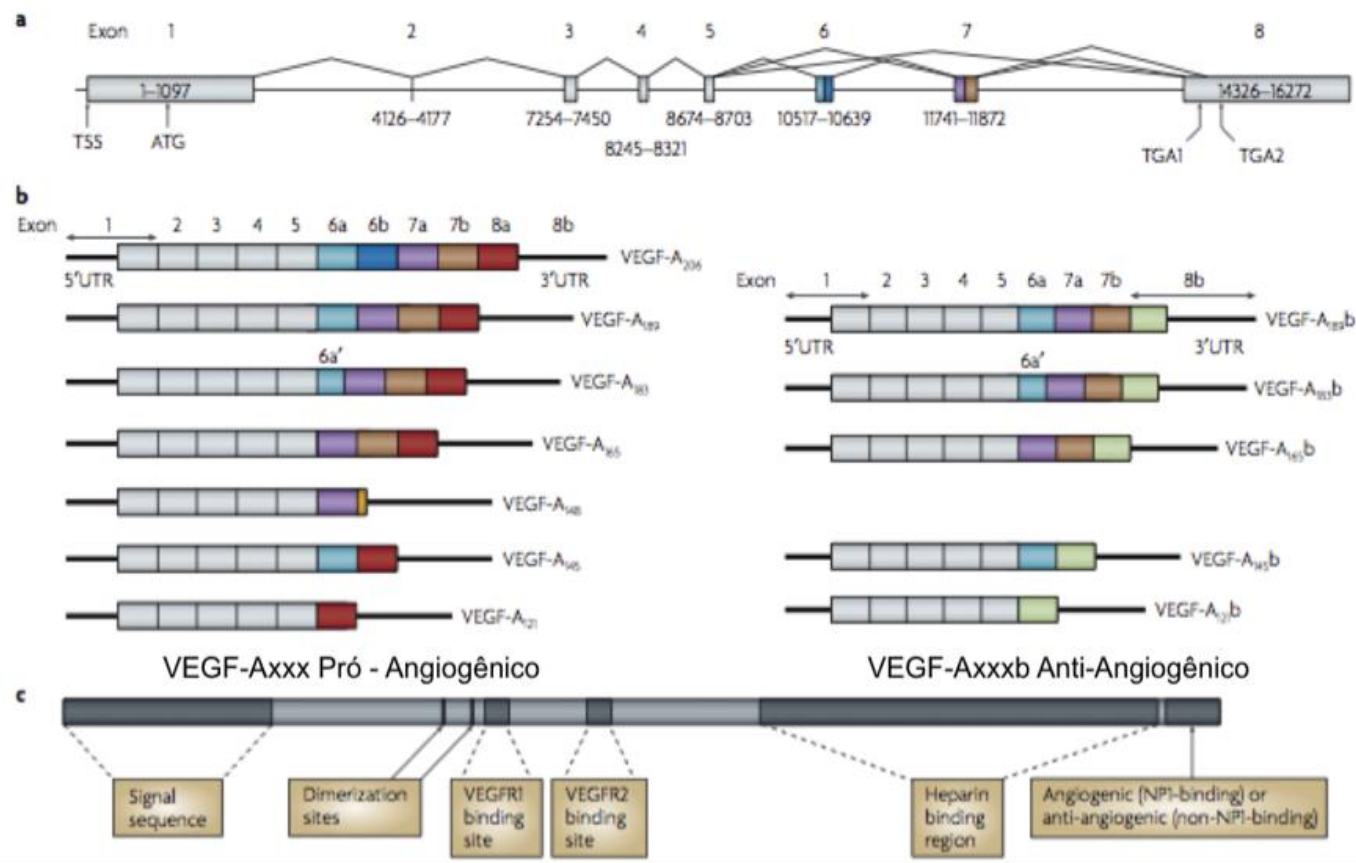

Figura 4. a) Esquema representativo da estrutura gênica do VEGF-A que apresenta 16.272 pares de bases e fica localizado no cromossomo $6 \mathrm{p} 12$ apresentando oito exons. Splicing alternativo nos exons 6, 7 e 8 originam várias isoformas. Os exons 6 e 7 codificam o domínios de ligação a heparina. TSS - sitio de início de transcrição e ATG - sítio de início de tradução localizados no exon 1. Códons de finalização alternativos no exon 8 são indicados TGA1 e TGA2. b) Duas famílias de isoformas de mRNA são produzidas, as isoformas pro-angiogênicas (VEGF-Axxx a esquerda) e as anti-angiogênicas (VEGF-Axxxb a direita). c) Estrutura da proteína do VEGF-A contendo os sítios de dimerização e ligação à heparina, sítios de ligação ao VEGFR-1 e -2 que estão presentes em todas as isoformas. Os seis aminoácidos na extremidade carboxi terminal da proteína podem ser próangiogênicos (CDKPRR codificados pelo exon 8a) ou anti-angiogênicos (SLTRKD codificados pelo exon 8b) (Adaptado de Harper et al., 2008 (68)) 
O VEGF-A 165 é a isoforma fisiologicamente mais abundante e também a mais bem estudada (16). Diversos tipos celulares como células endoteliais, leucócitos, macrófagos e células T ativadas, além de inúmeros outros tipos celulares, sintetizam o VEGF (9). Pouco se sabe a respeito dos mecanismos moleculares que regulam a expressão das diferentes isoformas. Hipóxia e hipoglicemia são condições indutoras da síntese de VEGF-A (16).

O VEGF-A é necessário para a quimiotaxia e diferenciação das células endoteliais precursoras, proliferação das células endoteliais, na montagem das células endoteliais em estruturas vasculares e na remodelação angiogênica (10). Esta molécula age promovendo inúmeras ações, tais como: ativação de proteínas quinase ativadoras da mitose (induzindo a proliferação celular), abertura de junções entre células endoteliais (aumentando a permeabilidade vascular), indução da atividade de metaloproteinases promovendo invasão, estímulo de migração por ativação do óxido nítrico, sobrevivência através de inibição de caspases e indução de Bcl2 e promove alterações do citoesqueleto e hiper regulação da expressão de integrinas (9). Algumas destas funções são igualmente importantes tanto no desenvolvimento vascular em adultos como na progressão tumoral (10).

O VEGF-A têm sido descrito como o mais importante regulador da angiogênese tumoral, sendo considerado um importante alvo terapêutico $(9,10)$. Atualmente, fármacos aprovados pelo Food Drugs Administration (FDA), que inibem a ação do VEGF-A, são utilizados 
como inibidores da angiogênese no tratamento de diversos tipos de neoplasias malignas (8).

\subsubsection{VEGF - B}

O VEGF-B (vascular endothelial growth factor B), até o momento, é o membro menos estudado da família dos VEGFs (70). Apresenta duas isoformas resultantes de splicing alternativo de um pré-mRNA sintetizado a partir de um único gene contendo sete exons. Após a remoção do peptídeo de sinal, são produzidos o VEGF-B ${ }_{167}$, que contém 167 aminoácidos, e o VEGF-B ${ }_{186}$ com 186 aminoácidos. A isoforma VEGF-B 167 é a predominante; in vivo não é encontrada em forma livre e difusa permanecendo ligada ao proteoglicano heparan sulfato, já a isoforma VEGF-B ${ }_{186}$ é secretadas e permanece livre $(16,57)$. O VEGF-B se liga ao receptor VEGFR-1, sendo que a isoforma 167 pode se ligar ao co-receptor neuropilin-1 (16) e apresenta ampla distribuição tecidual sendo especialmente proeminente no tecido muscular (69).

Ainda não está claro o papel biológico do VEGF-B e sua participação nas neoplasias humanas $(57,70)$. Diferentemente dos demais membros da família dos fatores de crescimento endotelial vascular o VEGF-B, em inúmeras condições, parece não afetar a angiogênese e a permeabilidade vascular. Aparentemente, este fator está relacionado a sobrevivência das células endoteliais, células musculares lisas e pericitos, funcionando como um fator de sobrevivência também para estes tipos celulares (70). 


\subsubsection{VEGF - C}

O VEGF-C (vascular endothelial growth factor $C$ ) é sintetizado como uma pré-proteína que posteriormente é submetida a um intrincado processamento proteolítico que irá gerar a forma madura deste fator de crescimento (57). Possui uma região com aproximadamente $30 \%$ de homologia ao VEGF-A $\mathrm{A}_{165}$, contudo está mais relacionado ao VEGF-D por compartilharem características na região $\mathrm{C}$ e $\mathrm{N}$ terminal que apenas ambos apresentam (69). O gene do VEGF-C possui sete exons, e altos níveis de mRNA podem ser encontrados no coração, ovário, placenta, músculo esquelético e intestino de humanos. Inúmeros outros tecidos produzem quantidades mais modestas deste fator de crescimento (57).

O VEGF-C apresenta modesta participação nos processos angiogênicos. Está envolvido na proliferação e migração de células endoteliais, no aumento da permeabilidade vascular e na linfangiogênese $(15,16)$. Na linfangiogênese, uma forma imatura do VEGF-C se liga ao VEGFR-3; já a forma madura se liga tanto ao receptor VEGFR-2 como ao VEGFR-3. Artigos recentes demonstraram a interação do VEGF-C com o co-receptor neuropilin-2 (16). Sua participação na linfangiogênese ocorre no desenvolvimento embrionário e na manutenção do endotélio linfático em adultos (57).

O VEGF-C representa um potencial alvo de terapias anti-câncer (57). O aumento deste fator em neoplasias malignas correlaciona-se com 
aumento da disseminação de células neoplásicas para os linfonodos regionais em vários carcinomas, sendo em algumas situações, um potencial indicador prognóstico (23).

\subsubsection{VEGF - D}

O VEGF-D (vascular endothelial growth factor $D$ ), de maneira similar ao VEGF-C, é sintetizado como uma pré-proteína que posteriormente é submetida a um intricado processamento proteolítico que irá gerar a forma madura deste fator de crescimento. O gene do VEGF-D possui sete exons e está localizado no cromossomo X. A forma imatura do VEGF-D irá se ligar ao receptor VEGFR-3, importante na linfangiogênese, enquanto que o VEGF-D maduro pode se ligar ao VEGFR-2 e ao VEGFR-3 (57).

As atividades biológicas relacionadas ao VEGF-D são: indução da proliferação e migração de células endoteliais, e participação na angiogênese e linfangiogênese (16). Inúmeros tecidos expressam níveis variáveis de VEGF-D. Altos níveis de transcritos podem ser encontrados no pulmão, coração, cólon e no músculo esquelético de humanos adultos (57). O VEGF-D é um importante fator relacionado à linfangiogênese. Descobertas recentes sugerem que a linfangiogênese tumoral, que é o crescimento de vasos linfáticos associados ao tumor, promove metástases linfáticas e que a expressão do VEGF-D encontra-se aumentada em uma série de neoplasias malignas $(30,32)$. Este fator de crescimento representa, 
portanto um potencial alvo terapêutico (57) além de um importante parâmetro prognóstico (32).

\subsubsection{PLGF}

O PLGF (placental growth factor) é uma glicoproteína que apresenta homologia de cerca de $42 \%$ de sua seqüência de aminoácidos, e uma estrutura terciária com características semelhantes ao VEGF-A (57). Esta glicoproteína foi inicialmente descrita na placenta, sendo expressa neste órgão durante todos os estágios da gestação em humanos. Contudo, transcritos de PLGF já foram identificados em outros tecidos como coração, pulmão e músculo esquelético (69). O gene do PLGF possui sete exons e quatro isoformas diferentes e podem ser geradas por splicing alternativo, PLGF $_{131}, \operatorname{PLGF}_{152}, \operatorname{PLGF}_{203}$ e $\operatorname{PLGF}_{224}(57,69)$. As isoformas PLGF 152 e PLGF $_{224}$ ligam-se ao proteoglicano heparan sulfato (57).

O PLGF se liga ao receptor VEGFR-1 sendo que a isoforma, PLGF $_{152}$, pode se ligar também aos co-receptores neuropilin-1 e 2. Aparentemente, o PLGF apresenta pouca ou nenhuma capacidade de indução de mitose ou aumento de permeabilidade vascular; porém na administração combinada com o VEGF-A ocorre um aumento da proliferação de células endoteliais, da permeabilidade vascular e da indução da angiogênese guiada pelo VEGF-A. O PLGF induz a migração de células endoteliais (16) e amplifica a ação do VEGF-A, podendo, 
inclusive, neutralizar terapias anti-câncer baseadas no bloqueio da ação do VEGF-A (57).

\subsection{Os receptores dos fatores de crescimento endotelial vascular (VEGFRs)}

Os VEGFRs (vascular endothelial growth factor receptor), VEGFR-1, VEGFR-2 e VEGFR-3, são proteínas tirosina quinase que consistem em um componente extracelular contendo sete domínios semelhantes à imunoglobulina, segmento transmembrana único, um segmento justamembranar, domínios intracelulares tirosina quinase e uma cauda carboxiterminal. Dois co-receptores não enzimáticos também compõem a família dos receptores de VEGFs: o neuropilin-1 e o neuropilin-2. Com a ligação do fator de crescimento ao domínio extracelular do receptor transmembranar, ocorre a dimerização do receptor, ativação da atividade proteína quinase, autofosforilação e subseqüente ativação de proteínas de vias intracelulares (71).

O VEGFR-1 é um receptor com $180 \mathrm{kDa}$ com alta afinidade para o VEGF-A, VEGF-B e PLGF. Células endoteliais vasculares e outros tipos celulares como monócitos, macrófagos e células precursoras hematopoiéticas expressam este receptor $(9,57,69)$. 
O VEGFR-2 é um receptor de 200 a 230 kDa com alta afinidade para o VEGF-A e para as formas maduras do VEGF-C e VEGF-D. Células endoteliais vasculares e linfáticas, e outros tipos celulares como megacariócitos e células precursoras hematopoiéticas secretam o VEGFR-2 $(9,57,69)$.

O VEGFR-3 é um receptor de 195 kDa com alta afinidade para VEGF-C e VEGF-D. Este receptor é sintetizado nas células endoteliais vasculares durante o desenvolvimento embrionário, com o decorrer do desenvolvimento sua produção diminui ficando restrita ao vasos linfáticos $(9,57,69)$.

Os VEGFs, e seus receptores tirosina quinase correspondentes, apresentam papel primordial e indispensável na regulação das múltiplas faces do processo angiogênico e linfangiogênico, assim como na indução do aumento da permeabilidade vascular e inflamação, tanto nos processos fisiológicos como patológicos. Por apresentarem tais características, a utilização de agentes bloqueadores dos receptores dos VEGFRs são, atualmente, uma nova e promissora abordagem de terapias antiangiogênicas (72). 
3 OBJETIVOS 
1 - A presente tese foi desenvolvida com o objetivo de avaliar a expressão imuno-histoquímica dos fatores de crescimento endotelial vascular VEGF (VEGF-A; VEGF-A 165 b; VEGF-B; VEGF-C e VEGF-D), de seus receptores VEGFR (VEGF-R1 e VEGF-R3) e a densidade vascular sanguínea e linfática em série de lesões malignas e benignas da tireóide.

\subsection{Objetivos Específicos}

1 - Avaliar a expressão imuno-histoquímica dos fatores de crescimento endotelial vascular (VEGF-A; VEGF-A ${ }_{165} \mathrm{~b}$; VEGF-B; VEGF-C e VEGF-D) e de seus receptores VEGFR (VEGFR-1 e VEGFR-3) nos carcinomas papilíferos e foliculares da tireóide bem como a expressão destes fatores no tecido adjacente ao tumor.

2 - Avaliar a expressão imuno-histoquímica dos fatores de crescimento endotelial vascular (VEGF-A; VEGF-A $165 \mathrm{~b}$; VEGF-B; VEGF-C e VEGF-D) e de seus receptores VEGFR (VEGFR-1 e VEGFR-3) nos casos de Bócio Adenomatoso, Tireoidite Linfocitária e Adenoma Folicular. 
3 - Correlacionar a expressão imuno-histoquímica dos fatores de crescimento endotelial vascular (VEGF-A; VEGF-A $165 \mathrm{~b}$; VEGF-B; VEGF-C e VEGF-D) e de seus receptores VEGFR (VEGFR-1 e VEGFR-3) com os dados clínico-patológico existentes.

4 - Correlacionar a densidade vascular sanguínea e linfática, peritumoral, intratumoral e total com os dados clínico-patológicos existentes.

5 - Correlacionar a expressão imuno-histoquímica dos fatores de crescimento endotelial vascular (VEGF-A; VEGF-A $165 \mathrm{~b}$; VEGF-B; VEGF-C e VEGF-D) e de seus receptores VEGFR (VEGFR-1 e VEGFR-3) e a densidade vascular sanguínea e linfática, peritumoral, intratumoral e total.

6 - Avaliar, por meio da correlação entre os resultados obtidos e os dados clínico-patológicos dos pacientes, o potencial dos fatores de crescimento endotelial vascular e de seus receptores como indicadores de agressividade e marcadores prognósticos nos carcinomas papilíferos e foliculares da tireóide. 
4 MÉTODOS 


\subsection{Casuística}

Realizamos estudo retrospectivo em 196 amostras de lesões tireoidianas malignas e benignas. Essas amostras foram anteriormente utilizadas por nosso grupo de pesquisa nos trabalhos científicos publicados citados a seguir $(18,42,73-75)$.

Todas as tireoidectomias totais foram realizadas pelo Prof. Dr. Roberto Souza Camargo, nos últimos 31 anos, segundo a padronização de Toledo (76) com modificações.

As indicações cirúrgicas partiram de diagnósticos clínico-laboratoriais

de carcinomas, adenomas, tireoidites e bócios e os pacientes foram avaliados quanto à função tireoidiana e apresentavam-se euro-tireoidianos no momento das cirurgias.

As informações sobre variáveis anátomo-patológicas e dados clínicos dos pacientes foram obtidas através da consulta dos prontuários e seguimentos.

Todas as amostras foram caracterizadas histopatologicamente segundo a classificação da Organização Mundial de Saúde (77) após revisão realizada por patologista com experiência em tireóide (estudo cego). Quando possível as regiões adjacentes de tecido morfologicamente normal 
ou as eventuais associações existentes, tireoidite linfocitária ou bócio adenomatoso, também foram avaliadas.

\subsubsection{Características clínico-patológicas da casuística estudada}

A partir da classificação da organização mundial da saúde o tipo histológico predominante foi o carcinoma papilífero que representou 42,9\% ( $n=84)$ da casuística estudada, seguido de, bócio adenomatoso 27\% ( $n=53)$; carcinoma folicular 17,3\% ( $n=34)$; tireoidite linfocitária $8,2 \%(n=16)$ e adenoma folicular $4,6 \%(n=9)$. O sexo feminino foi 5,125 vezes mais afetado do que o masculino (sexo feminino $83,7 \%$ casos e sexo masculino $16,3 \%$ casos) e a média de idade no momento do diagnóstico foi de 45,9 $\pm 14,2$ anos (média \pm D.P). O tamanho médio do tumor foi de $2,0 \mathrm{~cm} \pm 1,4$ (média \pm D.P) sendo encontrado predominantemente no lobo direito $(39,3 \%)$, esquerdo $(21,5 \%)$ ou com apresentação difusa $(22,4 \%)$. Os demais casos afetaram os lobos direito, esquerdo e istmo em diferentes combinações porem em nenhuma delas com freqüência maior do que as apresentadas acima. Levando-se em consideração todas as amostras estudadas, casos malignos e benignos, a invasão de cápsula esteve presente em 16,8\% $(n=33)$ dos casos e não foi detectada em $83,2 \%(n=163)$ e a invasão de vasos foi observada em $11,7 \%(n=23)$ dos casos e não foi detectada em $88,3 \%$ ( $n=173)$. Tecidos adjacentes ao tumor foram comprometidos e foi detectada 
metástase em $5,6 \%(n=11)$ dos casos e em $94,4 \%(n=185)$ não foi detectado comprometimento de adjacência e metástase tumoral. Os carcinomas papilíferos e foliculares da tireóide apresentaram estadiamento (TNM) I em 75,9\% ( $n=88)$, II em 14,7\% ( $n=17)$, III em $5,2 \%(n=6)$ e IVA em 4,3\% $(n=5)$ dos casos malignos estudados.

Um sumário das freqüências de cada variável clínico-patológica estudada pode ser observado na tabela 2 e fotomicrografias exemplificando os tipos histológicos estudados na figura 5 . 
Tabela 2 - Sumário da distribuição das variáveis clínico-patológicas registradas

\begin{tabular}{|c|c|c|c|}
\hline & & $\mathrm{n}$ & $\%$ \\
\hline \multicolumn{4}{|l|}{ Sexo } \\
\hline & M & 32 & $16,3 \%$ \\
\hline & $\mathrm{F}$ & 164 & $83,7 \%$ \\
\hline & Total & 196 & $100 \%$ \\
\hline \multicolumn{4}{|l|}{ Idade } \\
\hline & $<45$ anos & 97 & $51,3 \%$ \\
\hline & $>$ ou $=45$ anos & 92 & $48,7 \%$ \\
\hline & Total & 189 & $100 \%$ \\
\hline Idade Média (土 DP) & & \multicolumn{2}{|c|}{$45,9 \pm 14,2$} \\
\hline \multicolumn{4}{|c|}{ Diagnóstico } \\
\hline & Carcinoma Papilífero & 84 & $42,9 \%$ \\
\hline & Carcinoma Folicular & 34 & $17,3 \%$ \\
\hline & Bócio Adenomatoso & 53 & $27,0 \%$ \\
\hline & Tireoidite Linfocitária & 16 & $8,2 \%$ \\
\hline & Adenoma Folicular & 9 & $4,6 \%$ \\
\hline & Total & 196 & $100 \%$ \\
\hline Tamanho $(\mathrm{cm})$ Média $( \pm \mathrm{DP})$ & & \multicolumn{2}{|c|}{$2,0 \pm 1,4$} \\
\hline \multicolumn{4}{|l|}{ Lado } \\
\hline & Direito & 42 & $39,3 \%$ \\
\hline & Direito e Esquerdo & 4 & $3,7 \%$ \\
\hline & Direito e Istmo & 7 & $6,5 \%$ \\
\hline & Esquerdo & 23 & $21,5 \%$ \\
\hline & Esquerdo e Istmo & 1 & $0,9 \%$ \\
\hline & Istmo & 6 & $5,6 \%$ \\
\hline & Difuso & 24 & $22,4 \%$ \\
\hline & Total & 107 & $100 \%$ \\
\hline \multicolumn{4}{|l|}{ Invasão de Cápsula } \\
\hline & Presente & 33 & $16,8 \%$ \\
\hline & Não Detectada & 163 & $83,2 \%$ \\
\hline & Total & 196 & $100 \%$ \\
\hline \multicolumn{4}{|l|}{ Invasão de Vaso } \\
\hline & Presente & 23 & $11,7 \%$ \\
\hline & Não Detectada & 173 & $88,3 \%$ \\
\hline & Total & 196 & $100 \%$ \\
\hline \multicolumn{4}{|l|}{ Comprometimento de Adjacencia } \\
\hline & Presente & 11 & $5,6 \%$ \\
\hline & Não Detectada & 185 & $94,4 \%$ \\
\hline & Total & 196 & $100 \%$ \\
\hline \multicolumn{4}{|l|}{ Metástase } \\
\hline & Presente & 11 & $5,6 \%$ \\
\hline & Ausente & 185 & $94,4 \%$ \\
\hline & Total & 196 & $100 \%$ \\
\hline \multicolumn{4}{|l|}{ Estadiamento (TNM) } \\
\hline & 1 & 88 & $75,9 \%$ \\
\hline & II & 17 & $14,7 \%$ \\
\hline & III & 6 & $5,2 \%$ \\
\hline & IVA & 5 & $4,3 \%$ \\
\hline & Total & 116 & $100 \%$ \\
\hline
\end{tabular}



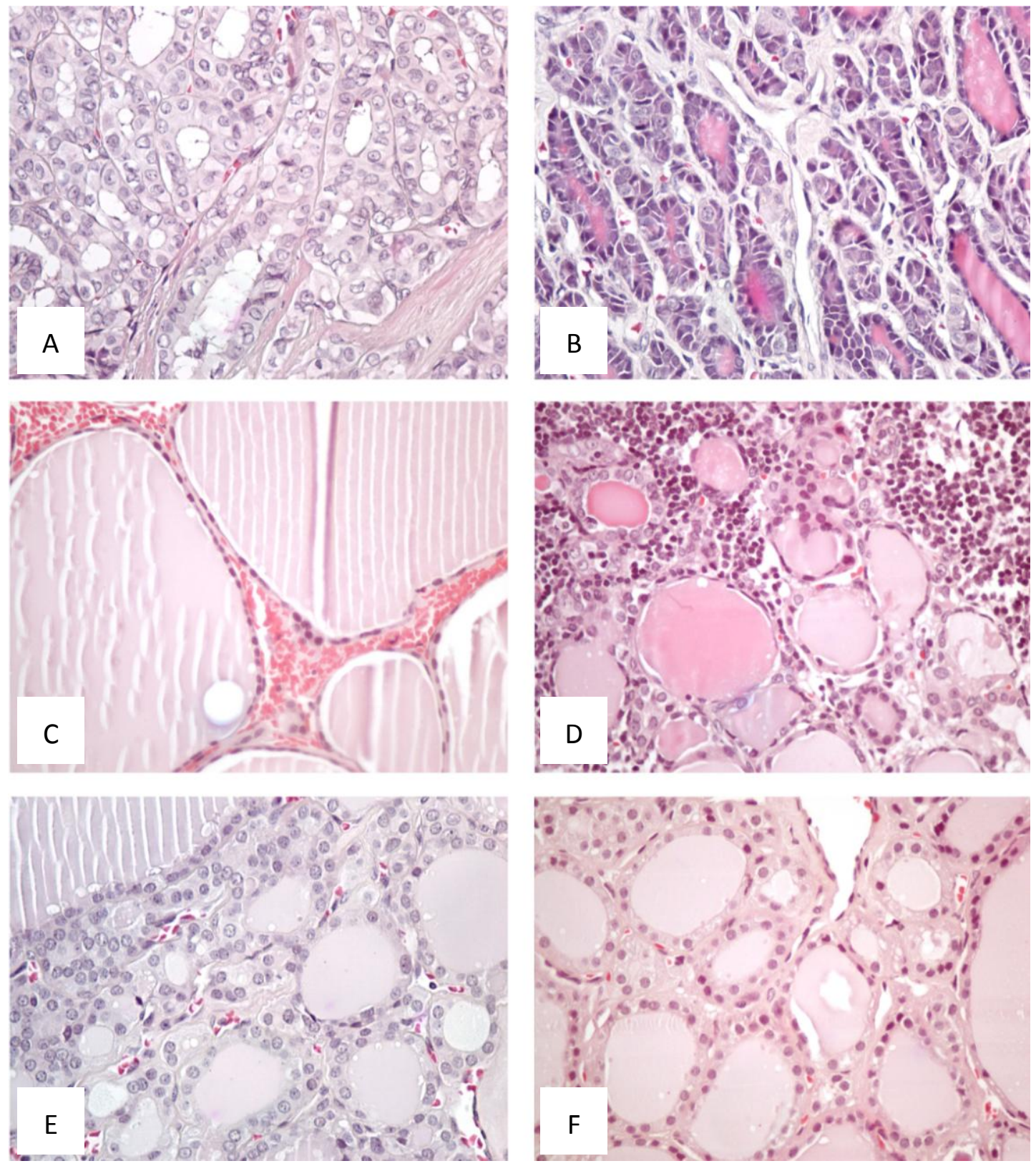

Figura 5. Fotomicrografias dos tipos histológicos de lesões tireoidianas estudadas coradas pela Hematoxilina - Eosina. (A) Carcinoma Papilífero (aumento 400X), (B) Carcinoma Folicular (aumento 400X), (C) Bócio Adenomatoso (aumento 400X), (D) Tireoidite Linfocitária (aumento 400X), (E) Adenoma Folicular (aumento 400X) e (F) Tireóide Normal (aumento 400X) 


\subsubsection{Características clínico-patológicas dos Carcinomas Papilíferos estudados}

Um total de 84 casos de carcinomas papilíferos da tireóide foram estudados. O tipo histológico carcinoma papilífero forma convencional representou $65,5 \%(n=55)$, carcinoma papilifero variante folicular $16,7 \%$ $(n=14)$, carcinoma papilífero variante oxifílica $3,6 \%(n=3)$, carcinoma papilífero padrão de células altas $1,2 \%(n=1)$, microcarcinoma papilífero $9,5 \%(n=8)$ e microcarcinoma papilifero variante folicular $3,6 \%(n=3)$ dos carcinomas papilíferos estudados. O sexo feminino foi 5,38 vezes mais afetado do que o masculino (sexo feminino $84,3 \%$ casos e sexo masculino $15,7 \%$ casos $)$ e $54,2 \%(n=45)$ e $45,8 \%(n=38)$ dos pacientes apresentaram idade inferior a 45 anos ou maior ou igual a 45 anos no momento do diagnóstico respectivamente. O tamanho médio do tumor foi de $1,78 \mathrm{~cm} \pm 1,5$ (média \pm D.P) sendo encontrado predominantemente no lobo direito $(31,1 \%)$, esquerdo $(24,3 \%)$ ou com apresentação difusa $(21,6 \%)$. Os demais casos afetaram os lobos direito, esquerdo e istmo em diferentes combinações porem em nenhuma delas com freqüência maior do que as apresentadas acima. Encontramos associação de bócio adenomatoso em $22,6 \%(n=19)$, tireoidite linfocitária em 17,9\% $(n=15)$ e bócio adenomatoso e tireoidite linfocitária em 1,2\% ( $n=1)$ dos carcinomas papilíferos estudados. Em 58,3\% ( $n=49)$ dos casos não detectamos nenhum tipo de associação. A invasão de cápsula esteve presente em 17,9\% $(n=15)$ dos casos e não foi detectada em $82,1 \%(n=69)$ e a invasão de vasos foi observada em 
$16,7 \%(n=14)$ dos casos e não foi detectada em $83,3 \%(n=70)$. Tecidos adjacentes ao tumor foram comprometidos em 10,7\% $(n=9)$ dos casos e em $89,3 \%$ ( $n=75)$ não detectamos comprometimento de adjacência. Metástase tumoral foi detectada em 13,1\% ( $n=11)$ e não foi observada em 86,9\% ( $n=73)$. Os carcinomas papilíferos da tireóide apresentaram estadiamento (TNM) I em 80,5\% ( $n=66)$, II em 8,5\% ( $n=7)$, III em 4,9\% $(n=4)$ e IVA em $6,1 \%(n=5)$ dos casos estudados.

Um sumário das freqüências de cada variável clínico-patológica dos carcinomas papilíferos estudados pode ser observado na tabela 3. 
Tabela 3 - Sumário da distribuição das variáveis clínico-patológicas dos carcinomas papilíferos estudados

\begin{tabular}{|c|c|c|c|}
\hline & & $\mathrm{n}$ & $\%$ \\
\hline \multicolumn{4}{|l|}{ Sexo } \\
\hline & M & 13 & $15,7 \%$ \\
\hline & $\mathrm{F}$ & 70 & $84,3 \%$ \\
\hline & Total & 83 & $100 \%$ \\
\hline \multicolumn{4}{|l|}{ Idade } \\
\hline & $<45$ anos & 45 & $54,2 \%$ \\
\hline & $>$ ou $=45$ anos & 38 & $45,8 \%$ \\
\hline & Total & 83 & $100 \%$ \\
\hline \multicolumn{4}{|l|}{ Tipo Histológico Carcinoma Papilífero } \\
\hline & Forma Convencional & 55 & $65,5 \%$ \\
\hline & Variante Folicular & 14 & $16,7 \%$ \\
\hline & Variante Oxifílica & 3 & $3,6 \%$ \\
\hline & Padrão de Células Altas & 1 & $1,2 \%$ \\
\hline & Microcarcinoma & 8 & $9,5 \%$ \\
\hline & Microcarcinoma Variante Folicular & 3 & $3,6 \%$ \\
\hline & Total & 84 & $100 \%$ \\
\hline Tamanho $(\mathrm{cm})$ Média (_ DP) & & \multicolumn{2}{|c|}{$1,78 \pm 1,5$} \\
\hline Lado & Direito & 23 & $31,1 \%$ \\
\hline & Direito e Esquerdo & 4 & $5,4 \%$ \\
\hline & Direito e Istmo & 6 & $8,1 \%$ \\
\hline & Esquerdo & 18 & $24,3 \%$ \\
\hline & Esquerdo e Istmo & 1 & $1,4 \%$ \\
\hline & Istmo & 6 & $8,1 \%$ \\
\hline & Difuso & 16 & $21,6 \%$ \\
\hline & Total & 74 & $100 \%$ \\
\hline \multicolumn{4}{|l|}{ Associações } \\
\hline & Bócio Adenomatoso & 19 & $22,6 \%$ \\
\hline & Tireoidite Linfocitária & 15 & $17,9 \%$ \\
\hline & $\begin{array}{r}\text { Bócio Adenomatoso e Tireoidite } \\
\text { Linfocitária }\end{array}$ & 1 & $1,2 \%$ \\
\hline & Ausentes & 49 & $58,3 \%$ \\
\hline & Total & 84 & $100 \%$ \\
\hline \multicolumn{4}{|l|}{ Invasão de Cápsula } \\
\hline & Presente & 15 & $17,9 \%$ \\
\hline & Não Detectada & 69 & $82,1 \%$ \\
\hline & Total & 84 & $100 \%$ \\
\hline \multicolumn{4}{|l|}{ Invasão de Vaso } \\
\hline & Presente & 14 & $16,7 \%$ \\
\hline & Não Detectada & 70 & $83,3 \%$ \\
\hline & Total & 84 & $100 \%$ \\
\hline \multicolumn{4}{|l|}{ Comprometimento de Adjacencia } \\
\hline & Presente & 9 & $10,7 \%$ \\
\hline & Não Detectada & 75 & $89,3 \%$ \\
\hline & Total & 84 & $100 \%$ \\
\hline \multicolumn{4}{|l|}{ Metástase } \\
\hline & Presente & 11 & $13,1 \%$ \\
\hline & Ausente & 73 & $86,9 \%$ \\
\hline & Total & 84 & $100 \%$ \\
\hline \multicolumn{4}{|l|}{ Estadiamento (TNM) } \\
\hline & I & 66 & $80,5 \%$ \\
\hline & II & 7 & $8,5 \%$ \\
\hline & III & 4 & $4,9 \%$ \\
\hline & IVA & 5 & $6,1 \%$ \\
\hline & Total & 82 & $100 \%$ \\
\hline
\end{tabular}




\subsubsection{Características clínico-patológicas dos Carcinomas Foliculares estudados}

Um total de 34 casos de carcinomas foliculares da tireóide foram estudados. O sexo feminino foi 7,4 vezes mais afetado do que o masculino (sexo feminino $88,2 \%$ casos e sexo masculino $11,8 \%$ casos) e $55,9 \%(n=19)$ e $44,1 \%(n=15)$ dos pacientes apresentaram idade inferior a 45 anos ou maior ou igual a 45 anos no momento do diagnóstico respectivamente. O tamanho médio do tumor foi de $2,55 \mathrm{~cm} \pm 0,98$ (média \pm D.P) sendo encontrado no lobo direito $(57,6 \%)$, esquerdo $(15,2 \%)$, direito e istmo $(3,0 \%)$ e com apresentação difusa (24,2\%). Encontramos associação de bócio adenomatoso em $17,6 \%(n=6)$, tireoidite linfocitária em 8,8\% ( $n=3)$ e bócio adenomatoso e tireoidite linfocitária em 5,9\% ( $n=2)$ dos carcinomas foliculares estudados. Em 67,6\% ( $n=23)$ dos casos não detectamos nenhum tipo de associação. A invasão de vaso esteve presente em $26,5 \%(n=9)$ dos casos e não foi detectada em 73,5\% $(n=25)$. Tecidos adjacentes ao tumor foram comprometidos em 5,9\% ( $n=2)$ dos casos e em $94,1 \%(n=32)$ não detectamos comprometimento de adjacência. Metástase tumoral não foi detectada em nenhum dos casos estudados. Os carcinomas foliculares da tireóide apresentaram estadiamento (TNM) I em 64,7\% ( $n=22$ ), II em 29,4\% $(n=10)$ e III em $5,9 \%(n=2)$ dos casos estudados.

Um sumário das freqüências de cada variável clínico-patológica dos carcinomas foliculares estudados pode ser observado na tabela 4. 
Tabela 4 - Sumário da distribuição das variáveis clínico-patológicas dos carcinomas foliculares estudados

\begin{tabular}{|c|c|c|c|}
\hline & & $\mathrm{n}$ & $\%$ \\
\hline \multicolumn{4}{|l|}{ Sexo } \\
\hline & $\mathrm{M}$ & 4 & $11,8 \%$ \\
\hline & $\mathrm{F}$ & 30 & $88,2 \%$ \\
\hline & Total & 34 & $100 \%$ \\
\hline \multicolumn{4}{|l|}{ Idade } \\
\hline & $<45$ anos & 19 & $55,9 \%$ \\
\hline & $>$ ou $=45$ anos & 15 & $44,1 \%$ \\
\hline & Total & 34 & $100 \%$ \\
\hline Tamanho (cm) Média ( \pm DP) & & \multicolumn{2}{|c|}{$2,55 \pm 0,98$} \\
\hline Lado & Direito & 19 & $57,6 \%$ \\
\hline & Direito e Istmo & 1 & $3,0 \%$ \\
\hline & Esquerdo & 5 & $15,2 \%$ \\
\hline & Difuso & 8 & 24,2 \\
\hline & Total & 33 & $100 \%$ \\
\hline \multicolumn{4}{|l|}{ Associações } \\
\hline & Bócio Adenomatoso & 6 & $17,6 \%$ \\
\hline & Tireoidite Linfocitária & 3 & $8,8 \%$ \\
\hline & $\begin{array}{l}\text { Bócio Adenomatoso e } \\
\text { Tireoidite Linfocitária }\end{array}$ & 2 & $5,9 \%$ \\
\hline & Ausentes & 23 & $67,6 \%$ \\
\hline & Total & 34 & $100 \%$ \\
\hline \multicolumn{4}{|l|}{ Invasão de Vaso } \\
\hline & Presente & 9 & $26,5 \%$ \\
\hline & Não Detectada & 25 & $73,5 \%$ \\
\hline & Total & 34 & $100 \%$ \\
\hline \multicolumn{4}{|l|}{ Comprometimento de Adjacencia } \\
\hline & Presente & 2 & $5,9 \%$ \\
\hline & Não Detectada & 32 & $94,1 \%$ \\
\hline & Total & 34 & $100 \%$ \\
\hline \multicolumn{4}{|l|}{ Metástase } \\
\hline & Ausente & 34 & $100 \%$ \\
\hline & Total & 34 & $100 \%$ \\
\hline \multicolumn{4}{|l|}{ Estadiamento (TNM) } \\
\hline & I & 22 & $64,7 \%$ \\
\hline & II & 10 & $29,4 \%$ \\
\hline & III & 2 & $5,9 \%$ \\
\hline & Total & 34 & $100 \%$ \\
\hline
\end{tabular}




\subsubsection{Variáveis idade e sexo nos bócios adenomatosos, tireoidites linfocitárias e adenomas foliculares estudados}

Dos 53 casos de bócio adenomatoso estudados 79,2\% $(n=42)$ acometeram mulheres e $20,8 \%(n=11)$ homens o que representa uma razão (Feminino : Masculino) de 3,8 mulheres para cada homem. No momento do diagnóstico 44,9\% $(n=22)$ dos pacientes apresentaram idade inferior a 45 anos e $55,1 \%(n=27)$ idade igual ou superior a 45 anos conforme demonstrado na tabela 5.

Tabela 5 - Distribuição das variáveis idade e sexo registradas nos bócios adenomatosos estudados

\begin{tabular}{|r|r|r|r|r|}
\hline & & $\mathrm{n}$ & $\%$ \\
\hline & Sexo & & & \\
\hline & & $\mathrm{M}$ & 11 & $20,8 \%$ \\
\hline & & 42 & $79,2 \%$ \\
\hline & Idade & Total & 53 & $100 \%$ \\
\hline & & & & \\
\hline
\end{tabular}

Foram estudados 16 casos de tireoidite linfocitária dos quais $93,8 \%$ $(n=15)$ acometeram mulheres e $6,3 \%(n=1)$ homens. Uma razão (Feminino : Masculino) de 14,8 mulheres para cada homem. No momento do diagnóstico 42,9\% $(n=6)$ dos pacientes apresentaram idade inferior a 45 anos e $57,1 \%(n=8)$ idade igual ou superior a 45 anos conforme demonstrado na tabela 6. 
Tabela 6 - Distribuição das variáveis idade e sexo registradas nas tireoidites linfocitárias estudadas

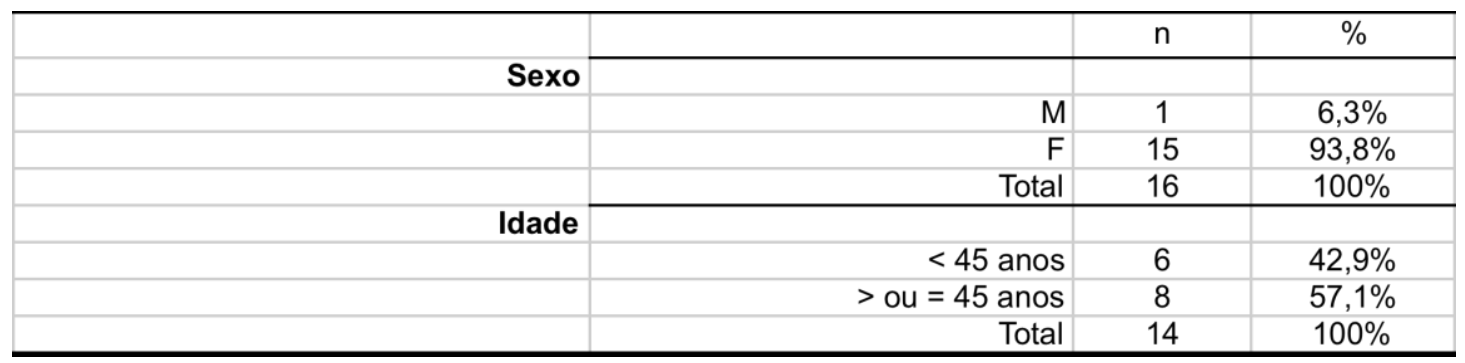

Os 9 casos de adenoma folicular estudados acometeram em 66,7\% $(n=6)$ mulheres e em $33,3 \%(n=3)$ homens o que representa uma razão (Feminino : Masculino) de 2 mulheres para cada homem. No momento do diagnóstico 55,6\% $(n=5)$ dos pacientes apresentaram idade inferior a 45 anos e 44,4\% ( $n=4)$ idade igual ou superior a 45 anos conforme demonstrado na tabela 7.

Tabela 7 - Distribuição das variáveis idade e sexo registradas nos adenomas foliculares estudados

\begin{tabular}{|c|c|c|c|}
\hline & & $n$ & $\%$ \\
\hline \multicolumn{4}{|l|}{ Sexo } \\
\hline & $\mathrm{M}$ & 3 & $33,3 \%$ \\
\hline & $\mathrm{F}$ & 6 & $66,7 \%$ \\
\hline & Total & 9 & $100 \%$ \\
\hline \multicolumn{4}{|l|}{ Idade } \\
\hline & $<45$ anos & 5 & $55,6 \%$ \\
\hline & $>$ ou $=45$ anos & 4 & $44,4 \%$ \\
\hline & Total & 9 & $100 \%$ \\
\hline
\end{tabular}




\subsection{Critérios de exclusão de amostras}

Os critérios de exclusão de amostras do estudo foram:

a) Para a avaliação da família VEGF e de seus receptores blocos de parafina com amostra insuficiente para a construção das micromatrizes teciduais (TMA);

b) Para a avaliação da DVL e DVS blocos de parafina com amostra insuficiente para a obtenção de lâminas histológicas de toda a amostra;

c) Blocos de parafina com amostra insuficiente para a avaliação de ao menos um dos métodos (avaliação imuno-histoquímica da família VEGF e de seus receptores ou da DVL e DVS).

\subsection{Obtenção de cortes histológicos e método de coloração}

Para possibilitar a caracterização histopatológica das amostras e para procedermos as análises imuno-histoquímicas da densidade vascular linfática (DVL) e da densidade vascular sanguínea (DVS) três cortes de $3 \mu \mathrm{M}$ de espessura, dos blocos de parafina originais, foram obtidos em micrótomo (Leica Instruments, Alemanha). Dois destes cortes foram reservados para 
imuno-histoquímica e um foi submetidos a coloração pelo método da hematoxilina-eosina conforme descrição abaixo:

- Desparafinização das lâminas em xilol a $60^{\circ} \mathrm{C}$ por 15 minutos e Xilol em temperatura ambiente por 15 minutos;

- Hidratação em concentrações decrescentes de etanol absoluto, etanol $95 \%$ e etanol $80 \%$;

- Hidratação em água corrente e água destilada;

- Coloração pela Hematoxilina de Harris por 3 minutos;

- Lavagem em água corrente e água destilada;

- Oito imersões em solução de hidróxido de amônio 0,5\%;

- Lavagem em água corrente e água destilada;

- Passagens sucessivas em concentrações crescentes de etanol $50 \%$, etanol $80 \%$ e etanol absoluto;

- Coloração pela Eosina por 2 minutos;

- Desidratação por quatro passagens em etanol absoluto;

- Diafanização por 4 passagens em xilol;

- Montagem em meio permanente (Entellan Merck, EUA) com lamínula. 


\subsection{Construção das micromatrizes teciduais (TMA)}

Para a avaliação da expressão dos membros da família VEGF e de seus receptores cortes histológicos representativos dos casos, corados pela hematoxilina e eosina, foram revisados e as áreas de interesse selecionadas nas lâminas. As mesmas áreas foram marcadas nos respectivos blocos de parafina doadores dos tecidos. Cilindros de $1 \mathrm{~mm}$ de diâmetro das áreas marcadas nos blocos de parafina doadores foram transportados para um bloco de parafina receptor através de um sistema mecanizado de precisão (Tissue Arrayer MTA-1 Beecher Instruments, EUA), com um intervalo de $0.3 \mathrm{~mm}$ entre os cilindros. Cada cilindro amostral foi alocado em uma posição do bloco receptor definida em um sistema cartesiano de coordenadas, e o conjunto das amostras constituiu uma micromatriz tecidual (TMA) (78). Anteriormente a construção dos blocos de TMA uma planilha contemplando cada posição e os respectivos casos contidos foi elaborada para posterior registro dos resultados.

Para orientação no momento da leitura, na primeira linha horizontal e nas primeiras três posições da primeira coluna foram dispostos fragmentos de pâncreas como tecidos controles. Sempre que possível as amostras foram dispostas em duplicata a fim de minimizar as eventuais perdas inerentes ao método de TMA. Blocos idênticos aos originais (bloco espelho) foram confeccionados simultaneamente para uma eventual necessidade. Neste estudo foram produzidos um total 14 blocos de TMA sendo 7 blocos espelhos. 
Uma vez prontos, os blocos de TMA foram cortados em secções histológicas de $3 \mu \mathrm{M}$ (Leica Instruments, Alemanha) e submetidos a imunohistoquímica.

\subsection{Procedimento Imuno-histoquímico}

Para a avaliação da expressão imuno-histoquímica dos fatores de crescimento endotelial vascular e seus receptores foram utilizadas as lâminas geradas a partir das micromatrizes teciduais enquanto que para a avaliação imuno-histoquímica DVL e da DVS utilizamos secções inteiras das amostras obtidas. Todas as amostras submetidas a imuno-histoquímica foram processadas de acordo com o protocolo descrito a seguir.

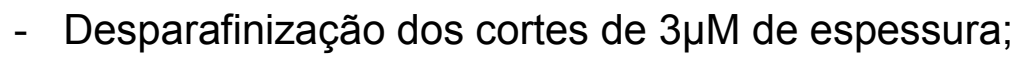

- Incubação com xilol a $60^{\circ} \mathrm{C}$ por 15 minutos seguido de outra incubação com xilol à temperatura ambiente por 15 minutos;

- Hidratação dos cortes em concentrações de etanol a 100\% com 3 banhos de 30 segundos cada, etanol a $95 \%$, $80 \%$ e $70 \%$ por 30 segundos;

- Lavagem em água corrente e água destilada;

- Recuperação antigênica (ver tabela anticorpos primários abaixo); 
- Bloqueio da peroxidase endógena com água oxigenada $\left(\mathrm{H}_{2} \mathrm{O}_{2}\right)$ a 6\% diluída v/v em metanol, em três banhos de 10 minutos cada;

- Lavagens em água corrente e água destilada;

- Lavagem com solução salina tamponada com fosfatos (PBS) 10 $\mathrm{mM} \mathrm{pH} \mathrm{7,4} \mathrm{por} 5$ minutos;

- Bloqueio de proteínas com Cas Block (Zymed, EUA) por 10 minutos a $37^{\circ} \mathrm{C}$

- Incubação das lâminas com anticorpo primário (ver tabela anticorpos primários abaixo) diluído em solução de albumina bovina (BSA) (SIGMA, EUA) a 1,0\% e azida sódica $\mathrm{NaN}_{3}$ (Inlab, Brasil) 0,1\% em PBS, em câmara úmida: 30 min. a $37^{\circ} \mathrm{C}$ e, em seguida, 18 horas (over night) a $4^{\circ} \mathrm{C}$;

- Lavagens em tampão PBS com 3 trocas de 5 minutos cada;

- Incubação com bloqueador pós-primário NovoLink (Novocastra, Reino Unido) por 30 minutos a $37^{\circ} \mathrm{C}$;

- Lavagens com tampão PBS com 3 trocas de 3 a 5 minutos cada;

- Incubação com polímero NovoLink (Novocastra, Reino Unido) por 30 minutos a $37^{\circ} \mathrm{C}$;

- Revelação com solução de substrato cromogênico contendo diaminobenzidina (Sigma, EUA) a 0,10\%, peróxido de hidrogênio a 0,06\%, dimetil sulfóxido (Labsynth, Brasil) a 1\% em PBS, em banho de 5 minutos, a $37^{\circ} \mathrm{C}$; 
- Lavagens em água corrente e água destilada;

- Contra-coloração com Hematoxilina de Harris por 1 minuto, lavagens em água corrente e água destilada. Imersão rápida em água amoniacal (solução de hidróxido de amônia 0,5\%) seguido de lavagens em água corrente e água destilada;

- Desidratação dos cortes em banhos de etanol a 50\%, 80\%, 95\% e etanol absoluto (3 trocas de 1 minuto cada);

- Diafanização em banhos de xilol;

- Montagem em meio permanente (Entellan Merck, EUA) com lamínula.

Para cada reação imuno-histoquímicas realizada foi feito um controle positivo, tecido sabidamente positivo para o anticorpo em estudo, e um controle negativo, com incubação em PBS, eliminação do anticorpo primário e execução de todos os demais procedimentos imuno-histoquímicos.

Um sumário dos anticorpos primários utilizados e suas respectivas condições ótimas de trabalho padronizadas pode ser observado na tabela 8. 
Tabela 8 - Descrição dos anticorpos primários utilizados e suas condições ótimas de trabalho com seus respectivos fabricantes, proteínas alvo, números dos catálogos, clones, métodos utilizados para recuperação antigênica, títulos e kit de revelação

\begin{tabular}{|c|c|c|c|c|c|c|}
\hline Fabricante & $\begin{array}{c}\text { Proteína } \\
\text { Alvo }\end{array}$ & $N^{\circ}$ Catálogo & Clone & $\begin{array}{c}\text { Recuperação } \\
\text { Antigênica }\end{array}$ & Título & Revelação \\
\hline Abcam & VEGF-A & ab1316 & VG-1 & $\begin{array}{l}\text { - panela vapor; } \\
\text { - citrato; } \\
\text { - pH 6,0 }\end{array}$ & $1: 800$ & NovoLink \\
\hline Abcam & VEGF-A165b & ab14994 & $\begin{array}{c}\text { MRVL56/ } \\
1\end{array}$ & $\begin{array}{l}\text { - panela vapor; } \\
\text { - citrato; } \\
\text { - pH 6,0 }\end{array}$ & $1: 50$ & NovoLink \\
\hline R\&D & VEGF-B & MAB751 & 58013 & $\begin{array}{l}\text { - panela vapor; } \\
\text { - citrato; } \\
\text { - pH 6,0 }\end{array}$ & $1: 50$ & NovoLink \\
\hline Zymed & VEGF-C & $18-2255$ & Z-CVC7 & $\begin{array}{l}\text { - panela vapor; } \\
\text { - citrato; } \\
\text { - pH 6,0 }\end{array}$ & $1: 200$ & NovoLink \\
\hline R\&D & VEGF-D & MAB286 & 78923 & $\begin{array}{l}\text { - panela vapor; } \\
\text { - citrato; } \\
\text { - pH 6,0 }\end{array}$ & $1: 200$ & NovoLink \\
\hline Abcam & VEGF-R1 & ab2350 & policlonal & $\begin{array}{l}\text { - panela vapor; } \\
\text { - citrato; } \\
\text { - pH 6,0 }\end{array}$ & $1: 100$ & NovoLink \\
\hline Abcam & VEGF-R3 & ab27278 & policlonal & $\begin{array}{l}\text { - panela vapor; } \\
\text { - citrato; } \\
\text { - pH 6,0 }\end{array}$ & $1: 100$ & NovoLink \\
\hline Abcam & $\begin{array}{l}\text { Von } \\
\text { Willebrand } \\
\text { Factor }\end{array}$ & ab6994 & policlonal & $\begin{array}{l}\text { - digestão } \\
\text { enzimática; } \\
\text { - Histo/Zyme; } \\
\text { - } 5 \text { min }\end{array}$ & $1: 25.000$ & NovoLink \\
\hline Dako & $\mathrm{D} 2-40$ & M3619-1 & D2-40 & $\begin{array}{l}\text { - panela vapor; } \\
\text { - citrato; } \\
\text { - pH 6,0 }\end{array}$ & $1: 200$ & NovoLink \\
\hline
\end{tabular}




\subsection{Interpretação das Reações Imuno-histoquímicas das Proteínas da Família VEGF}

A expressão imuno-histoquímica dos VEGF-A, VEGF-A ${ }_{165} b$, VEGF-B, VEGF-C, VEGF-D e dos VEGFR-1 e VEGFR-3 foi avaliada na forma de estudo cego, por semi-quantificação em aumento de 200x. Cada amostra da micromatriz tecidual foi considerada em sua totalidade e a localização da marcação obtida, se membranar, citoplasmática ou nuclear, também foi observada. O sistema de graduação utilizado pode ser observado na tabela abaixo.

\begin{tabular}{|c|l|}
\hline Código & \multicolumn{1}{|c|}{ Imunomarcação } \\
\hline \hline 0 & negativa não apresentou imunomarcação \\
\hline+ & imunomarcação positiva de até $10 \%$ das células \\
\hline++ & imunomarcação positiva de mais de $10 \%$ até $25 \%$ das células \\
\hline+++ & imunomarcação positiva de mais de $25 \%$ até $50 \%$ das células \\
\hline++++ & imunomarcação positiva de mais de $50 \%$ das células \\
\hline
\end{tabular}

Quando uma mesma amostra apresentou valores diferentes de imunomarcação entre suas duplicatas o maior valor foi considerado como definitivo. 


\subsection{Interpretação das Reações Imuno-histoquímicas para avaliação da DVL e DVS}

Para a avaliação da DVL e da DVS secções histológicas de $3 \mu \mathrm{M}$ (Leica Instruments, Alemanha) foram submetidas a marcação com anticorpos específicos para vasos sangüíneos (Von Willebrand Factor) e vasos linfáticos (D2-40).

A análise da positividade das reações foi realizada valorizando-se o conceito de "hot spot" (79), priorizando-se áreas selecionadas com concentração máxima de vasos e referindo sua topografia, se intra ou peritumoral, de onde foram contados 10 campos de cada área para cada caso selecionado para estudo. Foram avaliadas também a positividade desses marcadores nas células neoplásicas e adjacentes de aspecto normal.

O estudo foi realizado de acordo com o protocolo proposto por Longatto-Filho (80). Foram consideradas positivas as reações citoplasmáticas para Von Willebrand Factor (VW) e D2-40 que evidenciaram vasos cujos lumens foram claramente visíveis, separados de vasos adjacentes e de outros componentes do tecido conjuntivo. Vasos colapsados foram considerados como uma "unidade" vascular. Uma média da contagem de 10 campos de cada amostra foi considerada como a DVL e DVS do caso. Foi denominada densidade vascular linfática total ou densidade vascular sangüínea total a média da contagem dos 10 campos sem levar em 
consideração a topografia, se intra ou peritumoral. Todas as contagens foram feitas na forma de estudo cego.

\subsection{Aspectos éticos envolvidos}

Este projeto foi submetido a Comissão de Ética para Análise de Projetos de Pesquisa - CAPPesq da Diretoria Clínica do Hospital das Clínicas e da Faculdade de Medicina da Universidade de São Paulo e foi aprovado sob o protocolo de pesquisa número 0816/07.

Trata-se de estudo retrospectivo utilizando-se tecido humano emblocado em parafina obtidos de tireoidectomias.

Os potenciais benefícios advindos deste projeto apresentam grande relevância científica e social, e contribuem para a melhor compreensão do comportamento das neoplasias tireoidianas, o que acarretará benefícios futuros aos pacientes que sejam diagnosticados como portadores dessa gama de doenças.

Esse trabalho não proporcionou qualquer malefício aos pacientes cujas amostras foram utilizadas e os dados foram codificados para manter sigilo em relação às identidades. 


\subsection{Análise Estatística}

A relação dos ligandos e receptores da família VEGF e os parâmetros anatomo-clínicos foram examinadas para significância estatística usando-se os testes do qui-quadrado de Pearson $\left(X^{2}\right)$ ou exato de Fisher quando apropriado, ambos considerados significativos quando $p<0,05$. Para variáveis contínuas utilizamos o teste de Mann-Whitney. Os dados foram relacionados e analisados com o software SPSS (Statistical Package for Social Sciences for Windows, version 13.0, Chicago, EUA) (75). 
No fluxograma abaixo pode se observar um resumo das etapas desenvolvidas.

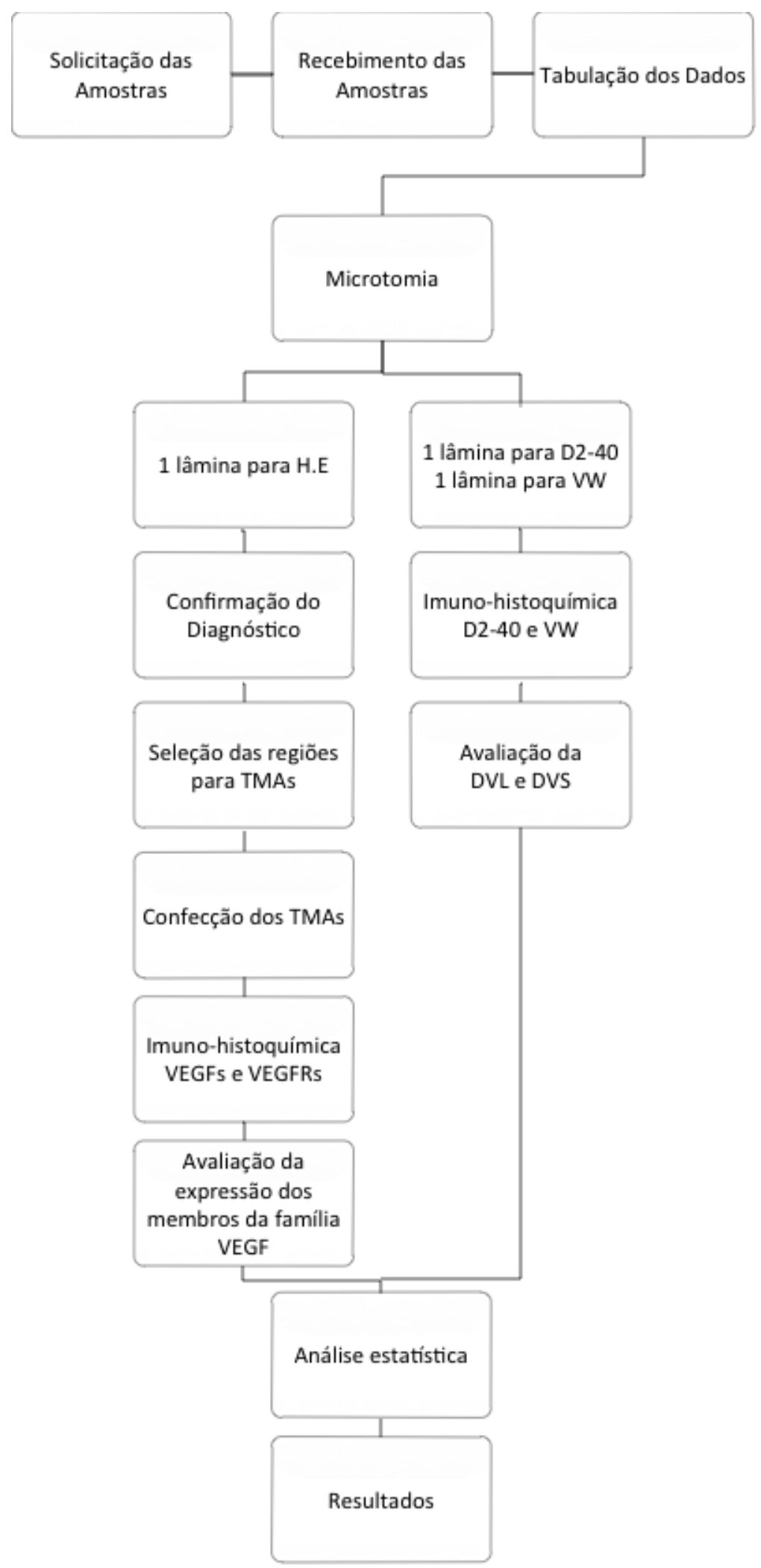


5 RESULTADOS 


\subsection{Expressão imuno-histoquímica dos fatores de crescimento endotelial vascular e de seus receptores nos carcinomas papilíferos estudados}

Foram avaliadas as expressões dos fatores de crescimento endotelial vascular (VEGF-A; VEGF-A ${ }_{165} \mathrm{~b}$; VEGF-B; VEGF-C; VEGF-D) e de seus receptores (VEGF-R1 e VEGF-R3) nos carcinomas papilíferos e em suas adjacências apresentando tecido normal, bócio adenomatoso e tireoidite linfocitária.

A Tabela 9 apresenta o número de casos de carcinomas papiliferos analisados para cada membro da família VEGF. Devido as perdas inerentes a técnica da micromatriz tecidual (TMA), dos 84 carcinomas papilíferos alguns casos foram perdidos na manipulação técnica conforme detalhado a seguir.

Tabela 9 - Número de amostras avaliadas quanto a expressão imuno-histoquímica dos VEGFs e VEGFRs nos carcinomas papiliferos e em suas regiões adjacentes contendo tecido normal, bócio adenomatoso e tireoidite linfocitária

\begin{tabular}{r|c|c|c|c|c|c|c|}
\hline & VEGF-A & VEGF-A165b & VEGF-B & VEGF-C & VEGF-D & VEGF-R1 & VEGF-R3 \\
\hline Normal & 38 & 37 & 39 & 36 & 38 & 38 & 39 \\
\hline Bócio Adenomatoso & 16 & 16 & 16 & 16 & 16 & 16 & 16 \\
\hline Tireoidite Linfocitária & 25 & 25 & 25 & 24 & 25 & 25 & 25 \\
\hline Carcinoma Papilífero & 66 & 63 & 66 & 65 & 66 & 66 & 64 \\
\hline
\end{tabular}




\subsubsection{VEGF-A}

A expressão imuno-histoquímica do VEGF-A foi realizada em 66 amostras da região tumoral $(78,5 \%$ do total de carcinomas papilíferos estudados) e em 38 regiões adjacentes aos carcinomas papilíferos apresentando tecido normal, 16 apresentando bócio adenomatoso e 25 apresentando tireoidite linfocitária (Tabela 9).

Em $88 \%$ dos casos das regiões tumorais as imunomarcações foram positivas ++++ , em $8 \%$ foram positivas +++ e em $5 \%$ foram negativas (0) para o VEGF-A. Nas regiões adjacentes normais $13 \%$ dos casos apresentaram imunomarcações positivas ++++, 13\% +++, $29 \%++, 29 \%+$ e $16 \%$ foram negativos (0). No tecido adjacente ao tumor com bócio adenomatoso $44 \%$ dos casos apresentaram imunomarcações positivas ,$++++ 25 \%+++, 6 \%++, 19 \%+$ e $6 \%$ foram negativos $(0)$. Nas tireoidites linfocitárias adjacentes $12 \%$ dos casos apresentaram imunomarcações positivas,$++++ 24 \%+++, 16 \%++, 16 \%+$ e $32 \%$ foram negativos (0) não apresentando imunomarcação para o VEGF-A (Figura 6). 
VEGF-A Carcinoma Papilífero

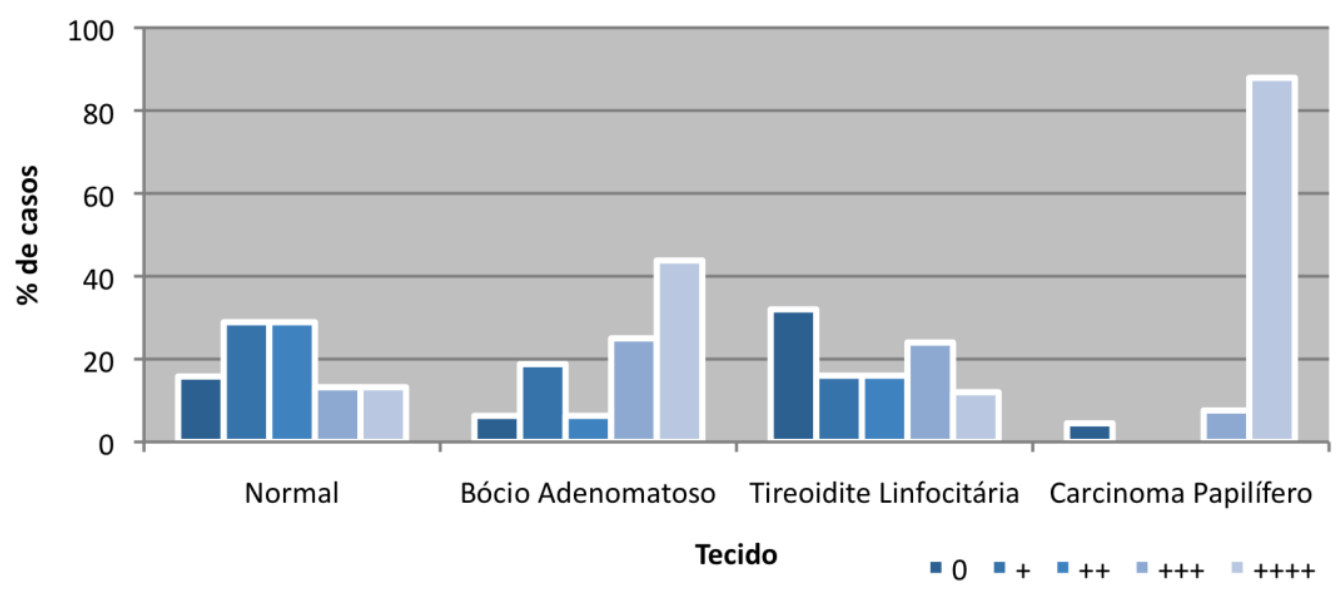

Figura 6. Expressão imuno-histoquímica do VEGF-A nos Carcinomas Papilíferos e suas adjacências apresentando tecido Normal, Bócio Adenomatoso e Tireoidite Linfocitária $(p<0,001)$

\subsubsection{VEGF-A $165 b$}

Foi possível avaliar a expressão imuno-histoquímica do VEGF-A ${ }_{165} b$ em 63 amostras da região tumoral (75\% do total de carcinomas papilíferos estudados) e em 37 regiões adjacentes aos carcinomas papilíferos apresentando tecido normal, 16 apresentando bócio adenomatoso e 25 apresentando tireoidite linfocitária (Tabela 9).

Em 54\% dos casos das regiões tumorais as imunomarcações foram positivas ++++ , em $18 \%$ foram positivas,$+++ 10 \%++, 2 \%+$ e em $18 \%$ foram negativas (0) para o VEGF-A ${ }_{165} \mathrm{~b}$. Nas regiões adjacentes normais $3 \%$ dos casos apresentaram imunomarcações positivas ++++, $16 \%+++, 27 \%++$, $41 \%+$ e $14 \%$ foram negativos (0). No tecido adjacente ao tumor com bócio adenomatoso $25 \%$ dos casos apresentaram imunomarcações positivas ,$++++ 25 \%++, 13 \%+$ e $38 \%$ foram negativos (0). Nas tireoidites linfocitárias 
adjacentes $3 \%$ dos casos apresentaram imunomarcações positivas ++++ , $12 \%++, 28 \%+$ e $48 \%$ foram negativos (0) não apresentando imunomarcação para o VEGF-A 165 b (Figura 7)

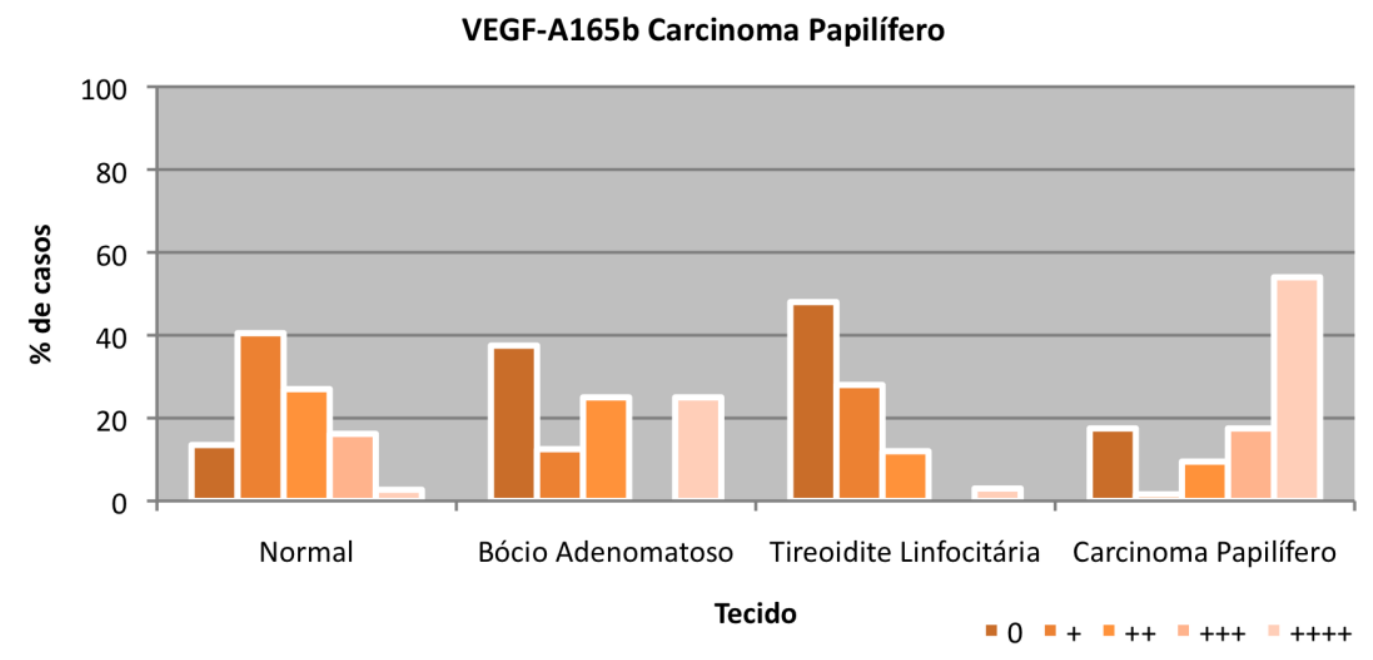

Figura 7. Expressão imuno-histoquímica do VEGF-A ${ }_{165} \mathrm{~b}$ nos Carcinomas Papilíferos e suas adjacências apresentando tecido Normal, Bócio Adenomatoso e Tireoidite Linfocitária $(p<0,001)$

\subsubsection{VEGF-B}

Foi possível avaliar a expressão imuno-histoquímica do VEGF-B em 66 amostras da região tumoral $(78,5 \%$ do total de carcinomas papilíferos estudados) e em 39 regiões adjacentes aos carcinomas papilíferos apresentando tecido normal, 16 apresentando bócio adenomatoso e 25 apresentando tireoidite linfocitária (Tabela 9). 
Em $2 \%$ dos casos das regiões tumorais as imunomarcações foram positivas +++ , em $6 \%$ foram positivas,$++ 20 \%+$, e em $73 \%$ foram negativas (0) para o VEGF-B. Nas regiões adjacentes normais $3 \%$ dos casos apresentaram imunomarcações positivas + e 97\% foram negativos (0). No tecido adjacente ao tumor com bócio adenomatoso $100 \%$ dos casos foram negativos (0). Nas tireoidites linfocitárias adjacentes $4 \%$ dos casos apresentaram imunomarcações positivas,$++ 24 \%+$ e $72 \%$ foram negativos (0) não apresentando imunomarcação para o VEGF-B (Figura 8).

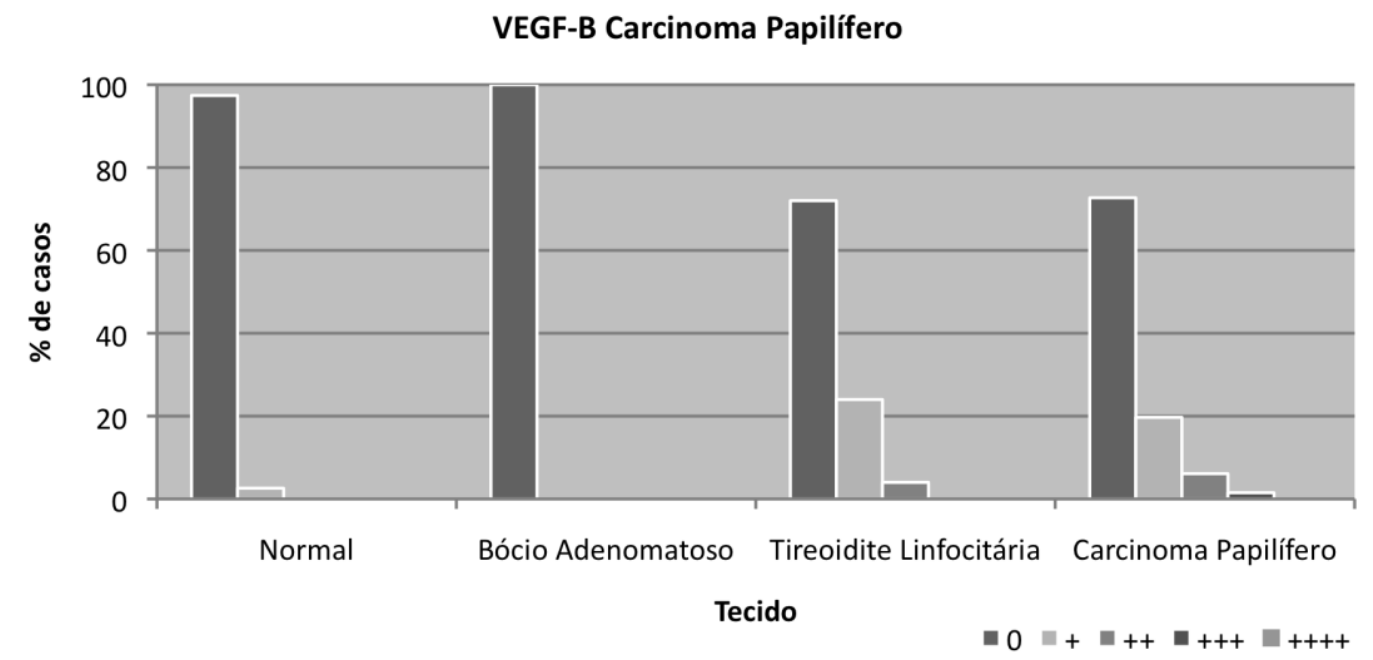

Figura 8. Expressão imuno-histoquímica do VEGF-B nos Carcinomas Papilíferos e suas adjacências apresentando tecido Normal, Bócio Adenomatoso e Tireoidite Linfocitária ( $\mathrm{p} 0,055)$

\subsubsection{VEGF-C}

Foi possível avaliar a expressão imuno-histoquímica do VEGF-C em 65 amostras da região tumoral $(77,3 \%$ do total de carcinomas papilíferos estudados) e em 36 regiões adjacentes aos carcinomas papilíferos 
apresentando tecido normal, 16 apresentando bócio adenomatoso e 24 apresentando tireoidite linfocitária (Tabela 9).

Em $51 \%$ dos casos das regiões tumorais as imunomarcações foram positivas ++++ , em $23 \%$ foram positivas,$+++ 12 \%++, 12 \%+$ e em $2 \%$ foram negativas (0) para o VEGF-C. Nas regiões adjacentes normais $3 \%$ dos casos apresentaram imunomarcações positivas,$++++ 3 \%+++, 39 \%+$ e $56 \%$ foram negativos (0). No tecido adjacente ao tumor com bócio adenomatoso $13 \%$ dos casos apresentaram imunomarcações positivas ,$++++ 25 \%+++, 6 \%++, 25+$ e $31 \%$ foram negativos $(0)$. Nas tireoidites linfocitárias adjacentes $13 \%$ dos casos apresentaram imunomarcações positivas,$++++ 21 \%+++, 29 \%++, 33 \%+$ e $4 \%$ foram negativos (0) não apresentando imunomarcação para o VEGF-C (Figura 9).

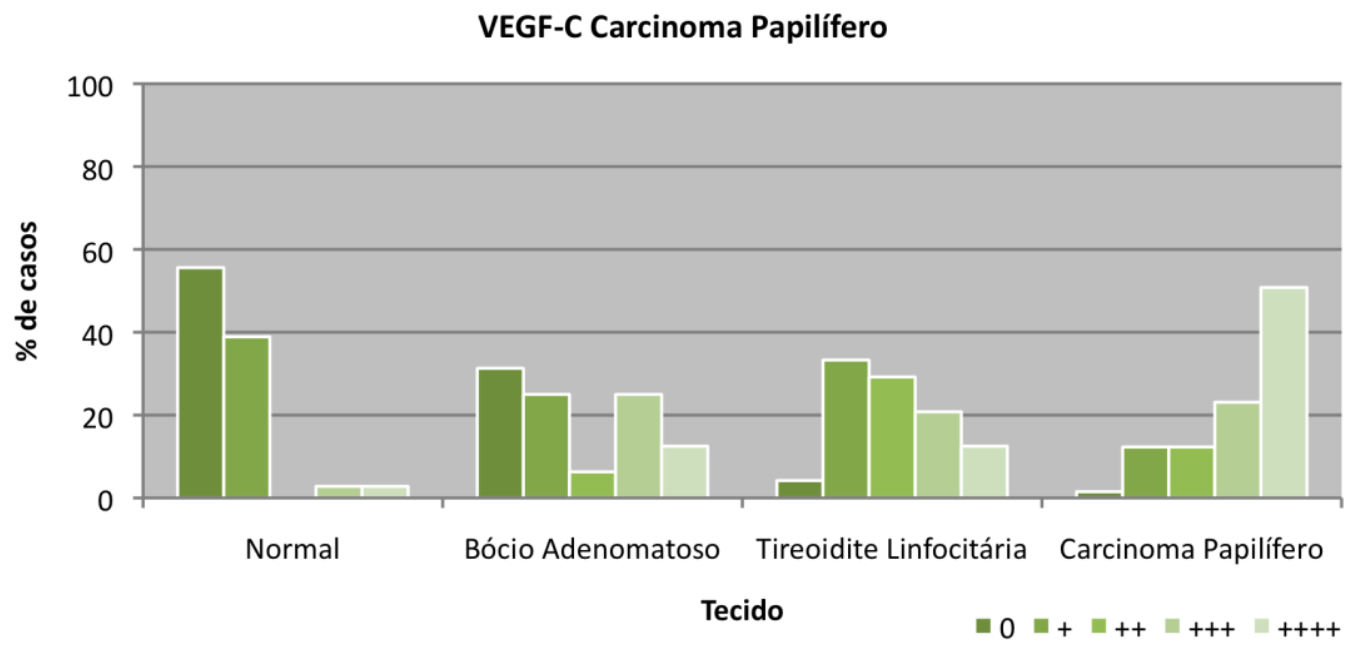

Figura 9. Expressão imuno-histoquímica do VEGF-C nos Carcinomas Papilíferos e suas adjacências apresentando tecido Normal, Bócio Adenomatoso e Tireoidite Linfocitária $(p<0,001)$ 


\subsubsection{VEGF-D}

Foi possível avaliar a expressão imuno-histoquímica do VEGF-D em 66 amostras da região tumoral $(78,5 \%$ do total de carcinomas papilíferos estudados) e em 38 regiões adjacentes aos carcinomas papilíferos apresentando tecido normal, 16 apresentando bócio adenomatoso e 25 apresentando tireoidite linfocitária (Tabela 9).

Em $89 \%$ dos casos das regiões tumorais as imunomarcações foram positivas ++++ , em $3 \%$ foram positivas +++ e em $8 \%$ foram positivas ++ para o VEGF-D. Nas regiões adjacentes normais $18 \%$ dos casos apresentaram imunomarcações positivas,$++++ 32 \%+++, 26 \%++, 18 \%+$ e $5 \%$ foram negativos (0). No tecido adjacente ao tumor com bócio adenomatoso $31 \%$ dos casos apresentaram imunomarcações positivas ++++, $13 \%+++$, $25 \%++, 25+$ e $6 \%$ foram negativos (0). Nas tireoidites linfocitárias adjacentes $16 \%$ dos casos apresentaram imunomarcações positivas ++++, $20 \%+++, 20 \%++, 32 \%+$ e $12 \%$ foram negativos (0) não apresentando imunomarcação para o VEGF-D (Figura 10). 


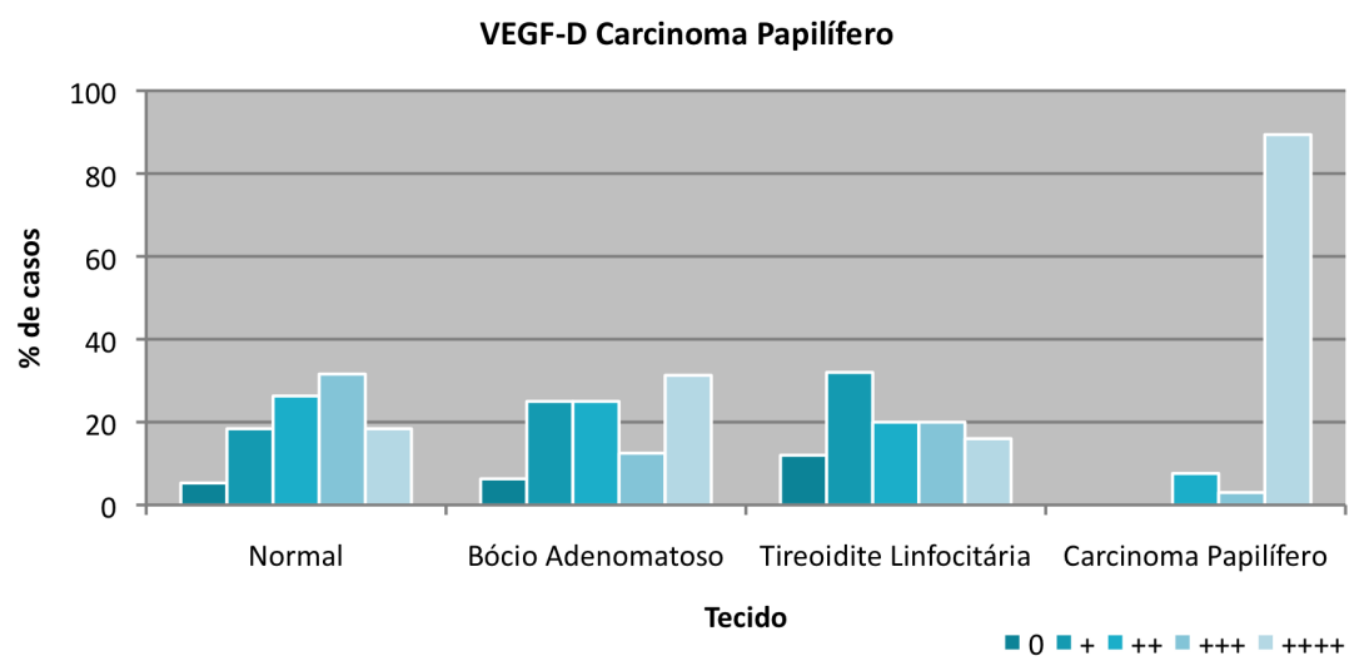

Figura 10. Expressão imuno-histoquímica do VEGF-D nos Carcinomas Papilíferos e suas adjacências apresentando tecido Normal, Bócio Adenomatoso e Tireoidite Linfocitária $(p<0,001)$

\subsubsection{VEGF-R1}

Foi possível avaliar a expressão imuno-histoquímica do VEGF-R1 em 66 amostras da região tumoral $(78,5 \%$ do total de carcinomas papilíferos estudados) e em 38 regiões adjacentes aos carcinomas papilíferos apresentando tecido normal, 16 apresentando bócio adenomatoso e 25 apresentando tireoidite linfocitária (Tabela 9).

Em $76 \%$ dos casos das regiões tumorais as imunomarcações foram positivas ++++ , em $11 \%$ foram positivas,$+++ 8 \%++$ e em $6 \%$ foram negativos (0) não apresentando imunomarcação para o VEGF-R1. Nas regiões adjacentes normais $3 \%$ dos casos apresentaram imunomarcações positivas,$++++ 8 \%+++, 13 \%++, 32 \%+$ e $45 \%$ foram negativos (0). No tecido adjacente ao tumor com bócio adenomatoso $19 \%$ dos casos 
apresentaram imunomarcações positivas ++++, 13\% +++, 13\% ++, $13+$ e $44 \%$ foram negativos (0). Nas tireoidites linfocitárias adjacentes $16 \%$ dos casos apresentaram imunomarcações positivas,$++++ 28 \%+++, 4 \%++$, $12 \%+$ e $40 \%$ foram negativos (0) não apresentando imunomarcação para o VEGF-R1 (Figura 11).

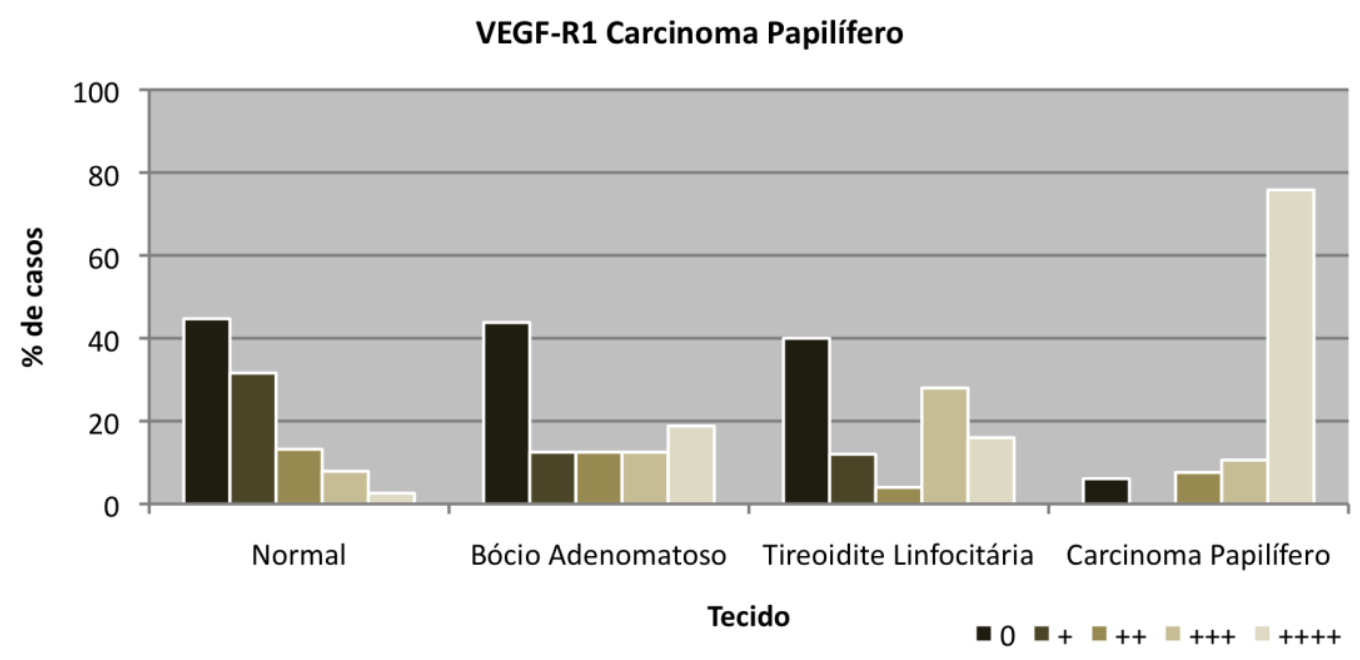

Figura 11. Expressão imuno-histoquímica do VEGF-R1 nos Carcinomas Papilíferos e suas adjacências apresentando tecido Normal, Bócio Adenomatoso e Tireoidite Linfocitária $(p<0,001)$

\subsubsection{VEGF-R3}

Foi possível avaliar a expressão imuno-histoquímica do VEGF-R3 em 64 amostras da região tumoral $(76,1 \%$ do total de carcinomas papilíferos estudados) e em 39 regiões adjacentes aos carcinomas papilíferos apresentando tecido normal, 16 apresentando bócio adenomatoso e 25 apresentando tireoidite linfocitária (Tabela 9). 
Em 94\% dos casos das regiões tumorais as imunomarcações foram positivas ++++ , em $3 \%$ foram positivas +++ e em $3 \%$ foram positivas + para o VEGF-R1. Nas regiões adjacentes normais $10 \%$ dos casos apresentaram imunomarcações positivas +++, $13 \%++, 26 \%+$ e $51 \%$ foram negativos (0). No tecido adjacente ao tumor com bócio adenomatoso $31 \%$ dos casos apresentaram imunomarcações positivas,$++++ 13 \%+++, 19 \%++, 25+$ e $13 \%$ foram negativos (0). Nas tireoidites linfocitárias adjacentes $28 \%$ dos casos apresentaram imunomarcações positivas ++++, $20 \%+++, 24 \%++$, $20 \%+$ e $8 \%$ foram negativos (0) não apresentando imunomarcação para o VEGF-R3 (Figura 12).

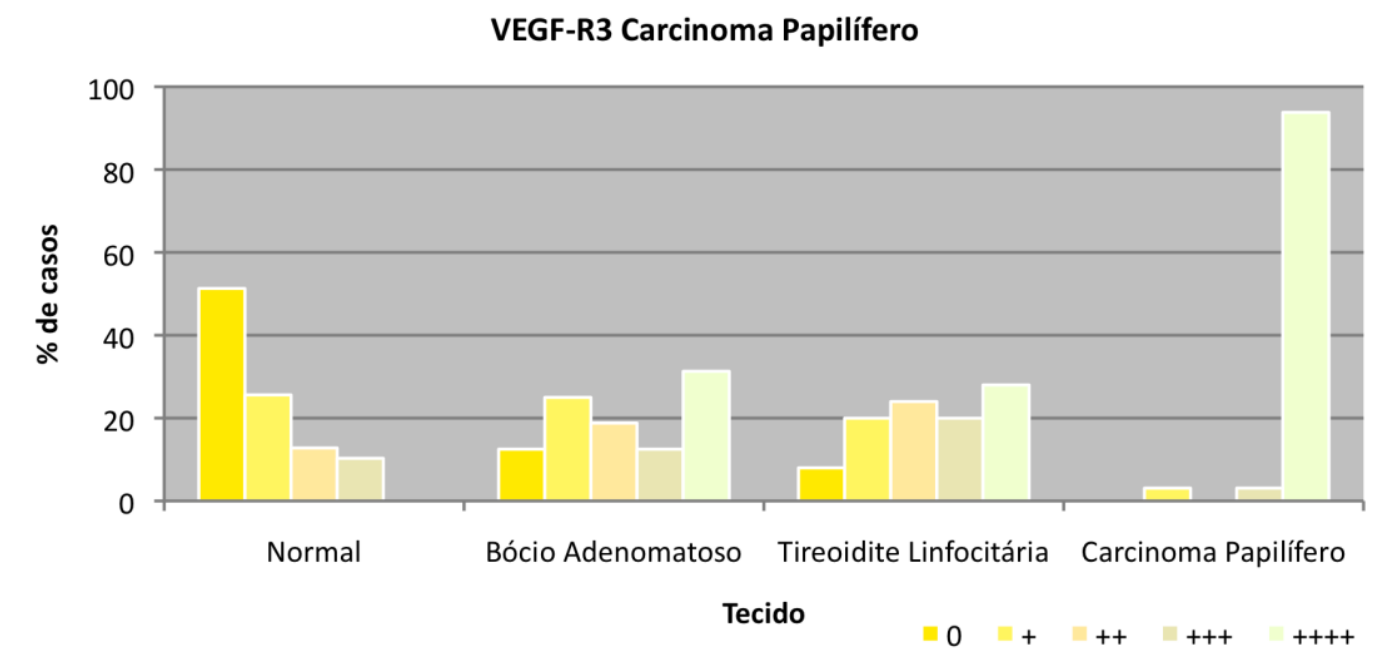

Figura 12. Expressão imuno-histoquímica do VEGF-R3 nos Carcinomas Papilíferos e suas adjacências apresentando tecido Normal, Bócio Adenomatoso e Tireoidite Linfocitária $(p<0,001)$ 


\subsection{Expressão imuno-histoquímica, dicotomizada em negativa ou positiva, dos fatores de crescimento endotelial vascular e de seus receptores nos carcinomas papilíferos estudados}

Com a finalidade de facilitar o entendimento dos resultados obtidos com os dados acima, as reações foram dicotomizadas em duas categorias: Negativas, somatória das amostras negativas e aquelas com até $10 \%$ de imunomarcação positiva; e Positivas, todas as amostras com imunomarcaçoes positivas maior do que $10 \%$.

A maioria dos carcinomas papilíferos estudados apresentaram expressão imuno-histoquímica positiva para o VEGF-A (positiva 96\% dos casos), VEGF-A ${ }_{165}$ b (positiva $81 \%$ dos casos), VEGF-C (positiva $86 \%$ dos casos), VEGF-D (positiva 100\% dos casos), VEGF-R1 (positiva 94\% dos casos) e VEGF-R3 (positiva $97 \%$ dos casos). Uma maior quantidade de casos negativos só foi observada na avaliação da expressão imunohistoquímica do VEGF-B (negativa 92\% dos casos).

Nas regiões adjacentes ao tumor o número de casos positivos para o VEGF-A, VEGF-A 165 b, VEGF-C, VEGF-D, VEGF-R1 e VEGFR-3 foi sempre inferior ao observado nos carcinomas papilíferos. Quanto a expressão imuno-histoquímica do VEGF-B, no tecido adjacente normal e no bócio adenomatoso, todos os casos foram negativos. Na tireoidite linfocitária $96 \%$ dos casos foram negativos e $4 \%$ foram positivos para o VEGF-B. 
Um sumário da porcentagem de casos negativos ou positivos para a expressão imuno-histoquímica dos fatores de crescimento endotelial vascular (VEGF-A; VEGF-A 165 b; VEGF-B; VEGF-C;VEGF-D) e de seus receptores (VEGF-R1 e VEGF-R3) nos carcinomas papilíferos e em suas adjacências apresentando tecido normal, bócio adenomatoso e tireoidite linfocitária pode ser observado na Tabela $10 \mathrm{e}$, as fotomicrografias exemplificando o padrão das expressões imuno-histoquímicas dos VEGFs e VEGFRs nos carcinomas papilíferos estudados estão representadas na Figura 13.

Tabela 10 - Porcentagem de casos com expressão imuno-histoquímica negativa (até $10 \%$ ) ou positiva (> do que 10\%) dos VEGFs e VEGFRs nos Carcinomas Papilíferos e suas adjacências apresentando tecido Normal, Bócio Adenomatoso e Tireoidite Linfocitária

\begin{tabular}{|c|c|c|c|c|c|}
\hline & Carcinoma Papilífero & Normal & Bócio Adenomatoso & Tireoidite Linfocitária & $\mathrm{p}$ \\
\hline & \multicolumn{5}{|c|}{ VEGF-A } \\
\hline Negativo & 5 & 45 & 25 & 48 & \multirow{2}{*}{$<0,001^{*}$} \\
\hline Positivo & 96 & 55 & 75 & 52 & \\
\hline & \multicolumn{5}{|c|}{ VEGF-A165b } \\
\hline Negativo & 19 & 54 & 50 & 76 & \multirow{2}{*}{$<0,001^{\star}$} \\
\hline Positivo & 81 & 46 & 50 & 24 & \\
\hline & \multicolumn{5}{|c|}{ VEGF-B } \\
\hline Negativo & 92 & 100 & 100 & 96 & \multirow{2}{*}{0,224} \\
\hline Positivo & 8 & 0 & 0 & 4 & \\
\hline & \multicolumn{5}{|c|}{ VEGF-C } \\
\hline Negativo & 14 & 94 & 56 & 38 & \multirow{2}{*}{$<0,001^{*}$} \\
\hline Positivo & 86 & 6 & 44 & 63 & \\
\hline & \multicolumn{5}{|c|}{ VEGF-D } \\
\hline Negativo & 0 & 24 & 31 & 44 & \multirow{2}{*}{$<0,001^{*}$} \\
\hline Positivo & 100 & 76 & 69 & 56 & \\
\hline & \multicolumn{5}{|c|}{ VEGF-R1 } \\
\hline Negativo & 6 & 76 & 56 & 52 & \multirow{2}{*}{$<0,001^{*}$} \\
\hline Positivo & 94 & 24 & 44 & 48 & \\
\hline & \multicolumn{5}{|c|}{ VEGF-R3 } \\
\hline Negativo & 3 & 77 & 38 & 28 & \multirow{2}{*}{$<0,001^{*}$} \\
\hline Positivo & 97 & 23 & 63 & 72 & \\
\hline
\end{tabular}



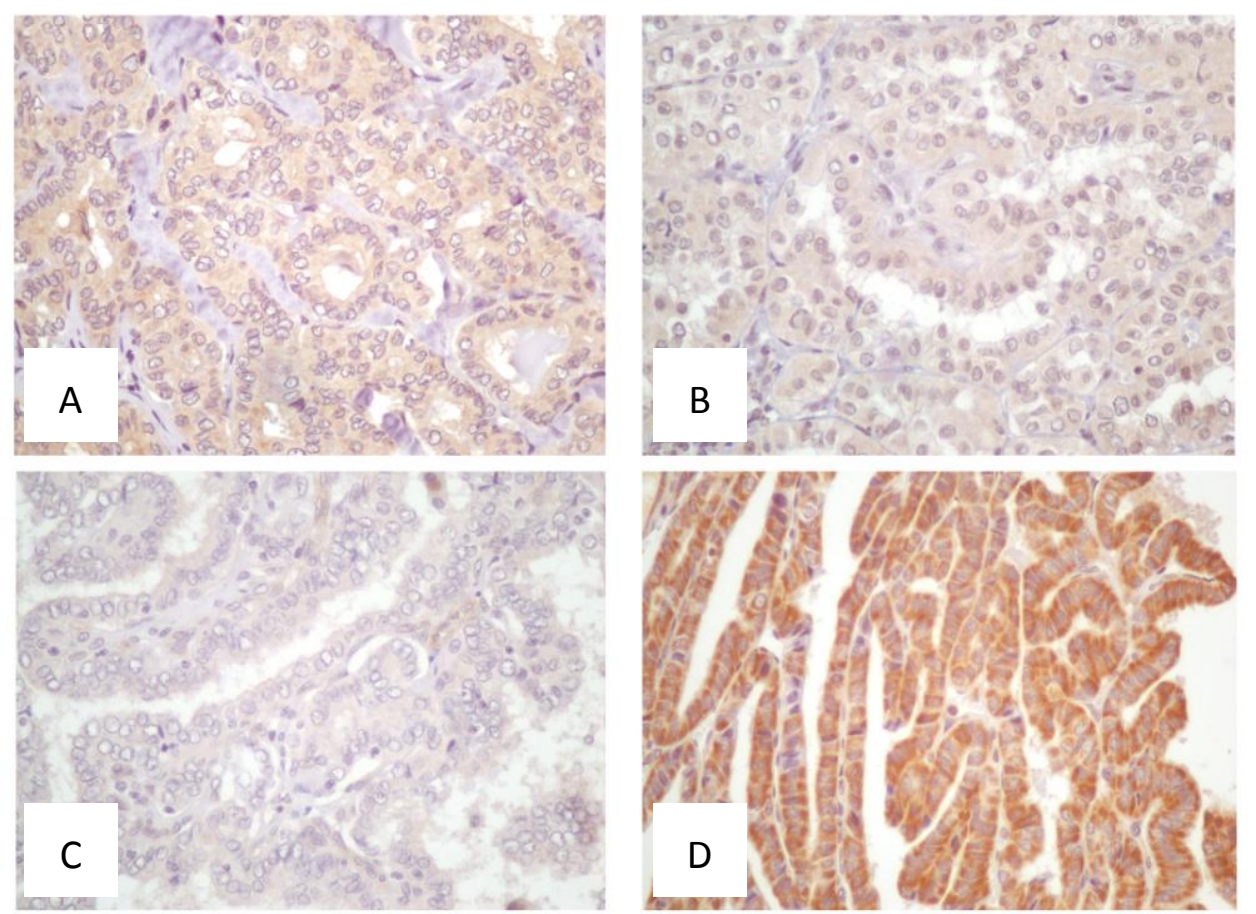

B
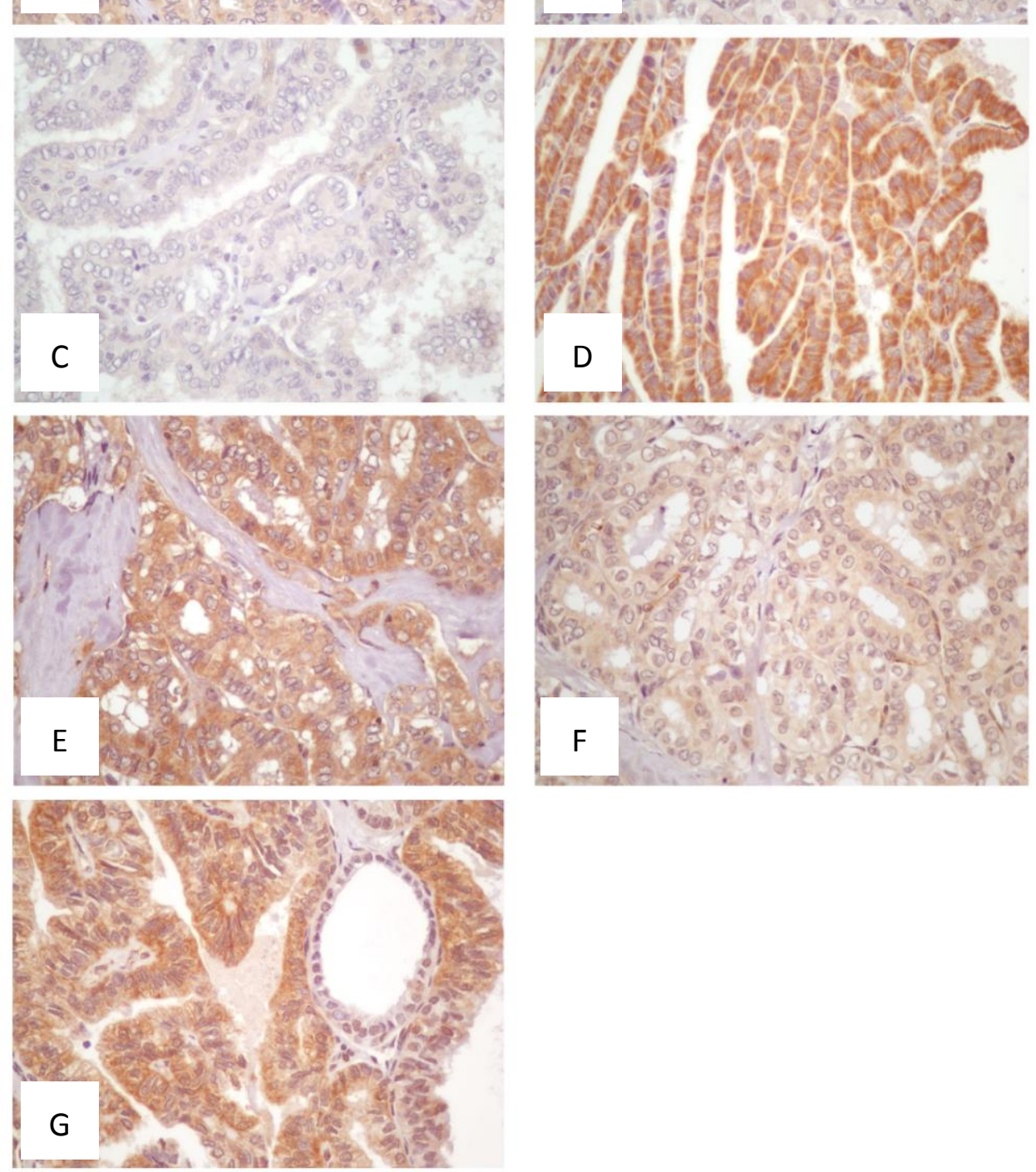

Figura 13. Fotomicrografias dos padrões de imunoexpressão do VEGF-A (A aumento 400X), VEGF-A ${ }_{165}$ b (B - aumento 400X), VEGF-B (C - aumento 400X), VEGF-C (D - aumento 400X), VEGF-D (E - aumento 400X), VEGF-R1 (F - aumento 400X) e VEGF-R3 (G - aumento 400X) nos carcinomas papilíferos 


\subsection{Correlações entre a expressão imuno-histoquímica dos fatores de crescimento endotelial vascular e de seus receptores e as variáveis clínico-patológicas dos carcinomas papilíferos estudados}

As imunoexpressões dos VEGFs (VEGF-A; VEGF-A ${ }_{165} \mathrm{~b}$; VEGF-B; VEGF-C;VEGF-D) e de seus receptores (VEGF-R1 e VEGF-R3) foram individualmente correlacionadas com os dados clínico-patológicos dos carcinomas papiliferos.

Quando analisadas as expressões dos VEGFs e VEGFRs de 0 a ++++, não houveram correlações estatisticamente significantes dos dados clínico-patológicos sexo, idade, lado, invasão de cápsula, invasão de vaso, comprometimento de adjacência, metástase, $\mathrm{T}, \mathrm{N}, \mathrm{M}$ e estadiamento com as imunoexpressões dos VEGF-A (Tabela 11), VEGF-A ${ }_{165} \mathrm{~b}$ (Tabela 12), VEGF-B (Tabela 13), VEGF-C (Tabela 14) e VEGF-R1 (Tabela 16).

Tanto o VEGF-D (Tabela 15) como o VEGF-R3 (Tabela 17) apresentaram correlações estatisticamente significantes apenas com 0 estadiamento (VEGF-D $p=0,004$ e VEGF-R3 $p=0,017$ ) dos carcinomas papilíferos.

Ao dicotomizarmos a expressão dos VEGFs e VEGFRs em duas categorias, negativos (até 10\% de imunomarcação positiva) e positivos (imunomarcação positiva maior do que 10\%) pudemos observar correlação estatisticamente significante do VEGF-A e a invasão de vasos ( $p=0,049)$, do VEGF-B e a idade dos pacientes $(p=0,047)$, do VEGF-R1 e do lobo 
acometido pelo tumor ( $p=0,010)$ e do VEGF-R3 com o estadio $(p=0,002)$ dos carcinomas papilíferos (Tabela 18).

Tabela 11 - Correlação das variáveis clínico-patológicas e da imunoexpressão do VEGF-A com freqüências absolutas e percentual de casos de acordo com o nível de imunoexpressão nos carcinomas papilíferos

\begin{tabular}{|c|c|c|c|c|c|c|c|c|c|c|c|c|}
\hline & & \multicolumn{11}{|c|}{ VEGF-A } \\
\hline & & \multicolumn{2}{|c|}{0} & \multicolumn{2}{|c|}{+} & \multicolumn{2}{|c|}{++} & \multicolumn{2}{|c|}{+++} & \multicolumn{2}{|c|}{++++} & \multirow{2}{*}{$\mathrm{p}$} \\
\hline & & $\mathrm{n}$ & $\%$ & $\mathrm{n}$ & $\%$ & $\mathrm{n}$ & $\%$ & $\mathrm{n}$ & $\%$ & $\mathrm{n}$ & $\%$ & \\
\hline \multicolumn{13}{|l|}{ Sexo } \\
\hline & M & 0 & 0 & - & - & - & - & 0 & 0 & 10 & 100 & \multirow{3}{*}{0,444} \\
\hline & $\mathrm{F}$ & 3 & 5,4 & - & - & - & - & 5 & 8,9 & 48 & 85,7 & \\
\hline & Total & 3 & 4,5 & - & - & - & - & 5 & 7,6 & 58 & 87,9 & \\
\hline \multicolumn{13}{|l|}{ Idade } \\
\hline & $<45$ anos & 2 & 5 & - & - & - & - & 4 & 10 & 34 & 85 & \multirow{3}{*}{0,657} \\
\hline & $>$ ou $=45$ anos & 1 & 4 & - & - & - & - & 1 & 4 & 23 & 92 & \\
\hline & Total & 3 & 4,6 & - & - & - & - & 5 & 7,7 & 57 & 87,7 & \\
\hline \multicolumn{13}{|l|}{ Lado } \\
\hline & Direito & 0 & 0 & - & - & - & - & 0 & 0 & 17 & 100 & \multirow{8}{*}{0,399} \\
\hline & Direito e Esquerdo & 1 & 25 & - & - & - & - & 1 & 25 & 2 & 50 & \\
\hline & Direito e Istmo & 0 & 0 & - & - & - & - & 0 & 0 & 5 & 100 & \\
\hline & Esquerdo & 1 & 7,7 & - & - & - & - & 1 & 7,7 & 11 & 84,6 & \\
\hline & Esquerdo e Istmo & 0 & 0 & - & - & - & - & 0 & 0 & 1 & 100 & \\
\hline & Istmo & 1 & 16,7 & - & - & - & - & 1 & 16,7 & 4 & 66,7 & \\
\hline & Difuso & 0 & 0 & - & - & - & - & 2 & 14,3 & 12 & 85,7 & \\
\hline & Total & 3 & 5 & - & - & - & - & 5 & 8,3 & 52 & 86,7 & \\
\hline \multicolumn{13}{|l|}{$\begin{array}{r}\text { Invasão de } \\
\text { Cápsula }\end{array}$} \\
\hline & Presente & 1 & 6,7 & - & - & - & - & 0 & 0 & 14 & 93,3 & \\
\hline & Não Detectada & 2 & 3,9 & - & - & - & - & 5 & 9,8 & 44 & 86,3 & 0,421 \\
\hline & Total & 3 & 4,5 & - & - & - & - & 5 & 7,6 & 58 & 87,9 & \\
\hline Invasão de Vaso & & & & & & & & & & & & \\
\hline & Presente & 2 & 14,3 & - & - & - & - & 1 & 7,1 & 11 & 78,6 & \\
\hline & Não Detectada & 1 & 1,9 & - & - & - & - & 4 & 7,7 & 47 & 90,4 & 0,143 \\
\hline & Total & 3 & 4,5 & - & - & - & - & 5 & 7,6 & 58 & 87,9 & \\
\hline $\begin{array}{r}\text { Comprometimento } \\
\text { de Adjacencia }\end{array}$ & & & & & & & & & & & & \\
\hline & Presente & 1 & 11,1 & - & - & - & - & 1 & 11,1 & 7 & 77,8 & \\
\hline & Não Detectada & 2 & 3,5 & - & - & - & - & 4 & 7 & 51 & 89,5 & 0,527 \\
\hline & Total & 3 & 4,5 & - & - & - & - & 5 & 7,6 & 58 & 87,9 & \\
\hline Metástase & & & & & & & & & & & & \\
\hline & Presente & 1 & 9,1 & - & - & - & - & 0 & 0 & 10 & 90,9 & \\
\hline & Ausente & 2 & 3,6 & - & - & - & - & 5 & 9,1 & 48 & 87,3 & 0,446 \\
\hline & Total & 3 & 4,5 & - & - & - & - & 5 & 7,6 & 58 & 87,9 & \\
\hline $\mathbf{T}$ & & & & & & & & & & & & \\
\hline & T1 & 2 & 4,3 & - & - & - & - & 3 & 6,5 & 41 & 89,1 & \\
\hline & T2 & 1 & 14,3 & - & - & - & - & 1 & 14,3 & 5 & 71,4 & \\
\hline & T3 & 0 & 0 & - & - & - & - & 1 & 10 & 9 & 90 & \\
\hline & T4 & 0 & 0 & - & - & - & - & 0 & 0 & 1 & 100 & 0,926 \\
\hline & T4A & 0 & 0 & - & - & - & - & 0 & 0 & 2 & 100 & \\
\hline & Total & 3 & 4,5 & - & - & - & - & 5 & 7,6 & 58 & 87,9 & \\
\hline $\mathbf{N}$ & & & & & & & & & & & & \\
\hline & NO & 2 & 3,8 & - & - & - & - & 5 & 9,4 & 46 & 86,8 & \\
\hline & N1 & 0 & 0 & - & - & - & - & 0 & 0 & 3 & 100 & \\
\hline & N1A & 0 & 0 & - & - & - & - & 0 & 0 & 1 & 100 & 0,879 \\
\hline & N1B & 1 & 11,1 & - & - & - & - & 0 & 0 & 8 & 88,9 & \\
\hline & Total & 3 & 4,5 & - & - & - & - & 5 & 7,6 & 58 & 87,9 & \\
\hline $\mathbf{M}$ & & & & & & & & & & & & \\
\hline & MO & 3 & 4,7 & - & - & - & - & 5 & 7,8 & 56 & 87,5 & \\
\hline & Total & 3 & 4,7 & - & - & - & - & 5 & 7,8 & 56 & 87,5 & - \\
\hline $\begin{array}{r}\text { Estadiamento } \\
\text { (TNM) }\end{array}$ & & & & & & & & & & & & \\
\hline & I & 3 & 5,4 & - & - & - & - & 3 & 5,4 & 50 & 89,3 & \\
\hline & II & 0 & 0 & - & - & - & - & 1 & 33,3 & 2 & 66,7 & \\
\hline & III & 0 & 0 & - & - & - & - & 1 & 50 & 1 & 50 & 0,161 \\
\hline & IVA & 0 & 0 & - & - & - & - & 0 & 0 & 5 & 100 & \\
\hline & Total & 3 & 4,5 & - & - & - & - & 5 & 7,6 & 58 & 87,9 & \\
\hline
\end{tabular}

(o símbolo - foi aplicado para indicar que não há valor para esta variável) 
Tabela 12 - Correlação das variáveis clínico-patológicas e da imunoexpressão do VEGF-A ${ }_{165}$ b com freqüências absolutas e percentual de casos de acordo com o nível de imunoexpressão nos carcinomas papilíferos

\begin{tabular}{|c|c|c|c|c|c|c|c|c|c|c|c|c|}
\hline & & \multicolumn{11}{|c|}{ VEGF-A165b } \\
\hline & & \multicolumn{2}{|c|}{0} & \multicolumn{2}{|c|}{+} & \multicolumn{2}{|c|}{++} & \multicolumn{2}{|c|}{+++} & \multicolumn{2}{|c|}{++++} & \multirow{2}{*}{$\mathrm{p}$} \\
\hline & & $\mathrm{n}$ & $\%$ & $\mathrm{n}$ & $\%$ & $\mathrm{n}$ & $\%$ & $\mathrm{n}$ & $\%$ & $\mathrm{n}$ & $\%$ & \\
\hline \multicolumn{13}{|l|}{ Sexo } \\
\hline & $\mathrm{M}$ & 2 & 22,2 & 0 & 0 & 1 & 11,1 & 0 & 0 & 34 & 54 & \multirow{3}{*}{0,649} \\
\hline & $\mathrm{F}$ & 9 & 16,7 & 1 & 1,9 & 5 & 9,3 & 11 & 20,4 & 28 & 51,9 & \\
\hline & Total & 11 & 17,5 & 1 & 1,6 & 6 & 9,5 & 11 & 17,5 & 6 & 66,7 & \\
\hline \multirow[t]{4}{*}{ Idade } & & & & & & & & & & & & \\
\hline & $<45$ anos & 6 & 16,2 & 0 & 0 & 4 & 10,8 & 6 & 16,2 & 21 & 56,8 & \multirow{3}{*}{0,725} \\
\hline & $>\mathrm{ou}=45$ anos & 5 & 20 & 1 & 4 & 2 & 8 & 5 & 20 & 12 & 48 & \\
\hline & Total & 11 & 17,7 & 1 & 1,6 & 6 & 9,7 & 11 & 17,7 & 33 & 53,2 & \\
\hline \multirow[t]{9}{*}{ Lado } & & & & & & & & & & & & \\
\hline & Direito & 2 & 12,5 & 0 & 0 & 3 & 18,8 & 1 & 6,3 & 10 & 62,5 & \multirow{8}{*}{0,129} \\
\hline & Direito e Esquerdo & 3 & 75 & 0 & 0 & 1 & 25 & 0 & 0 & 0 & 0 & \\
\hline & Direito e Istmo & 1 & 20 & 0 & 0 & 1 & 20 & 2 & 40 & 1 & 20 & \\
\hline & Esquerdo & 3 & 23,1 & 1 & 7,7 & 0 & 0 & 2 & 15,4 & 7 & 53,8 & \\
\hline & Esquerdo e Istmo & 0 & 0 & 0 & 0 & 0 & 0 & 1 & 100 & 0 & 0 & \\
\hline & Istmo & 0 & 0 & 0 & 0 & 0 & 0 & 2 & 33,3 & 4 & 66,7 & \\
\hline & Difuso & 2 & 14,3 & 0 & 0 & 1 & 7,1 & 1 & 7,1 & 10 & 71,4 & \\
\hline & Total & 11 & 18,6 & 1 & 1,7 & 6 & 10,2 & 9 & 15,3 & 32 & 54,2 & \\
\hline \multirow[t]{4}{*}{$\begin{array}{r}\text { Invasão de } \\
\text { Cápsula }\end{array}$} & & & & & & & & & & & & \\
\hline & Presente & 2 & 13,3 & 0 & 0 & 1 & 6,7 & 3 & 20 & 9 & 60 & \\
\hline & Não Detectada & 9 & 18,8 & 1 & 2,1 & 5 & 10,4 & 8 & 16,7 & 25 & 52,1 & 0,928 \\
\hline & Total & 11 & 17,5 & 1 & 1,6 & 6 & 9,5 & 11 & 17,5 & 34 & 54 & \\
\hline Invasão de Vaso & & & & & & & & & & & & \\
\hline & Presente & 2 & 15,4 & 0 & 0 & 1 & 7,7 & 4 & 30,8 & 6 & 46,2 & \\
\hline & Não Detectada & 9 & 18 & 1 & 2 & 5 & 10 & 7 & 14 & 28 & 56 & 0,698 \\
\hline & Total & 11 & 17,5 & 1 & 1,6 & 6 & 9,5 & 11 & 17,5 & 34 & 54 & \\
\hline $\begin{array}{r}\text { Comprometimento } \\
\text { de Adjacencia }\end{array}$ & & & & & & & & & & & & \\
\hline & Presente & 2 & 22,2 & 0 & 0 & 2 & 22,2 & 1 & 11,1 & 4 & 44,4 & \\
\hline & Não Detectada & 9 & 16,7 & 1 & 1,9 & 4 & 7,4 & 10 & 18,5 & 30 & 55,6 & 0,645 \\
\hline & Total & 11 & 17,5 & 1 & 1,6 & 6 & 9,5 & 11 & 17,5 & 34 & 54 & \\
\hline Metástase & & & & & & & & & & & & \\
\hline & Presente & 2 & 18,2 & 0 & 0 & 2 & 18,2 & 0 & 0 & 7 & 63,6 & \\
\hline & Ausente & 9 & 17,3 & 1 & 1,9 & 4 & 7,7 & 11 & 21,2 & 27 & 51,9 & 0,431 \\
\hline & Total & 11 & 17,5 & 1 & 1,6 & 6 & 9,5 & 11 & 17,5 & 34 & 54 & \\
\hline $\begin{array}{ll}T \\
\end{array}$ & & & & & & & & & & & & \\
\hline & T1 & 8 & 18,2 & 1 & 2,3 & 4 & 9,1 & 9 & 20,5 & 22 & 50 & \\
\hline & $\mathrm{T} 2$ & 1 & 14,3 & 0 & 0 & 1 & 14,3 & 1 & 14,3 & 4 & 57,1 & \\
\hline & T3 & 1 & 11,1 & 0 & 0 & 1 & 11,1 & 1 & 11,1 & 6 & 66,7 & 0,944 \\
\hline & T4 & 1 & 100 & 0 & 0 & 0 & 0 & 0 & 0 & 0 & 0 & 0,944 \\
\hline & T4A & 0 & 0 & 0 & 0 & 0 & 0 & 0 & 0 & 2 & 100 & \\
\hline & Total & 11 & 17,5 & 1 & 1,6 & 6 & 9,5 & 11 & 17,5 & 34 & 54 & \\
\hline $\mathbf{N}$ & & & & & & & & & & & & \\
\hline & NO & 9 & 18 & 1 & 2 & 3 & 6 & 11 & 22 & 26 & 52 & \\
\hline & N1 & 0 & 0 & 0 & 0 & 1 & 33,3 & 0 & 0 & 2 & 66,7 & \\
\hline & N1A & 0 & 0 & 0 & 0 & 0 & 0 & 0 & 0 & 1 & 100 & 0,743 \\
\hline & N1B & 2 & 22,2 & 0 & 0 & 2 & 22,2 & 0 & 0 & 5 & 55,6 & \\
\hline & Total & 11 & 17,5 & 1 & 1,6 & 6 & 9,5 & 11 & 17,5 & 34 & 54 & \\
\hline M & & & & & & & & & & & & \\
\hline & MO & 11 & 18 & 1 & 1,6 & 5 & 8,2 & 11 & 18 & 33 & 54,1 & \\
\hline & Total & 11 & 18 & 1 & 1,6 & 5 & 8,2 & 11 & 18 & 33 & 54,1 & - \\
\hline $\begin{array}{r}\text { Estadiamento } \\
\text { (TNM) }\end{array}$ & & & & & & & & & & & & \\
\hline & 1 & 9 & 17 & 1 & 1,9 & 5 & 9,4 & 11 & 20,8 & 27 & 50,9 & \\
\hline & II & 0 & 0 & 0 & 0 & 0 & 0 & 0 & 0 & 3 & 100 & \\
\hline & III & 1 & 50 & 0 & 0 & 0 & 0 & 0 & 0 & 1 & 50 & 0,895 \\
\hline & IVA & 1 & 20 & 0 & 0 & 1 & 20 & 0 & 0 & 3 & 60 & \\
\hline & Total & 11 & 17,5 & 1 & 1,6 & 6 & 9,5 & 11 & 17,5 & 34 & 54 & \\
\hline
\end{tabular}

(o símbolo - foi aplicado para indicar que não há valor para esta variável) 
Tabela 13 - Correlação das variáveis clínico-patológicas e da imunoexpressão do VEGF-B com freqüências absolutas e percentual de casos de acordo com o nível de imunoexpressão nos carcinomas papilíferos

\begin{tabular}{|c|c|c|c|c|c|c|c|c|c|c|c|c|}
\hline & & \multicolumn{11}{|c|}{ VEGF-B } \\
\hline & & \multicolumn{2}{|c|}{0} & \multicolumn{2}{|c|}{+} & \multicolumn{2}{|c|}{++} & \multicolumn{2}{|c|}{+++} & \multicolumn{2}{|c|}{++++} & \multirow[b]{2}{*}{$p$} \\
\hline & & $\mathrm{n}$ & $\%$ & $\mathrm{n}$ & $\%$ & $\mathrm{n}$ & $\%$ & $\mathrm{n}$ & $\%$ & $\mathrm{n}$ & $\%$ & \\
\hline \multicolumn{13}{|l|}{ Sexo } \\
\hline & $\mathrm{M}$ & 7 & 70 & 3 & 30 & 0 & 0 & 0 & 0 & - & - & \multirow{3}{*}{0,673} \\
\hline & $\mathrm{F}$ & 41 & 73,2 & 10 & 17,9 & 4 & 7,1 & 1 & 1,8 & - & - & \\
\hline & Total & 48 & 72,7 & 13 & 19,7 & 4 & 6,1 & 1 & 1,5 & - & - & \\
\hline \multicolumn{13}{|l|}{ Idade } \\
\hline & $<45$ anos & 32 & 80 & 7 & 17,5 & 1 & 2,5 & 0 & 0 & - & - & \multirow{3}{*}{0,218} \\
\hline & $>$ ou $=45$ anos & 16 & 64 & 5 & 20 & 3 & 12 & 1 & 4 & - & - & \\
\hline & Total & 48 & 73,8 & 12 & 18,5 & 4 & 6,2 & 1 & 1,5 & - & - & \\
\hline \multicolumn{13}{|l|}{ Lado } \\
\hline & Direito & 12 & 70,6 & 4 & 23,5 & 0 & 0 & 1 & 5,9 & - & - & \multirow{8}{*}{0,105} \\
\hline & Direito e Esquerdo & 3 & 75 & 1 & 25 & 0 & 0 & 0 & 0 & - & - & \\
\hline & Direito e Istmo & 2 & 40 & 3 & 60 & 0 & 0 & 0 & 0 & - & - & \\
\hline & Esquerdo & 10 & 76,9 & 2 & 15,4 & 1 & 7,7 & 0 & 0 & - & - & \\
\hline & Esquerdo e Istmo & 1 & 100 & 0 & 0 & 0 & 0 & 0 & 0 & - & - & \\
\hline & Istmo & 2 & 33,3 & 2 & 33,3 & 2 & 33,3 & 0 & 0 & - & - & \\
\hline & Difuso & 14 & 100 & 0 & 0 & 0 & 0 & 0 & 0 & - & - & \\
\hline & Total & 44 & 73,3 & 12 & 20 & 3 & 5 & 1 & 1,7 & - & - & \\
\hline \multicolumn{13}{|l|}{$\begin{array}{r}\text { Invasão de } \\
\text { Cápsula }\end{array}$} \\
\hline & Presente & 14 & 93,3 & 1 & 6,7 & 0 & 0 & 0 & 0 & - & - & \\
\hline & Não Detectada & 34 & 66,7 & 12 & 23,5 & 4 & 7,8 & 1 & 2 & - & - & 0,233 \\
\hline & Total & 48 & 72,7 & 13 & 19,7 & 4 & 6,1 & 1 & 1,5 & - & - & \\
\hline Invasão de Vaso & & & & & & & & & & & & \\
\hline & Presente & 9 & 64,3 & 4 & 28,6 & 1 & 7,1 & 0 & 0 & - & - & \\
\hline & Não Detectada & 39 & 75 & 9 & 17,3 & 3 & 5,8 & 1 & 1,9 & - & - & 0,756 \\
\hline & Total & 48 & 72,7 & 13 & 19,7 & 4 & 6,1 & 1 & 1,5 & - & - & \\
\hline $\begin{array}{r}\text { Comprometimento } \\
\text { de Adjacencia }\end{array}$ & & & & & & & & & & & & \\
\hline & Presente & 8 & 88,9 & 1 & 11,1 & 0 & 0 & 0 & 0 & - & - & \\
\hline & Não Detectada & 40 & 70,2 & 12 & 21,1 & 4 & 7,0 & 1 & 1,8 & - & - & 0,670 \\
\hline & Total & 48 & 72,7 & 13 & 19,7 & 4 & 6,1 & 1 & 1,5 & - & - & \\
\hline Metástase & & & & & & & & & & & & \\
\hline & Presente & 10 & 90,9 & 1 & 9,1 & 0 & 0 & 0 & 0 & - & - & \\
\hline & Ausente & 38 & 69,1 & 12 & 21,8 & 4 & 7,3 & 1 & 1,8 & - & - & 0,502 \\
\hline & Total & 48 & 72,7 & 13 & 19,7 & 4 & 6,1 & 1 & 1,5 & - & - & \\
\hline $\mathbf{T}$ & & & & & & & & & & & & \\
\hline & $\mathrm{T} 1$ & 31 & 67,4 & 10 & 21,7 & 4 & 8,7 & 1 & 2,2 & - & - & \\
\hline & T2 & 6 & 85,7 & 1 & 14,3 & 0 & 0 & 0 & 0 & - & - & \\
\hline & T3 & 9 & 90 & 1 & 10 & 0 & 0 & 0 & 0 & - & - & 0959 \\
\hline & T4 & 1 & 100 & 0 & 0 & 0 & 0 & 0 & 0 & - & - & 0,959 \\
\hline & T4A & 1 & 50 & 1 & 50 & 0 & 0 & 0 & 0 & - & - & \\
\hline & Total & 48 & 72,7 & 13 & 19,7 & 4 & 6,1 & 1 & 1,5 & - & - & \\
\hline $\mathbf{N}$ & & & & & & & & & & & & \\
\hline & No & 37 & 69,8 & 11 & 20,8 & 4 & 7,5 & 1 & 1,9 & - & - & \\
\hline & N1 & 2 & 66,7 & 1 & 33,3 & 0 & 0 & 0 & 0 & - & - & \\
\hline & $\mathrm{N} 1 \mathrm{~A}$ & 1 & 100 & 0 & 0 & 0 & 0 & 0 & 0 & - & - & 0,979 \\
\hline & N1B & 8 & 88,9 & 1 & 11,1 & 0 & 0 & 0 & 0 & - & - & \\
\hline & Total & 48 & 72,7 & 13 & 19,7 & 4 & 6,1 & 1 & 1,5 & - & - & \\
\hline $\mathbf{M}$ & & & & & & & & & & & & \\
\hline & MO & 47 & 73,4 & 12 & 18,8 & 4 & 6,3 & 1 & 1,6 & - & - & 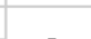 \\
\hline & Total & 47 & 73,4 & 12 & 18,8 & 4 & 6,3 & 1 & 1,6 & - & - & - \\
\hline $\begin{array}{r}\text { Estadiamento } \\
\text { (TNM) }\end{array}$ & & & & & & & & & & & & \\
\hline & I & 39 & 69,6 & 12 & 21,4 & 4 & 7,1 & 1 & 1,8 & - & - & \\
\hline & II & 3 & 100 & 0 & 0 & 0 & 0 & 0 & 0 & - & - & \\
\hline & III & 2 & 100 & 0 & 0 & 0 & 0 & 0 & 0 & - & - & 0,979 \\
\hline & IVA & 4 & 80 & 1 & 20 & 0 & 0 & 0 & 0 & - & - & \\
\hline & Total & 48 & 72,7 & 13 & 19,7 & 4 & 6,1 & 1 & 1,5 & - & - & \\
\hline
\end{tabular}

(o símbolo - foi aplicado para indicar que não há valor para esta variável) 
Tabela 14 - Correlação das variáveis clínico-patológicas e da imunoexpressão do VEGF-C com freqüências absolutas e percentual de casos de acordo com o nível de imunoexpressão nos carcinomas papilíferos

\begin{tabular}{|c|c|c|c|c|c|c|c|c|c|c|c|c|}
\hline & & \multicolumn{11}{|c|}{ VEGF-C } \\
\hline & & \multicolumn{2}{|c|}{0} & \multicolumn{2}{|c|}{+} & \multicolumn{2}{|c|}{++} & \multicolumn{2}{|c|}{+++} & \multicolumn{2}{|c|}{++++} & \multirow{2}{*}{$p$} \\
\hline & & $\mathrm{n}$ & $\%$ & $\mathrm{n}$ & $\%$ & $\mathrm{n}$ & $\%$ & $\mathrm{n}$ & $\%$ & $\mathrm{n}$ & $\%$ & \\
\hline \multicolumn{13}{|l|}{ Sexo } \\
\hline & $\mathrm{M}$ & 0 & 0 & 0 & 0 & 2 & 20 & 4 & 40 & 4 & 40 & \multirow{3}{*}{0,414} \\
\hline & $\mathrm{F}$ & 1 & 1,8 & 8 & 14,5 & 6 & 10,9 & 11 & 20 & 29 & 52,7 & \\
\hline & Total & 1 & 1,5 & 8 & 12,3 & 8 & 12,3 & 15 & 23,1 & 33 & 50,8 & \\
\hline \multicolumn{13}{|l|}{ Idade } \\
\hline & $<45$ anos & 1 & 2,5 & 4 & 10 & 4 & 10 & 10 & 25 & 21 & 52,5 & \multirow{3}{*}{0,706} \\
\hline & $>$ ou $=45$ anos & 0 & 0 & 4 & 16,7 & 4 & 16,7 & 4 & 16,7 & 12 & 50 & \\
\hline & Total & 1 & 1,6 & 8 & 12,5 & 8 & 12,5 & 14 & 21,9 & 33 & 51,6 & \\
\hline \multicolumn{13}{|l|}{ Lado } \\
\hline & Direito & 0 & 0 & 0 & 0 & 3 & 17,6 & 5 & 29,4 & 9 & 52,9 & \multirow{8}{*}{0,079} \\
\hline & Direito e Esquerdo & 0 & 0 & 2 & 50 & 0 & 0 & 2 & 50 & 0 & 0 & \\
\hline & Direito e Istmo & 0 & 0 & 1 & 25 & 0 & 0 & 1 & 25 & 2 & 50 & \\
\hline & Esquerdo & 0 & 0 & 4 & 30,8 & 1 & 7,7 & 1 & 7,7 & 7 & 53,8 & \\
\hline & Esquerdo e Istmo & 0 & 0 & 0 & 0 & 0 & 0 & 1 & 100 & 0 & 0 & \\
\hline & Istmo & 0 & 0 & 0 & 0 & 0 & 0 & 4 & 66,7 & 2 & 33,3 & \\
\hline & Difuso & 1 & 7,1 & 1 & 7,1 & 3 & 21,4 & 0 & 0 & 9 & 64,3 & \\
\hline & Total & 1 & 1,7 & 8 & 13,6 & 7 & 11,9 & 14 & 23,7 & 29 & 49,2 & \\
\hline \multicolumn{13}{|l|}{$\begin{array}{r}\text { Invasão de } \\
\text { Cápsula }\end{array}$} \\
\hline & Presente & 0 & 0 & 1 & 6,7 & 1 & 6,7 & 4 & 26,7 & 9 & 60 & \\
\hline & Não Detectada & 1 & 2 & 7 & 14 & 7 & 14 & 11 & 22 & 24 & 48 & 0,783 \\
\hline & Total & 1 & 1,5 & 8 & 12,3 & 8 & 12,3 & 15 & 23,1 & 33 & 50,8 & \\
\hline Invasão de Vaso & & & & & & & & & & & & \\
\hline & Presente & 0 & 0 & 1 & 7,1 & 3 & 21,4 & 5 & 35,7 & 5 & 35,7 & \\
\hline & Não Detectada & 1 & 2 & 7 & 13,7 & 5 & 9,8 & 10 & 19,6 & 28 & 54,9 & 0,420 \\
\hline & Total & 1 & 1,5 & 8 & 12,3 & 8 & 12,3 & 15 & 23,1 & 33 & 50,8 & \\
\hline $\begin{array}{r}\text { Comprometimento } \\
\text { de Adjacencia }\end{array}$ & & & & & & & & & & & & \\
\hline & Presente & 0 & 0 & 2 & 22,2 & 0 & 0 & 3 & 33,3 & 4 & 44,4 & \\
\hline & Não Detectada & 1 & 1,8 & 6 & 10,7 & 8 & 14,3 & 12 & 21,4 & 29 & 51,8 & 0,585 \\
\hline & Total & 1 & 1,5 & 8 & 12,3 & 8 & 12,3 & 15 & 23,1 & 33 & 50,8 & \\
\hline Metástase & & & & & & & & & & & & \\
\hline & Presente & 0 & 0 & 2 & 18,2 & 0 & 0 & 1 & 9,1 & 8 & 72,7 & \\
\hline & Ausente & 1 & 1,9 & 6 & 11,1 & 8 & 14,8 & 14 & 25,9 & 25 & 46,3 & 0,333 \\
\hline & Total & 1 & 1,5 & 8 & 12,3 & 8 & 12,3 & 15 & 23,1 & 33 & 50,8 & \\
\hline$T$ & & & & & & & & & & & & \\
\hline & T1 & 1 & 2,2 & 6 & 13 & 6 & 13 & 12 & 26,1 & 21 & 45,7 & \\
\hline & T2 & 0 & 0 & 1 & 16,7 & 1 & 16,7 & 1 & 16,7 & 3 & 50 & \\
\hline & T3 & 0 & 0 & 1 & 10 & 1 & 10 & 2 & 20 & 6 & 60 & \\
\hline & $\mathrm{T} 4$ & 0 & 0 & 0 & 0 & 0 & 0 & 0 & 0 & 1 & 100 & 0,998 \\
\hline & T4A & 0 & 0 & 0 & 0 & 0 & 0 & 0 & 0 & 2 & 100 & \\
\hline & Total & 1 & 1,5 & 8 & 12,3 & 8 & 12,3 & 15 & 23,1 & 33 & 50,8 & \\
\hline $\mathbf{N}$ & & & & & & & & & & & & \\
\hline & No & 1 & 1,9 & 6 & 11,5 & 8 & 15,4 & 14 & 26,9 & 23 & 44,2 & \\
\hline & N1 & 0 & 0 & 0 & 0 & 0 & 0 & 0 & 0 & 3 & 100 & \\
\hline & N1A & 0 & 0 & 0 & 0 & 0 & 0 & 0 & 0 & 1 & 100 & 0,778 \\
\hline & N1B & 0 & 0 & 2 & 22,2 & 0 & 0 & 1 & 11,1 & 6 & 66,7 & \\
\hline & Total & 1 & 1,5 & 8 & 12,3 & 8 & 12,3 & 15 & 23,1 & 33 & 50,8 & \\
\hline M & & & & & & & & & & & & \\
\hline & M0 & 1 & 1,6 & 8 & 12,7 & 8 & 12,7 & 14 & 22,2 & 32 & 50,8 & \\
\hline & Total & 1 & 1,6 & 8 & 12,7 & 8 & 12,7 & 14 & 22,2 & 32 & 50,8 & - \\
\hline $\begin{array}{r}\text { Estadiamento } \\
\text { (TNM) }\end{array}$ & & & & & & & & & & & & \\
\hline & 1 & 1 & 1,8 & 7 & 12,7 & 8 & 14,5 & 13 & 23,6 & 26 & 47,3 & \\
\hline & II & 0 & 0 & 0 & 0 & 0 & 0 & 1 & 33,3 & 2 & 66,7 & \\
\hline & III & 0 & 0 & 1 & 50 & 0 & 0 & 0 & 0 & 1 & 50 & 0,878 \\
\hline & IVA & 0 & 0 & 0 & 0 & 0 & 0 & 1 & 20 & 4 & 80 & \\
\hline & Total & 1 & 1,5 & 8 & 12,3 & 8 & 12,3 & 15 & 23,1 & 33 & 50,8 & \\
\hline
\end{tabular}

(o símbolo - foi aplicado para indicar que não há valor para esta variável) 
Tabela 15 - Correlação das variáveis clínico-patológicas e da imunoexpressão do VEGF-D com freqüências absolutas e percentual de casos de acordo com o nível de imunoexpressão nos carcinomas papilíferos

\begin{tabular}{|c|c|c|c|c|c|c|c|c|c|c|c|c|}
\hline & & \multicolumn{11}{|c|}{ VEGF-D } \\
\hline & & \multicolumn{2}{|c|}{0} & \multicolumn{2}{|c|}{+} & \multicolumn{2}{|c|}{++} & \multicolumn{2}{|c|}{+++} & \multicolumn{2}{|c|}{++++} & \multirow[b]{2}{*}{$p$} \\
\hline & & $\mathrm{n}$ & $\%$ & $\mathrm{n}$ & $\%$ & $\mathrm{n}$ & $\%$ & $\mathrm{n}$ & $\%$ & $\mathrm{n}$ & $\%$ & \\
\hline \multicolumn{13}{|l|}{ Sexo } \\
\hline & M & - & - & - & - & 0 & 0 & 0 & 0 & 10 & 100 & \multirow{3}{*}{0,497} \\
\hline & $\mathrm{F}$ & - & - & - & - & 5 & 8,9 & 2 & 3,6 & 49 & 87,5 & \\
\hline & Total & - & - & - & - & 5 & 7,6 & 2 & 3 & 59 & 89,4 & \\
\hline \multicolumn{13}{|l|}{ Idade } \\
\hline & $<45$ anos & - & - & - & - & 4 & 10 & 0 & 0 & 36 & 90 & \multirow{3}{*}{0,140} \\
\hline & $>$ ou $=45$ anos & - & - & - & - & 1 & 4 & 2 & 8 & 22 & 88 & \\
\hline & Total & - & - & - & - & 5 & 7,7 & 2 & 3,1 & 58 & 89,2 & \\
\hline \multicolumn{13}{|l|}{ Lado } \\
\hline & Direito & - & - & - & - & 1 & 5,9 & 0 & 0 & 16 & 94,1 & \multirow{8}{*}{0,147} \\
\hline & Direito e Esquerdo & - & - & - & - & 2 & 50 & 0 & 0 & 2 & 50 & \\
\hline & Direito e Istmo & - & - & - & - & 0 & 0 & 0 & 0 & 5 & 100 & \\
\hline & Esquerdo & - & - & - & - & 0 & 0 & 1 & 7,1 & 12 & 92,3 & \\
\hline & Esquerdo e Istmo & - & - & - & - & 0 & 0 & 0 & 0 & 1 & 100 & \\
\hline & Istmo & - & - & - & - & 1 & 16,7 & 1 & 16,7 & 4 & 66,7 & \\
\hline & Difuso & - & - & - & - & 1 & 7,1 & 0 & 0 & 13 & 92,9 & \\
\hline & Total & - & - & - & - & 5 & 8,3 & 2 & 3,3 & 53 & 88,3 & \\
\hline \multicolumn{13}{|l|}{$\begin{array}{r}\text { Invasão de } \\
\text { Cápsula }\end{array}$} \\
\hline & Presente & - & - & - & - & 2 & 13,3 & 0 & 0 & 13 & 86,7 & \\
\hline & Não Detectada & - & - & - & - & 3 & 5,9 & 2 & 3,9 & 46 & 90,2 & 0,483 \\
\hline & Total & - & - & - & - & 5 & 7,6 & 2 & 3 & 59 & 89,4 & \\
\hline Invasão de Vaso & & & & & & & & & & & & \\
\hline & Presente & - & - & - & - & 3 & 21,4 & 0 & 0 & 11 & 78,6 & \\
\hline & Não Detectada & - & - & - & - & 2 & 3,8 & 2 & 3,8 & 48 & 92,3 & 0,072 \\
\hline & Total & - & - & - & - & 5 & 7,6 & 2 & 3 & 59 & 89,4 & \\
\hline $\begin{array}{r}\text { Comprometimento } \\
\text { de Adjacencia }\end{array}$ & & & & & & & & & & & & \\
\hline & Presente & - & - & - & - & 1 & 11,1 & 1 & 11,1 & 7 & 77,8 & \\
\hline & Não Detectada & - & - & - & - & 4 & 7 & 1 & 1,8 & 52 & 91,2 & 0,276 \\
\hline & Total & - & - & - & - & 5 & 7,6 & 2 & 3 & 59 & 89,4 & \\
\hline Metástase & & & & & & & & & & & & \\
\hline & Presente & - & - & - & - & 1 & 9,1 & 0 & 0 & 10 & 90,9 & \\
\hline & Ausente & - & - & - & - & 4 & 7,3 & 2 & 3,6 & 49 & 89,1 & 0,801 \\
\hline & Total & - & - & - & - & 5 & 7,6 & 2 & 3 & 59 & 89,4 & \\
\hline $\mathbf{T}$ & & & & & & & & & & & & \\
\hline & T1 & - & - & - & - & 2 & 4,3 & 1 & 2,2 & 43 & 93,5 & \\
\hline & T2 & - & - & - & - & 2 & 28,6 & 0 & 0 & 5 & 71,4 & \\
\hline & T3 & - & - & - & - & 1 & 10 & 1 & 10 & 8 & 80 & 0483 \\
\hline & T4 & - & - & - & - & 0 & 0 & 0 & 0 & 1 & 100 & 0,483 \\
\hline & T4A & - & - & - & - & 0 & 0 & 0 & 0 & 2 & 100 & \\
\hline & Total & - & - & - & - & 5 & 7,6 & 2 & 3 & 59 & 89,4 & \\
\hline $\mathbf{N}$ & & & & & & & & & & & & \\
\hline & No & - & - & - & - & 4 & 7,5 & 2 & 3,8 & 47 & 88,7 & \\
\hline & $\mathrm{N} 1$ & - & - & - & - & 0 & 0 & 0 & 0 & 3 & 100 & \\
\hline & N1A & - & - & - & - & 0 & 0 & 0 & 0 & 1 & 100 & 0,986 \\
\hline & N1B & - & - & - & - & 1 & 11,1 & 0 & 0 & 8 & 88,9 & \\
\hline & Total & - & - & - & - & 5 & 7,6 & 2 & 3 & 59 & 89,4 & \\
\hline M & & & & & & & & & & & & \\
\hline & M0 & - & - & - & - & 5 & 7,8 & 2 & 3,1 & 57 & 89,1 & - \\
\hline & Total & - & - & - & - & 5 & 7,8 & 2 & 3,1 & 57 & 89,1 & - \\
\hline $\begin{array}{r}\text { Estadiamento } \\
\text { (TNM) }\end{array}$ & & & & & & & & & & & & \\
\hline & I & - & - & - & - & 4 & 7,1 & 1 & 1,8 & 51 & 91,1 & \\
\hline & II & - & - & - & - & 1 & 33,3 & 0 & 0 & 2 & 66,7 & \\
\hline & III & - & - & - & - & 0 & 0 & 1 & 50 & 1 & 50 & $0,004^{*}$ \\
\hline & IVA & - & - & - & - & 0 & 0 & 0 & 0 & 5 & 100 & \\
\hline & Total & - & - & - & - & 5 & 7,6 & 2 & 3 & 59 & 89,4 & \\
\hline
\end{tabular}

(o símbolo - foi aplicado para indicar que não há valor para esta variável) 
Tabela 16 - Correlação das variáveis clínico-patológicas e da imunoexpressão do VEGF-R1 com freqüências absolutas e percentual de casos de acordo com o nível de imunoexpressão nos carcinomas papilíferos

\begin{tabular}{|c|c|c|c|c|c|c|c|c|c|c|c|c|}
\hline & & \multicolumn{11}{|c|}{ VEGF-R1 } \\
\hline & & \multicolumn{2}{|c|}{0} & \multicolumn{2}{|c|}{+} & \multicolumn{2}{|c|}{++} & \multicolumn{2}{|c|}{+++} & \multicolumn{2}{|c|}{++++} & \multirow[b]{2}{*}{$p$} \\
\hline & & $\mathrm{n}$ & $\%$ & $\mathrm{n}$ & $\%$ & $\mathrm{n}$ & $\%$ & $\mathrm{n}$ & $\%$ & $\mathrm{n}$ & $\%$ & \\
\hline \multicolumn{13}{|l|}{ Sexo } \\
\hline & $\mathrm{M}$ & 0 & 0 & - & - & 0 & 0 & 1 & 10 & 41 & 73,2 & \multirow{3}{*}{0,588} \\
\hline & $\mathrm{F}$ & 4 & 7,1 & - & - & 5 & 8,9 & 6 & 10,7 & 9 & 90 & \\
\hline & Total & 4 & 6,1 & - & - & 5 & 7,6 & 7 & 10,6 & 50 & 75,8 & \\
\hline \multicolumn{13}{|l|}{ Idade } \\
\hline & $<45$ anos & 2 & 5 & - & - & 5 & 12,5 & 4 & 10 & 29 & 72,5 & \multirow{3}{*}{0,318} \\
\hline & $>$ ou $=45$ anos & 2 & 8 & - & - & 0 & 0 & 3 & 12 & 20 & 80 & \\
\hline & Total & 4 & 6,2 & - & - & 5 & 7,7 & 7 & 10,8 & 49 & 75,4 & \\
\hline \multicolumn{13}{|l|}{ Lado } \\
\hline & Direito & 0 & 0 & - & - & 1 & 5,9 & 4 & 23,5 & 12 & 70,6 & \multirow{8}{*}{0,109} \\
\hline & Direito e Esquerdo & 2 & 50 & - & - & 0 & 0 & 0 & 0 & 2 & 50 & \\
\hline & Direito e Istmo & 0 & 0 & - & - & 0 & 0 & 1 & 20 & 4 & 80 & \\
\hline & Esquerdo & 2 & 15,4 & - & - & 2 & 15,4 & 0 & 0 & 9 & 69,2 & \\
\hline & Esquerdo e Istmo & 0 & 0 & - & - & 0 & 0 & 0 & 0 & 1 & 100 & \\
\hline & Istmo & 0 & 0 & - & - & 1 & 16,7 & 1 & 16,7 & 4 & 66,7 & \\
\hline & Difuso & 0 & 0 & - & - & 0 & 0 & 1 & 7,1 & 13 & 92,9 & \\
\hline & Total & 4 & 6,7 & - & - & 4 & 6,7 & 7 & 11,7 & 45 & 75 & \\
\hline \multicolumn{13}{|l|}{$\begin{array}{r}\text { Invasão de } \\
\text { Cápsula }\end{array}$} \\
\hline & Presente & 0 & 0 & - & - & 1 & 6,7 & 0 & 0 & 14 & 93,3 & \\
\hline & Não Detectada & 4 & 7,8 & - & - & 4 & 7,8 & 7 & 13,7 & 36 & 70,6 & 0,256 \\
\hline & Total & 4 & 6,1 & - & - & 5 & 7,6 & 7 & 10,6 & 50 & 75,8 & \\
\hline Invasão de Vaso & & & & & & & & & & & & \\
\hline & Presente & 1 & 7,1 & - & - & 2 & 14,3 & 0 & 0 & 11 & 78,6 & \\
\hline & Não Detectada & 3 & 5,8 & - & - & 3 & 5,8 & 7 & 13,5 & 39 & 75 & 0,393 \\
\hline & Total & 4 & 6,1 & - & - & 5 & 7,6 & 7 & 10,6 & 50 & 75,8 & \\
\hline $\begin{array}{r}\text { Comprometimento } \\
\text { de Adjacencia }\end{array}$ & & & & & & & & & & & & \\
\hline & Presente & 1 & 11,1 & - & - & 1 & 11,1 & 0 & 0 & 7 & 77,8 & \\
\hline & Não Detectada & 3 & 5,3 & - & - & 4 & 7 & 7 & 12,3 & 43 & 75,4 & 0,632 \\
\hline & Total & 4 & 6,1 & - & - & 5 & 7,6 & 7 & 10,6 & 50 & 75,8 & \\
\hline Metástase & & & & & & & & & & & & \\
\hline & Presente & 1 & 9,1 & - & - & 0 & 0 & 0 & 0 & 10 & 90,9 & \\
\hline & Ausente & 3 & 5,5 & - & - & 5 & 9,1 & 7 & 12,7 & 40 & 72,7 & 0,392 \\
\hline & Total & 4 & 6,1 & - & - & 5 & 7,6 & 7 & 10,6 & 50 & 75,8 & \\
\hline $\mathbf{T}$ & & & & & & & & & & & & \\
\hline & T1 & 2 & 4,3 & - & - & 4 & 8,7 & 6 & 13 & 34 & 73,9 & \\
\hline & T2 & 1 & 14,3 & - & - & 0 & 0 & 1 & 14,3 & 5 & 71,4 & \\
\hline & T3 & 1 & 10 & - & - & 1 & 10 & 0 & 0 & 8 & 80 & 0976 \\
\hline & T4 & 0 & 0 & - & - & 0 & 0 & 0 & 0 & 1 & 100 & 0,916 \\
\hline & T4A & 0 & 0 & - & - & 0 & 0 & 0 & 0 & 2 & 100 & \\
\hline & Total & 4 & 6,1 & - & - & 5 & 7,6 & 7 & 10,6 & 50 & 75,8 & \\
\hline $\mathbf{N}$ & & & & & & & & & & & & \\
\hline & No & 3 & 5,7 & - & - & 5 & 9,4 & 6 & 11,3 & 39 & 73,6 & \\
\hline & $\mathrm{N} 1$ & 0 & 0 & - & - & 0 & 0 & 1 & 33,3 & 2 & 66,7 & \\
\hline & N1A & 0 & 0 & - & - & 0 & 0 & 0 & 0 & 1 & 100 & 0,855 \\
\hline & N1B & 1 & 11,1 & - & - & 0 & 0 & 0 & 0 & 8 & 88,9 & \\
\hline & Total & 4 & 6,1 & - & - & 5 & 7,6 & 7 & 10,6 & 50 & 75,8 & \\
\hline M & & & & & & & & & & & & \\
\hline & M0 & 4 & 6,3 & - & - & 5 & 7,8 & 7 & 10,9 & 48 & 75 & \\
\hline & Total & 4 & 6,3 & - & - & 5 & 7,8 & 7 & 10,9 & 48 & 75 & - \\
\hline $\begin{array}{r}\text { Estadiamento } \\
\text { (TNM) }\end{array}$ & & & & & & & & & & & & \\
\hline & I & 3 & 5,4 & - & - & 5 & 8,9 & 7 & 12,5 & 41 & 73,2 & \\
\hline & II & 0 & 0 & - & - & 0 & 0 & 0 & 0 & 3 & 100 & \\
\hline & III & 1 & 50 & - & - & 0 & 0 & 0 & 0 & 1 & 50 & 0,360 \\
\hline & IVA & 0 & 0 & - & - & 0 & 0 & 0 & 0 & 5 & 100 & \\
\hline & Total & 4 & 6,1 & - & - & 5 & 7,6 & 7 & 10,6 & 50 & 75,8 & \\
\hline
\end{tabular}

(o símbolo - foi aplicado para indicar que não há valor para esta variável) 
Tabela 17 - Correlação das variáveis clínico-patológicas e da imunoexpressão do VEGF-R3 com freqüências absolutas e percentual de casos de acordo com o nível de imunoexpressão nos carcinomas papilíferos

\begin{tabular}{|c|c|c|c|c|c|c|c|c|c|c|c|c|}
\hline & & \multicolumn{11}{|c|}{ VEGF-R3 } \\
\hline & & \multicolumn{2}{|c|}{0} & \multicolumn{2}{|c|}{+} & \multicolumn{2}{|c|}{++} & \multicolumn{2}{|c|}{+++} & \multicolumn{2}{|c|}{++++} & \multirow[b]{2}{*}{$p$} \\
\hline & & $\mathrm{n}$ & $\%$ & $\mathrm{n}$ & $\%$ & $\mathrm{n}$ & $\%$ & $\mathrm{n}$ & $\%$ & $\mathrm{n}$ & $\%$ & \\
\hline \multicolumn{13}{|l|}{ Sexo } \\
\hline & M & - & - & 0 & 0 & - & - & 0 & 0 & 10 & 100 & \multirow{3}{*}{0,674} \\
\hline & $\mathrm{F}$ & - & - & 2 & 3,7 & - & - & 2 & 3,7 & 50 & 92,6 & \\
\hline & Total & - & - & 2 & 3,1 & - & - & 2 & 3,1 & 60 & 93,8 & \\
\hline \multirow[t]{4}{*}{ Idade } & & & & & & & & & & & & \\
\hline & $<45$ anos & - & - & 1 & 2,6 & - & - & 2 & 5,1 & 36 & 92,3 & \multirow{3}{*}{0,504} \\
\hline & $>$ ou $=45$ anos & - & - & 1 & 4,2 & - & - & 0 & 0 & 23 & 95,8 & \\
\hline & Total & - & - & 2 & 3,2 & - & - & 2 & 3,2 & 59 & 93,7 & \\
\hline \multirow[t]{9}{*}{ Lado } & & & & & & & & & & & & \\
\hline & Direito & - & - & 0 & 0 & - & - & 2 & 12,5 & 14 & 87,5 & \multirow{8}{*}{0,365} \\
\hline & Direito e Esquerdo & - & - & 1 & 25 & - & - & 0 & 0 & 3 & 75 & \\
\hline & Direito e Istmo & - & - & 0 & 0 & - & - & 0 & 0 & 4 & 100 & \\
\hline & Esquerdo & - & - & 1 & 7,7 & - & - & 0 & 0 & 12 & 92,3 & \\
\hline & Esquerdo e Istmo & - & - & 0 & 0 & - & - & 0 & 0 & 1 & 100 & \\
\hline & Istmo & - & - & 0 & 0 & - & - & 0 & 0 & 6 & 100 & \\
\hline & Difuso & - & - & 0 & 0 & - & - & 0 & 0 & 14 & 100 & \\
\hline & Total & - & - & 2 & 3,4 & - & - & 2 & 3,4 & 54 & 93,1 & \\
\hline \multirow[t]{4}{*}{$\begin{array}{r}\text { Invasão de } \\
\text { Cápsula }\end{array}$} & & & & & & & & & & & & \\
\hline & Presente & - & - & 0 & 0 & - & - & 0 & 0 & 15 & 100 & \\
\hline & Não Detectada & - & - & 2 & 4,1 & - & - & 2 & 4,1 & 45 & 91,8 & 0,520 \\
\hline & Total & - & - & 2 & 3,1 & - & - & 2 & 3,1 & 60 & 93,8 & \\
\hline Invasão de Vaso & & & & & & & & & & & & \\
\hline & Presente & - & - & 0 & 0 & - & - & 0 & 0 & 14 & 100 & \\
\hline & Não Detectada & - & - & 2 & 4 & - & - & 2 & 4 & 46 & 92 & 0,550 \\
\hline & Total & - & - & 2 & 3,1 & - & - & 2 & 3,1 & 60 & 93,8 & \\
\hline $\begin{array}{r}\text { Comprometimento } \\
\text { de Adjacencia }\end{array}$ & & & & & & & & & & & & \\
\hline & Presente & - & - & 1 & 11,1 & - & - & 0 & 0 & 8 & 88,9 & \\
\hline & Não Detectada & - & - & 1 & 1,8 & - & - & 2 & 3,6 & 52 & 94,5 & 0,288 \\
\hline & Total & - & - & 2 & 3,1 & - & - & 2 & 3,1 & 60 & 93,8 & \\
\hline Metástase & & & & & & & & & & & & \\
\hline & Presente & - & - & 0 & 0 & - & - & 0 & 0 & 11 & 100 & \\
\hline & Ausente & - & - & 2 & 3,8 & - & - & 2 & 3,8 & 49 & 92,5 & 0,642 \\
\hline & Total & - & - & 2 & 3,1 & - & - & 2 & 3,1 & 60 & 93,8 & \\
\hline $\mathbf{T}$ & & & & & & & & & & & & \\
\hline & T1 & - & - & 1 & 2,2 & - & - & 1 & 2,2 & 43 & 95,6 & \\
\hline & T2 & - & - & 0 & 0 & - & - & 1 & 16,7 & 5 & 83,3 & \\
\hline & T3 & - & - & 1 & 10 & - & - & 0 & 0 & 9 & 90 & 0640 \\
\hline & T4 & - & - & 0 & 0 & - & - & 0 & 0 & 1 & 100 & 0,640 \\
\hline & T4A & - & - & 0 & 0 & - & - & 0 & 0 & 2 & 100 & \\
\hline & Total & - & - & 2 & 3,1 & - & - & 2 & 3,1 & 60 & 93,8 & \\
\hline $\mathbf{N}$ & & & & & & & & & & & & \\
\hline & No & - & - & 2 & 3,9 & - & - & 2 & 3,9 & 47 & 92,2 & \\
\hline & N1 & - & - & 0 & 0 & - & - & 0 & 0 & 3 & 100 & \\
\hline & N1A & - & - & 0 & 0 & - & - & 0 & 0 & 1 & 100 & 0,982 \\
\hline & N1B & - & - & 0 & 0 & - & - & 0 & 0 & 9 & 100 & \\
\hline & Total & - & - & 2 & 3,1 & - & - & 2 & 3,1 & 60 & 93,8 & \\
\hline M & & & & & & & & & & & & \\
\hline & MO & - & - & 2 & 3,2 & - & - & 2 & 3,2 & 58 & 93,5 & \\
\hline & Total & - & - & 2 & 3,2 & - & - & 2 & 3,2 & 58 & 93,5 & - \\
\hline $\begin{array}{r}\text { Estadiamento } \\
\text { (TNM) }\end{array}$ & & & & & & & & & & & & \\
\hline & I & - & - & 1 & 1,9 & - & - & 2 & 3,7 & 51 & 94,4 & \\
\hline & II & - & - & 0 & 0 & - & - & 0 & 0 & 3 & 100 & \\
\hline & III & - & - & 1 & 50 & - & - & 0 & 0 & 1 & 50 & $0,017^{*}$ \\
\hline & IVA & - & - & 0 & 0 & - & - & 0 & 0 & 5 & 100 & \\
\hline & Total & - & - & 2 & 3,1 & - & - & 2 & 3,1 & 60 & 93,8 & \\
\hline
\end{tabular}

(o símbolo - foi aplicado para indicar que não há valor para esta variável) 
Tabela 18 - Sumário das significâncias das correlações entre a expressão imunohistoquímica negativa (até 10\%) ou positiva (> do que 10\%) dos VEGFs e VEGFRs e das variáveis clínico-patológicas dos carcinomas papilíferos estudados

\begin{tabular}{|r|c|c|c|c|c|c|c|}
\hline & VEGF-A & VEGF-A165b & VEGF-B & VEGF-C & VEGF-D & \multicolumn{1}{l|}{ VEGF-R1 } & VEGF-R3 \\
\hline & $\mathrm{p}$ & $\mathrm{p}$ & $\mathrm{p}$ & $\mathrm{p}$ & $\mathrm{p}$ & $\mathrm{p}$ & $\mathrm{p}$ \\
\hline Idade & 0,852 & 0,447 & $\mathbf{0 , 0 4 7 ^ { * }}$ & 0,642 & - & 0,624 & 0,725 \\
\hline Sexo & 0,454 & 0,793 & 0,326 & 0,168 & - & 0,383 & 0,536 \\
\hline Lado & 0,300 & 0,090 & 0,197 & 0,095 & - & $\mathbf{0 , 0 1 0 ^ { * }}$ & 0,257 \\
\hline $\begin{array}{r}\text { Invasão de } \\
\text { Cápsula }\end{array}$ & 0,654 & 0,518 & 0,207 & 0,359 & - & 0,263 & 0,427 \\
\hline $\begin{array}{r}\text { Invasão de Vaso } \\
\text { Comprometimento }\end{array}$ & $\mathbf{0 , 0 4 9}$ & 0,706 & 0,945 & 0,412 & - & 0,848 & 0,447 \\
\hline de Adjacência & 0,309 & 0,793 & 0,355 & 0,433 & - & 0,494 & 0,137 \\
\hline Metástase & 0,428 & 0,936 & 0,298 & 0,648 & - & 0,645 & 0,513 \\
\hline $\mathbf{T}$ & 0,707 & 0,263 & 0,671 & 0,949 & - & 0,820 & 0,741 \\
\hline $\mathbf{N}$ & 0,763 & 0,794 & 0,723 & 0,758 & - & 0,879 & 0,913 \\
\hline $\mathbf{M}$ & - & - & - & - & - & - & - \\
\hline Estadio & 0,905 & 0,582 & 0,809 & 0,321 & - & 0,062 & $\mathbf{0 , 0 0 2}{ }^{*}$ \\
\hline
\end{tabular}

(o símbolo - foi aplicado para indicar que não há valor para esta variável)

\subsection{Expressão imuno-histoquímica dos fatores de crescimento endotelial vascular e de seus receptores nos carcinomas foliculares estudados}

Foram avaliadas as expressões dos fatores de crescimento endotelial vascular (VEGF-A; VEGF-A 165 ; VEGF-B; VEGF-C;VEGF-D) e de seus receptores (VEGF-R1 e VEGF-R3) nos carcinomas foliculares e em suas adjacências apresentando tecido normal, bócio adenomatoso e tireoidite linfocitária. A Tabela 19 apresenta o número de casos de carcinomas foliculares analisados para cada membro da família VEGF. Devido as perdas inerentes a técnica da micromatriz tecidual (TMA), dos 34 carcinomas foliculares alguns casos foram perdidos na manipulação técnica conforme detalhado a seguir. 
Tabela 19 - Número de amostras avaliadas quanto a expressão imuno-histoquímica dos VEGFs e VEGFRs nos carcinomas foliculares e em suas regiões adjacentes contendo tecido normal, bócio adenomatoso e tireoidite linfocitária

\begin{tabular}{r|c|c|c|c|c|c|c|}
\hline & \multirow{2}{*}{ VEGF-A } & VEGF-A165b & VEGF-B & VEGF-C & VEGF-D & VEGF-R1 & VEGF-R3 \\
& & & & & & & \\
\hline Normal & 15 & 14 & 15 & 16 & 14 & 15 & 13 \\
\hline Bócio Adenomatoso & 9 & 9 & 9 & 9 & 10 & 9 & 9 \\
\hline Tireoidite Linfocitária & 9 & 9 & 9 & 9 & 9 & 9 & 9 \\
\hline Carcinoma Folicular & 19 & 19 & 23 & 23 & 23 & 23 & 22 \\
\hline
\end{tabular}

\subsubsection{VEGF-A}

Dos 34 casos de carcinomas foliculares da tireóide foi possível avaliar a expressão imuno-histoquímica do VEGF-A em 19 amostras da região tumoral $(55,8 \%$ do total de carcinomas foliculares estudados) e em 15 regiões adjacentes aos carcinomas foliculares apresentando tecido normal, 9 apresentando bócio adenomatoso e 9 apresentando tireoidite linfocitária (Tabela 19).

Em $84 \%$ dos casos das regiões tumorais as imunomarcações foram positivas ++++ , em $5 \%$ foram positivas ++ e em $11 \%$ foram negativas ( 0 ) para o VEGF-A. Nas regiões adjacentes normais $13 \%$ dos casos apresentaram imunomarcações positivas ++++, $7 \%+++, 13 \%++, 20 \%+$ e $47 \%$ foram negativos (0). No tecido adjacente ao tumor com bócio adenomatoso $44 \%$ dos casos apresentaram imunomarcações positivas ++++, $33 \%++$ e $22 \%$ +. Nas tireoidites linfocitárias adjacentes $22 \%$ dos casos apresentaram imunomarcações positivas ++++, $33 \%+++, 33 \%+\mathrm{e}$ 
$11 \%$ foram negativos (0) não apresentando imunomarcação para o VEGF-A (Figura 14).

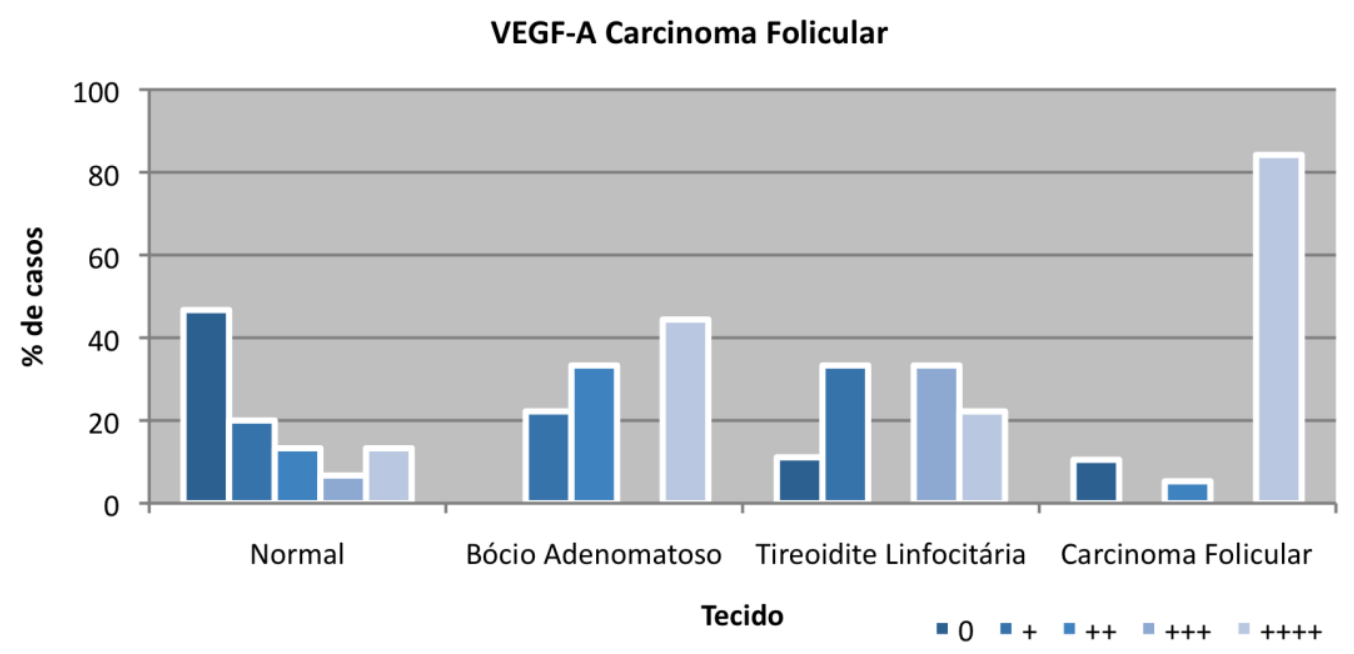

Figura 14. Expressão imuno-histoquímica do VEGF-A nos Carcinomas Foliculares e suas adjacências apresentando tecido Normal, Bócio Adenomatoso e Tireoidite Linfocitária $(p<0,001)$

\subsubsection{VEGF-A $A_{165} b$}

Foi possível avaliar a expressão imuno-histoquímica do VEGF-A ${ }_{165} b$ em 19 amostras da região tumoral $(55,8 \%$ do total de carcinomas foliculares estudados) e em 14 regiões adjacentes aos carcinomas foliculares apresentando tecido normal, 9 apresentando bócio adenomatoso e 9 apresentando tireoidite linfocitária (Tabela 19).

Em $74 \%$ dos casos das regiões tumorais as imunomarcações foram positivas ++++ , em $5 \%$ foram positivas,$+++ 5 \%++$ e em $16 \%$ foram negativas (0) para o VEGF-A 165 $_{16} \mathrm{~b}$. Nas regiões adjacentes normais $7 \%$ dos 
casos apresentaram imunomarcações positivas +++, $21 \%++, 43 \%+$ e $29 \%$ foram negativos (0). No tecido adjacente ao tumor com bócio adenomatoso $44 \%$ dos casos apresentaram imunomarcações positivas ++++, $11 \%+++$, $33 \%++$ e $11 \%$ foram negativos (0). Nas tireoidites linfocitárias adjacentes $33 \%$ dos casos apresentaram imunomarcações positivas,$++++ 11 \%+++$, $11 \%$ ++ e $44 \%$ foram negativos (0) não apresentando imunomarcação para o VEGF-A 165 b (Figura 15).

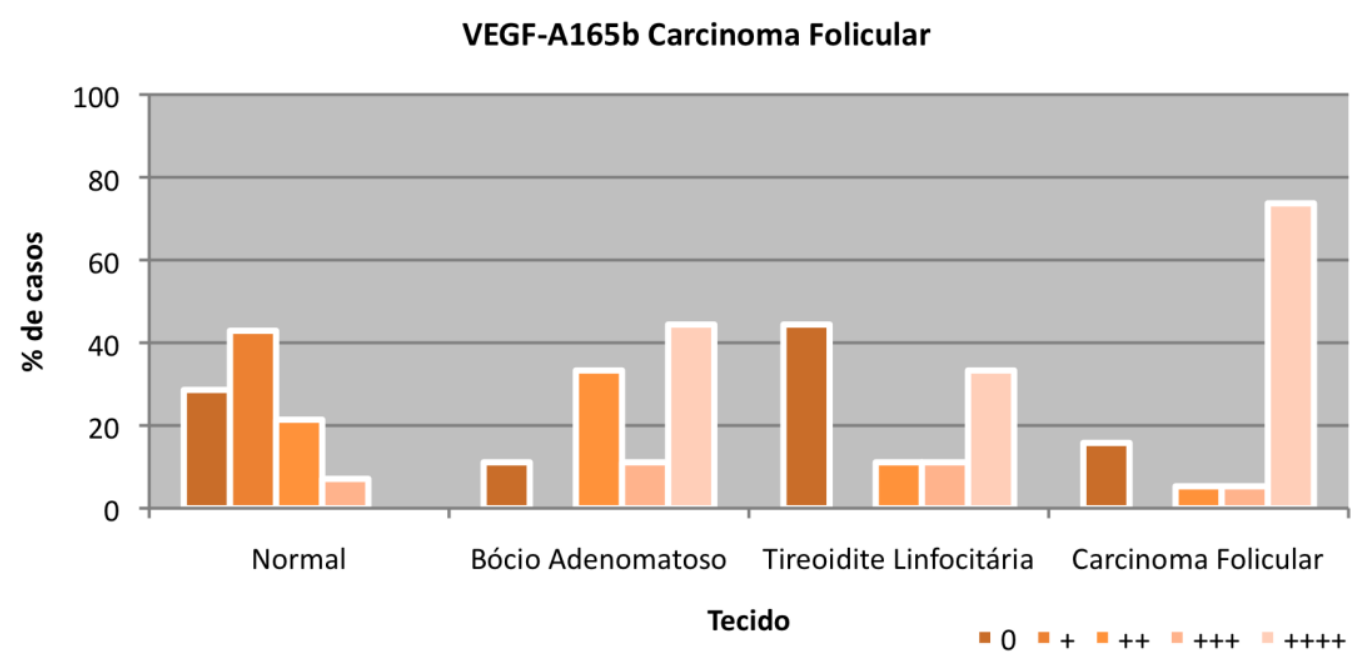

Figura 15. Expressão imuno-histoquímica do VEGF-A ${ }_{165} \mathrm{~b}$ nos Carcinomas Foliculares e suas adjacências apresentando tecido Normal, Bócio Adenomatoso e Tireoidite Linfocitária $(p<0,001)$

\subsubsection{VEGF-B}

Foi possível avaliar a expressão imuno-histoquímica do VEGF-B em 23 amostras da região tumoral $(67,6 \%$ do total de carcinomas foliculares estudados) e em 15 regiões adjacentes aos carcinomas foliculares 
apresentando tecido normal, 9 apresentando bócio adenomatoso e 9 apresentando tireoidite linfocitária (Tabela 19).

Em 9\% dos casos das regiões tumorais as imunomarcações foram positivas ++ e em $91 \%$ foram negativas (0) para o VEGF-B. Nas regiões adjacentes normais $100 \%$ dos casos foram negativos (0). No tecido adjacente ao tumor com bócio adenomatoso $100 \%$ dos casos foram negativos (0). Nas tireoidites linfocitárias adjacentes $11 \%$ dos casos apresentaram imunomarcações positivas + e $89 \%$ foram negativos (0) não apresentando imunomarcação para o VEGF-B (Figura 16).

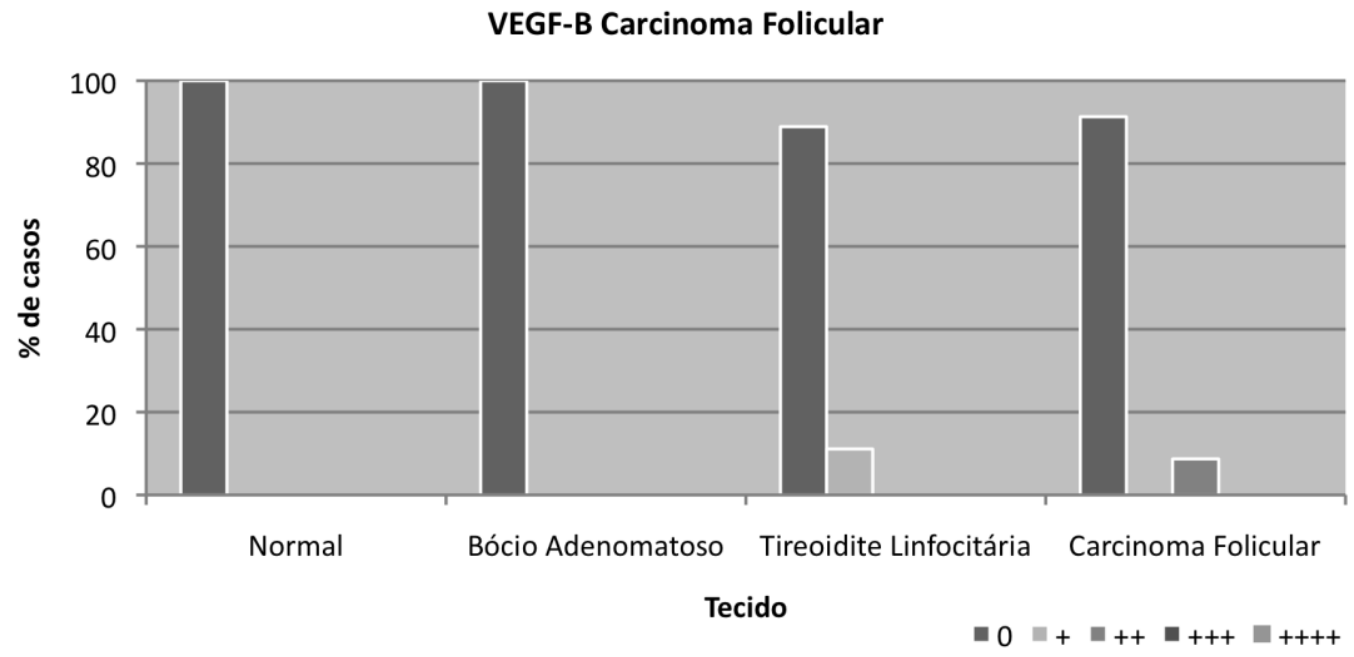

Figura 16. Expressão imuno-histoquímica do VEGF-B nos Carcinomas Foliculares e suas adjacências apresentando tecido Normal, Bócio Adenomatoso e Tireoidite Linfocitária $(p=0,222)$ 


\subsubsection{VEGF-C}

Foi possível avaliar a expressão imuno-histoquímica do VEGF-C em 23 amostras da região tumoral $(67,6 \%$ do total de carcinomas foliculares estudados) e em 16 regiões adjacentes aos carcinomas foliculares apresentando tecido normal, 9 apresentando bócio adenomatoso e 9 apresentando tireoidite linfocitária (Tabela 19).

Em $61 \%$ dos casos das regiões tumorais as imunomarcações foram positivas ++++ , em $13 \%$ foram positivas,$+++ 4 \%++$ e em $22 \%+$ para 0 VEGF-C. Nas regiões adjacentes normais $19 \%$ dos casos apresentaram imunomarcações positivas + e $81 \%$ foram negativos $(0)$. No tecido adjacente ao tumor com bócio adenomatoso $22 \%$ dos casos apresentaram imunomarcações positivas ++++, 11\% +++, 33\% ++, $22+$ e $11 \%$ foram negativos (0). Nas tireoidites linfocitárias adjacentes $22 \%$ dos casos apresentaram imunomarcações positivas ++++, $11 \%+++, 44 \%++$ e $22 \%+$ para o VEGF-C (Figura 17).

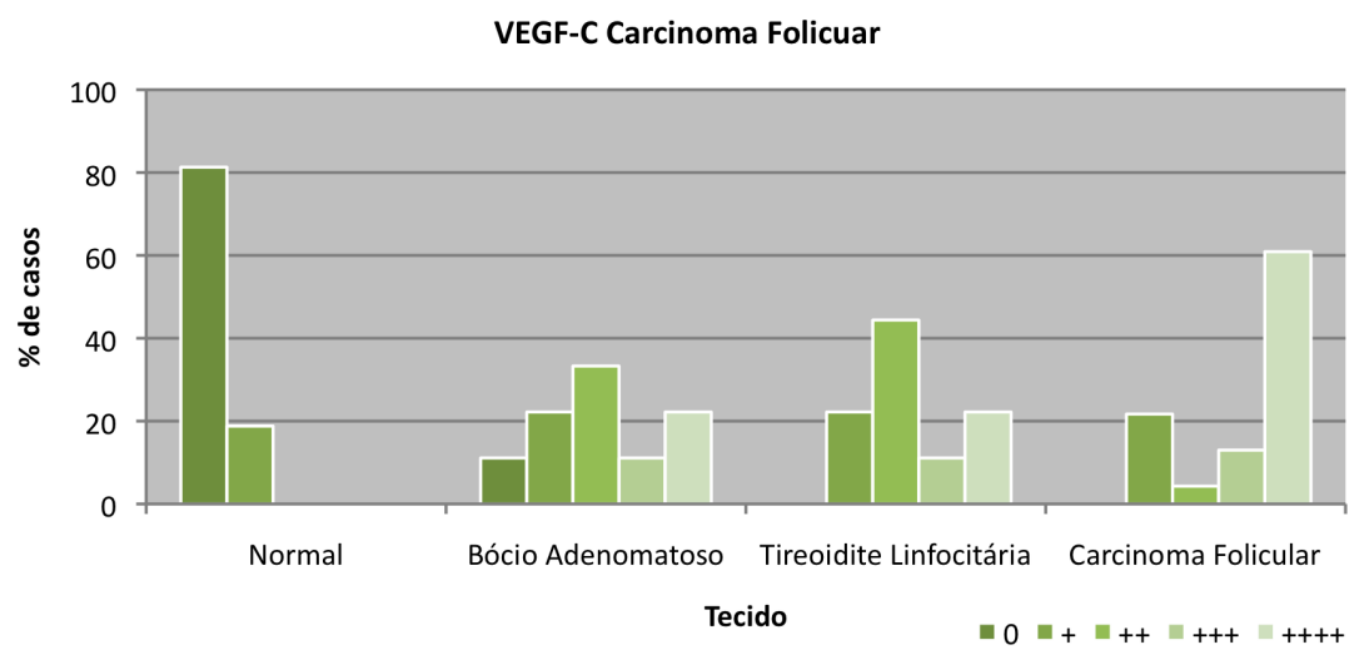

Figura 17. Expressão imuno-histoquímica do VEGF-C nos Carcinomas Foliculares e suas adjacências apresentando tecido Normal, Bócio Adenomatoso e Tireoidite Linfocitária $(p<0,001)$ 


\subsubsection{VEGF-D}

Foi possível avaliar a expressão imuno-histoquímica do VEGF-D em 23 amostras da região tumoral $(67,6 \%$ do total de carcinomas foliculares estudados) e em 14 regiões adjacentes aos carcinomas foliculares apresentando tecido normal, 10 apresentando bócio adenomatoso e 9 apresentando tireoidite linfocitária (Tabela 19).

Em $78 \%$ dos casos das regiões tumorais as imunomarcações foram positivas ++++ , em $4 \%$ foram positivas,$++ 4 \%+$ e em $13 \%$ foram negativos (0) para o VEGF-D. Nas regiões adjacentes normais $21 \%$ dos casos apresentaram imunomarcações positivas ++++, $50 \%+++, 14 \%++$ e $14 \%+$. No tecido adjacente ao tumor com bócio adenomatoso $40 \%$ dos casos apresentaram imunomarcações positivas,$++++ 50 \%+++$ e $10 \%+$. Nas tireoidites linfocitárias adjacentes $33 \%$ dos casos apresentaram imunomarcações positivas,$++++ 44 \%+++, 11 \%+$ e $11 \%$ foram negativos (0) não apresentando imunomarcação para o VEGF-D (Figura 18).

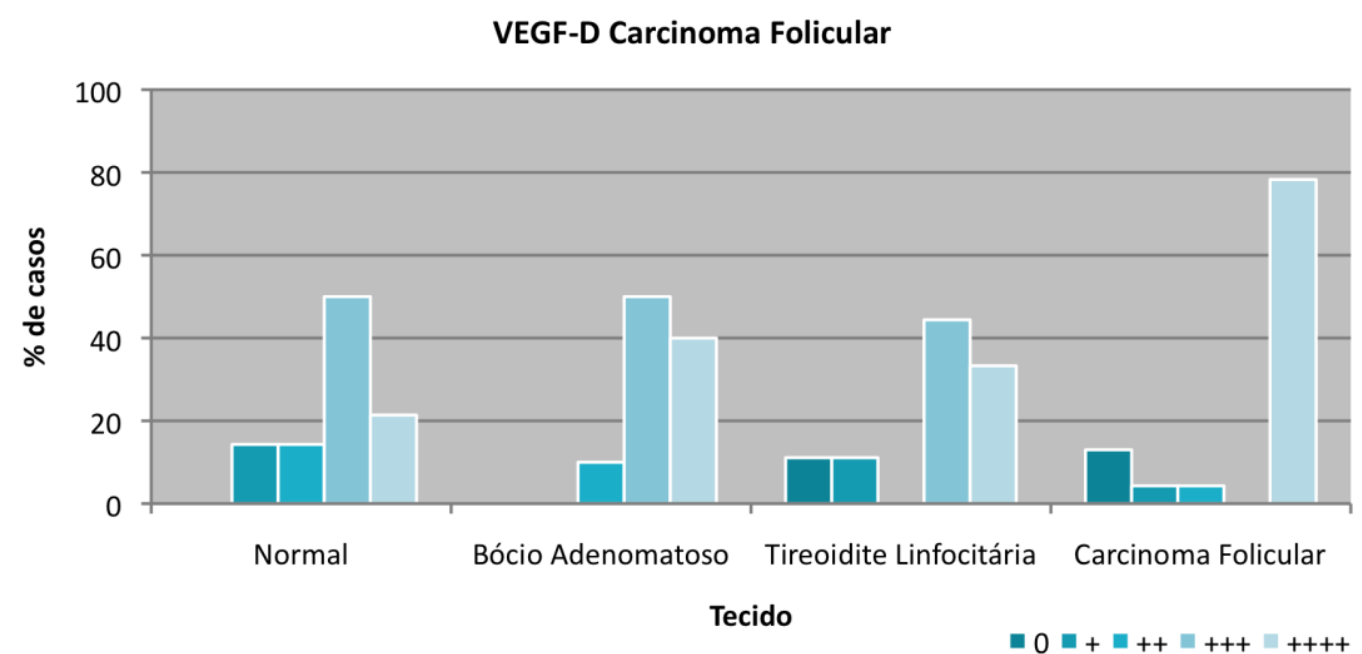

Figura 18. Expressão imuno-histoquímica do VEGF-D nos Carcinomas Foliculares e suas adjacências apresentando tecido Normal, Bócio Adenomatoso e Tireoidite Linfocitária $(p=0,014)$ 


\subsubsection{VEGF-R1}

Foi possível avaliar a expressão imuno-histoquímica do VEGF-R1 em 23 amostras da região tumoral $(67,6 \%$ do total de carcinomas foliculares estudados) e em 15 regiões adjacentes aos carcinomas foliculares apresentando tecido normal, 9 apresentando bócio adenomatoso e 9 apresentando tireoidite linfocitária (Tabela 19).

Em $74 \%$ dos casos das regiões tumorais as imunomarcações foram positivas ++++ , em $4 \%$ foram positivas,$+++ 9 \%++$ e em $13 \%$ foram negativos (0) não apresentando imunomarcação para o VEGF-R1. Nas regiões adjacentes normais $7 \%$ dos casos apresentaram imunomarcações positivas,$+++ 7 \%++, 13 \%+$ e $73 \%$ foram negativos (0). No tecido adjacente ao tumor com bócio adenomatoso $33 \%$ dos casos apresentaram imunomarcações positivas ++++, $11 \%+++, 33 \%++, 11+$ e $11 \%$ foram negativos (0). Nas tireoidites linfocitárias adjacentes $33 \%$ dos casos apresentaram imunomarcações positivas ++++, $11 \%+++, 22 \%++$, $22 \%+$ e $11 \%$ foram negativos (0) não apresentando imunomarcação para o VEGF-R1 (Figura 19). 


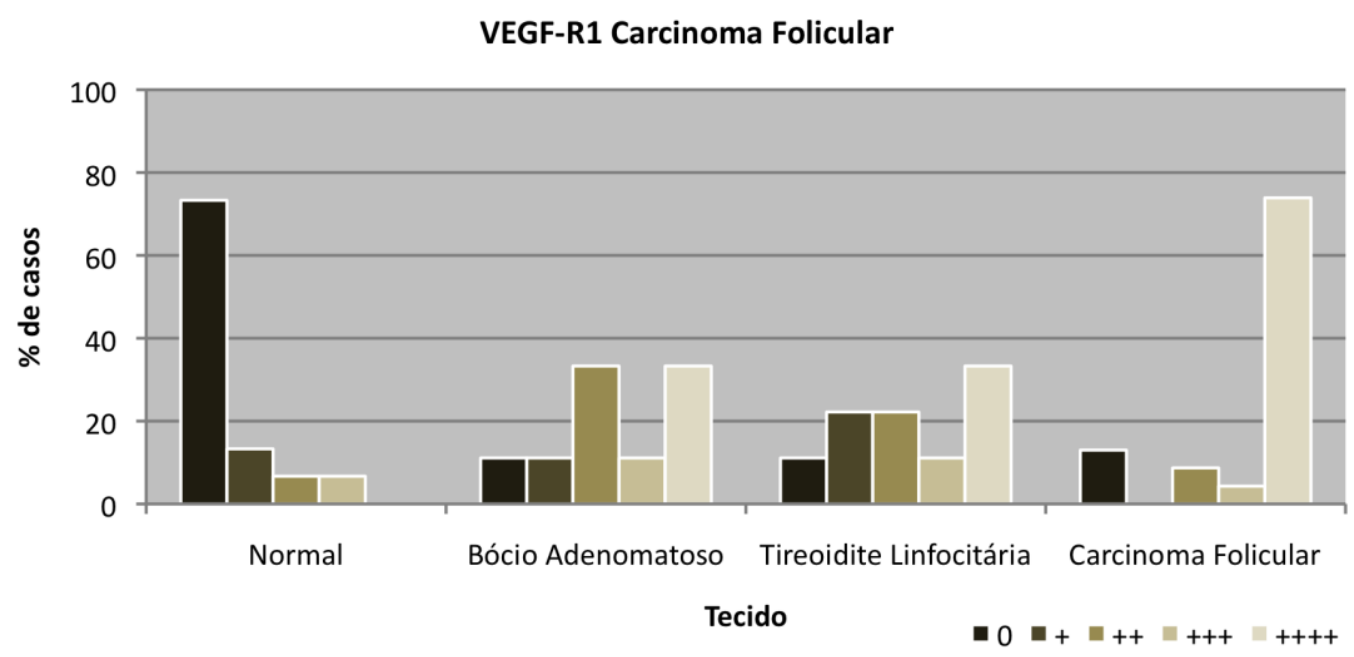

Figura 19. Expressão imuno-histoquímica do VEGF-R1 nos Carcinomas Foliculares e suas adjacências apresentando tecido Normal, Bócio Adenomatoso e Tireoidite Linfocitária $(p<0,001)$

\subsubsection{VEGF-R3}

Foi possível avaliar a expressão imuno-histoquímica do VEGF-R3 em 22 amostras da região tumoral $(64,7 \%$ do total de carcinomas foliculares estudados) e em 13 regiões adjacentes aos carcinomas foliculares apresentando tecido normal, 9 apresentando bócio adenomatoso e 9 apresentando tireoidite linfocitária (Tabela 19).

Em $91 \%$ dos casos das regiões tumorais as imunomarcações foram positivas ++++ e em $9 \%$ foram positivas + para o VEGF-R1. Nas regiões adjacentes normais $8 \%$ dos casos apresentaram imunomarcações positivas ,$+++ 31 \%++, 39 \%+$ e $23 \%$ foram negativos $(0)$. No tecido adjacente ao tumor com bócio adenomatoso $22 \%$ dos casos apresentaram imunomarcações positivas ++++, $11 \%+++, 56 \%++$ e $11 \%+$ +. Nas tireoidites 
linfocitárias adjacentes $33 \%$ dos casos apresentaram imunomarcações positivas,$++++ 22 \%+++, 11 \%++$ e $33 \%+$ para o VEGF-R3 (Figura 20).

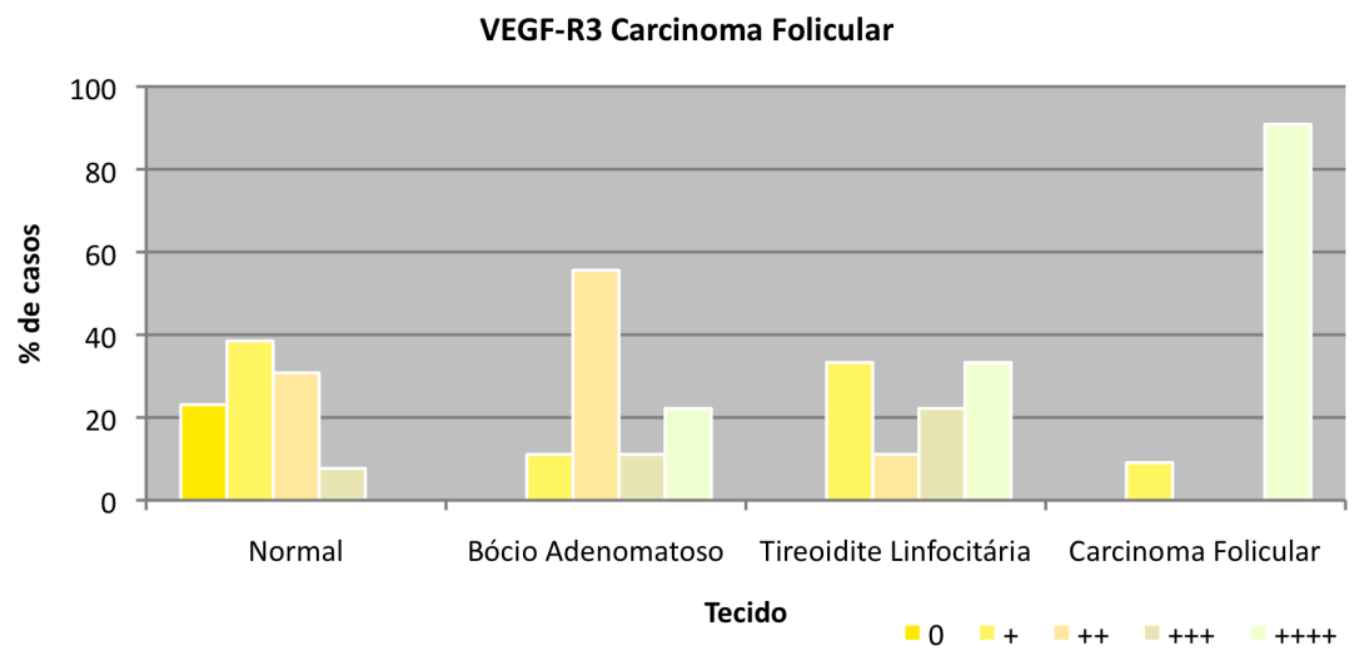

Figura 20. Expressão imuno-histoquímica do VEGF-R3 nos Carcinomas Foliculares e suas adjacências apresentando tecido Normal, Bócio Adenomatoso e Tireoidite Linfocitária $(p<0,001)$

\subsection{Expressão imuno-histoquímica, dicotomizada em negativa} ou positiva, dos fatores de crescimento endotelial vascular e de seus receptores nos carcinomas foliculares estudados

Com a finalidade de facilitar o entendimento dos resultados obtidos, os dados acima apresentados, foram também dicotomizados em duas categorias. Negativos, amostras com até $10 \%$ de imunomarcação positiva; e positivos, amostras com imunomarcação positiva maior do que $10 \%$.

A maioria dos carcinomas foliculares estudados apresentaram expressão imuno-histoquímica positiva para o VEGF-A (positiva $90 \%$ dos 
casos), VEGF-A ${ }_{165} \mathrm{~b}$ (positiva $84 \%$ dos casos), VEGF-C (positiva $78 \%$ dos casos), VEGF-D (positiva $83 \%$ dos casos), VEGF-R1 (positiva $87 \%$ dos casos) e VEGF-R3 (positiva 91\% dos casos). Uma maior quantidade de casos negativos só foi observada na avaliação da expressão imunohistoquímica do VEGF-B (negativa 91\% dos casos).

Nas regiões adjacentes ao tumor o número de casos positivos para o VEGF-A, VEGF-R1 e VEGFR-3 foi sempre inferior ao observado nos carcinomas foliculares. A positividade imuno-histoquímica para o VEGF-A $A_{165}$ b na região adjacente com bócio adenomatoso (positiva $89 \%$ dos casos) foi maior do que na região do carcinoma folicular (positiva $84 \%$ dos casos). O número de casos positivos e negativos (negativa $22 \%$ e positiva $78 \%$ ) para o VEGF-C nos carcinomas foliculares e nas regiões adjacentes com bócio adenomatoso foi igual. Nas regiões dos carcinomas foliculares a expressão imuno-histoquímica do VEGF-D foi positiva em $83 \%$, enquanto que nas regiões adjacentes com bócio adenomatoso $100 \%$ dos casos foram positivos para o VEGF-D. Quanto a expressão imuno-histoquímica do VEGF-B, no tecido adjacente normal, bócio adenomatoso e na tireoidite linfocitária todos os casos foram negativos.

Um sumário da porcentagem de casos negativos ou positivos para a expressão imuno-histoquímica dos fatores de crescimento endotelial vascular (VEGF-A; VEGF-A 165 ; VEGF-B; VEGF-C;VEGF-D) e de seus receptores (VEGF-R1 e VEGF-R3) nos carcinomas foliculares e em suas adjacências apresentando tecido normal, bócio adenomatoso e tireoidite linfocitária pode ser observado na tabela 20 e fotomicrografias 
exemplificando o padrão das expressões imuno-histoquímicas dos VEGFs e

VEGFRs nos carcinomas foliculares estudados na figura 21.

Tabela 20 - Porcentagem de casos com expressão imuno-histoquímica negativa (até $10 \%$ ) ou positiva (> do que 10\%) dos VEGFs e VEGFRs nos Carcinomas Foliculares e suas adjacências apresentando tecido Normal, Bócio Adenomatoso e Tireoidite Linfocitária

\begin{tabular}{|c|c|c|c|c|c|}
\hline & Carcinoma Folicular & Normal & Bócio Adenomatoso & Tireoidite Linfocitária & $p$ \\
\hline & \multicolumn{5}{|c|}{ VEGF-A } \\
\hline Negativo & 11 & 67 & 22 & 44 & \multirow{2}{*}{$0,005^{*}$} \\
\hline Positivo & 90 & 33 & 78 & 56 & \\
\hline & \multicolumn{5}{|c|}{ VEGF-A165b } \\
\hline Negativo & 16 & 71 & 11 & 44 & \multirow{2}{*}{$0,003^{*}$} \\
\hline Positivo & 84 & 29 & 89 & 56 & \\
\hline & \multicolumn{5}{|c|}{ VEGF-B } \\
\hline Negativo & 91 & 100 & 100 & 100 & \multirow{2}{*}{0,395} \\
\hline Positivo & 9 & 0 & 0 & 0 & \\
\hline & \multicolumn{5}{|c|}{ VEGF-C } \\
\hline Negativo & 22 & 100 & 33 & 22 & \multirow{2}{*}{$<0,001^{*}$} \\
\hline Positivo & 78 & 0 & 67 & 78 & \\
\hline & \multicolumn{5}{|c|}{ VEGF-D } \\
\hline Negativo & 17 & 14 & 0 & 22 & \multirow{2}{*}{0,510} \\
\hline Positivo & 83 & 86 & 100 & 78 & \\
\hline & \multicolumn{5}{|c|}{ VEGF-R1 } \\
\hline Negativo & 13 & 87 & 22 & 33 & \multirow{2}{*}{$<0,001^{*}$} \\
\hline Positivo & 87 & 13 & 78 & 67 & \\
\hline & \multicolumn{5}{|c|}{ VEGF-R3 } \\
\hline Negativo & 9 & 62 & 11 & 33 & \multirow{2}{*}{$0,005^{*}$} \\
\hline Positivo & 91 & 39 & 89 & 67 & \\
\hline
\end{tabular}



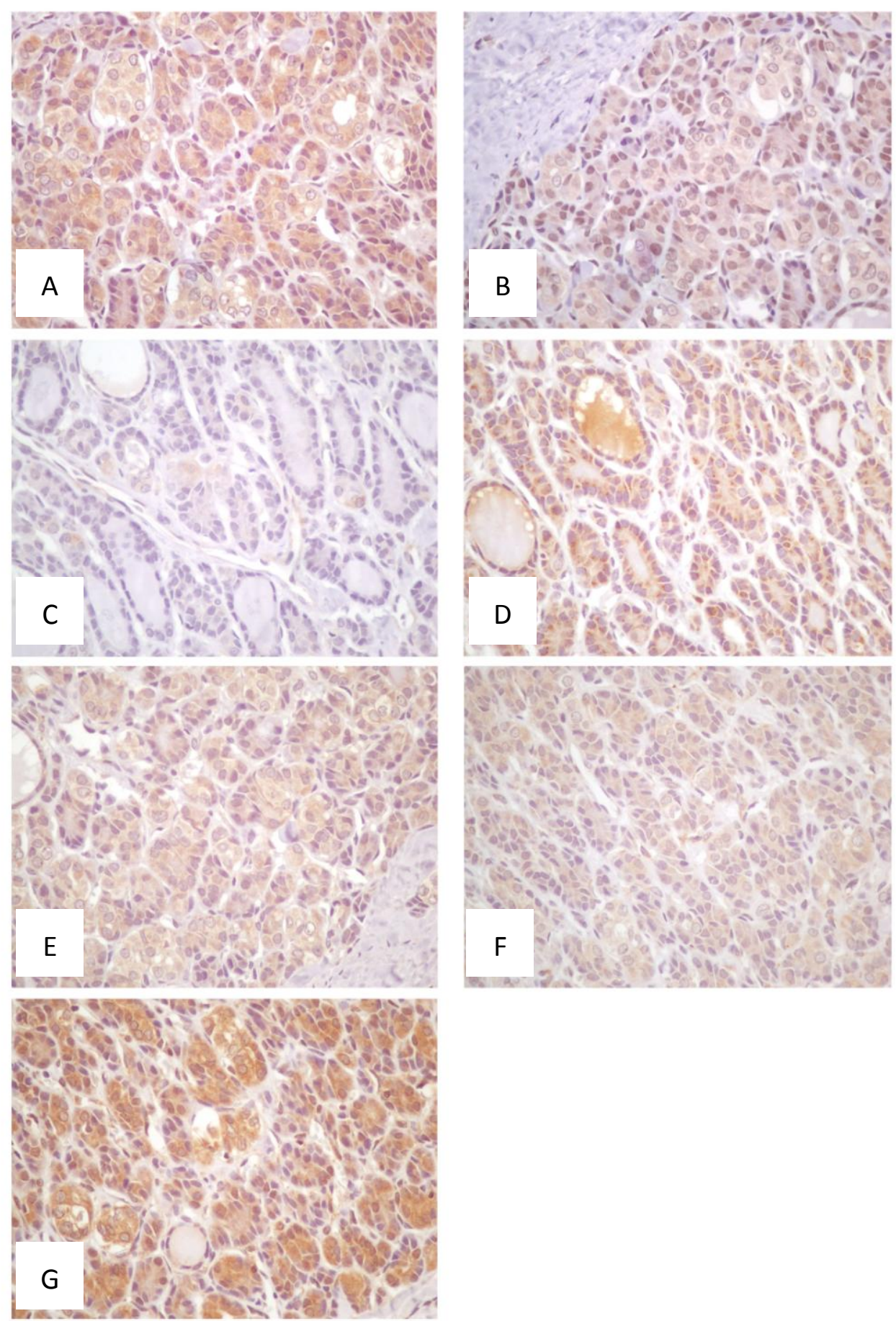

Figura 21. Fotomicrografias dos padrões de imunoexpressão do VEGF-A (A aumento 400X), VEGF-A ${ }_{165} \mathrm{~b}$ (B - aumento 400X), VEGF-B (C - aumento 400X), VEGF-C (D - aumento 400X), VEGF-D (E - aumento 400X), VEGF-R1 (F - aumento 400X) e VEGF-R3 (G - aumento 400X) nos carcinomas foliculares 


\subsection{Correlações entre a expressão imuno-histoquímica dos fatores de crescimento endotelial vascular e de seus receptores e as variáveis clínico-patológicas dos carcinomas foliculares estudados}

As imunoexpressões dos VEGFs (VEGF-A; VEGF-A 165 ; VEGF-B; VEGF-C;VEGF-D) e de seus receptores (VEGF-R1 e VEGF-R3) também foram individualmente correlacionadas com os dados clínico-patológicos dos carcinomas foliculares.

Quando analisadas as expressões dos VEGFs e VEGFRs de 0 a ++++, não houve correlações estatisticamente significantes dos dados clínico-patológicos sexo, idade, lado, invasão de vaso, comprometimento de adjacência, metástase, $\mathrm{T}, \mathrm{N}, \mathrm{M}$ e estadiamento com as imunoexpressões dos VEGF-A (Tabela 21), VEGF-A 165 b (Tabela 22), VEGF-B (Tabela 23), VEGF-C (Tabela 24), VEGF-D (Tabela 25), VEGF-R1 (Tabela 26) e VEGF-R3 (Tabela 27) nos carcinomas foliculares estudados.

Ao dicotomizarmos a expressão dos VEGFs e VEGFRs em duas categorias, negativos (até 10\% de imunomarcação positiva) e positivos (imunomarcação positiva maior do que 10\%) também não observamos correlações estatisticamente significantes entre a expressão dos VEGFs e VEGFRs e as variáveis clínico-patológicas dos carcinomas foliculares estudados (Tabela 28). 
Tabela 21 - Correlação das variáveis clínico-patológicas e da imunoexpressão do VEGF-A com freqüências absolutas e percentual de casos de acordo com o nível de imunoexpressão nos carcinomas foliculares

\begin{tabular}{|c|c|c|c|c|c|c|c|c|c|c|c|c|}
\hline & & \multicolumn{11}{|c|}{ VEGF-A } \\
\hline & & \multicolumn{2}{|c|}{0} & \multicolumn{2}{|c|}{+} & \multicolumn{2}{|c|}{++} & \multicolumn{2}{|c|}{+++} & \multicolumn{2}{|c|}{++++} & \multirow{2}{*}{$p$} \\
\hline & & $\mathrm{n}$ & $\%$ & $\mathrm{n}$ & $\%$ & $\mathrm{n}$ & $\%$ & $\mathrm{n}$ & $\%$ & $\mathrm{n}$ & $\%$ & \\
\hline \multicolumn{13}{|l|}{ Sexo } \\
\hline & M & 0 & 0 & - & - & 0 & 0 & - & - & 2 & 100 & \multirow{3}{*}{0,811} \\
\hline & $\mathrm{F}$ & 2 & 11,8 & - & - & 1 & 5,9 & - & - & 14 & 82,4 & \\
\hline & Total & 2 & 10,5 & - & - & 1 & 5,3 & - & - & 16 & 84,2 & \\
\hline \multicolumn{13}{|l|}{ Idade } \\
\hline & $<45$ anos & 1 & 10 & - & - & 1 & 10 & - & - & 8 & 80 & \multirow{3}{*}{0,622} \\
\hline & $>$ ou $=45$ anos & 1 & 11,1 & - & - & 0 & 0 & - & - & 8 & 88,9 & \\
\hline & Total & 2 & 10,5 & - & - & 1 & 5,3 & - & - & 16 & 84,2 & \\
\hline \multicolumn{13}{|l|}{ Lado } \\
\hline & Direito & 1 & 8,3 & - & - & 1 & 8,3 & - & - & 10 & 83,3 & \multirow{6}{*}{0,602} \\
\hline & Direito e Esquerdo & - & - & - & - & - & - & - & - & - & - & \\
\hline & Direito e Istmo & 0 & 0 & - & - & 0 & 0 & - & - & 1 & 100 & \\
\hline & Esquerdo & 1 & 50 & - & - & 0 & 0 & - & - & 1 & 50 & \\
\hline & Difuso & 0 & 0 & - & - & 0 & 0 & - & - & 4 & 100 & \\
\hline & Total & 2 & 10,5 & - & - & 1 & 5,3 & - & - & 16 & 84,2 & \\
\hline \multicolumn{13}{|l|}{ Invasão de Vaso } \\
\hline & Presente & 2 & 25 & - & - & 0 & 0 & - & - & 6 & 75 & \multirow{3}{*}{0,164} \\
\hline & Não Detectada & 0 & 0 & - & - & 1 & 9,1 & - & - & 10 & 90,9 & \\
\hline & Total & 2 & 10,5 & - & - & 1 & 5,3 & - & - & 16 & 84,2 & \\
\hline \multirow[t]{4}{*}{$\begin{array}{r}\text { Comprometimento } \\
\text { de Adjacencia }\end{array}$} & & & & & & & & & & & & \\
\hline & Presente & 0 & 0 & - & - & 0 & 0 & - & - & 1 & 100 & \multirow{3}{*}{0,906} \\
\hline & Não Detectada & 2 & 11,1 & - & - & 1 & 5,6 & - & - & 15 & 83,3 & \\
\hline & Total & 2 & 10,5 & - & - & 1 & 5,3 & - & - & 16 & 84,2 & \\
\hline \multirow[t]{3}{*}{ Metástase } & & & & & & & & & & & & \\
\hline & Ausente & 2 & 10,5 & - & - & 1 & 5,3 & - & - & 16 & 84,2 & \multirow{2}{*}{-} \\
\hline & Total & 2 & 10,5 & - & - & 1 & 5,3 & - & - & 16 & 84,2 & \\
\hline \multirow[t]{5}{*}{$\begin{array}{llll}\mathbf{T} & & \end{array}$} & & & & & & & & & & & & \\
\hline & T1 & 1 & 16,7 & - & - & 0 & 0 & - & - & 5 & 83,3 & \\
\hline & T2 & 1 & 8,3 & - & - & 1 & 8,3 & - & - & 10 & 83,3 & 0911 \\
\hline & T3 & 0 & 0 & - & - & 0 & 0 & - & - & 1 & 100 & 0,911 \\
\hline & Total & 2 & 10,5 & - & - & 1 & 5,3 & - & - & 16 & 84,2 & \\
\hline $\mathbf{N}$ & & & & & & & & & & & & \\
\hline & NO & 2 & 10,5 & - & - & 1 & 5,3 & - & - & 16 & 84,2 & - \\
\hline & Total & 2 & 10,5 & - & - & 1 & 5,3 & - & - & 16 & 84,2 & \\
\hline M & & & & & & & & & & & & \\
\hline & M0 & 2 & 10,5 & - & - & 1 & 5,3 & - & - & 16 & 84,2 & \\
\hline & Total & 2 & 10,5 & - & - & 1 & 5,3 & - & - & 16 & 84,2 & - \\
\hline $\begin{array}{r}\text { Estadiamento } \\
\text { (TNM) }\end{array}$ & & & & & & & & & & & & \\
\hline & I & 2 & 15,4 & - & - & 1 & 7,7 & - & - & 10 & 76,9 & \\
\hline & II & 0 & 0 & - & - & 0 & 0 & - & - & 5 & 100 & 0801 \\
\hline & III & 0 & 0 & - & - & 0 & 0 & - & - & 1 & 100 & 0,801 \\
\hline & Total & 2 & 10,5 & - & - & 1 & 5,3 & - & - & 16 & 84,2 & \\
\hline
\end{tabular}

(o símbolo - foi aplicado para indicar que não há valor para esta variável) 
Tabela 22 - Correlação das variáveis clínico-patológicas e da imunoexpressão do VEGF-A ${ }_{165} \mathrm{~b}$ com freqüências absolutas e percentual de casos de acordo com o nível de imunoexpressão nos carcinomas foliculares

\begin{tabular}{|c|c|c|c|c|c|c|c|c|c|c|c|c|}
\hline & & \multicolumn{11}{|c|}{ VEGF-A165b } \\
\hline & & \multicolumn{2}{|c|}{0} & \multicolumn{2}{|c|}{+} & \multicolumn{2}{|c|}{++} & \multicolumn{2}{|c|}{+++} & \multicolumn{2}{|c|}{++++} & \multirow{2}{*}{$\mathrm{p}$} \\
\hline & & $\mathrm{n}$ & $\%$ & $\mathrm{n}$ & $\%$ & $\mathrm{n}$ & $\%$ & $\mathrm{n}$ & $\%$ & $\mathrm{n}$ & $\%$ & \\
\hline \multicolumn{13}{|l|}{ Sexo } \\
\hline & M & 0 & 0 & - & - & 0 & 0 & 0 & 0 & 2 & 100 & \multirow{3}{*}{0,850} \\
\hline & $\mathrm{F}$ & 3 & 17,6 & - & - & 1 & 5,9 & 1 & 5,9 & 12 & 70,6 & \\
\hline & Total & 3 & 15,8 & - & - & 1 & 5,3 & 1 & 5,3 & 14 & 73,7 & \\
\hline \multirow[t]{4}{*}{ Idade } & & & & & & & & & & & & \\
\hline & $<45$ anos & 1 & 10 & - & - & 1 & 10 & 1 & 10 & 7 & 70 & \multirow{3}{*}{0,515} \\
\hline & $>$ ou $=45$ anos & 2 & 22,2 & - & - & 0 & 0 & 0 & 0 & 7 & 77,8 & \\
\hline & Total & 3 & 15,8 & - & - & 1 & 5,3 & 1 & 5,3 & 14 & 73,7 & \\
\hline \multirow[t]{6}{*}{ Lado } & & & & & & & & & & & & \\
\hline & Direito & 2 & 16,7 & - & - & 1 & 8,3 & 1 & 8,3 & 8 & 66,7 & \multirow{5}{*}{0,901} \\
\hline & Direito e Istmo & 0 & 0 & - & - & 0 & 0 & 0 & 0 & 1 & 100 & \\
\hline & Esquerdo & 1 & 50 & - & - & 0 & 0 & 0 & 0 & 1 & 50 & \\
\hline & Difuso & 0 & 0 & - & - & 0 & 0 & 0 & 0 & 4 & 100 & \\
\hline & Total & 3 & 15,8 & - & - & 1 & 5,3 & 1 & 5,3 & 14 & 73,7 & \\
\hline \multicolumn{13}{|l|}{ Invasão de Vaso } \\
\hline & Presente & 2 & 25 & - & - & 0 & 0 & 1 & 12,5 & 5 & 62,5 & \multirow{3}{*}{0,380} \\
\hline & Não Detectada & 1 & 9,1 & - & - & 1 & 9,1 & 0 & 0 & 9 & 81,8 & \\
\hline & Total & 3 & 15,8 & - & - & 1 & 5,3 & 1 & 5,3 & 14 & 73,7 & \\
\hline \multirow[t]{4}{*}{$\begin{array}{r}\text { Comprometimento } \\
\text { de Adjacencia }\end{array}$} & & & & & & & & & & & & \\
\hline & Presente & 0 & 0 & - & - & 0 & 0 & 0 & 0 & 1 & 100 & \multirow{3}{*}{0,945} \\
\hline & Não Detectada & 3 & 16,7 & - & - & 1 & 5,6 & 1 & 5,6 & 13 & 72,2 & \\
\hline & Total & 3 & 15,8 & - & - & 1 & 5,3 & 1 & 5,3 & 14 & 73,7 & \\
\hline \multirow[t]{3}{*}{ Metástase } & & & & & & & & & & & & \\
\hline & Ausente & 3 & 15,8 & - & - & 1 & 5,3 & 1 & 5,3 & 14 & 73,7 & \multirow{2}{*}{-} \\
\hline & Total & 3 & 15,8 & - & - & 1 & 5,3 & 1 & 5,3 & 14 & 73,7 & \\
\hline \multirow[t]{5}{*}{$T$} & & & & & & & & & & & & \multirow{5}{*}{0,802} \\
\hline & T1 & 2 & 33,3 & - & - & 0 & 0 & 0 & 0 & 4 & 66,7 & \\
\hline & $\mathrm{T} 2$ & 1 & 8,3 & - & - & 1 & 8,3 & 1 & 8,3 & 9 & 75 & \\
\hline & T3 & 0 & 0 & - & - & 0 & 0 & 0 & 0 & 1 & 100 & \\
\hline & Total & 3 & 15,8 & - & - & 1 & 5,3 & 1 & 5,3 & 14 & 73,7 & \\
\hline $\mathbf{N}$ & & & & & & & & & & & & \\
\hline & No & 3 & 15,8 & - & - & 1 & 5,3 & 1 & 5,3 & 14 & 73,7 & - \\
\hline & Total & 3 & 15,8 & - & - & 1 & 5,3 & 1 & 5,3 & 14 & 73,7 & \\
\hline M & & & & & & & & & & & & \\
\hline & M0 & 3 & 15,8 & - & - & 1 & 5,3 & 1 & 5,3 & 14 & 73,7 & \\
\hline & Total & 3 & 15,8 & - & - & 1 & 5,3 & 1 & 5,3 & 14 & 73,7 & - \\
\hline $\begin{array}{r}\text { Estadiamento } \\
\text { (TNM) }\end{array}$ & & & & & & & & & & & & \\
\hline & I & 3 & 23,1 & - & - & 1 & 7,7 & 1 & 7,7 & 8 & 61,5 & \\
\hline & II & 0 & 0 & - & - & 0 & 0 & 0 & 0 & 5 & 100 & 0792 \\
\hline & III & 0 & 0 & - & - & 0 & 0 & 0 & 0 & 1 & 100 & 0,702 \\
\hline & Total & 3 & 15,8 & - & - & 1 & 5,3 & 1 & 5,3 & 14 & 73,7 & \\
\hline
\end{tabular}

(o símbolo - foi aplicado para indicar que não há valor para esta variável) 
Tabela 23 - Correlação das variáveis clínico-patológicas e da imunoexpressão do VEGF-B com freqüências absolutas e percentual de casos de acordo com o nível de imunoexpressão nos carcinomas foliculares

\begin{tabular}{|c|c|c|c|c|c|c|c|c|c|c|c|c|}
\hline & & \multicolumn{11}{|c|}{ VEGF-B } \\
\hline & & \multicolumn{2}{|c|}{0} & \multicolumn{2}{|c|}{+} & \multicolumn{2}{|c|}{++} & \multicolumn{2}{|c|}{+++} & \multicolumn{2}{|c|}{++++} & \multirow{2}{*}{$p$} \\
\hline & & $\mathrm{n}$ & $\%$ & $\mathrm{n}$ & $\%$ & $\mathrm{n}$ & $\%$ & $\mathrm{n}$ & $\%$ & $\mathrm{n}$ & $\%$ & \\
\hline \multicolumn{13}{|l|}{ Sexo } \\
\hline & $\mathrm{M}$ & 3 & 100 & - & - & 0 & 0 & - & - & - & - & \multirow{3}{*}{0,567} \\
\hline & $\mathrm{F}$ & 18 & 90 & - & - & 2 & 10 & - & - & - & - & \\
\hline & Total & 21 & 91,3 & - & - & 2 & 8,7 & - & - & - & - & \\
\hline \multicolumn{13}{|l|}{ Idade } \\
\hline & $<45$ anos & 10 & 83,3 & - & - & 2 & 16,7 & - & - & - & - & \multirow{3}{*}{0,156} \\
\hline & $>$ ou $=45$ anos & 11 & 100 & - & - & 0 & 0 & - & - & - & - & \\
\hline & Total & 21 & 91,3 & - & - & 2 & 8,7 & - & - & - & - & \\
\hline \multicolumn{13}{|l|}{ Lado } \\
\hline & Direito & 12 & 85,7 & - & - & 2 & 14,3 & - & - & - & - & \multirow{5}{*}{0,704} \\
\hline & Direito e Istmo & 1 & 100 & - & - & 0 & 0 & - & - & - & - & \\
\hline & Esquerdo & 3 & 100 & - & - & 0 & 0 & - & - & - & - & \\
\hline & Difuso & 5 & 100 & - & - & 0 & 0 & - & - & - & - & \\
\hline & Total & 21 & 91,3 & - & - & 2 & 8,7 & - & - & - & - & \\
\hline \multicolumn{13}{|l|}{ Invasão de Vaso } \\
\hline & Presente & 7 & 87,5 & - & - & 1 & 12,5 & - & - & - & - & \multirow{3}{*}{0,636} \\
\hline & Não Detectada & 14 & 93,3 & - & - & 1 & 6,7 & - & - & - & - & \\
\hline & Total & 21 & 91,3 & - & - & 2 & 8,7 & - & - & - & - & \\
\hline \multirow[t]{4}{*}{$\begin{array}{r}\text { Comprometimento } \\
\text { de Adjacencia }\end{array}$} & & & & & & & & & & & & \\
\hline & Presente & 1 & 100 & - & - & 0 & 0 & - & - & - & - & \multirow{3}{*}{0,913} \\
\hline & Não Detectada & 20 & 90,9 & - & - & 2 & 9,1 & - & - & - & - & \\
\hline & Total & 21 & 91,3 & - & - & 2 & 8,7 & - & - & - & - & \\
\hline \multicolumn{13}{|l|}{ Metástase } \\
\hline & Ausente & 21 & 91,3 & - & - & 2 & 8,7 & - & - & - & - & \multirow{2}{*}{ - } \\
\hline & Total & 21 & 91,3 & - & - & 2 & 8,7 & - & - & - & - & \\
\hline \multirow[t]{5}{*}{$\mathrm{T}$} & & & & & & & & & & & & \\
\hline & T1 & 5 & 83,3 & - & - & 1 & 16,7 & - & - & - & - & \multirow{4}{*}{0,706} \\
\hline & T2 & 15 & 93,8 & - & - & 1 & 6,3 & - & - & - & - & \\
\hline & T3 & 1 & 100 & - & - & 0 & 0 & - & - & - & - & \\
\hline & Total & 21 & 91,3 & - & - & 2 & 8,7 & - & - & - & - & \\
\hline $\mathbf{N}$ & & & & & & & & & & & & \\
\hline & NO & 21 & 91,3 & - & - & 2 & 8,7 & - & - & - & - & - \\
\hline & Total & 21 & 91,3 & - & - & 2 & 8,7 & - & - & - & - & - \\
\hline $\mathbf{M}$ & & & & & & & & & & & & \\
\hline & MO & 21 & 91,3 & - & - & 2 & 8,7 & - & - & - & - & \\
\hline & Total & 21 & 91,3 & - & - & 2 & 8,7 & - & - & - & - & - \\
\hline $\begin{array}{r}\text { Estadiamento } \\
\text { (TNM) }\end{array}$ & & & & & & & & & & & & \\
\hline & I & 13 & 86,7 & - & - & 2 & 13,3 & - & - & - & - & \\
\hline & II & 7 & 100 & - & - & 0 & 0 & - & - & - & - & 0558 \\
\hline & III & 1 & 100 & - & - & 0 & 0 & - & - & - & - & u,558 \\
\hline & Total & 21 & 91,3 & - & - & 2 & 8,7 & - & - & - & - & \\
\hline
\end{tabular}

(o símbolo - foi aplicado para indicar que não há valor para esta variável) 
Tabela 24 - Correlação das variáveis clínico-patológicas e da imunoexpressão do VEGF-C com freqüências absolutas e percentual de casos de acordo com o nível de imunoexpressão nos carcinomas foliculares

\begin{tabular}{|c|c|c|c|c|c|c|c|c|c|c|c|c|}
\hline & & \multicolumn{11}{|c|}{ VEGF-C } \\
\hline & & \multicolumn{2}{|c|}{0} & \multicolumn{2}{|r|}{+} & \multicolumn{2}{|c|}{++} & \multicolumn{2}{|c|}{+++} & \multicolumn{2}{|c|}{++++} & \multirow{2}{*}{$\mathrm{p}$} \\
\hline & & $\mathrm{n}$ & $\%$ & $\mathrm{n}$ & $\%$ & $\mathrm{n}$ & $\%$ & $\mathrm{n}$ & $\%$ & $\mathrm{n}$ & $\%$ & \\
\hline \multicolumn{13}{|l|}{ Sexo } \\
\hline & M & - & - & 1 & 33,3 & 0 & 0 & 1 & 33,3 & 1 & 33,3 & \multirow{3}{*}{0,597} \\
\hline & $\mathrm{F}$ & - & - & 4 & 20 & 1 & 5 & 2 & 10 & 13 & 65 & \\
\hline & Total & - & - & 5 & 21,7 & 1 & 4,3 & 3 & 13 & 14 & 60,9 & \\
\hline \multirow[t]{4}{*}{ Idade } & & & & & & & & & & & & \\
\hline & $<45$ anos & - & - & 2 & 16,7 & 1 & 8,3 & 3 & 25 & 6 & 50 & \multirow{3}{*}{0,217} \\
\hline & $>$ ou $=45$ anos & - & - & 3 & 27,3 & 0 & 0 & 0 & 0 & 8 & 72,7 & \\
\hline & Total & - & - & 5 & 21,7 & 1 & 4,3 & 3 & 13 & 14 & 60,9 & \\
\hline \multirow[t]{6}{*}{ Lado } & & & & & & & & & & & & \\
\hline & Direito & - & - & 4 & 28,6 & 1 & 7,1 & 2 & 14,3 & 7 & 50 & \multirow{5}{*}{0,706} \\
\hline & Direito e Istmo & - & - & 0 & 0 & 0 & 0 & 0 & 0 & 1 & 100 & \\
\hline & Esquerdo & - & - & 1 & 33,3 & 0 & 0 & 1 & 33,3 & 1 & 33,3 & \\
\hline & Difuso & - & - & 0 & 0 & 0 & 0 & 0 & 0 & 5 & 100 & \\
\hline & Total & - & - & 5 & 21,7 & 1 & 4,3 & 3 & 13 & 14 & 60,9 & \\
\hline \multicolumn{13}{|l|}{ Invasão de Vaso } \\
\hline & Presente & - & - & 1 & 12,5 & 1 & 12,5 & 0 & 0 & 6 & 75 & \multirow{3}{*}{0,225} \\
\hline & Não Detectada & - & - & 4 & 26,7 & 0 & 0 & 3 & 20 & 8 & 53,3 & \\
\hline & Total & - & - & 5 & 21,7 & 1 & 4,3 & 3 & 13 & 14 & 60,9 & \\
\hline \multirow[t]{4}{*}{$\begin{array}{r}\text { Comprometimento } \\
\text { de Adjacencia }\end{array}$} & & & & & & & & & & & & \\
\hline & Presente & - & - & 1 & 100 & 0 & 0 & 0 & 0 & 0 & 0 & \multirow{3}{*}{0,288} \\
\hline & Não Detectada & - & - & 4 & 18,2 & 1 & 4,5 & 3 & 13,6 & 14 & 63,6 & \\
\hline & Total & - & - & 5 & 21,7 & 1 & 4,3 & 3 & 13 & 14 & 60,9 & \\
\hline \multirow[t]{3}{*}{ Metástase } & & & & & & & & & & & & \\
\hline & Ausente & - & - & 5 & 21,7 & 1 & 4,3 & 3 & 13 & 14 & 60,9 & \multirow{2}{*}{-} \\
\hline & Total & - & - & 5 & 21,7 & 1 & 4,3 & 3 & 13 & 14 & 60,9 & \\
\hline \multirow[t]{5}{*}{$\mathbf{T}$} & & & & & & & & & & & & \multirow{5}{*}{0,786} \\
\hline & T1 & - & - & 1 & 16,7 & 0 & 0 & 0 & 0 & 5 & 83,3 & \\
\hline & T2 & - & - & 4 & 25 & 1 & 6,3 & 3 & 18,8 & 8 & 50 & \\
\hline & T3 & - & - & 0 & 0 & 0 & 0 & 0 & 0 & 1 & 100 & \\
\hline & Total & - & - & 5 & 21,7 & 1 & 4,3 & 3 & 13 & 14 & 60,9 & \\
\hline $\mathbf{N}$ & & & & & & & & & & & & \\
\hline & No & - & - & 5 & 21,7 & 1 & 4,3 & 3 & 13 & 14 & 60,9 & - \\
\hline & Total & - & - & 5 & 21,7 & 1 & 4,3 & 3 & 13 & 14 & 60,9 & \\
\hline M & & & & & & & & & & & & \\
\hline & MO & - & - & 5 & 21,7 & 1 & 4,3 & 3 & 13 & 14 & 60,9 & \\
\hline & Total & - & - & 5 & 21,7 & 1 & 4,3 & 3 & 13 & 14 & 60,9 & - \\
\hline $\begin{array}{r}\text { Estadiamento } \\
\text { (TNM) }\end{array}$ & & & & & & & & & & & & \\
\hline & I & - & - & 3 & 20 & 1 & 6,7 & 3 & 20 & 8 & 53,3 & \\
\hline & II & - & - & 2 & 28,6 & 0 & 0 & 0 & 0 & 5 & 71,4 & 0804 \\
\hline & III & - & - & 0 & 0 & 0 & 0 & 0 & 0 & 1 & 100 & 0,004 \\
\hline & Total & - & - & 5 & 21,7 & 1 & 4,3 & 3 & 13 & 14 & 60,9 & \\
\hline
\end{tabular}

(o símbolo - foi aplicado para indicar que não há valor para esta variável) 
Tabela 25 - Correlação das variáveis clínico-patológicas e da imunoexpressão do VEGF-D com freqüências absolutas e percentual de casos de acordo com o nível de imunoexpressão nos carcinomas foliculares

\begin{tabular}{|c|c|c|c|c|c|c|c|c|c|c|c|c|}
\hline & & \multicolumn{11}{|c|}{ VEGF-D } \\
\hline & & \multicolumn{2}{|c|}{0} & \multicolumn{2}{|c|}{+} & \multicolumn{2}{|c|}{++} & \multicolumn{2}{|c|}{+++} & \multicolumn{2}{|c|}{++++} & \multirow{2}{*}{$\mathrm{p}$} \\
\hline & & $\mathrm{n}$ & $\%$ & $\mathrm{n}$ & $\%$ & $\mathrm{n}$ & $\%$ & $\mathrm{n}$ & $\%$ & $\mathrm{n}$ & $\%$ & \\
\hline \multicolumn{13}{|l|}{ Sexo } \\
\hline & M & 1 & 33,3 & 0 & 0 & 0 & 0 & - & - & 2 & 66,7 & \multirow{3}{*}{0,694} \\
\hline & $\mathrm{F}$ & 2 & 10 & 1 & 5 & 1 & 5 & - & - & 16 & 80 & \\
\hline & Total & 3 & 13 & 1 & 4,3 & 1 & 4,3 & - & - & 18 & 78,3 & \\
\hline \multirow[t]{4}{*}{ Idade } & & & & & & & & & & & & \\
\hline & $<45$ anos & 2 & 16,7 & 1 & 8,3 & 1 & 8,3 & - & - & 8 & 66,7 & \multirow{3}{*}{0,472} \\
\hline & $>$ ou $=45$ anos & 1 & 9,1 & 0 & 0 & 0 & 0 & - & - & 10 & 90,9 & \\
\hline & Total & 3 & 13 & 1 & 4,3 & 1 & 4,3 & - & - & 18 & 78,3 & \\
\hline \multirow[t]{6}{*}{ Lado } & & & & & & & & & & & & \\
\hline & Direito & 1 & 7,1 & 1 & 7,1 & 1 & 7,1 & - & - & 11 & 78,6 & \multirow{5}{*}{0,335} \\
\hline & Direito e Istmo & 0 & 0 & 0 & 0 & 0 & 0 & - & - & 1 & 100 & \\
\hline & Esquerdo & 2 & 66,7 & 0 & 0 & 0 & 0 & - & - & 1 & 33,3 & \\
\hline & Difuso & 0 & 0 & 0 & 0 & 0 & 0 & - & - & 5 & 100 & \\
\hline & Total & 3 & 13 & 1 & 4,3 & 1 & 4,3 & - & - & 18 & 78,3 & \\
\hline \multicolumn{13}{|l|}{ Invasão de Vaso } \\
\hline & Presente & 1 & 12,5 & 1 & 12,5 & 0 & 0 & - & - & 6 & 75 & \multirow{3}{*}{0,488} \\
\hline & Não Detectada & 2 & 13,3 & 0 & 0 & 1 & 6,7 & - & - & 12 & 80 & \\
\hline & Total & 3 & 13 & 1 & 4,3 & 1 & 4,3 & - & - & 18 & 78,3 & \\
\hline \multirow[t]{4}{*}{$\begin{array}{r}\text { Comprometimento } \\
\text { de Adjacencia }\end{array}$} & & & & & & & & & & & & \\
\hline & Presente & 0 & 0 & 0 & 0 & 0 & 0 & - & - & 1 & 100 & \multirow{3}{*}{0,962} \\
\hline & Não Detectada & 3 & 13,6 & 1 & 4,5 & 1 & 4,5 & - & - & 17 & 77,3 & \\
\hline & Total & 3 & 13 & 1 & 4,3 & 1 & 4,3 & - & - & 18 & 78,3 & \\
\hline \multirow[t]{3}{*}{ Metástase } & & & & & & & & & & & & \\
\hline & Ausente & 3 & 13 & 1 & 4,3 & 1 & 4,3 & - & - & 18 & 78,3 & \multirow{2}{*}{-} \\
\hline & Total & 3 & 13 & 1 & 4,3 & 1 & 4,3 & - & - & 18 & 78,3 & \\
\hline \multirow[t]{5}{*}{$T$} & & & & & & & & & & & & \\
\hline & T1 & 1 & 16,7 & 0 & 0 & 0 & 0 & - & - & 5 & 83,3 & \multirow{4}{*}{0,978} \\
\hline & T2 & 2 & 12,5 & 1 & 6,3 & 1 & 6,3 & - & - & 12 & 75 & \\
\hline & T3 & 0 & 0 & 0 & 0 & 0 & 0 & - & - & 1 & 100 & \\
\hline & Total & 3 & 13 & 1 & 4,3 & 1 & 4,3 & - & - & 18 & 78,3 & \\
\hline $\mathbf{N}$ & & & & & & & & & & & & \\
\hline & No & 3 & 13 & 1 & 4,3 & 1 & 4,3 & - & - & 18 & 78,3 & - \\
\hline & Total & 3 & 13 & 1 & 4,3 & 1 & 4,3 & - & - & 18 & 78,3 & \\
\hline M & & & & & & & & & & & & \\
\hline & M0 & 3 & 13 & 1 & 4,3 & 1 & 4,3 & - & - & 18 & 78,3 & - \\
\hline & Total & 3 & 13 & 1 & 4,3 & 1 & 4,3 & - & - & 18 & 78,3 & 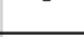 \\
\hline $\begin{array}{r}\text { Estadiamento } \\
\text { (TNM) }\end{array}$ & & & & & & & & & & & & \\
\hline & I & 3 & 20 & 1 & 6,7 & 1 & 6,7 & - & - & 10 & 66,7 & \\
\hline & II & 0 & 0 & 0 & 0 & 0 & 0 & - & - & 7 & 100 & 0756 \\
\hline & III & 0 & 0 & 0 & 0 & 0 & 0 & - & - & 1 & 100 & 0 \\
\hline & Total & 3 & 13 & 1 & 4,3 & 1 & 4,3 & - & - & 18 & 78,3 & \\
\hline
\end{tabular}

(o símbolo - foi aplicado para indicar que não há valor para esta variável) 
Tabela 26 - Correlação das variáveis clínico-patológicas e da imunoexpressão do VEGF-R1 com freqüências absolutas e percentual de casos de acordo com o nível de imunoexpressão nos carcinomas foliculares.

\begin{tabular}{|c|c|c|c|c|c|c|c|c|c|c|c|c|}
\hline & & \multicolumn{11}{|c|}{ VEGF-R1 } \\
\hline & & \multicolumn{2}{|c|}{0} & \multicolumn{2}{|c|}{+} & \multicolumn{2}{|c|}{++} & \multicolumn{2}{|c|}{+++} & \multicolumn{2}{|c|}{++++} & \multirow{2}{*}{$\mathrm{p}$} \\
\hline & & $\mathrm{n}$ & $\%$ & $\mathrm{n}$ & $\%$ & $\mathrm{n}$ & $\%$ & $\mathrm{n}$ & $\%$ & $\mathrm{n}$ & $\%$ & \\
\hline \multicolumn{13}{|l|}{ Sexo } \\
\hline & M & 0 & 0 & - & - & 1 & 33,3 & 0 & 0 & 15 & 75 & \multirow{3}{*}{0,387} \\
\hline & $\mathrm{F}$ & 3 & 15 & - & - & 1 & 5 & 1 & 5 & 2 & 66,7 & \\
\hline & Total & 3 & 13 & - & - & 2 & 8,7 & 1 & 4,3 & 17 & 73,9 & \\
\hline \multirow[t]{4}{*}{ Idade } & & & & & & & & & & & & \\
\hline & $<45$ anos & 1 & 8,3 & - & - & 1 & 8,3 & 1 & 8,3 & 9 & 75 & \multirow{3}{*}{0,717} \\
\hline & $>$ ou $=45$ anos & 2 & 18,2 & - & - & 1 & 9,1 & 0 & 0 & 8 & 72,7 & \\
\hline & Total & 3 & 13 & - & - & 2 & 8,7 & 1 & 4,3 & 17 & 73,9 & \\
\hline \multirow[t]{6}{*}{ Lado } & & & & & & & & & & & & \\
\hline & Direito & 2 & 14,3 & - & - & 1 & 7,1 & 1 & 7,1 & 10 & 71,4 & \multirow{5}{*}{0,712} \\
\hline & Direito e Istmo & 0 & 0 & - & - & 0 & 0 & 0 & 0 & 1 & 100 & \\
\hline & Esquerdo & 1 & 33,3 & - & - & 1 & 33,3 & 0 & 0 & 1 & 33,3 & \\
\hline & Difuso & 0 & 0 & - & - & 0 & 0 & 0 & 0 & 5 & 100 & \\
\hline & Total & 3 & 13 & - & - & 2 & 8,7 & 1 & 4,3 & 17 & 73,9 & \\
\hline \multicolumn{13}{|l|}{ Invasão de Vaso } \\
\hline & Presente & 1 & 12,5 & - & - & 1 & 12,5 & 0 & 0 & 6 & 75 & \multirow{3}{*}{0,863} \\
\hline & Não Detectada & 2 & 13,3 & - & - & 1 & 6,7 & 1 & 6,7 & 11 & 73,3 & \\
\hline & Total & 3 & 13 & - & - & 2 & 8,7 & 1 & 4,3 & 17 & 73,9 & \\
\hline \multirow[t]{4}{*}{$\begin{array}{r}\text { Comprometimento } \\
\text { de Adjacencia }\end{array}$} & & & & & & & & & & & & \\
\hline & Presente & 0 & 0 & - & - & 0 & 0 & 0 & 0 & 1 & 100 & \multirow{3}{*}{0,947} \\
\hline & Não Detectada & 3 & 13,6 & - & - & 2 & 9,1 & 1 & 4,5 & 16 & 72,7 & \\
\hline & Total & 3 & 13 & - & - & 2 & 8,7 & 1 & 4,3 & 17 & 73,9 & \\
\hline \multirow[t]{3}{*}{ Metástase } & & & & & & & & & & & & \\
\hline & Ausente & 3 & 13 & - & - & 2 & 8,7 & 1 & 4,3 & 17 & 73,9 & \multirow{2}{*}{-} \\
\hline & Total & 3 & 13 & - & - & 2 & 8,7 & 1 & 4,3 & 17 & 73,9 & \\
\hline \multirow[t]{5}{*}{$\mathbf{T}$} & & & & & & & & & & & & \multirow{5}{*}{0,966} \\
\hline & T1 & 1 & 16,7 & - & - & 1 & 16,7 & 0 & 0 & 4 & 66,7 & \\
\hline & T2 & 2 & 12,5 & - & - & 1 & 6,3 & 1 & 6,3 & 12 & 75 & \\
\hline & T3 & 0 & 0 & - & - & 0 & 0 & 0 & 0 & 1 & 100 & \\
\hline & Total & 3 & 13 & - & - & 2 & 8,7 & 1 & 4,3 & 17 & 73,9 & \\
\hline $\mathbf{N}$ & & & & & & & & & & & & \\
\hline & No & 3 & 13 & - & - & 2 & 8,7 & 1 & 4,3 & 17 & 73,9 & - \\
\hline & Total & 3 & 13 & - & - & 2 & 8,7 & 1 & 4,3 & 17 & 73,9 & \\
\hline M & & & & & & & & & & & & \\
\hline & MO & 3 & 13 & - & - & 2 & 8,7 & 1 & 4,3 & 17 & 73,9 & \\
\hline & Total & 3 & 13 & - & - & 2 & 8,7 & 1 & 4,3 & 17 & 73,9 & - \\
\hline $\begin{array}{r}\text { Estadiamento } \\
\text { (TNM) }\end{array}$ & & & & & & & & & & & & \\
\hline & I & 2 & 13,3 & - & - & 2 & 13,3 & 1 & 6,7 & 10 & 66,7 & \\
\hline & II & 1 & 14,3 & - & - & 0 & 0 & 0 & 0 & 6 & 85,7 & 0913 \\
\hline & III & 0 & 0 & - & - & 0 & 0 & 0 & 0 & 1 & 100 & 0,910 \\
\hline & Total & 3 & 13 & - & - & 2 & 8,7 & 1 & 4,3 & 17 & 73,9 & \\
\hline
\end{tabular}

(o símbolo - foi aplicado para indicar que não há valor para esta variável) 
Tabela 27 - Correlação das variáveis clínico-patológicas e da imunoexpressão do VEGF-R3 com freqüências absolutas e percentual de casos de acordo com o nível de imunoexpressão nos carcinomas foliculares

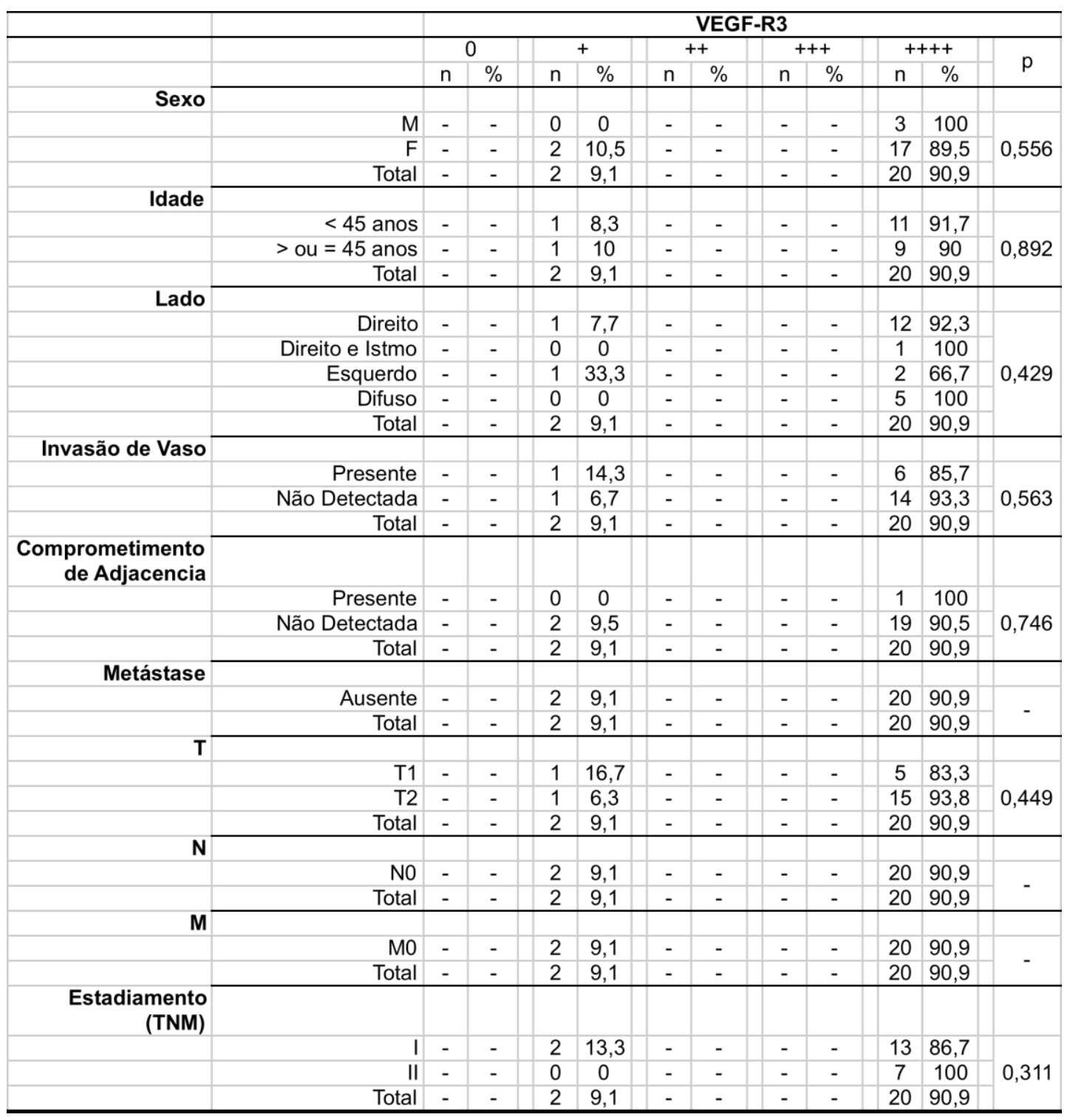

(o símbolo - foi aplicado para indicar que não há valor para esta variável) 
Tabela 28 - Sumário das significâncias das correlações entre a expressão imunohistoquímica negativa (até 10\%) ou positiva (> do que 10\%) dos VEGFs e VEGFRs e das variáveis clínico-patológicas dos carcinomas foliculares estudados

\begin{tabular}{|c|c|c|c|c|c|c|c|}
\hline & VEGF-A & VEGF-A165b & VEGF-B & VEGF-C & VEGF-D & VEGF-R1 & VEGF-R3 \\
\hline & $p$ & $p$ & $p$ & $p$ & $p$ & $p$ & $p$ \\
\hline Idade & 0,937 & 0,466 & 0,156 & 0,538 & 0,315 & 0,484 & 0,892 \\
\hline Sexo & 0,608 & 0,517 & 0,567 & 0,602 & 0,435 & 0,472 & 0,556 \\
\hline Lado & 0,266 & 0,439 & 0,704 & 0,515 & 0,093 & 0,571 & 0,429 \\
\hline Invasão de Vaso & 0,080 & 0,348 & 0,636 & 0,433 & 0,482 & 0,955 & 0,563 \\
\hline $\begin{array}{r}\text { Comprometimento } \\
\text { de Adjacência }\end{array}$ & 0,725 & 0,656 & 0,752 & 0,052 & 0,639 & 0,692 & 0,746 \\
\hline Metástase & - & - & - & - & - & - & - \\
\hline $\mathbf{T}$ & 0,811 & 0,354 & 0,706 & 0,791 & 0,890 & 0,894 & 0,449 \\
\hline $\mathbf{N}$ & - & - & - & - & - & - & - \\
\hline $\mathbf{M}$ & - & - & - & - & - & - & - \\
\hline Estadio & 0,597 & 0,440 & 0,558 & 0,780 & 0,275 & 0,923 & 0,311 \\
\hline
\end{tabular}

(o símbolo - foi aplicado para indicar que não há valor para esta variável)

\subsection{Expressão imuno-histoquímica dos fatores de} crescimento endotelial vascular e de seus receptores nos bócios adenomatosos, tireoidites linfocitárias e adenomas foliculares estudados

Foram avaliadas as expressões dos fatores de crescimento endotelial vascular (VEGF-A; VEGF-A 165 b; VEGF-B; VEGF-C;VEGF-D) e de seus receptores (VEGF-R1 e VEGF-R3) nos bócios adenomatosos, tireoidites linfocitárias e adenomas foliculares.

A Tabela 29 apresenta o número de casos de lesões tireoidianas benignas analisadas para cada membro da família VEGF. Devido as perdas inerentes a técnica da micromatriz tecidual (TMA), dos 78 casos, alguns foram perdidos na manipulação técnica conforme detalhado a seguir. 
Tabela 29 - Número de amostras avaliadas quanto a expressão imuno-histoquímica dos VEGFs e VEGFRs nos bócios adenomatosos, tireoidites linfocitárias e adenomas foliculares

\begin{tabular}{|r|c|c|c|c|c|c|c|}
\hline & \multirow{2}{*}{ VEGF-A } & VEGF-A165b & VEGF-B & VEGF-C & VEGF-D & VEGF-R1 & VEGF-R3 \\
& & & & & & & \\
\hline Bócio Adenomatoso & 51 & 50 & 49 & 51 & 49 & 49 & 48 \\
\hline Tireoidite Linfocitária & 16 & 16 & 16 & 16 & 16 & 16 & 16 \\
\hline Adenoma Folicular & 6 & 6 & 6 & 6 & 6 & 6 & 6 \\
\hline
\end{tabular}

\subsubsection{VEGF-A}

Dos 53 casos de bócio adenomatoso, 16 casos de tireoidite linfocitária e 9 casos de adenoma folicular foi possível avaliar a expressão imunohistoquímica do VEGF-A em 51, 16 e 6 amostras respectivamente (96,2\%, $100 \%$ e $66,6 \%$ do total de casos estudados) (Tabela 29).

Nos bócios adenomatosos em $67 \%$ dos casos as imunomarcações foram positivas ++++ , em $10 \%$ foram positivas +++ , em $16 \%++$ e em $8 \%+$ para o VEGF-A. Nas tireoidites linfocitárias $29 \%$ dos casos apresentaram imunomarcações positivas ++++, $12 \%+++, 24 \%++, 12 \%+$ e $24 \%$ foram negativos (0). Nos adenomas foliculares $50 \%$ dos casos apresentaram imunomarcações positivas ++++, 17\% +++, 17\% ++ e 17\% +. para o VEGF-A (Figura 22). 


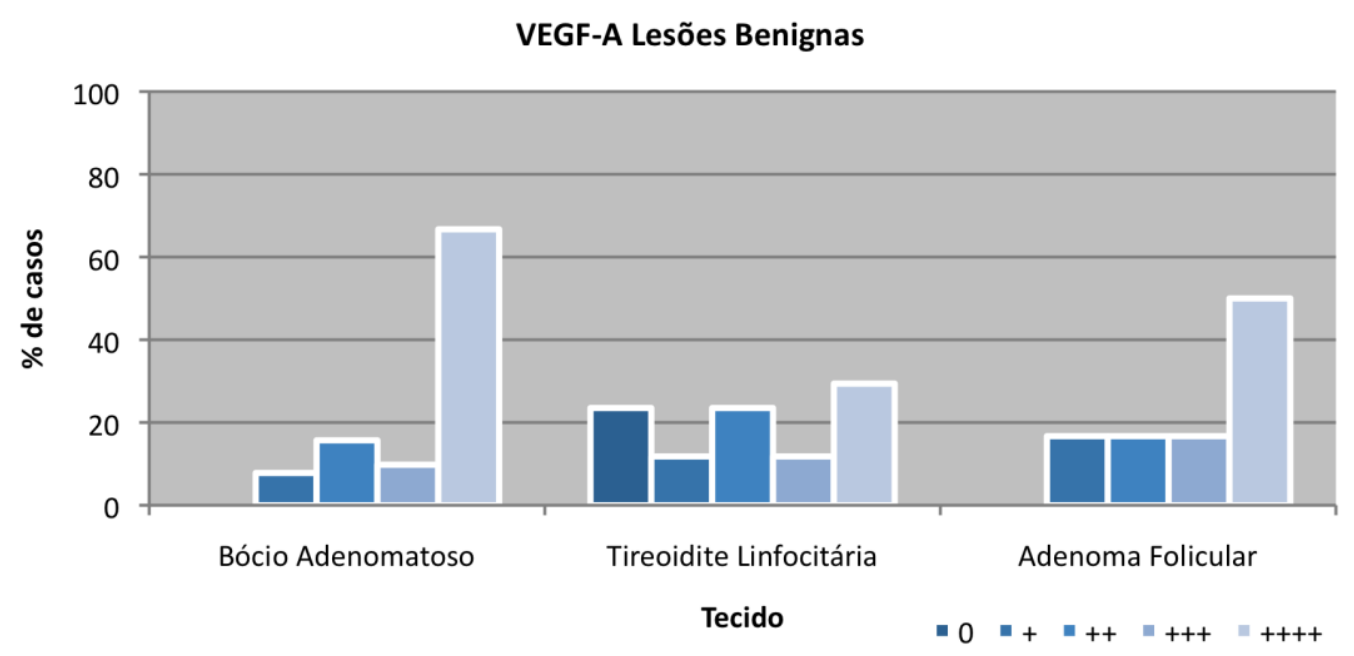

Figura 22. Expressão imuno-histoquímica do VEGF-A nos Bócios Adenomatosos, Tireoidites Linfocitárias e Adenomas Foliculares $(p=0,012)$

\subsubsection{VEGF-A $A_{165} b$}

Foi possível avaliar a expressão imuno-histoquímica do VEGF-A ${ }_{165} b$ em 50 amostras de bócio adenomatoso, 16 de tireoidite linfocitária e 6 de adenoma folicular $(94,3 \%, 100 \%$ e $66,6 \%$ do total de casos estudados) (Tabela 29).

Nos bócios adenomatosos, 30\% dos casos as imunomarcações foram positivas ++++ , em $18 \%$ foram positivas +++ , em $24 \%++, 18 \%+$, e em $10 \%$ foi negativa (0) para o VEGF-A 165 $_{16}$ b. Nas tireoidites linfocitárias $6 \%$ dos casos apresentaram imunomarcações positivas,$++++ 12 \%+++, 12 \%++, 24 \%+$ e $47 \%$ foram negativos (0). Nos adenomas foliculares $17 \%$ dos casos apresentaram imunomarcações positivas ++++, $17 \%++$ e $67 \%$ foram negativos para o VEGF-A 165 b (Figura 23). 


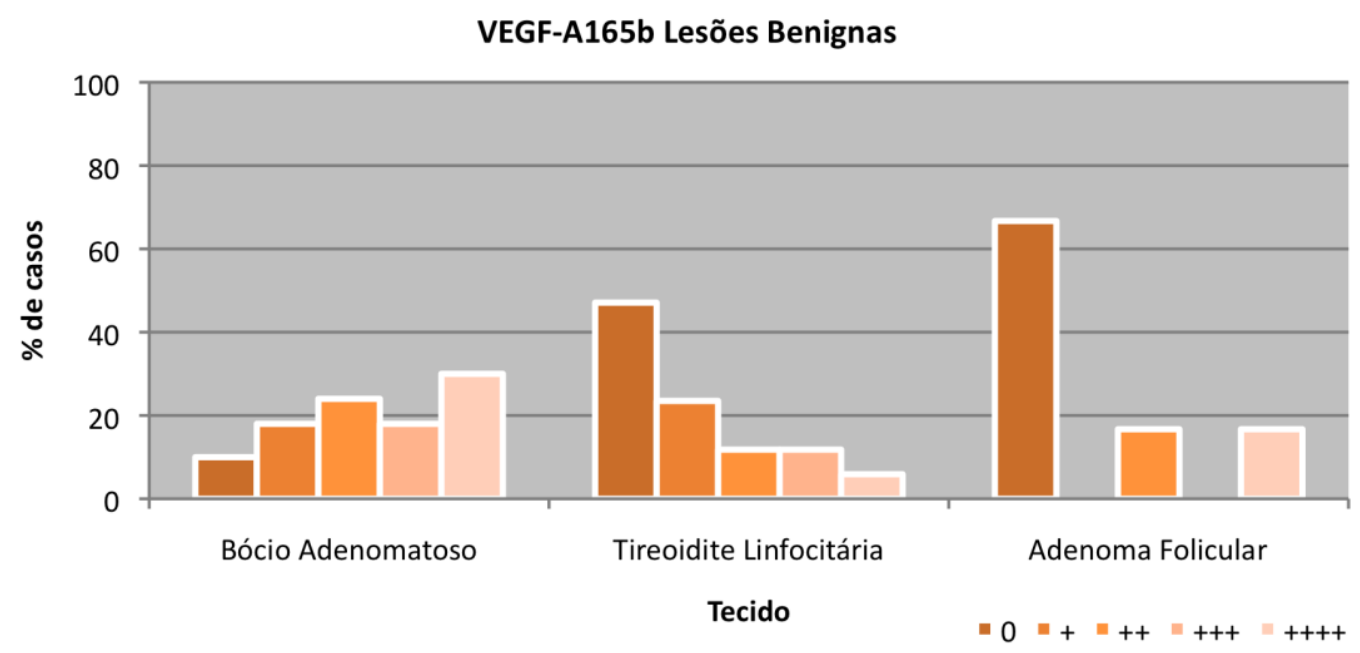

Figura 23. Expressão imuno-histoquímica do VEGF-A $A_{165} b$ nos Bócios Adenomatosos, Tireoidites Linfocitárias e Adenomas Foliculares $(p=0,003)$

\subsubsection{VEGF-B}

Foi possível avaliar a expressão imuno-histoquímica do VEGF-B em 49 amostras de bócio adenomatoso, 16 de tireoidite linfocitária e 6 de adenoma folicular $(92,4 \%, 100 \%$ e $66,6 \%$ do total de casos estudados) (Tabela 29).

Nos bócios adenomatosos em $12 \%$ dos casos as imunomarcações foram positivas + e em $88 \%$ foi negativa (0) para o VEGF-B. Nas tireoidites linfocitárias e nos adenomas foliculares $100 \%$ dos casos apresentaram imunomarcações negativas (0) para o VEGF-B (Figura 24). 


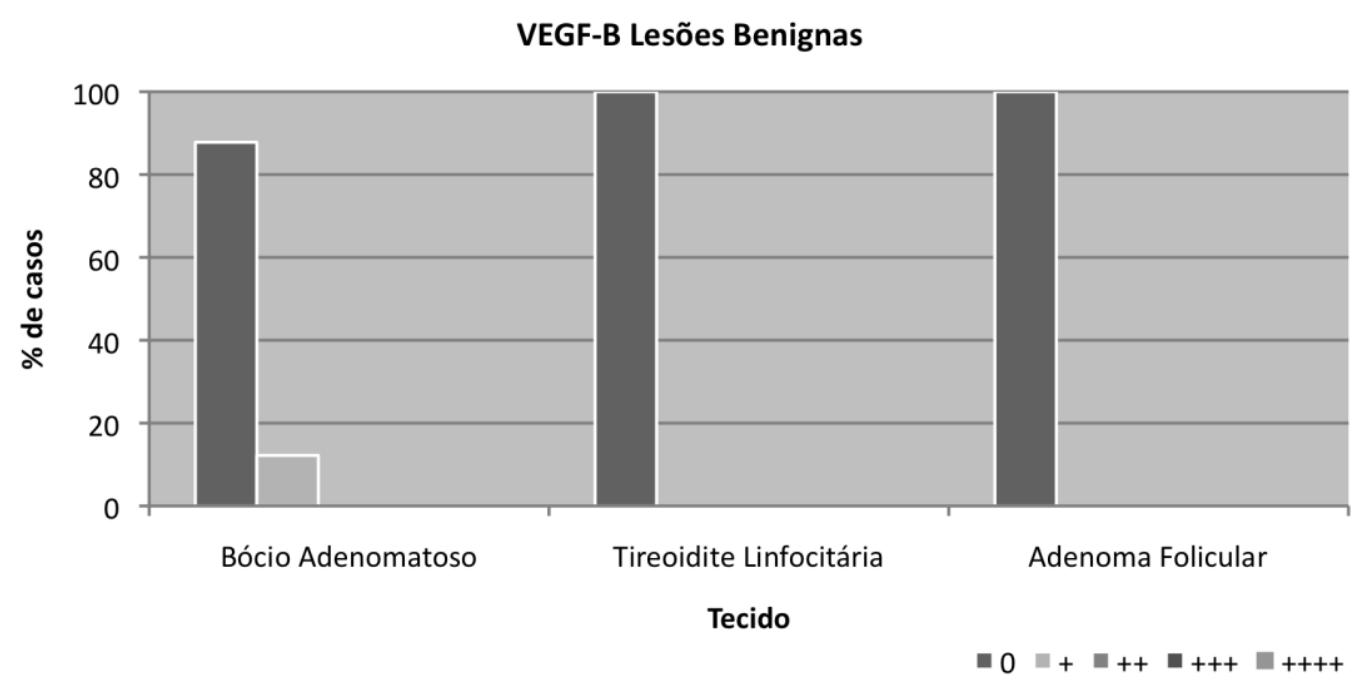

Figura 24. Expressão imuno-histoquímica do VEGF-B nos Bócios Adenomatosos, Tireoidites Linfocitárias e Adenomas Foliculares $(p=0,163)$

\subsubsection{VEGF-C}

Foi possível avaliar a expressão imuno-histoquímica do VEGF-C em 51 amostras de bócio adenomatoso, 16 de tireoidite linfocitária e 6 de adenoma folicular $(96,2 \%, 100 \%$ e $66,6 \%$ do total de casos estudados, respectivamente) (Tabela 29$)$.

Nos bócios adenomatosos em $6 \%$ dos casos as imunomarcações foram positivas ++++ , em $8 \%$ foram positivas +++ , em $22 \%++, 49 \%+$, e em $16 \%$ foi negativa (0) para o VEGF-C. Nas tireoidites linfocitárias $12 \%$ dos casos apresentaram imunomarcações positivas,$++++ 24 \%+++, 29 \%++$ e $36 \%+$. Nos adenomas foliculares $17 \%$ dos casos apresentaram imunomarcações positivas ++, $67 \%+$ e $17 \%$ foram negativos para o VEGF-C (Figura 25). 


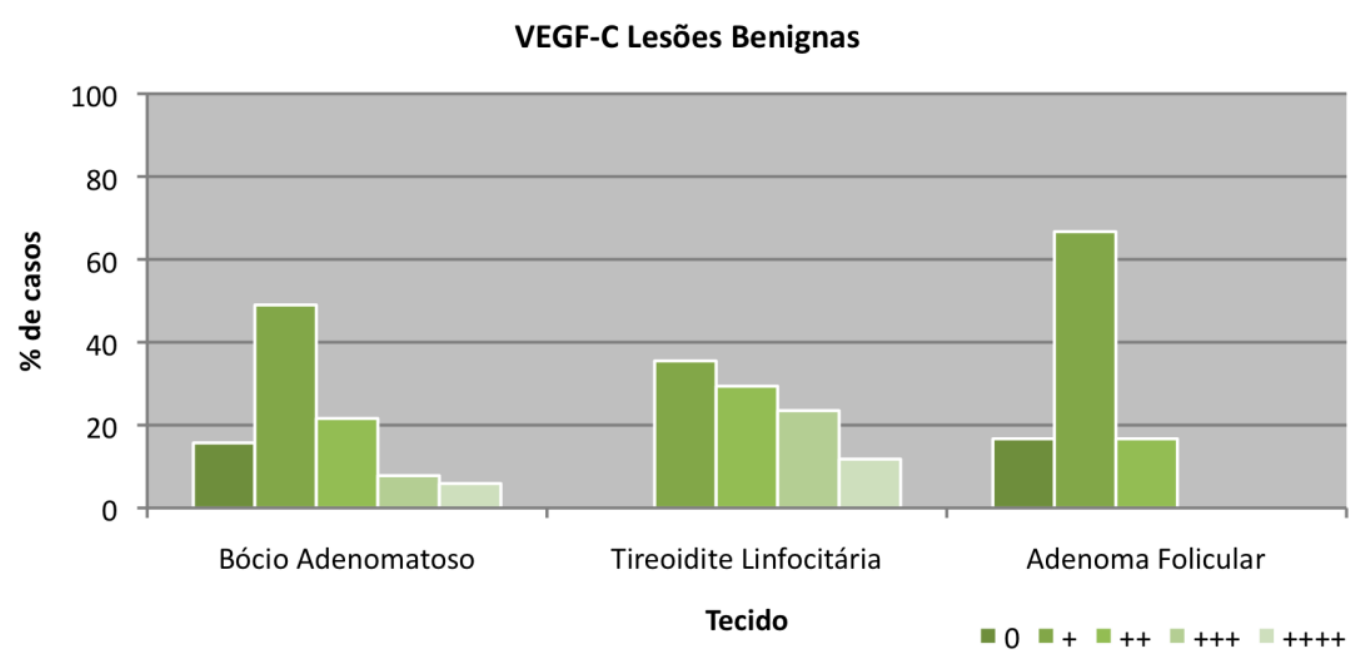

Figura 25. Expressão imuno-histoquímica do VEGF-C nos Bócios Adenomatosos, Tireoidites Linfocitárias e Adenomas Foliculares $(p=0,013)$

\subsubsection{VEGF-D}

Foi possível avaliar a expressão imuno-histoquímica do VEGF-D em 49 amostras de bócio adenomatoso, 16 de tireoidite linfocitária e 6 de adenoma folicular $(92,4 \%, 100 \%$ e $66,6 \%$ do total de casos estudados, respectivamente) (Tabela 29).

Nos bócios adenomatosos em $25 \%$ dos casos as imunomarcações foram positivas ++++ , em $29 \%$ foram positivas +++ , em $25 \%++, 18 \%+$, e em $4 \%$ foi negativa (0) para o VEGF-D. Nas tireoidites linfocitárias $24 \%$ dos casos apresentaram imunomarcações positivas ++++, $18 \%+++, 24 \%++$, $24 \%+$ e $12 \%$ foi negativa (0). Nos adenomas foliculares $17 \%$ dos casos apresentaram imunomarcações positivas +++, $17 \%++, 33 \%+$ e $33 \%$ foram negativos para o VEGF-D (Figura 26). 


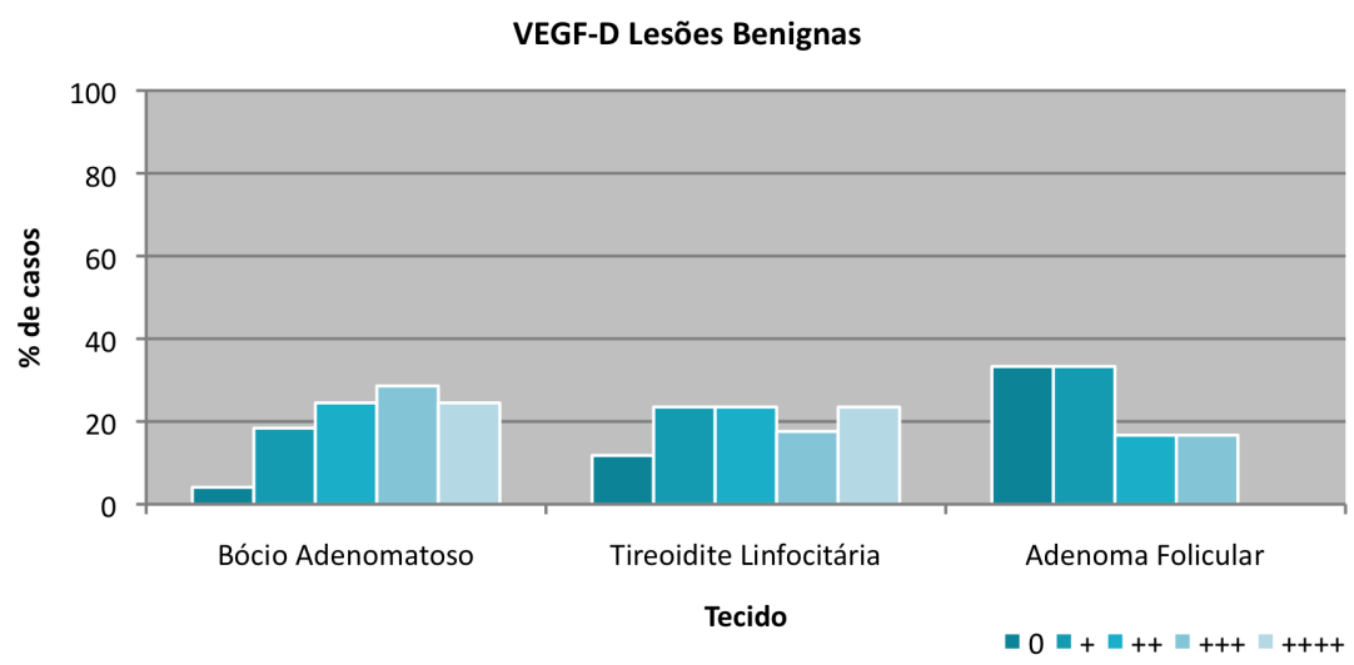

Figura 26. Expressão imuno-histoquímica do VEGF-D nos Bócios Adenomatosos, Tireoidites Linfocitárias e Adenomas Foliculares $(p=0,299)$

\subsubsection{VEGF-R1}

Foi possível avaliar a expressão imuno-histoquímica do VEGF-R1 em 49 amostras de bócio adenomatoso, 16 de tireoidite linfocitária e 6 de adenoma folicular $(92,4 \%, 100 \%$ e $66,6 \%$ do total de casos estudados, respectivamente) (Tabela 29$)$.

Nos bócios adenomatosos em $14 \%$ dos casos as imunomarcações foram positivas ++++ , em $6 \%$ foram positivas +++ , em $22 \%++, 14 \%+$, e em $43 \%$ foi negativa (0) para o VEGF-R1. Nas tireoidites linfocitárias $24 \%$ dos casos apresentaram imunomarcações positivas ++++, $24 \%+++, 24 \%++$, $12 \%+$ e $18 \%$ foi negativa (0). Nos adenomas foliculares $17 \%$ dos casos apresentaram imunomarcações positivas ++++, 33\% ++, 17\% + e 33\% foram negativos para o VEGF-R1 (Figura 27). 


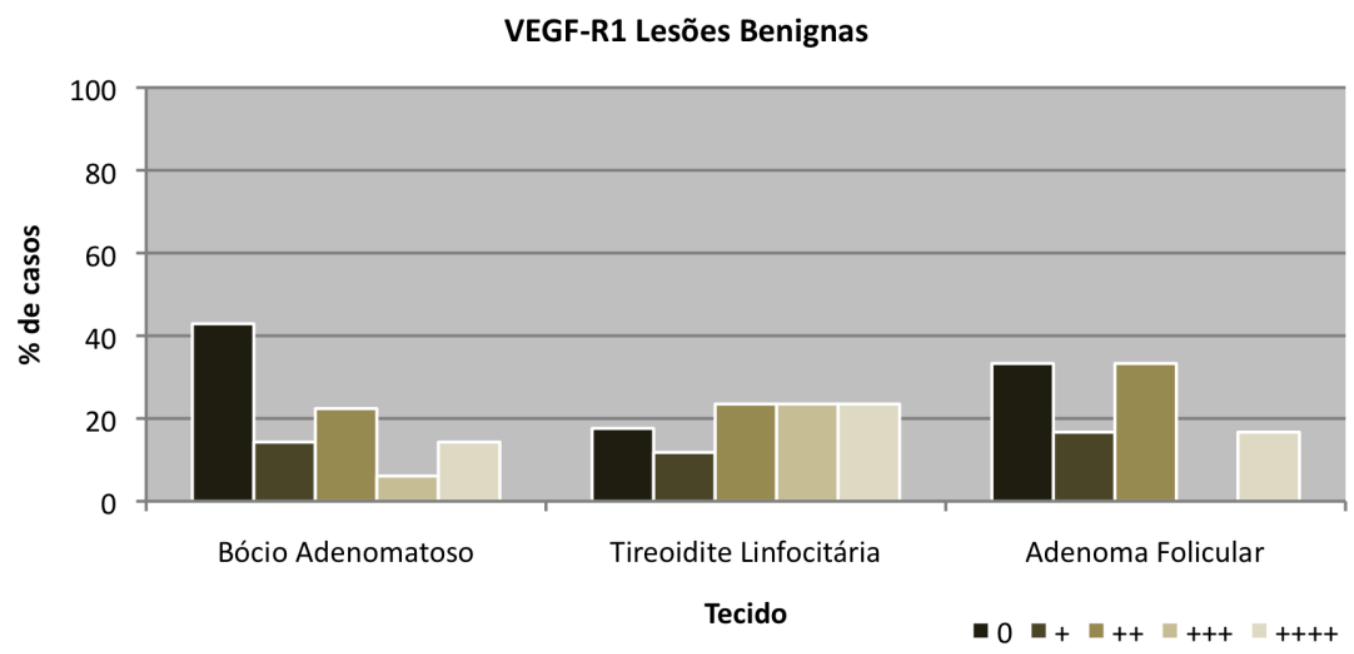

Figura 27. Expressão imuno-histoquímica do VEGF-R1 nos Bócios Adenomatosos, Tireoidites Linfocitárias e Adenomas Foliculares $(p=0,734)$

\subsubsection{VEGF-R3}

Foi possível avaliar a expressão imuno-histoquímica do VEGF-R3 em 48 amostras de bócio adenomatoso, 16 de tireoidite linfocitária e 6 de adenoma folicular $(90,5 \%, 100 \%$ e $66,6 \%$ do total de casos estudados, respectivamente) (Tabela 29$)$.

Nos bócios adenomatosos em $42 \%$ dos casos as imunomarcações foram positivas ++++ , em $27 \%$ foram positivas +++ , em $15 \%++, 10 \%+$, e em $6 \%$ foi negativa (0) para o VEGF-R3. Nas tireoidites linfocitárias $29 \%$ dos casos apresentaram imunomarcações positivas ++++, $18 \%+++, 18 \%++$, $29 \%+$ e $6 \%$ foi negativa (0). Nos adenomas foliculares $17 \%$ dos casos apresentaram imunomarcações positivas ++++, $17 \%+++, 17 \%+, 33 \%++$ e 33\% foram negativos para o VEGF-R3 (Figura 28). 


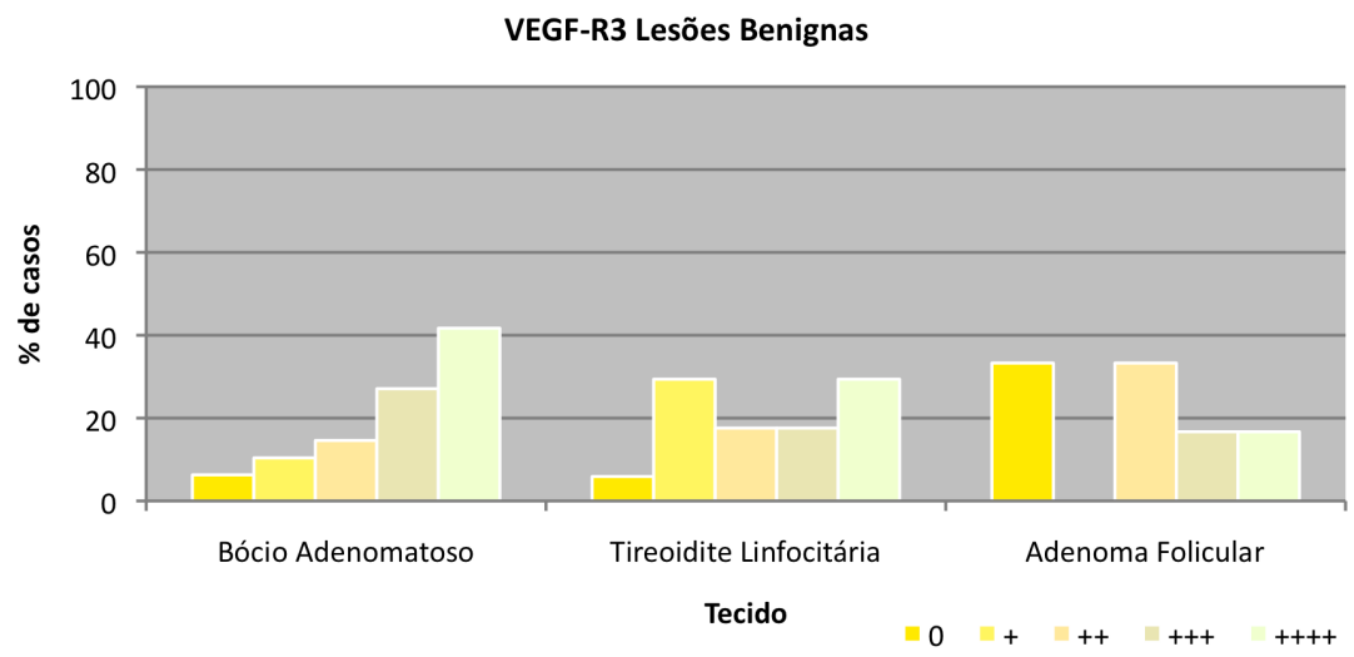

Figura 28. Expressão imuno-histoquímica do VEGF-R3 nos Bócios Adenomatosos, Tireoidites Linfocitárias e Adenomas Foliculares $(p=0,009)$

\subsection{Expressão imuno-histoquímica, dicotomizada em negativa} ou positiva, dos fatores de crescimento endotelial vascular e de seus receptores nos bócios adenomatosos, tireoidites linfocitárias e adenomas foliculares estudados

Os dados acima apresentados, foram também dicotomizados em duas categorias. Negativos, amostras com até $10 \%$ de imunomarcação positiva, e positivos, amostras com imunomarcação positiva maior que $10 \%$.

A maioria dos bócios adenomatosos estudados apresentaram expressão imuno-histoquímica positiva para o VEGF-A (positiva 92\% dos casos), VEGF-A ${ }_{165}$ b (positiva $72 \%$ dos casos), VEGF-D (positiva $78 \%$ dos casos) e VEGF-R3 (positiva $83 \%$ dos casos). Uma maior quantidade de 
casos negativos foi observada na avaliação da expressão imunohistoquímica do VEGF-B (negativa 100\% dos casos), VEGF-C (negativa $65 \%$ dos casos) e VEGF-R1 (negativa $57 \%$ dos casos).

Nas tireoidites linfocitárias estudadas encontramos uma maior quantidade de casos com expressão imuno-histoquímica positiva para o VEGF-A (positiva $65 \%$ dos casos), VEGF-C (positiva $65 \%$ dos casos), VEGF-D (positiva $65 \%$ dos casos), VEGF-R1 (positiva $71 \%$ dos casos) e VEGF-R3 (positiva 65\% dos casos), e uma maior quantidade de casos negativos para o VEGF-A $165 \mathrm{~b}$ (negativa $71 \%$ dos casos) e o VEGF-B (negativa $100 \%$ dos casos).

Nos adenomas foliculares uma maior quantidade de casos com expressão imuno-histoquímica positiva foi encontrada apenas no VEGF-A (positiva $83 \%$ dos casos) e no VEGF-R3 (positiva $67 \%$ dos casos). Cinqüenta por cento dos casos de adenoma folicular estudados apresentaram expressão imuno-histoquímica positiva e 50\% negativa para o VEGF-R1. Uma maioria de casos com expressão imuno-histoquímica negativa foi encontrada para o VEGF-A ${ }_{165} b$ (negativa $67 \%$ dos casos), VEGF-B (negativa $100 \%$ dos casos), VEGF-C (negativa $83 \%$ dos casos) e VEGF-D (negativa $67 \%$ dos casos).

Um sumário da porcentagem de casos negativos ou positivos para a expressão imuno-histoquímica dos fatores de crescimento endotelial vascular (VEGF-A; VEGF-A ${ }_{165} \mathrm{~b}$; VEGF-B; VEGF-C;VEGF-D) e de seus receptores (VEGF-R1 e VEGF-R3) nos bócios adenomatosos, tireoidites linfocitárias e adenomas foliculares pode ser observado na Tabela 30 e 
fotomicrografias exemplificando o padrão das expressões imunohistoquímicas dos VEGFs e VEGFRs nas lesões benignas estudados na Figura 29.

Tabela 30 - Porcentagem de casos com expressão imuno-histoquímica negativa (até $10 \%$ ) ou positiva (> do que 10\%) dos VEGFs e VEGFRs nos bócios adenomatosos, tireoidites linfocitárias e adenomas foliculares

\begin{tabular}{|c|c|c|c|c|}
\hline & Bócio Adenomatoso & Tireoidite Linfocitária & Adenoma Folicular & $p$ \\
\hline & \multicolumn{4}{|c|}{$\begin{array}{l}\text { VEGF-A } \\
\end{array}$} \\
\hline Negativo & 8 & 35 & 17 & \multirow{2}{*}{$0,003^{*}$} \\
\hline Positivo & 92 & 65 & 83 & \\
\hline & \multicolumn{4}{|c|}{ VEGF-A165b } \\
\hline Negativo & 28 & 71 & 67 & \multirow{2}{*}{$0,010^{*}$} \\
\hline Positivo & 72 & 29 & 33 & \\
\hline & \multicolumn{4}{|c|}{ VEGF-B } \\
\hline Negativo & 100 & 100 & 100 & \multirow{2}{*}{-} \\
\hline Positivo & 0 & 0 & 0 & \\
\hline & \multicolumn{4}{|c|}{ VEGF-C } \\
\hline Negativo & 65 & 35 & 83 & \multirow{2}{*}{$<0,001^{*}$} \\
\hline Positivo & 35 & 65 & 17 & \\
\hline & \multicolumn{4}{|c|}{ VEGF-D } \\
\hline Negativo & 22 & 35 & 67 & \multirow{2}{*}{0,129} \\
\hline Positivo & 78 & 65 & 33 & \\
\hline & \multicolumn{4}{|c|}{ VEGF-R1 } \\
\hline Negativo & 57 & 29 & 50 & \multirow{2}{*}{0,252} \\
\hline Positivo & 43 & 71 & 50 & \\
\hline & \multicolumn{4}{|c|}{ VEGF-R3 } \\
\hline Negativo & 17 & 35 & 33 & \multirow{2}{*}{$<0,001^{*}$} \\
\hline Positivo & 83 & 65 & 67 & \\
\hline
\end{tabular}

(o símbolo - foi aplicado para indicar que não há valor para esta variável) 

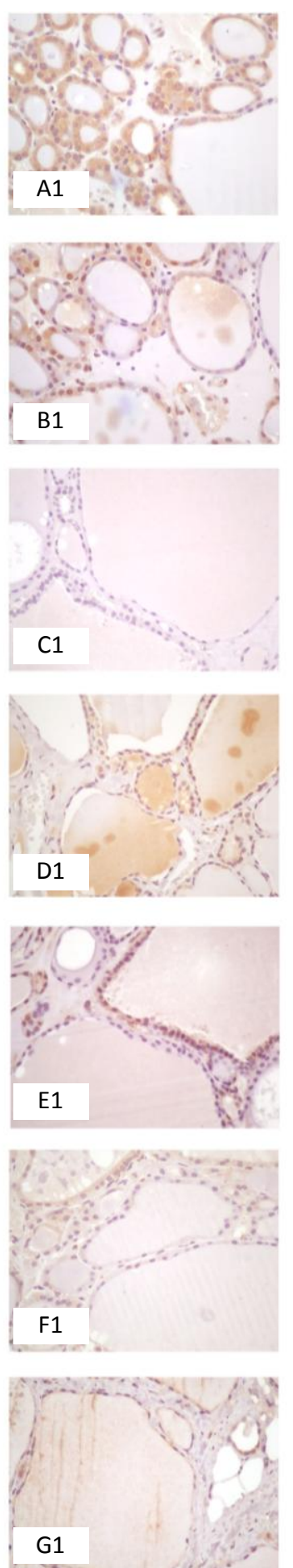
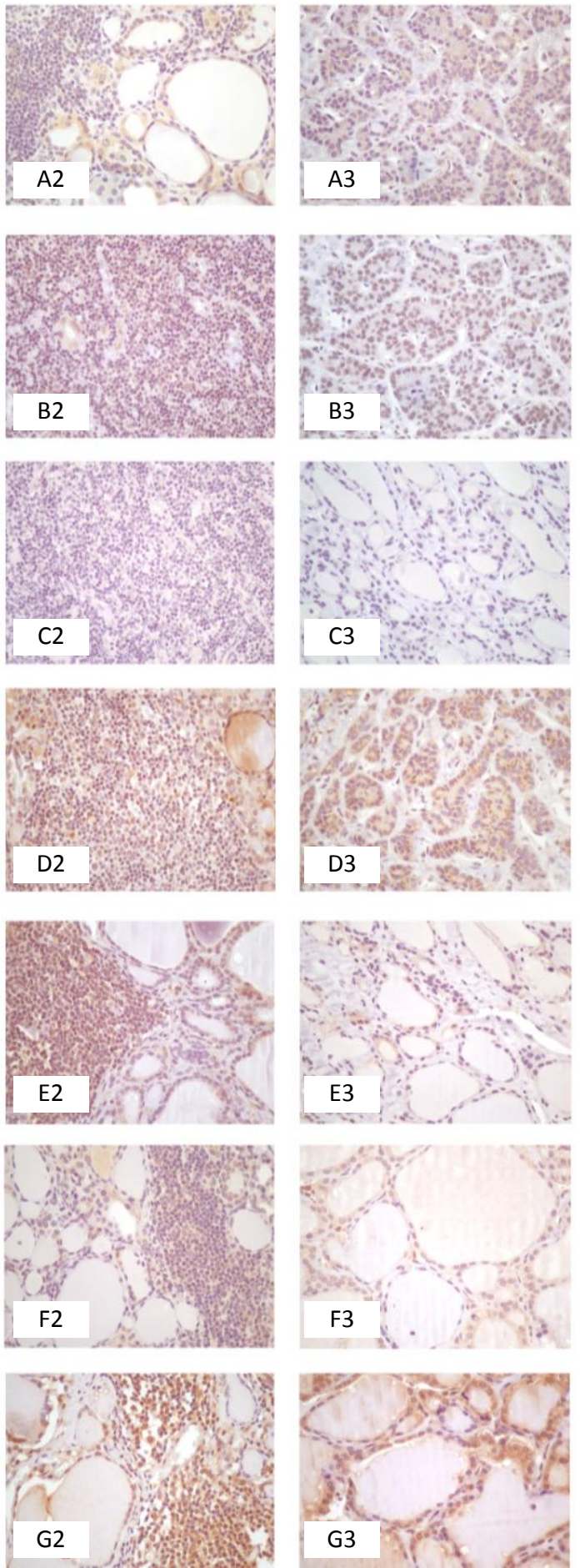

Figura 29. Fotomicrografias dos padrões de imunoexpressão do VEGF-A (A1, A2 e A3), VEGF-A ${ }_{165} b$ (B1, B2 e B3), VEGF-B (C1, C2 e C3), VEGF-C (D1, D2 e D3), VEGF-D (E1, E2 e E3), VEGF-R1 (F1, F2 e F3) e VEGF-R3 (G1, G2 e G3) nos bócios adenomatosos (coluna 1), tireoidites linfocitárias (coluna 2) e adenomas foliculares (coluna 3) (aumento 400X). 


\subsection{Densidades vasculares linfáticas e densidades vasculares} sanguíneas dos carcinomas papilíferos, carcinomas foliculares, bócios adenomatosos, tireoidites linfocitárias e adenomas foliculares estudados

Uma média da densidade vascular linfática (DVL) e da densidade vascular sanguínea (DVS) total, intratumoral e peritumoral dos carcinomas papiliferos, carcinomas foliculares e dos adenomas foliculares foi obtida. Nos bócios adenomatosos e tireoidites linfocitárias, devido as características inerentes a estes tipos de lesões benignas, apenas a DVL e DVS total foi calculada. Os diferentes tipos de lesões tireoidianas apresentaram diferentes padrões de densidade vascular e em todos os casos a DVS foi maior do que a DVL (Figura 30).

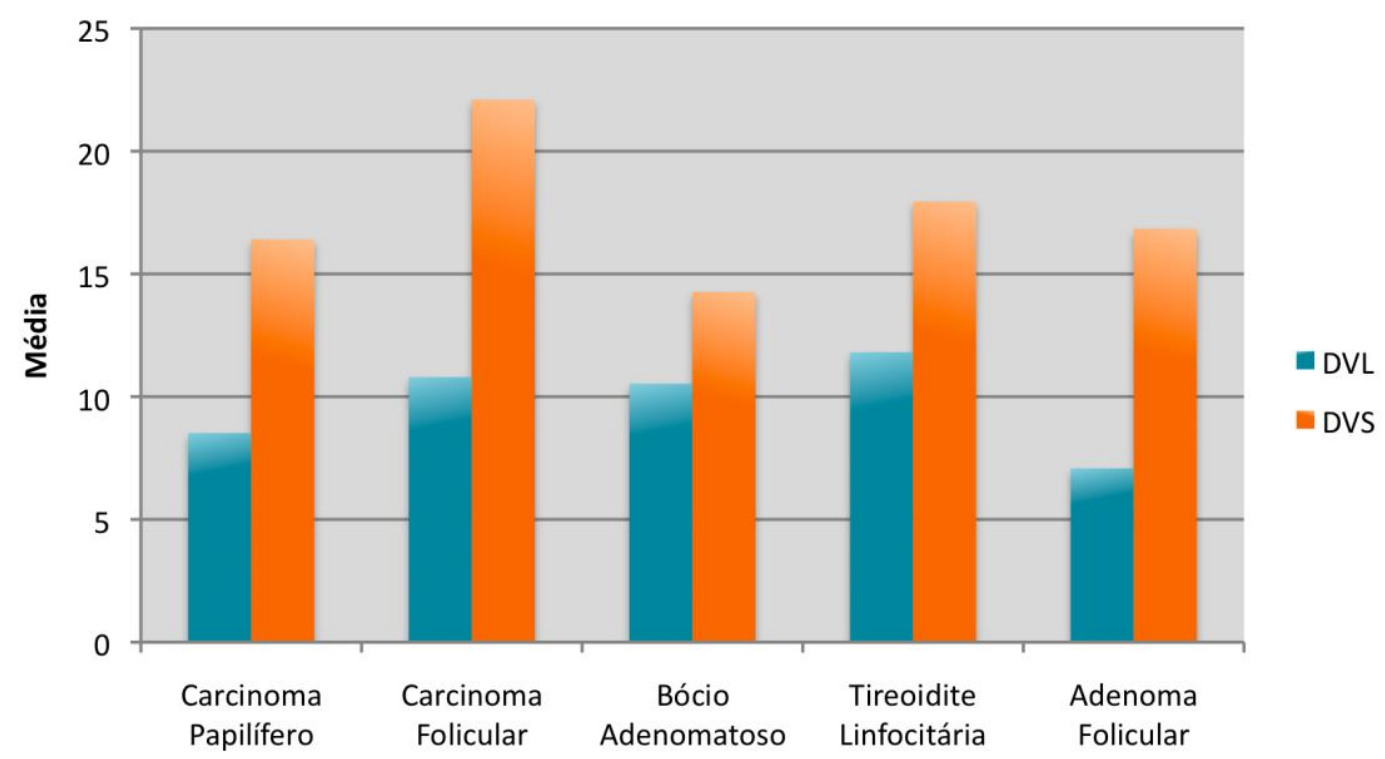

Figura 30. Média da DVL e DVS total nos diferentes tipos de lesões tireoidianas estudadas 
Um sumário das freqüências absolutas, médias e desvio padrão das DVL e DVS dos casos estudados pode ser observado na Tabela 31.

Tabela 31 - Freqüência absoluta, média e desvio padrão da DVL e DVS total, intratumoral e peritumoral dos carcinomas papilíferos, carcinomas foliculares e adenomas foliculares e da DVL e DVS total dos bócios adenomatosos e tireoidites linfocitárias.

\begin{tabular}{|r|c|c|c|c|c|c|c|c|c|c|c|c|c|c|c|c|c|c|c|c|}
\hline & \multicolumn{9}{c|}{ DVL } & \multicolumn{1}{c|}{ DVS } \\
\hline & n & Média & DP & n & Média & DP & n & Média & DP & n & Média & DP & n & Média DP & n & Média DP \\
\hline $\begin{array}{r}\text { Carcinoma } \\
\text { Papilífero }\end{array}$ & 40 & 8,52 & 2,5 & 40 & 7,10 & 3,0 & 40 & 9,07 & 3,6 & 40 & 16,41 & 4,7 & 40 & 16,27 & 5,9 & 40 & 16,63 & 5,0 \\
\hline $\begin{array}{r}\text { Carcinoma } \\
\text { Folicular }\end{array}$ & 5 & 10,80 & 4,7 & 5 & 9,42 & 6,5 & 5 & 11,06 & 3,3 & 5 & 22,10 & 5,6 & 5 & 26,44 & 8,7 & 5 & 15,38 & 5,0 \\
\hline $\begin{array}{r}\text { Bócio } \\
\text { Adenomatoso }\end{array}$ & 33 & 10,53 & 4,4 & - & - & - & - & - & - & 33 & 14,27 & 3,4 & - & - & - & - & - & - \\
\hline $\begin{array}{r}\text { Tireoidite } \\
\text { Linfocitária }\end{array}$ & 15 & 11,81 & 4,9 & - & - & - & - & - & - & 15 & 17,95 & 5,8 & - & - & - & - & - & - \\
\hline $\begin{array}{r}\text { Adenoma } \\
\text { Folicular }\end{array}$ & 7 & 7,08 & 2,5 & 6 & 5,28 & 2,1 & 6 & 8,08 & 3,5 & 7 & 16,84 & 3,7 & 6 & 17,07 & 4,0 & 6 & 17,84 & 4,0 \\
\hline
\end{tabular}

(o símbolo - foi aplicado para indicar que não há valor para esta variável)

A DVL peritumoral foi sempre maior que a intratumoral nos carcinomas papilíferos, carcinomas foliculares e nos adenomas foliculares. Nos carcinomas papilíferos e nos adenomas foliculares a DVS total, intra e peritumoral foi semelhante enquanto que nos carcinomas foliculares a DVS intratumoral foi quase o dobro da peritumoral (Tabela 31).

Quando correlacionados, os carcinomas papilíferos, carcinomas foliculares e adenomas foliculares apresentaram diferenças estatisticamente significantes na DVL total $(p=0,019)$, DVS total $(p=0,002)$ e DVS intratumoral $(p=0,018)$ (Tabela 32). 
Tabela 32 - Correlações entre a DVL total, intra e peritumoral e a DVS total intra e peritumoral dos carcinomas papilíferos, carcinomas foliculares e adenomas foliculares estudados

\begin{tabular}{|c|c|c|c|c|c|c|c|c|c|c|c|c|c|c|c|c|c|c|}
\hline & \multicolumn{9}{|c|}{ DVL } & \multicolumn{9}{|c|}{ DVS } \\
\hline & \multicolumn{3}{|c|}{ Total } & \multicolumn{3}{|c|}{ Intratumoral } & \multicolumn{3}{|c|}{ Peritumoral } & \multicolumn{3}{|c|}{ Total } & \multicolumn{3}{|c|}{ Intratumoral } & \multicolumn{3}{|c|}{ Peritumoral } \\
\hline & Média & $\mathrm{DP}$ & $p$ & Média & DP & $\mathrm{p}$ & Média & $\mathrm{DP}$ & $p$ & Média & DP & $p$ & Média & DP & $p$ & Média & DP & $\mathrm{p}$ \\
\hline $\begin{array}{r}\text { Carcinoma } \\
\text { Papilífero }\end{array}$ & 8,52 & 2,5 & \multirow{3}{*}{0,019 * } & 7,10 & 3,0 & \multirow{3}{*}{0,325} & 9,07 & 3,6 & \multirow{3}{*}{0,312} & 16,41 & 4,7 & \multirow{3}{*}{$0,002^{*}$} & 16,27 & 5,9 & \multirow{3}{*}{$0,018^{*}$} & 16,63 & 5,0 & \multirow{3}{*}{0,579} \\
\hline $\begin{array}{l}\text { Carcinoma } \\
\text { Folicular }\end{array}$ & 10,80 & 4,7 & & 9,42 & 6,5 & & 11,06 & 3,3 & & 22,10 & 5,6 & & 26,44 & 8,7 & & 15,38 & 5,0 & \\
\hline $\begin{array}{l}\text { Adenoma } \\
\text { Folicular }\end{array}$ & 7,08 & 2,5 & & 5,28 & 2,1 & & 8,08 & 3,5 & & 16,84 & 3,7 & & 17,07 & 4,0 & & 17,84 & 4,0 & \\
\hline
\end{tabular}

Ao agruparmos as lesões tireoidianas estudadas em malignas (carcinomas papilíferos e carcinomas foliculares) e benignas (bócios adenomatosos, tireoidites linfocitárias e adenomas foliculares) encontramos diferença estatisticamente significante apenas na DVL total (DVL total $p=0,033^{*}$, DVS total $\left.p=0,307\right)$.

\subsubsection{Correlações entre a DVL e DVS total, intra e peritumoral e}

\section{as variáveis clínico-patológicas dos carcinomas papilíferos estudados}

A DVL intratumoral, peritumoral e total e a DVS intratumoral, peritumoral e total foram correlacionadas com os dados clínico-patológicos dos carcinomas papilíferos.

$\mathrm{Na}$ comparação entre os dados clínico-patológicos e a DVL intratumoral, peritumoral e total não houveram correlações estatisticamente significantes. Ao compararmos a DVS intratumoral, peritumoral e total com os achados clínico-patológicos observamos correlações estatisticamente 
significantes entre a variável sexo e a DVS peritumoral $(p=0,020)$ e a invasão de vaso e a DVS intratumoral $(p=0,013)$, peritumoral $(p=0,008)$ e total $(p=0,004)($ Tabela 33).

Tabela 33 - Correlações das variáveis clínico-patológicas e da DVL intratumoral, peritumoral e total e da DVS intratumoral, peritumoral e total nos carcinomas papilíferos estudados

\begin{tabular}{|c|c|c|c|c|c|c|c|c|c|c|c|c|c|c|c|c|c|c|c|}
\hline & & \multicolumn{3}{|c|}{$\begin{array}{c}\mathrm{DVL} \\
\text { Intratumoral }\end{array}$} & \multicolumn{3}{|c|}{$\begin{array}{c}\text { DVL } \\
\text { Peritumoral }\end{array}$} & \multicolumn{3}{|c|}{ DVL Total } & \multicolumn{3}{|c|}{$\begin{array}{c}\text { DVS } \\
\text { Intratumoral }\end{array}$} & \multicolumn{3}{|c|}{ DVS Peritumoral } & \multicolumn{3}{|c|}{ DVS Total } \\
\hline & & Média & DP & $p$ & Média & DP & $p$ & Média & DP & $\mathrm{p}$ & Média & DP & $p$ & Média & DP & $\mathrm{p}$ & Média & DP & $\mathrm{p}$ \\
\hline \multicolumn{20}{|l|}{ Sexo } \\
\hline & $M$ & 6,63 & 2,3 & 0,892 & $\begin{array}{l}8,65 \\
918\end{array}$ & 4,5 & 0,933 & \begin{tabular}{|l|}
8,17 \\
861
\end{tabular} & $\begin{array}{l}1,6 \\
27\end{array}$ & 0,813 & 13,82 & 4,9 & 0,182 & 13,45 & 2,7 & $0,020^{*}$ & 13,60 & 2,8 & 0,063 \\
\hline & $\mathrm{F}$ & 7,22 & 3,2 & & 9,18 & 3,4 & & 8,61 & 2,7 & 0,010 & 16,88 & 6,0 & & 17,43 & 5,2 & & & & \\
\hline \multicolumn{20}{|l|}{ Idade } \\
\hline & $\begin{array}{r}<4 \text { anos } \\
>04\end{array}$ & 7,27 & 3,1 & 0,610 & 8,57 & 3,4 & 0,488 & 8,30 & 2,3 & 0,955 & 15,83 & 5,6 & 0,380 & 17,44 & 5,5 & 0,257 & 16,59 & 4,9 & 0,932 \\
\hline & $>\mathrm{ou}=45$ anos & 6,77 & 3,1 & & 9,46 & 3,9 & & 8,65 & 2,9 & & 17,40 & 6,0 & & & 4,4 & 0,201 & 16,46 & 4,5 & \\
\hline \multicolumn{20}{|c|}{$\begin{array}{r}\text { Invasão de } \\
\text { Cápsula }\end{array}$} \\
\hline & Presente & 6,09 & 2,7 & & 11,13 & 2,6 & 0,084 & 8,88 & 2,2 & 0,656 & 18,86 & 7,2 & 0,336 & 15,97 & 3,2 & 0,545 & 17,48 & 4,8 & 0,557 \\
\hline & Não Detectada & 7,32 & 3,1 & 0,354 & 8,63 & 3,7 & 0,084 & 8,45 & 2,6 & 0,050 & 15,72 & 5,5 & 0,030 & 16,77 & 5,3 & 0,040 & 16,18 & 4,7 & 0,551 \\
\hline \multicolumn{20}{|c|}{ Invasão de Vaso } \\
\hline & Presente & 7,15 & 3,6 & 0876 & 8,29 & 2,4 & 0317 & 8,07 & 1,3 & 0779 & 13,59 & 7,3 & $0013^{*} x-2 x$ & 13,22 & 3,5 & 0008 * & 13,39 & 4,8 & $0004^{*}$ \\
\hline & Não Detectada & 7,09 & 2,9 & $0,8 / 6$ & 9,33 & 3,9 & 0,311 & 8,68 & 2,8 & 0,179 & 17,16 & 5,2 & 0,013 & 17,77 & 5,0 & $0,008^{\circ}$ & 17,41 & 4,2 & 0,004 \\
\hline \multicolumn{20}{|c|}{$\begin{array}{r}\text { Comprometimento } \\
\text { de Adjacencia }\end{array}$} \\
\hline & Presente & 5,95 & 2,8 & & 8,59 & 4,1 & & 8,17 & 1,5 & & 20,43 & 6,6 & & 18,17 & 2,7 & & 19,21 & 4,1 & \\
\hline & Não Detectada & 7,35 & 3,1 & 0,270 & 9,17 & 3,6 & 0,845 & 8,60 & 2,7 & 0,972 & 15,38 & 5,4 & 0,057 & 16,31 & 5,3 & 0,345 & 15,81 & 4,6 & 0,072 \\
\hline \multicolumn{20}{|c|}{ Metástase } \\
\hline & Presente & 6,89 & 3,4 & & 9,11 & 4,5 & 0,090 & 8,94 & 2,0 & & 17,52 & 7,6 & 0887 & 15,53 & 4,1 & & 16,43 & 5,3 & \\
\hline & Ausente & 7,15 & 3,0 & $0,8 / 3$ & 9,06 & 3,5 & 0,499 & 8,44 & 2,7 & 0,423 & 16,00 & 5,5 & 0,881 & 16,87 & 5,2 & $0,4 / 6$ & 16,40 & 4,6 & 0,929 \\
\hline \multicolumn{20}{|c|}{ 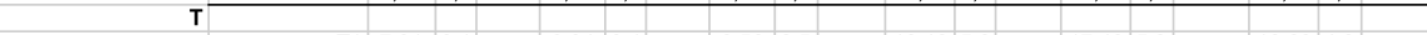 } \\
\hline & T1 & 7,31 & 3,1 & \multirow{4}{*}{0,717} & 9,04 & 3,4 & \multirow{4}{*}{0,531} & 8,56 & 2,5 & \multirow{4}{*}{0,775} & 16,12 & 5,6 & \multirow{4}{*}{0,588} & 17,40 & 5,2 & \multirow{4}{*}{0,280} & 16,68 & 4,6 & \multirow{4}{*}{0,467} \\
\hline & T2 & 5,00 & - & & 6,60 & - & & 6,00 & - & & 10,90 & - & & 9,30 & - & & 10,10 & - & \\
\hline & T3 & 6,28 & 3,1 & & 9,33 & 1,6 & & 8,08 & 1,4 & & 19,07 & 8,3 & & 15,45 & 4,2 & & 17,29 & 6,0 & \\
\hline & $\mathrm{T} 4$ & 4,60 & - & & 12,30 & - & & 8,45 & - & & 13,33 & - & & 14,71 & - & & 14,08 & - & \\
\hline \multirow[t]{5}{*}{$\mathbf{N}$} & & & & & & & & & & & & & & & & & & & \\
\hline & No & 7,28 & 3,0 & \multirow{4}{*}{0,132} & 9,27 & 2,9 & \multirow{4}{*}{0,348} & 8,50 & 2,3 & & 16,06 & 5,8 & & 17,19 & 5,4 & & 16,57 & 4,8 & \\
\hline & N1 & 3,90 & - & & 6,30 & - & & 5,10 & - & 0,187 & 14,30 & - & 0.873 & 12,90 & - & 0.426 & 13,60 & - & 0.670 \\
\hline & N1A & 11,60 & - & & 13,60 & - & & 12,60 & - & & 20,40 & - & 0,013 & 20,00 & - & 0,426 & 20,27 & - & 0,010 \\
\hline & N1B & 5,72 & 2,8 & & 8,21 & 4,1 & & 7,90 & 1,7 & & 17,40 & 7,6 & & 15,33 & 3,9 & & 16,27 & 5,2 & \\
\hline $\begin{array}{r}\text { Estadiamento } \\
\text { (TNM) }\end{array}$ & & & & & & & & & & & & & & & & & & & \\
\hline & I & 7,19 & 3,1 & & 8,93 & 3,2 & & 8,39 & 2,4 & & 15,80 & 5,4 & & 16,73 & 5,3 & & 16,20 & 4,6 & \\
\hline & III & 7,10 & - & 0,225 & 10,10 & - & 0,319 & 8,60 & - & 0,921 & 22,40 & - & 0,294 & 19,90 & - & 0,784 & 21,15 & - & 0,409 \\
\hline & IVA & 3,93 & 0,9 & & 11,70 & 0,8 & & 8,65 & 0,2 & & 23,42 & 14,2 & & 16,71 & 2,8 & & 20,09 & 8,5 & \\
\hline
\end{tabular}

(o símbolo - foi aplicado para indicar que não há valor para esta variável) 


\subsubsection{Correlações entre a DVL e DVS total, intra e peritumoral e}

\section{as variáveis clínico-patológicas dos carcinomas foliculares estudados}

A DVL intratumoral, peritumoral e total e a DVS intratumoral, peritumoral e total foram correlacionadas com os dados clínico-patológicos dos carcinomas foliculares. No entanto, o estudo das densidades vasculares foi possível em apenas 5 casos de carcinomas foliculares da presente série o que certamente limitou esta análise estatística.

Não houveram correlações estatisticamente significantes na comparação entre os dados clínico-patológicos e a DVL intratumoral, peritumoral e total e a DVS intratumoral, peritumoral e total (Tabela 34).

Tabela 34 - Correlações das variáveis clínico-patológicas e da DVL intratumoral, peritumoral e total e da DVS intratumoral, peritumoral e total nos carcinomas foliculares estudados

\begin{tabular}{|c|c|c|c|c|c|c|c|c|c|c|c|c|c|c|c|c|c|c|c|}
\hline & & \multicolumn{3}{|c|}{$\begin{array}{c}\mathrm{DVL} \\
\text { Intratumoral }\end{array}$} & \multicolumn{3}{|c|}{$\begin{array}{c}\text { DVL } \\
\text { Peritumoral }\end{array}$} & \multicolumn{3}{|c|}{ DVL Total } & \multicolumn{3}{|c|}{$\begin{array}{c}\text { DVS } \\
\text { Intratumoral }\end{array}$} & \multicolumn{3}{|c|}{$\begin{array}{c}\text { DVS } \\
\text { Peritumoral }\end{array}$} & \multicolumn{3}{|c|}{ DVS Total } \\
\hline & & Média & DP & $p$ & Média & DP & $p$ & Média & DP & $\mathrm{p}$ & Média & DP & $\mathrm{p}$ & Média & DP & $p$ & Média & DP & $\mathrm{p}$ \\
\hline \multicolumn{20}{|l|}{ Sexo } \\
\hline & $\frac{M}{F}$ & $\frac{-}{942}$ & $\frac{-}{65}$ & - & 1106 & 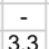 & - & $\frac{-}{1080}$ & $\overline{4}$ & - & $\frac{-}{26.44}$ & $8 \overline{8}$ & - & $\frac{-}{1538}$ & 5 & - & $\frac{-}{2270}$ & - & - \\
\hline \multicolumn{20}{|l|}{ Idade } \\
\hline & $\begin{array}{r}<45 \text { anos } \\
>04=45 \text { anos }\end{array}$ & $\begin{array}{l}9,58 \\
880\end{array}$ & 7,5 & 1,00 & $\begin{array}{l}10,55 \\
13,10\end{array}$ & 3,6 & 1,00 & $\begin{array}{l}10,76 \\
10,95\end{array}$ & 5,4 & 1,00 & \begin{tabular}{|l|}
22,70 \\
41,40
\end{tabular} & 2,8 & 0,157 & 13,55 & 3,4 & 0,157 & 20,36 & 2,6 & 0,157 \\
\hline \multicolumn{20}{|c|}{ Invasão de Vaso } \\
\hline & Presente & 8,90 & 0,1 & \multirow{2}{*}{0,564} & 13,35 & 0,3 & \multirow{2}{*}{0,248} & 11,13 & 0,2 & \multirow{2}{*}{0,564} & 30,05 & 16 & \multirow{2}{*}{1,00} & 20,70 & 2,8 & \multirow{2}{*}{0,083} & 25,38 & 9,4 & \multirow{2}{*}{0,564} \\
\hline & Não Detectada & 9,77 & 9,2 & & 9,53 & 3,7 & & 10,59 & 6,6 & & 24,03 & 1,3 & & 11,83 & 0,7 & & 20,91 & 2,8 & \\
\hline \multicolumn{20}{|c|}{$\begin{array}{r}\text { Comprometimento } \\
\text { de Adjacencia }\end{array}$} \\
\hline & Presente & - & - & & - & - & & - & - & & - & - & \multirow{2}{*}{ - } & - & - & \multirow[b]{2}{*}{ - } & - & - & \multirow{2}{*}{-} \\
\hline & Não Detectada & 9,42 & 6,5 & & 11,06 & 3,3 & & 10,80 & 4,7 & & 26,44 & 8,7 & & 15,38 & 5,0 & & 22,70 & 5,6 & \\
\hline Metástase & & & & & & & & & & & & & & & & & & & \\
\hline & Presente & - & - & -1 & - & - & - & - & - & 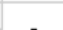 & - & - & -1 & - & - & -1 & - & - & 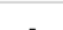 \\
\hline & Ausente & 9,42 & 6,5 & - & 11,06 & 3,3 & - & 10,80 & 4,7 & - & 26,44 & 8,7 & - & 15,38 & 5,0 & - & 22,70 & 5,6 & - \\
\hline $\mathbf{T}$ & & & & & & & & & & & & & & & & & & & \\
\hline & T1 & 12,60 & 6,4 & 0.083 & 13,32 & 0,2 & 0.083 & 13,44 & 4,0 & 0.083 & 28,47 & 11,6 & 0.564 & 17,80 & 5,4 & 0564 & 24,33 & 6,9 & 0.564 \\
\hline & $\mathrm{T} 2$ & 4,65 & 3,7 & & 7,67 & 2,5 & & 6,84 & 2,2 & & 23,40 & 0,9 & & 11,75 & 1,0 & & 20,25 & 3,7 & \\
\hline $\mathbf{N}$ & & & & & & & & & & & & & & & & & & & \\
\hline & No & 9,42 & 6,5 & - & 11,06 & 3,3 & - & 10,80 & 4,7 & - & 26,44 & 8,7 & - & 15,38 & 5,0 & - & 22,70 & 5,6 & - \\
\hline $\begin{array}{r}\text { Estadiamento } \\
\text { (TNM) }\end{array}$ & & & & & & & & & & & & & & & & & & & \\
\hline & I & 9,42 & 6,5 & - & 11,06 & 3,3 & - & 10,80 & 4,7 & - & 26,44 & 8,7 & - & 15,38 & 5,0 & - & 22,70 & 5,6 & - \\
\hline
\end{tabular}

(o símbolo - foi aplicado para indicar que não há valor para esta variável) 


\subsubsection{Correlações entre a DVL e DVS total, intra e peritumoral e as expressões dos fatores de crescimento endotelial vascular e seus receptores nos carcinomas papilíferos}

As densidades vasculares linfáticas e sanguíneas foram correlacionadas com as expressões dos VEGFs e VEGFRs nos carcinomas papilíferos estudados.

Não observamos diferenças estatisticamente significantes; no entanto, podemos notar as seguintes variáveis: nos casos com alta imunoexpressão do VEGF-A (+++ e ++++), a DVL e a DVS intra, peritumoral e total foi maior que nos casos negativos (0). Em relação a imunoexpressão do VEGF-A ${ }_{165}$ b, a DVL intra, peritumoral e total apresentou pouca variação independentemente do grau de imunoexpressão observado; porém, quanto maior a imunoexpressão, menor foi a DVS intra, peritumoral e total. Nos casos com imunoexpressão positiva $(+,++$ ou +++$)$ ou negativos $(0)$ para o VEGF-B, a DVL e a DVS intra, peritumoral e total observou-se apenas discretas variações. Todos os carcinomas papilíferos apresentaram imunoexpressão positiva para o VEGF-C $(+,++,+++$ ou ++++$)$ sendo que a DVL peritumoral foi discretamente maior nos casos com maior imunoexpressão $(++++)$; Todos os carcinomas papilíferos mostraram imunoexpressão positiva para o VEGF-D $(++,+++$ ou ++++$)$ sendo que nos casos com maior imunoexpressão houve um discreto aumento da DVL e da DVS intra, peritumoral e total. Nos casos com alta imunoexpressão do VEGF-R1 (++++) a DVL e a DVS intra, peritumoral e total foi discretamente 
maior que nos casos negativos (0). Todos os casos apresentaram imunoexpressão positiva $(+,+++$ e +++$)$ do VEGF-R3 (Tabela 35).

Tabela 35 - Correlação da DVL intratumoral, peritumoral e total e da DVS intratumoral, peritumoral e total com a imunoexpressão dos VEGFs e VEGFRs nos carcinomas papilíferos estudados

\begin{tabular}{|c|c|c|c|c|c|c|c|c|c|c|c|c|c|c|c|c|c|}
\hline & \multicolumn{3}{|c|}{$\begin{array}{l}\text { DVL Média } \\
\text { Intratumoral }\end{array}$} & \multicolumn{3}{|c|}{$\begin{array}{l}\text { DVL Média } \\
\text { Peritumoral }\end{array}$} & \multicolumn{3}{|c|}{$\begin{array}{l}\text { DVL Média } \\
\text { Total }\end{array}$} & \multicolumn{3}{|c|}{$\begin{array}{l}\text { DVS Média } \\
\text { Intratumoral }\end{array}$} & \multicolumn{3}{|c|}{$\begin{array}{l}\text { DVS Média } \\
\text { Peritumoral }\end{array}$} & \multicolumn{2}{|c|}{$\begin{array}{l}\text { DVS Média } \\
\text { Total }\end{array}$} \\
\hline & Média & DP & $\mathrm{p}$ & Média & DP & $\mathrm{p}$ & Média & DP & $\mathrm{p}$ & Média & DP & $\mathrm{p}$ & Média & DP & $\mathrm{p}$ & Média DP & $p$ \\
\hline \multicolumn{18}{|c|}{ VEGF-A } \\
\hline 0 & 5 & 0 & \multirow{3}{*}{0,788} & 6,03 & 0,4 & & 5,79 & 0,3 & \multirow{3}{*}{0,259} & 13,12 & 3,1 & \multirow{3}{*}{0,694} & 13,48 & 5,9 & \multirow{3}{*}{0,309} & $13,304,5$ & \\
\hline +++ & 7,05 & 0 & & 9,75 & 0,4 & 0,265 & 8,55 & 0,7 & & 16,30 & 8,6 & & 20,10 & 0,2 & & $18,204,1$ & 0,526 \\
\hline++++ & 7,13 & 3,2 & & 9,24 & 3,3 & & 8,56 & 2,4 & & 16,57 & 6,1 & & 16,81 & 5,2 & & $16,634,8$ & \\
\hline \multicolumn{18}{|c|}{ VEGF-A165b } \\
\hline 0 & 7,01 & 2,8 & \multirow{5}{*}{0,916} & 10,70 & 2,9 & & 9,07 & 2,3 & \multirow{5}{*}{0,579} & 17,52 & 5,1 & \multirow{5}{*}{0,534} & 19,13 & 5,5 & \multirow{5}{*}{0,722} & $18,284,9$ & \multirow{5}{*}{0,669} \\
\hline+ & 5 & - & & 6 & - & & 5,57 & - & & 15,33 & - & & 17,67 & - & & $16,50-$ & \\
\hline++ & 6,39 & 3,7 & & 6,38 & 4,6 & 0,212 & 8,03 & 2,2 & & 21,46 & 8,7 & & 16,04 & 3,8 & & $18,275,4$ & \\
\hline+++ & 6,47 & 2,7 & & 9,88 & 2,4 & & 8,61 & 2,0 & & 14,54 & 7,9 & & 15,97 & 5,8 & & $15,285,9$ & \\
\hline++++ & 7,28 & 3,4 & & 8,75 & 3,0 & & 8,11 & 2,6 & & 15,61 & 4,7 & & 16,29 & 4,8 & & $15,954,0$ & \\
\hline \multicolumn{18}{|c|}{ VEGF-B } \\
\hline 0 & 6,43 & 2,5 & \multirow{4}{*}{0,455} & 8,90 & 3,2 & & 8,06 & 2,2 & \multirow{4}{*}{0,221} & 17,36 & 5,0 & \multirow{4}{*}{0,199} & 17,20 & 4,9 & \multirow{4}{*}{0,887} & $17,234,4$ & \multirow{4}{*}{0,375} \\
\hline+ & 8,20 & 4,0 & & 9,84 & 3,6 & ר?5 ר & 9,32 & 2,6 & & 14,37 & 7,8 & & 16,73 & 5,0 & & $15,455,3$ & \\
\hline++ & 8,57 & 3,1 & & 9,47 & 0,9 &, $5<2$ & 9,24 & 1,7 & & 13,68 & 7,2 & & 13,31 & 8,0 & & $13,516,4$ & \\
\hline+++ & 4,80 & - & & 5,70 & - & & 5,25 & - & & 21,00 & - & & 18,70 & - & & $19,85-$ & \\
\hline & & & & & & & & & EGF-C & & & & & & & & \\
\hline+ & 7,74 & 2,6 & & 7,89 & 4,9 & & 8,56 & 2,8 & & 17,18 & 6,0 & & 19,20 & 6,1 & & $18,055,6$ & \\
\hline++ & 5,13 & 3,1 & 0312 & 8,55 & 1,1 & & 7,34 & 1,7 & 0815 & 14,16 & 2,3 & 0825 & 14,39 & 2,8 & & $14,282,5$ & \\
\hline+++ & 7,34 & 3,2 & 0,312 & 9,38 & 2,7 & $1<0$ & 8,54 & 2,1 & 0,815 & 17,42 & 7,9 & $0,8<0$ & 17,24 & 4,8 & & $17,285,3$ & \\
\hline++++ & 6,92 & 3,3 & & 9,61 & 3,0 & & 8,53 & 2,5 & & 15,76 & 5,2 & & 15,99 & 5,2 & & $15,834,3$ & \\
\hline & & & & & & & & & EGF-[ & & & & & & & & \\
\hline++ & 6 & 1,4 & & 8 & 1,9 & & 7,25 & 1,7 & & 10,55 & 0,4 & & 14,80 & 7,7 & & $12,683,6$ & \\
\hline+++ & 7,55 & 0,6 & 0,748 & 10,30 & 0,2 & 0,639 & 9,26 & 0,9 & 0,610 & 17,70 & 6,6 & 0,273 & 12,25 & 10,8 & 0,703 & $14,988,7$ & 0,486 \\
\hline++++ & 7,05 & 3,2 & & 9,10 & 3,3 & & 8,43 & 2,4 & & 16,64 & 6,1 & & 17,20 & 4,7 & & $16,854,6$ & \\
\hline & & & & & & & & & EGF-R & & & & & & & & \\
\hline 0 & 6,03 & 1,1 & & 8,03 & 2,0 & & 7,17 & 1,6 & & 14,71 & 5,6 & & 16,79 & 5,1 & & $15,754,5$ & \\
\hline++ & 7,15 & 3,2 & 090 & 7,18 & 2,1 & 0630 & 7,71 & 1,8 & 0620 & 19,73 & 7,9 & 0521 & 20,83 & 8,4 & 0229 & $20,287,9$ & \\
\hline+++ & 5,89 & 1,5 & & 9,53 & 2,7 & & 7,96 & 1,8 & & 13,83 & 5,5 & $0,5<1$ & 13,67 & 5,1 & & $13,593,1$ & \\
\hline++++ & 7,44 & 3,5 & & 9,41 & 3,6 & & 8,85 & 2,6 & & 16,74 & 5,9 & & 16,93 & 4,2 & & $16,784,3$ & \\
\hline & & & & & & & & & EGF- & & & & & & & & \\
\hline+ & 7,05 & 0 & & 9,75 & 0,4 & & 8,55 & 0 & & 16,30 & 8,6 & & 20,10 & 0,2 & & $18,204,1$ & \\
\hline+++ & 6,10 & - & 0,924 & 8,80 & - & 0,853 & 7,45 & - & 0,892 & 9,10 & - & 0,367 & 19,60 & - & 0,408 & $14,35-$ & 0,690 \\
\hline++++ & 7,04 & 3,2 & & 9,08 & 3,3 & & 8,43 & 2,4 & & 16,59 & 6,0 & & 16,54 & 5,2 & & $16,504,9$ & \\
\hline
\end{tabular}

(o símbolo - foi aplicado para indicar que não há valor para esta variável)

Ao dicotomizarmos a expressão dos VEGFs e VEGFRs em duas categorias, negativos (até $10 \%$ de imunomarcação positiva) e positivos (imunomarcação positiva maior do que 10\%) também não observamos correlações estatisticamente significantes entre a expressão dos VEGFs e VEGFRs e a densidade vascular linfática e sanguínea intra, peritumoral e 
total. A imunoexpressão do VEGF-D foi positiva em todos os casos estudados (Tabela 36).

Tabela 36 - Sumário das significâncias das correlações entre a imunoexpressão negativa (até 10\%) ou positiva (> do que 10\%) dos VEGFs e VEGFRs e das densidades vasculares linfáticas e sanguíneas dos carcinomas papilíferos estudados

\begin{tabular}{|r|c|c|c|c|c|c|}
\hline & \multicolumn{3}{|c|}{ DVL } & \multicolumn{3}{c|}{ DVS } \\
\hline & Intratumoral & Peritumoral & Total & Intratumoral & Peritumoral & Total \\
\hline & $\mathrm{p}$ & $\mathrm{p}$ & $\mathrm{p}$ & $\mathrm{p}$ & $\mathrm{p}$ & $\mathrm{p}$ \\
\hline VEGF-A & 0,556 & 0,117 & 0,102 & 0,395 & 0,295 & 0,360 \\
\hline VEGF-A165b & 0,702 & 0,207 & 0,618 & 0,485 & 0,173 & 0,219 \\
\hline VEGF-B & 0,409 & 0,617 & 0,962 & 0,887 & 0,686 & 0,536 \\
\hline VEGF-C & 0,275 & 0,337 & 0,955 & 0,611 & 0,275 & 0,397 \\
\hline VEGF-D & - & - & - & - & - & - \\
\hline VEGF-R1 & 0,886 & 0,446 & 0,318 & 0,601 & 0,924 & 0,887 \\
\hline VEGF-R3 & 0,695 & 0,601 & 0,794 & 0,896 & 0,239 & 0,472 \\
\hline
\end{tabular}

(o símbolo - foi aplicado para indicar que não há valor para esta variável)

5.9.4 Correlações entre a DVL e DVS total, intra e peritumoral e as expressões dos fatores de crescimento endotelial vascular e seus receptores nos carcinomas foliculares

As densidades vasculares linfáticas e sanguíneas foram correlacionadas com as expressões dos VEGFs e VEGFRs nos carcinomas foliculares estudados.

Não houveram diferenças estatisticamente significativas, no entanto, podemos notar as seguintes variáveis: nos casos com alta imunoexpressão do VEGF-A (++++), a DVL e a DVS intra, peritumoral e total foi maior que nos casos com menor imunoexpressão do VEGF-A (++). Nos casos com alta 
imunoexpressão do VEGF-A $165 \mathrm{~b}(++++)$, a DVL intra, peritumoral e total foi maior do que nos casos que não apresentaram imunoexpressão; porém, em relação a DVS intra, peritumoral e total foi observado o oposto, uma menor DVS nos casos com alta imunoexpressão de VEGF-A $\mathrm{A}_{165} \mathrm{~b}$; Nos casos com imunoexpressão do VEGF-B (++) a DVL intratumoral e total apresentaram valores semelhantes, e a DVL peritumoral foi discretamente maior do que a observada nos casos negativos. Em relação a DVS intratumoral e total, os casos com imunoexpressão do VEGF-B (++) apresentaram DVS menor do que o casos negativos e a DVS peritumoral foi maior nos casos que apresentara imunoexpressão do VEGF-B (++). Todos os carcinomas foliculares apresentaram alta imunoexpressão do VEGF-C (++++). Nos casos com alta imunoexpressão do VEGF-D (++++), a DVL e a DVS intra, peritumoral e total foi maior que nos casos negativos. Nos casos com alta imunoexpressão do VEGF-R1 (++++) a DVL e a DVS intra, peritumoral e total foi maior que nos com menor imunoexpressão $(++)$ ou negativos para o VEGF-R1. Em relação a DVS intra, peritumoral e total os casos com imunoexpressão de 10 a $25 \%$ das células (++) foram os que apresentaram maior DVS. Nos casos com alta imunoexpressão do VEGF-R3 (++++), a DVL e a DVS intra, peritumoral e total foi maior que nos casos com baixa imunoexpressão (+) (Tabela 37). 
Tabela 37 - Correlação da DVL intratumoral, peritumoral e total e da DVS intratumoral, peritumoral e total com a imunoexpressão dos VEGFs e VEGFRs nos carcinomas foliculares estudados

\begin{tabular}{|c|c|c|c|c|c|c|c|c|c|c|c|c|c|c|c|c|c|c|}
\hline & \multicolumn{3}{|c|}{$\begin{array}{l}\text { DVL Média } \\
\text { Intratumoral }\end{array}$} & \multicolumn{3}{|c|}{$\begin{array}{l}\text { DVL Média } \\
\text { Peritumoral }\end{array}$} & \multicolumn{3}{|c|}{ DVL Média Total } & \multicolumn{3}{|c|}{$\begin{array}{l}\text { DVS Média } \\
\text { Intratumoral }\end{array}$} & \multicolumn{3}{|c|}{$\begin{array}{l}\text { DVS Média } \\
\text { Peritumoral }\end{array}$} & \multicolumn{3}{|c|}{ DVS Média Total } \\
\hline & Média & DP & $p$ & Média & $\mathrm{DP}$ & $p$ & Média & DP & $p$ & Média & DP & $p$ & Média & DP & $p$ & Média & DP & p \\
\hline \multicolumn{19}{|c|}{ VEGF-A } \\
\hline $\begin{array}{c}++ \\
++++\end{array}$ & $\begin{array}{c}2 \\
12,60\end{array}$ & $\frac{-}{6,4}$ & 0,180 & $\begin{array}{l}5,83 \\
13,32\end{array}$ & $\frac{-}{0,2}$ & 0,180 & $\begin{array}{c}5,29 \\
13,44\end{array}$ & $\frac{-}{4,0}$ & 0,180 & \begin{tabular}{|l|}
24,10 \\
28,47
\end{tabular} & $\frac{-}{11,6}$ & 0,655 & $\begin{array}{c}11 \\
17,80\end{array}$ & $\frac{-}{5,4}$ & 0,180 & $\begin{array}{l}22,91 \\
24,33\end{array}$ & $\frac{-}{6,9}$ & 0,655 \\
\hline \multicolumn{19}{|c|}{ VEGF-A165b } \\
\hline 0 & 5,40 & 4,8 & \multirow{2}{*}{0,121} & 9,47 & 5,1 & 0121 & 8,12 & 4,0 & \multirow{2}{*}{0,121} & 32,75 & 12,2 & \multirow{2}{*}{0,439} & 16,85 & 8,2 & \multirow{2}{*}{1,00} & 27,48 & 6,4 & \multirow{2}{*}{0,121} \\
\hline++++ & 14,50 & 7,7 & & 13,43 & 0,2 & $0,1<1$ & 14,69 & 4,7 & & 22 & 4,6 & & 15,35 & 4,7 & & 20,47 & 2,4 & \\
\hline \multicolumn{19}{|c|}{ VEGF-B } \\
\hline 0 & 10,27 & 9,0 & \multirow{2}{*}{0,655} & 10,73 & 4,2 & \multirow{2}{*}{0,180} & 11,44 & 6,4 & \multirow{2}{*}{0,655} & 30,27 & 9,6 & \multirow{2}{*}{0,180} & 15,23 & 6,4 & \multirow{2}{*}{0,655} & 25,73 & 5,4 & \multirow{2}{*}{0,180} \\
\hline++ & 9 & - & & 13,60 & - & & 11,30 & - & & 18,70 & - & & 18,70 & - & & 18,70 & - & \\
\hline \multicolumn{19}{|c|}{ VEGF-C } \\
\hline++++ & 9,95 & 7,4 & - & 11,45 & 3,7 & - & 11,40 & 5,2 & - & 27,38 & 9,7 & - & 16,10 & 5,5 & - & 23,97 & 5,6 & - \\
\hline \multicolumn{19}{|c|}{ VEGF-D } \\
\hline 0 & 2 & - & \multirow{2}{*}{0,180} & 5,83 & - & \multirow{2}{*}{0,180} & 5,29 & - & 180 & 24,10 & - & 0655 & 11 & - & O 180 & 22,91 & - & 0655 \\
\hline++++ & 12,60 & 6,4 & & 13,32 & 0,2 & & 13,44 & 4,0 & 100 & 28,47 & 11,6 & 0,050 & 17,80 & 5,4 & 0,100 & 24,33 & 6,9 & U,050 \\
\hline & & & & & & & & & EGF-R & & & & & & & & & \\
\hline 0 & 2 & - & & 5,83 & - & & 5,29 & - & & 24,10 & - & & 11 & - & & 22,91 & - & \\
\hline++ & 8,80 & - & 0,259 & 13,10 & - & 0,259 & 10,95 & - & 0,259 & 41,40 & - & 0,407 & 22,10 & - & 0,259 & 32,05 & - & 0,259 \\
\hline++++ & 14,50 & 7,7 & & 13,43 & 0,2 & & 14,69 & 4,7 & & 22 & 4,6 & & 15,35 & 4,7 & & 20,47 & 2,4 & \\
\hline & & & & & & & & & $\mathbf{r}$ & & & & & & & & & \\
\hline+ & 2 & - & 0180 & 5,83 & - & 0180 & 5,29 & - & 0.180 & 24,10 & - & 0655 & 11 & - & 0180 & 22,91 & - & 0.655 \\
\hline++++ & 12,60 & 6,4 & & 13,32 & 0,2 & & 13,44 & 4,0 & 0,100 & 28,47 & 11,6 & & 17,80 & 5,4 & & 24,33 & 6,9 & \\
\hline
\end{tabular}

(o símbolo - foi aplicado para indicar que não há valor para esta variável)

Ao dicotomizarmos a expressão dos VEGFs e VEGFRs em duas categorias, negativos (até $10 \%$ de imunomarcação positiva) e positivos (imunomarcação positiva maior do que 10\%) também não observamos correlações estatisticamente significantes entre a expressão dos VEGFs e VEGFRs e a densidade vascular linfática e sanguínea intra, peritumoral e total. A imunoexpressão do VEGF-A e do VEGF-C foi positiva em todos os casos estudados (Tabela 38). 
Tabela 38 - Sumário das significâncias das correlações entre a imunoexpressão negativa (até 10\%) ou positiva (> do que 10\%) dos VEGFs e VEGFRs e das densidades vasculares linfáticas e sanguíneas dos carcinomas foliculares estudados

\begin{tabular}{|r|c|c|c|c|c|c|}
\hline & \multicolumn{3}{|c|}{ DVL } & \multicolumn{3}{c|}{ DVS } \\
\hline & Intratumoral & Peritumoral & Total & Intratumoral & Peritumoral & Total \\
\hline & $\mathrm{p}$ & $\mathrm{p}$ & $\mathrm{p}$ & $\mathrm{p}$ & $\mathrm{p}$ & $\mathrm{p}$ \\
\hline VEGF-A & - & - & - & - & - & - \\
\hline VEGF-A165b & 0,121 & 0,121 & 0,121 & 0,439 & 1 & 0,121 \\
\hline VEGF-B & 0,655 & 0,180 & 0,655 & 0,180 & 0,655 & 0,180 \\
\hline VEGF-C & - & - & - & - & - & - \\
\hline VEGF-D & 0,180 & 0,180 & 0,180 & 0,655 & 0,180 & 0,655 \\
\hline VEGF-R1 & 0,180 & 0,180 & 0,180 & 0,655 & 0,180 & 0,655 \\
\hline VEGF-R3 & 0,180 & 0,180 & 0,180 & 0,655 & 0,180 & 0,655 \\
\hline
\end{tabular}

(o símbolo - foi aplicado para indicar que não há valor para esta variável)

\subsubsection{Correlações entre a DVL e DVS total, intra e peritumoral e} as expressões dos fatores de crescimento endotelial vascular e seus receptores nos bócios adenomatosos, tireoidites linfocitárias e adenomas foliculares estudados

As densidades vasculares linfáticas e sanguíneas foram correlacionadas com as expressões dos VEGFs e VEGFRs nos bócios adenomatosos, tireoidites linfocitárias e adenomas foliculares estudados.

Os diferentes tipos de lesões benignas apresentaram diferentes padrões de DVL e DVS total sendo que os maiores valores foram observados nas tireoidites linfocitárias (Tabela 39).

Ao considerarmos todas as lesões benignas estudadas como um único grupo e avaliarmos a correlação entre a imunoexpressão dos VEGFs e VEGFRs, de 0 a ++++, ou a imunoexpressão positiva ou negativa destes 
fatores, com a DVL e a DVS total, não observamos correlações estatisticamente significantes (Tabela 40)

Tabela 39 - Média e desvio padrão da DVL e DVS total dos bócios adenomatosos e tireoidites linfocitárias e DVL e DVS total, intratumoral e peritumoral dos adenomas foliculares estudados

\begin{tabular}{|c|c|c|c|c|c|c|c|c|c|c|c|c|}
\hline & \multicolumn{2}{|c|}{$\begin{array}{l}\text { DVL Média } \\
\text { Intratumoral }\end{array}$} & \multicolumn{2}{|c|}{$\begin{array}{l}\text { DVL Média } \\
\text { Peritumoral }\end{array}$} & \multicolumn{2}{|c|}{$\begin{array}{l}\text { DVL Média } \\
\text { Total }\end{array}$} & \multicolumn{2}{|c|}{$\begin{array}{l}\text { DVS Média } \\
\text { Intratumoral }\end{array}$} & \multicolumn{2}{|c|}{$\begin{array}{l}\text { DVS Média } \\
\text { Peritumoral }\end{array}$} & \multicolumn{2}{|c|}{$\begin{array}{c}\text { DVS Média } \\
\text { Total }\end{array}$} \\
\hline & Média & $\mathrm{DP}$ & Média & DP & Média & DP & Média & DP & Média & DP & Média & DP \\
\hline $\begin{array}{r}\text { Bócio } \\
\text { Adenomatoso }\end{array}$ & - & - & - & - & 10,53 & 4,4 & - & - & - & - & 14,27 & 3,4 \\
\hline $\begin{array}{r}\text { Tireoidite } \\
\text { Linfocitária }\end{array}$ & - & - & - & - & 11,81 & 4,9 & - & - & - & - & 17,95 & 5,8 \\
\hline $\begin{array}{r}\text { Adenoma } \\
\text { Folicular }\end{array}$ & 5,28 & 2,1 & 8,08 & 3,5 & 7,08 & 2,5 & 17,07 & 4,0 & 17,84 & 4,0 & 16,84 & 3,7 \\
\hline
\end{tabular}

(o símbolo - foi aplicado para indicar que não há valor para esta variável)

Tabela 40 - Sumário das significâncias das correlações entre a imunoexpressão de 0 a ++++ e negativa (até $10 \%$ ) ou positiva (> do que 10\%) dos VEGFs e VEGFRs e das densidades vasculares linfáticas e sanguíneas nas lesões benignas estudadas

\begin{tabular}{|r|c|c|c|c|}
\hline & \multicolumn{2}{|c|}{ De 0 a ++++ } & \multicolumn{2}{c|}{ Positivo e Negativo } \\
\hline & DVL Total & DVS Total & DVL Total & DVS Total \\
\hline VEGF-A & 0,803 & 0,439 & 0,622 & 0,114 \\
\hline VEGF-A165b & 0,183 & 0,523 & 0,084 & 0,151 \\
\hline VEGF-B & 0,418 & 0,101 & - & - \\
\hline VEGF-C & 0,332 & 0,215 & 0,142 & 0,145 \\
\hline VEGF-D & 0,807 & 0,312 & 0,991 & 0,154 \\
\hline VEGF-R1 & 0,605 & 0,835 & 0,960 & 0,363 \\
\hline VEGF-R3 & 0,365 & 0,570 & 0,236 & 0,269 \\
\hline
\end{tabular}

(o símbolo - foi aplicado para indicar que não há valor para esta variável) 
6 DISCUSSÃO 
O presente trabalho avaliou a expressão imuno-histoquímica dos fatores de crescimento endotelial vascular (VEGF-A, - $\mathrm{A}_{165} \mathrm{~b},-\mathrm{B},-\mathrm{C}$ e -D) e de seus receptores (VEGF-R1 e -R3), bem como, o significado da densidade vascular sanguínea e linfática em lesões benignas e malignas da tireóide. Os achados foram correlacionados com os dados clínico-patológicos existentes.

Demonstramos que existem significativas diferenças na expressão dos VEGFs e seus receptores entre as lesões tireoidianas benignas e malignas estudadas, que ficam mais evidentes quando dicotomizamos as expressões imuno-histoquímicas em positivas e negativas, lembrando que negativa é a expressão de 0 a $10 \%$ das células, e que positiva maior do que $10 \%$. Observamos que, na maioria dos casos, a expressão dos membros da família VEGF tendem a ser maior nas neoplasias malignas do que nas lesões benignas. Estes achados corroboram estudos prévios que demonstraram uma maior expressão dos fatores de crescimento endotelial vascular, tanto angiogênicos como linfangiogênicos, em neoplasias da tireóide $(21,81)$; eventos esses que ocorrem de forma semelhante em outros tipos de neoplasias malignas como, por exemplo, pulmão, bexiga, colo uterino, mama e rim (82). No presente estudo foi encontrado um crescimento gradual no padrão de expressão dos fatores de proliferação vascular, e de seus receptores, a partir de tecido tireoidiano de fenótipo 
normal, lesões proliferativas benignas e regiões neoplásicas malignas. Em relação às densidades vasculares, todos os tipos de lesões analisadas apresentaram densidade vascular sanguínea superior à densidade vascular linfática, sendo o carcinoma folicular o que apresentou a maior densidade vascular sanguínea; e a tireoidite linfocitária, a maior densidade vascular linfática. Ao correlacionarmos, nos carcinomas estudados, as imunoexpressões dos VEGFs e seus receptores, os dados clínico patológicos disponíveis e a densidade vascular sanguínea e linfática, observamos algumas correlações estatisticamente significativas apenas nos carcinomas papilíferos.

\subsection{Expressão dos VEGFs e VEGFRs nos carcinomas papilíferos e carcinomas foliculares da tireóide}

A maioria dos VEGFs e VEGFRs analisados foram intensamente expressos nos carcinomas papilíferos e nos carcinomas foliculares. Nestas neoplasias o número de casos com imuno-expressão positiva para o VEGF-A, VEGF-A ${ }_{165} b$, VEGF-C, VEGF-D, VEGF-R1 e VEGF-R3 foram superiores a $75 \%$ chegando a $100 \%$ de casos positivos para o VEGF-D nos carcinomas papilíferos. Apenas o VEGF-B teve imuno-expressão discreta, com apenas $8 \%$ de casos positivos nos carcinomas papilíferos e $9 \%$ nos carcinomas foliculares. 


\subsubsection{Expressão do VEGF-A e VEGF-A $165 b$}

Ambos os tipos de neoplasia mostraram expressão imunohistoquímica do VEGF-A com significativa diferença da área neoplásica em comparação a sua expressão em zonas de tireoidite linfocitária, bócio adenomatoso e tecido adjacente morfologicamente normal. Esse achado é relevante porque a expressão do VEGF-A está freqüentemente associada com o crescimento tumoral devido ao potencial aporte de nutrientes oriundos da proliferação angiogênica. Em concordância com demais artigos da literatura, nosso estudo demonstra que os níveis de imuno-expressão do VEGF-A nas regiões adjacentes morfologicamente normais é inferior ao encontrado nas neoplasias papilíferas e foliculares da tireóide (83). Observamos que quase $100 \%$ dos carcinomas papilíferos e foliculares apresentaram imuno-expressão positiva de VEGF-A nas células neoplásicas. Em contrapartida, em $81 \%$ dos carcinomas papilíferos e $84 \%$ dos carcinomas foliculares observamos imuno-expressão do VEGF-A $A_{165} b$, uma isoforma inibidora da angiogênese (68). Até o presente momento não foi descrito na literatura a participação do VEGF-A ${ }_{165} b$ nas neoplasias tireoidianas; esta importante observação pode justificar, ao menos em parte, o comportamento indolente da maioria dos carcinomas tireoidianos e demonstra a existência de um equilíbrio entre fatores pró e antiangiogênicos. Não pudemos observar variações na expressão imunohistoquímica do VEGF-A ${ }_{165} \mathrm{~b}$ nas diferentes variantes do carcinoma papilífero. 
Nos tecidos adjacentes aos carcinomas papilíferos de fenótipo normal, bócio adenomatoso ou tireoidite linfocitária a imuno-expressão dos VEGFs e seus receptores foi sempre inferior a encontrada na região neoplásica. Apesar disso, os níveis de expressão do VEGF-A observados foram expressivos chegando a $75 \%$ de casos positivos nos bócios adenomatosos.

Nas regiões adjacentes aos carcinomas foliculares o número de casos positivos para o VEGF-A, VEGF-R1 e VEGFR-3 foi sempre inferior. Conforme observado nos carcinomas papilíferos, o número de casos positivos para o VEGF-A nas regiões adjacentes apresentando bócio adenomatoso e tireoidite linfocitária, apesar de inferiores ao observado na região neoplásica, foram expressivos (78\% e $56 \%$ respectivamente). No entanto, a positividade imuno-histoquímica para o VEGF-A $\mathrm{A}_{165} \mathrm{~b}$ na região adjacente com bócio adenomatoso (positiva em $89 \%$ dos casos) foi maior do que na região do carcinoma folicular (positiva em $84 \%$ dos casos).

A tireoidite linfocitária e o bócio adenomatoso apresentam elevada expressão de TSH (hormônio tireo-estimulante), a primeira por destruição dos folículos, e a segunda por apresentar deficiência da síntese dos hormônios tireoidianos causada principalmente por deficiência de suprimento de iodo. Ambas as alterações levam ao aumento do TSH, reconhecidamente, um importante regulador da expressão do VEGF-A (84). Este fato justifica os altos níveis de VEGF-A observados nas regiões adjacentes aos carcinomas papilíferos e foliculares contendo bócio 
adenomatoso e tireoidite linfocitária. Além disso, a alta expressão imuno-histoquímica do principal mediador da angiogênese é compatível com o expressivo aumento da neovascularização nos quadros de inflamação crônica e também com o fato da tireóide, em virtude de suas funções endócrinas, necessitar de uma regulação precisa de sua microvasculatura (85). Segundo Klein et al. (85) os processos inflamatórios tireoidianos podem ser acompanhados pelo desenvolvimento da vasculatura e aumento da permeabilidade vascular, o que explica o edema geralmente observado nas tireoidites. Em concordância com nossos achados, importantes níveis de expressão do VEGF-A, em tireoidites de diferentes etiologias, tem sido observados na literatura (86). A angiogênese mediada pelo VEGF-A está particularmente relacionada às reações inflamatórias como um todo, pois, citosinas inflamatórias, incluindo aquelas envolvidas com a tireoidite, são mediadores da expressão do VEGF-A, como por exemplo, a interleucina-6 (87). Apesar de encontrarmos, nas lesões benignas e até mesmo nos tecidos tireoidianos morfologicamente normais adjacentes aos carcinomas papilíferos e foliculares, altos níveis de imunoexpressão positiva para o VEGF-A, observamos também uma importante imuno-expressão do VEGF-A ${ }_{165} \mathrm{~b}$ que por suas características antiangiogênicas irá se contrapor aos estímulos angiogênicos oriundos do VEGF-A. 


\subsubsection{Expressão do VEGF-B}

Em relação à imuno-expressão do VEGF-B, pode-se observar casos positivos em apenas $8 \%$ dos carcinomas papilíferos e em $4 \%$ das tireoidites linfocitárias adjacentes a esta neoplasia. Tanto no tecido adjacente morfologicamente normal, como no tecido adjacente apresentando bócio adenomatoso, $100 \%$ dos casos foram negativos. Nos carcinomas foliculares, apenas $9 \%$ dos casos apresentaram imuno-expressão positiva para 0 VEGF-B e todos os tecidos adjacentes foram negativos. Tanaka et al. (22) investigando a expressão do mRNA de VEGF-B em 41 amostras de carcinomas papilíferos da tireóide observaram a expressão desta molécula em $100 \%$ dos casos estudados. Mesmo se considerarmos a expressão imuno-histoquímica positiva total feita em nosso estudo, apenas $28 \%$ dos carcinomas papilíferos e $9 \%$ dos carcinomas foliculares apresentam algum nível de imuno-expressão do VEGF-B; portanto, nossos achados divergem daqueles do artigo supra citado. As diferentes metodologias utilizadas são uma possível explicação para tal divergência.

O VEGF-B é o membro da família VEGF menos estudado. Pouco se sabe a respeito de seu papel fisiológico in vivo (85) e de sua participação nas neoplasias humanas $(57,70)$. Tem sido demonstrado que a expressão deste fator de crescimento não é induzida por hipóxia e que ainda em inúmeras condições, este fator parece não afetar a angiogênese e a permeabilidade vascular. Aparentemente, VEGF-B funciona como um fator de sobrevivência para as células endoteliais e demais tipos celulares 
relacionados as estruturas dos vasos, como por exemplo, os pericitos e células musculares lisas (70). O papel do VEGF-B nos diferentes tipos de lesões tireoidianas continua obscuro e como dados contraditórios.

\subsubsection{Expressão do VEGF-C}

A expressão imuno-histoquímica do VEGF-C nos carcinomas papilíferos da tireóide foi positiva em $86 \%$ dos casos estudados. Em contrapartida, nos tecidos adjacentes morfologicamente normais da grande maioria dos casos (94\%) não observamos imuno-expressão. Nas lesões benignas, adjacentes ao carcinoma papilífero, observou-se valores intermediários de imuno-expressão: $44 \%$ de casos positivos nos bócios adenomatosos e $63 \%$ de casos positivo nas tireoidites linfocitárias. Nos carcinomas foliculares e nas regiões adjacentes a esta neoplasia apresentando tireoidite linfocitária $78 \%$ dos casos foram positivos para 0 VEGF-C. Em todas as regiões adjacentes morfologicamente normais não observamos nenhum nível de imuno-expressão e na região adjacente contendo bócio adenomatoso, assim como nos carcinomas papilíferos, observamos valores intermediários (67\% de casos positivos) de imunoexpressão para o VEGF-C.

Nossos achados corroboram estudos prévios que comparam a expressão do VEGF-C nas diferentes neoplasias tireoidianas e observaram os maiores níveis de expressão nos carcinomas papilíferos $(19,31)$. 
O VEGF-C tem sido apontado na literatura como um dos principais mediadores da linfangiogênese (9). Em diversas neoplasias humanas, sua super expressão parece estar consistentemente relacionada não só com a linfangiogênese propriamente dita, mas também com a invasão dos linfáticos e metástase para linfonodos $(30,88)$. A importância prognóstica da expressão do VEGF-C nos carcinomas tireoidianos ainda é controversa $(75,89)$.

\subsubsection{Expressão do VEGF-D}

Todos os carcinomas papilíferos e $83 \%$ dos carcinomas foliculares da presente série foram positivos para a imuno-expressão do VEGF-D. Este achado corrobora observação de estudo previamente realizado que relata a expressão generalizada de mRNA de VEGF-D nos carcinomas papilíferos (32). Nos tecidos adjacentes, morfologicamente normais, bócios adenomatosos e tireoidites linfocitárias também observamos imunoexpressão generalizada deste fator de crescimento.

O VEGF-D é um potente fator angiogênico e linfangiogênico (16) e seu envolvimento na promoção da angiogênese e linfangiogênese tumoral tem sido documentada (90). Em concordância com a literatura, demonstramos que a expressão imuno-histoquímica do VEGF-C e VEGF-D, os principais mediadores da linfangiogênese, foi maior nos carcinomas papilíferos do que nos foliculares, o que é compatível com dos carcinomas 
papilíferos metastatizarem preferencialmente por via linfática

Além disso, a expressão do VEGF-D tem sido correlacionada a um maior risco de metástase linfonodal e com uma maior densidade vascular linfática tumoral $(32,85)$.

\subsubsection{Expressão do VEGFR-1}

A expressão imuno-histoquímica do VEGF-R1 foi positiva em 94\% dos carcinomas papilíferos e $87 \%$ dos carcinomas foliculares. Nas regiões adjacentes aos carcinomas papilíferos contendo tecido morfologicamente normal, bócio adenomatoso e tireoidite linfocitária, a positividade e a intensidade das imuno-expressões observadas foram inferiores $(24 \%, 44 \%$ e $48 \%$ respectivamente). As regiões adjacentes dos carcinomas foliculares, tecido morfologicamente normal, bócio adenomatoso e tireoidite linfocitária, com exceção da região normal, apresentaram uma maior incidência de casos com imuno-expressão positiva (13\%, 78\% e $67 \%$ respectivamente) quando comparado as regiões adjacentes dos carcinomas papilíferos. O VEGF-R1 é um receptor de alta afinidade para o VEGF-A, VEGF-B e PLGF, e tem importante participação na migração de células endoteliais, monócitos/macrófagos e na angiogênese patológica $(9,57,69)$. 


\subsubsection{Expressão do VEGFR-3}

Em relação ao VEGF-R3, em $97 \%$ dos carcinomas papilíferos e $91 \%$ dos carcinomas foliculares observamos imuno-expressão positiva. Nas regiões adjacentes de tecido morfologicamente normal, bócio adenomatoso e tireoidite linfocitária os níveis de imuno-expressão para o VEGF-R3 foram inferiores aqueles encontrados nos carcinomas papilíferos $(23 \%, 63 \%$ e $72 \%$ respectivamente) e carcinomas foliculares $(39 \%, 89 \%$ e $67 \%$ respectivamente). O VEGFR-3 é um receptor com alta afinidade para VEGF-C e VEGF-D que está principalmente relacionado à linfangiogênese $(9,57,69)$.

Em concordância com a literatura, demonstramos a imuno-expressão do VEGF-R1 e VEGF-R3 nas células endoteliais e neoplásicas dos carcinomas papilíferos e foliculares da tireóide. A presença dos VEGFRs nas células neoplásicas dos carcinomas tireoidianos permitem que tais células respondam aos estímulos promovidos pelos fatores de crescimento da família VEGF (91).

A alta expressão da família VEGF e de seus receptores em inúmeras neoplasias humanas, em conjunto com demais indícios existentes na literatura, sugerem que estas proteínas estão envolvidas em vias de sinalizações, autócrinas e parácrinas, relacionadas ao crescimento e sobrevivência das células neoplásicas $(92,93)$. Os altos níveis de expressão do VEGF-C e VEGF-D relatados nas tireoidites linfocitárias (15), justificam o 
fato da alta expressão do VEGF-R3 neste tipo de lesão uma vez que estes três fatores estão intimamente ligados a linfangiogênese.

\subsection{Valor prognóstico da expressão dos VEGFs e VEGFRs nos carcinomas papilíferos e foliculares da tireóide}

Em relação ao valor prognóstico da expressão do VEGFs nos carcinomas diferenciados da tireóide os estudos existentes são controversos. Ao considerarmos nos carcinomas papiliferos a expressão imunohistoquímica dos VEGFs e seus receptores de 0 a ++++, não observamos correlações estatisticamente significantes dos dados clínico-patológicos estudados com a expressão do VEGF-A, VEGF-A ${ }_{165} b$, VEGF-B, VEGF-C e VEGF-R1. Em contrapartida, a imuno-expressão do VEGF-D $(p=0,004)$ e do VEGF-R3 $(p=0,017)$ apresentaram correlações estatisticamente significantes com o estadiamento tumoral. Quando dicotomizamos as imuno-expressões em positivas e negativas e correlacionamos com os dados clínico-patológicos, observamos correlações estatisticamente significantes do VEGF-A e a invasão de vaso $(p=0,049)$, do VEGF-B e a idade dos pacientes $(p=0,047)$, do VEGF-R1 e do lobo acometido pelo tumor $(p=0,010)$ e do VEGF-R3 e o estadio $(p=0,002)$ dos carcinomas papilíferos.

A correlação entre a expressão do VEGF-D e o estadiamento tumoral deixa de existir, ao dividirmos a imuno-expressão em positiva e negativa, 
pois todos os carcinomas papilíferos apresentaram imuno-expressão positiva para o VEGF-D o que impossibilitou a análise comparativa.

Nos carcinomas foliculares estudados, não observamos nenhuma correlação estatisticamente significante entre os dados clínico-patológicos estudados e a expressão do VEGF-A, VEGF-A 165 b, VEGF-B, VEGF-C, VEGF-D, VEGF-R1 e VEGF-R3, independentemente do fato de analisarmos a imuno-expressão de forma subjetiva ou simplesmente dividida em positiva ou negativa.

Diferentemente de nossos achados, alguns estudos demonstraram uma significativa associação entre o tamanho do tumor e altos níveis de expressão do VEGF-A no carcinoma papilífero da tireóide $(21,94,95)$. O VEGF-A foi apontado como um marcador independente para a ocorrência de metástase linfonodal ou sistêmica no momento da tireoidectomia por carcinoma papilífero (96). Em outro estudo, a expressão do VEGF-A, esteve fortemente associada com recorrência local e distante e diminuição da sobrevida livre de doença (97). Em contrapartida, Huang et al. (98) demonstrou que não houve correlação entre a expressão imunohistoquímica do VEGF-A e o tamanho do tumor, extensão da invasão, classificação no sistema AGES (idade do paciente, tamanho do tumor, grau histológico, extensão tumoral e metástase distante) ou no sistema MACIS (metástase, idade, plenitude da ressecção, invasão e tamanho do tumor) na análise de 76 carcinomas papilíferos. O autor conclui, em concordância com nossos resultados, que a determinação do fenótipo angiogênico, baseada apenas na avaliação da expressão do VEGF-A, aparenta ter valor limitado 
para o prognóstico de pacientes com carcinoma papilífero da tireóide. As diferentes técnicas para a quantificação da expressão do VEGF-A e os diferentes anticorpos utilizados devem explicar, ao menos em parte, os resultados conflitantes.

Embora existam relatos da expressão do VEGF-B em diversos tipos de neoplasias $(93,99)$, assim como no tecido tireoidiano (22), pouco se sabe a respeito do possível valor prognóstico do VEGF-B. Em nosso estudo observamos uma fraca e vaga correlação entre a idade dos pacientes e uma maior expressão do VEGF-B nos carcinomas papilíferos da tireóide. Estudos futuros são necessários para uma melhor avaliação deste membro da família VEGF e de sua importância prognóstica nas lesões tireoidianas.

O aumento do VEGF-C em neoplasias malignas primárias tem sido correlacionado com o aumento da disseminação de células neoplásicas malignas para os linfonodos regionais em vários carcinomas (23). As metástases precoces em linfonodos são um achado clínico importante freqüentemente relacionado com mau prognóstico (29). Nos carcinomas tireoidianos, tem sido demonstrado aumento significativo da expressão de VEGF-C em pacientes apresentando comprometimento dos linfonodos. Além disso, há evidências de correlação positiva entre o número de linfonodos com metástases e a expressão de mRNA de VEGF-C no tumor primário (22). Em concordância com alguns relatos, nosso estudo não mostrou nenhuma correlação estatisticamente significativa entre a expressão do VEGF-C e os dados clínico-patológicos estudados $(21,31)$. No entanto, fica evidente, pelos altos níveis de expressão deste fator de 
crescimento nos carcinomas papilíferos, sua importante participação nesta neoplasia. Similarmente, o VEGF-D apresenta-se como um poderoso indutor de neovascularização linfática em carcinomas papilíferos da tireóide. Tem sido relatado por alguns autores como um importante parâmetro prognóstico para a disseminação neoplásica, além de estar, correlacionado com o comprometimento de linfonodos nos carcinomas papilíferos da tireóide (32). Em nosso estudo, observamos uma forte correlação estatística entre imuno-expressão mais intensa do VEGF-D e pior estadiamento tumoral $(p=0,004)$, o que demonstra a importância prognóstica deste fator; no entanto, em concordância com alguns estudos anteriores, não detectamos nenhuma correlação entre a expressão do VEGF-D e o comprometimento de linfonodos (22).

Os altos níveis de expressão do VEGF-R1 e VEGF-R3 observados nos carcinomas tireoidianos (91) e a correlação entre a expressão do VEGF-R3 e o estadiamento tumoral nos carcinomas papilíferos estudados, são indícios, da importante participação destes fatores na carcinogênese tireoidiana. A comunidade científica tem demonstrado grande interesse pelos receptores da família de crescimento endotelial vascular. Atualmente, cerca de 44 novos inibidores dos VEGFRs estão sendo desenvolvidos (100). Um exemplo de novo medicamento é o Axitinib, uma potente droga ministrada por via oral que apresenta capacidade inibidora seletiva para os receptores dos fatores de crescimento endotelial vascular (VEGF-R1, VEGF-R2 e VEGF-R3). Atualmente, inúmeros estudos clínicos com o Axitinib, drogas similares e novas terapias estão ocorrendo na busca de 
alternativas terapêuticas, em especial, no caso das neoplasias tireoidianas, para as variantes mais agressivas, carcinomas indiferenciados, medulares, anaplásicos e resistentes a terapia com iodo radioativo. Os promissores resultados preliminares existentes apontam para uma nova e importante alternativa terapêutica baseada na inibição dos VEGFRs $(101,102)$.

\subsection{Expressão dos VEGFs e VEGFRs nos bócios adenomatosos, tireoidites linfocitárias e adenomas foliculares}

A glândula tireóide é vascularizada com uma das maiores taxas de fluxo sanguíneo por unidade de peso de todo o corpo (21). Neste contexto, a angiogênese é um fenômeno necessário não somente para o crescimento neoplásico, mas também para a hiperplasia das células tireoidianas (103) e manutenção de sua microvasculatura (85).

Em concordância com a literatura, com exceção da imuno-expressão do VEGF-A no bócio adenomatoso que apresentou valor similar ao encontrado nas neoplasias diferenciadas estudadas, nas lesões tireoidianas benignas observamos valores de imuno-expressão inferiores aos detectados nas neoplasias papilíferas e foliculares da tireóide $(21,104)$. Nos bócios adenomatosos, a expressão imuno-histoquímica para o VEGF-A, VEGF-A ${ }_{165} b$, VEGF-D e VEGF-R3 foi positiva em mais de $70 \%$ dos casos, chegando a um máximo de $92 \%$ dos casos com imuno-expressão positiva 
para o VEGF-A. Apenas $35 \%$ dos casos foram positivos para o VEGF-C e 43\% para o VEGF-R1. Nas tireoidites linfocitárias, imuno-expressões positivas do VEGF-A, VEGF-C, VEGF-D e VEGF-R3 foram observadas em $65 \%$ dos casos e do VEGF-R1 em $71 \%$. Em apenas $29 \%$ das tireoidites observamos imuno-expressão positiva para o VEGF-A ${ }_{165} b$. Nos adenomas foliculares, níveis superiores a $50 \%$ de imuno-expressão positiva foram observados apenas para o VEGF-A e VEGF-R3 $\quad(83 \%$ e $\quad 67 \%$ respectivamente), e em $50 \%$ dos casos observamos imuno-expressão do VEGF-R1. Níveis inferiores a $35 \%$ de casos com imuno-expressão positiva foram observados para o VEGF-A ${ }_{165} \mathrm{~b}$, VEGF-C e VEGF-D. Em todos os casos de todos os tipos de lesões benignas estudadas, observamos imunoexpressão negativa para o VEGF-B.

Os altos níveis de VEGF-A expressos pelas lesões benignas, podem ser justificados, ao menos em parte, pela elevada expressão de TSH destas lesões, uma vez que, conforme dito previamente, o TSH é um importante regulador da expressão do VEGF-A (84). Um elevado nível de expressão, em especial do VEGF-A, tem sido observado nos bócios adenomatosos, tireoidites linfocitárias $(21,85,90)$ e adenoma folicular (19). Além do estímulo para síntese de VEGF-A proveniente dos altos níveis de TSH (84) e da mediação da expressão dos VEGFs por citocinas inflamatórias envolvidas nas tireoidites (87), os neutrófilos e plaquetas possuem grandes quantidades de VEGFs (105). A regulação da expressão dos fatores de crescimento da família VEGF e de seus receptores é mediada por complexos mecanismos dependentes ou não de hipóxia, e a liberação 
destes fatores por células inflamatórias pode ocorrer independentemente da oxigenação durante os processos inflamatórios. Além disso, o hipotireoidismo e a inflamação pós operatória podem influenciar os níveis de VEGF-A encontrado no soro de pacientes (19). Apesar da alta expressão de VEGF-A nas lesões benignas, níveis importantes de imuno-expressão do VEGF-A ${ }_{165} \mathrm{~b}$, uma variante anti-angiogênica da família VEGF (68), foram expressos. Este fator anti-angiogênico irá contrapor o estímulo pró neovascularização do VEGF-A e equilibrar com alguma importância o crescimento da massa tireoidiana.

Tanto nas regiões adjacentes às neoplasias malignas como nos bócios adenomatosos, tireoidites linfocitárias e adenomas foliculares, a imuno-expressão para o VEGF-B foi predominantemente negativa. Somente na tireoidite linfocitária adjacente ao carcinoma papilífero da tireóide e nos carcinomas papilíferos e foliculares encontramos um discreto e pontual nível de imuno-expressão.

Nas lesões benignas estudadas, assim como em relatos da literatura, observamos níveis de imuno-expressão para o VEGF-C e VEGF-D inferiores aos encontrados nas neoplasias malignas da tireóide (85). Em contrapartida, níveis importantes destes fatores são expressos mesmo nas lesões benignas. Tanto o processo inflamatório relacionado à tireoidite linfocitária, quanto o alto nível de expressão dos ligandos da família VEGF justificam, em parte, a alta expressão dos receptores VEGF-R1 e VEGF-R3 nas lesões benignas estudadas. 


\subsection{A densidade vascular linfática (DVL) e sanguínea (DVS) nos carcinomas papilíferos, carcinomas foliculares, bócios adenomatosos, tireoidites linfocitárias e adenomas foliculares}

Com a expressão de fatores de crescimento pró neovascularização em quantidades superiores aos inibidores ocorre o aumento da microvasculatura dos tecidos. Sendo assim, a quantificação das densidades vasculares sanguíneas e linfáticas são formas indiretas, mas muitas vezes importantes, da medição dos estímulos pró neovascularização e de seu significado clínico. O aumento da densidade vascular linfática e sanguínea tem sido relatada como um dos principais parâmetros associados ao comportamento mais agressivo de determinados tumores (89).

Nas lesões hiperplásicas e neoplásicas da tireóide, o aumento da proliferação celular necessita do aumento da vasculatura para um maior aporte de nutrientes (21). No que diz respeito às densidades vasculares linfáticas e as densidades vasculares sanguíneas, em concordância com a literatura, observamos diferentes padrões entre os diferentes tipos de lesões tireoidianas estudadas $(106,107)$.

Ao agruparmos as lesões tireoidianas estudadas em malignas (carcinomas papilíferos e carcinomas foliculares) e benignas (bócios adenomatosos, tireoidites linfocitárias e adenomas foliculares) encontramos diferença estatisticamente significante apenas na DVL total ( $p=0,033$ ). 
Ainda em relação aos vasos linfáticos, a DVL peritumoral foi maior que a intratumoral nos carcinomas papilíferos, carcinomas foliculares e adenomas foliculares (103).

Estudos anteriores sugerem que a DVS está aumentada nos carcinomas papilíferos em comparação ao tecido tireoidiano normal (108). No presente estudo, observamos que nos carcinomas papilíferos e nos adenomas foliculares a DVS total, intra e peritumoral foi semelhante, enquanto que, nos carcinomas foliculares a DVS intratumoral foi quase o dobro da peritumoral. Este achado é compatível com o fato dos carcinomas foliculares metastatizarem preferencialmente por via sanguínea (103). Assim, como anteriormente descrito na literatura, a DVS nos bócios adenomatosos e tireoidites linfocitárias foi semelhante à observada nos adenomas foliculares (21). Em valores absolutos, nos diferentes tipos de lesões benignas observamos diferentes padrões de DVL e DVS total, sendo que os maiores valores foram observados nas tireoidites linfocitárias.

Ao correlacionarmos as densidades vasculares observadas nos carcinomas papilíferos, carcinomas foliculares e adenomas foliculares constatamos diferença estatística significativa na DVL total $(p=0,019)$, DVS total $(p=0,002)$ e DVS intratumoral $(p=0,018)$. Entre estas três categorias diagnósticas, o adenoma folicular apresentou a menor e o carcinoma folicular a maior DVL. Estas diferenças de perfis linfangiogênicos podem vir a ser uma nova ferramenta para a difícil diferenciação entre adenomas e carcinomas foliculares $(51,79,110)$. Nossos resultados são confirmados em parte pelos reportados por Giorgadze e colaboradores que demonstraram 
diferenças entre as DVL das lesões foliculares da tireóide (106). Em relação à DVS observamos no carcinoma papilífero e no adenoma folicular valores semelhantes, enquanto que nos carcinomas foliculares a DVS mostrou se mais proeminente. Uma discreta DVS pode se correlacionar com aumento da hipóxia e, conseqüentemente, com maior expressão de membros pró angiogênicos da família VEGF (109). A angiogênese e linfangiogênese tumoral são eventos dinâmicos e avaliações imuno-histoquímicas são apenas visões estáticas destes processos; sendo assim, o fato de observarmos níveis equivalentes de DVS e DVL entre as lesões proliferativas benignas e as neoplasias pode estar relacionado ao momento do desenvolvimento dessas mesmas lesões (21).

Não observamos correlações estatisticamente significativas entre a expressão dos VEGFs e seus receptores e as densidades vasculares linfáticas e sanguíneas nas categorias diagnósticas estudadas.

Ao compararmos os dados clínico-patológicos dos carcinomas papilíferos e a DVL intratumoral, peritumoral e total não observamos correlações estatisticamente significativas. Este achado deve estar relacionado ao bom prognóstico da maioria dos carcinomas papilíferos da tireóide (21).

Ainda em relação aos carcinomas papilíferos, no comparativo entre a DVS intratumoral, peritumoral e total, e os achados clínico-patológicos, observamos correlações estatisticamente significativas entre a variável sexo e a DVS peritumoral $(p=0,020)$. Além disso, houve correlação estatisticamente significativa entre a invasão de vaso e a DVS intratumoral ( $p=0,013)$, 
peritumoral $(p=0,008)$ e total $(p=0,004)$. Surpreendentemente os casos aonde não foi detectada invasão vascular foram aqueles aonde observamos uma maior DVS. Akslen e colaboradores, em concordância com nossos resultados, demonstraram que uma DVS reduzida pode estar associada a tumores mais indiferenciados com pior prognóstico e sobrevida (108). Em contrapartida, outros relatos demonstram aumento de recorrência com redução da sobrevida livre de doença nos tumores papilíferos mais vascularizados (103). A utilização de diferentes marcadores endoteliais linfáticos e sanguíneos e diferentes técnicas de quantificação da DVL e DVS certamente contribuem para os diferentes resultados observados na literatura $(21,79)$.

Nos carcinomas foliculares, o estudo das densidades vasculares limitou-se à apenas 5 casos da presente série, o que certamente foi um importante limitante das análises estatísticas e do valor dos resultados obtidos. Não houve correlações estatisticamente significativas na comparação entre os dados clínico-patológicos e a DVL intratumoral, peritumoral e total e a DVS intratumoral, peritumoral e total.

\subsection{Considerações finais}

A observação dos aspectos bioquímicos, moleculares e celulares são importantes ferramentas para uma conduta assertiva no tratamento das enfermidades tireoidianas. Um melhor entendimento da biologia dos 
carcinomas tireoidianos certamente favorecerão uma conduta mais adequada podendo sanar questões ainda controversas da literatura.

A angiogênese e a linfangiogênese tem sido alvo de interesse científico constante pelo crescente uso desses parâmetros em diagnóstico, avaliação prognóstica e potencial alvo terapêutico de neoplasias malignas.

Diversos fármacos baseados no bloqueio da angiogênese e linfangiogênese já estão sendo utilizados com o objetivo de neutralizar a neovascularização oriunda da atividade dessas moléculas. A partir destas experiências, novas questões a respeito do papel das moléculas próneovascularização estão surgindo.

O estudo destes fatores contribuirá para um melhor entendimento desses processos auxiliando na busca de melhores métodos diagnósticos, avaliação prognóstica e possibilidades terapêuticas.

Segundo Folkman (8), o cirurgião criador da hipótese da neovascularização tumoral, e Carmeliet (58), um dos maiores estudiosos do assunto, "A pesquisa da angiogênese irá provavelmente mudar a face da medicina nas próximas décadas, com mais de 500 milhões de pessoas no mundo beneficiadas por tratamentos pró ou anti-angiogênicos". 


\section{CONCLUSÕES}


1 - Os carcinomas papilíferos, carcinomas foliculares, bócios adenomatosos, tireoidites linfocitárias e adenomas foliculares apresentam diferentes perfis de expressão imuno-histoquímica do VEGF-A, VEGF-A ${ }_{165} b$, VEGF-B, VEGF-C, VEGF-D, VEGF-R1 e VEGF-R3 havendo um crescimento gradual na intensidade de expressão destes fatores de crescimento e seus receptores a partir do tecido tireoidiano com fenótipo normal, lesões proliferativas benignas e neoplasias malignas.

2 - Há profusa expressão de VEGF-A em ambos os carcinomas; porém há também importante expressão de seu antagonista VEGF-A $165 \mathrm{~b}$, o que pode explicar em parte o freqüente comportamento indolente destas neoplasias.

3 - Com a ampla imuno-expressão do VEGF-A, a determinação do fenótipo angiogênico, baseada apenas na avaliação da expressão deste fator, tem valor limitado para o prognóstico de pacientes com carcinoma papilífero e folicular da tireóide. 
4 - A expressão imuno-histoquímica do VEGF-B é predominantemente negativa no tecido tireoidiano normal e lesões benignas. Nos carcinomas papilíferos, foliculares e na tireoidite linfocitária há uma discreta expressão deste fator de crescimento.

5 - Nos carcinomas papilíferos e foliculares da tireóide há uma forte expressão imuno-histoquímica dos principais fatores de crescimento (VEGF-C e VEGF-D) e receptores (VEGF-R1 e VEGF-R3) envolvidos na linfangiogêse. No tecido tireoidiano adjacente normal a expressão do VEGF-C é predominantemente negativa.

6 - As expressões imuno-histoquímicas do VEGF-D e do VEGF-R3 estão associadas a um pior estadiamento tumoral nos carcinomas papilíferos da tireóide possibilitando a utilização destes parâmetros como indicativos prognósticos.

7 - A densidade vascular sanguínea é superior a densidade vascular linfática nos carcinomas papilíferos, carcinomas foliculares, bócios adenomatosos, tireoidites linfocitárias e adenomas foliculares sendo que os carcinomas foliculares apresentam a maior densidade vascular sanguínea e as tireoidites linfocitárias a maior densidade vascular linfática. 
8 - A densidade de vasos linfáticos na periferia dos tumores é maior do que na região intratumoral.

9 - A diferença de perfil linfangiogênico dos adenomas foliculares e carcinomas foliculares pode ser utilizada para a diferenciação destas categorias diagnósticas.

10 - Não existe correlação entre a expressão imuno-histoquímica dos VEGFs e seus receptores e as densidades vasculares linfáticas e sanguíneas nas categorias diagnósticas estudadas.

11 - Nos carcinomas papilíferos uma menor densidade vascular sanguínea esta associada a invasão vascular. 


\section{REFERÊNCIAS}


1. Goldmann E. The Growth of Malignant Disease in Man and the Lower Animals, with special reference to the Vascular System. Proc $R$ Soc Med. 1908;1(Surg Sect):1-13.

2. Fidler IJ. The pathogenesis of cancer metastasis: the 'seed and soil' hypothesis revisited. Nat Rev Cancer. 2003 Jun;3(6):453-8.

3. Folkman J. Tumor angiogenesis: therapeutic implications. $N$ Engl $J$ Med. 1971 Nov 18;285(21):1182-6.

4. Carmeliet P, Jain RK. Angiogenesis in cancer and other diseases. Nature. 2000 Sep 14;407(6801):249-57.

5. Kerbel R, Folkman J. Clinical translation of angiogenesis inhibitors. Nat Rev Cancer. 2002 Oct;2(10):727-39.

6. Carmeliet P. Manipulating angiogenesis in medicine. J Intern Med. 2004 May;255(5):538-61.

7. News. FaDA. FDA Approves First Angiogenesis Inhibitor to Treat Colorectal Cancer. . 2004 [cited 201014 march 2010 ]; Available from: http://www.fda.gov/NewsEvents/Newsroom/PressAnnouncements/2004 /ucm108252.htm.

8. Folkman J. Angiogenesis: an organizing principle for drug discovery? Nat Rev Drug Discov. 2007 Apr;6(4):273-86.

9. Ferrara N. Vascular endothelial growth factor: basic science and clinical progress. Endocr Rev. 2004 Aug;25(4):581-611. 
10. Adams $\mathrm{RH}$, Alitalo $\mathrm{K}$. Molecular regulation of angiogenesis and lymphangiogenesis. Nat Rev Mol Cell Biol. 2007 Jun;8(6):464-78.

11. Niki $T$, Iba $S$, Tokunou $M$, Yamada $T$, Matsuno $\mathrm{Y}$, Hirohashi $\mathrm{S}$. Expression of vascular endothelial growth factors $A, B, C$, and $D$ and their relationships to lymph node status in lung adenocarcinoma. Clin Cancer Res. 2000 Jun;6(6):2431-9.

12. Pepper MS. Lymphangiogenesis and tumor metastasis: myth or reality? Clin Cancer Res. 2001 Mar;7(3):462-8.

13. Senger DR, Galli SJ, Dvorak AM, Perruzzi CA, Harvey VS, Dvorak HF. Tumor cells secrete a vascular permeability factor that promotes accumulation of ascites fluid. Science. 1983 Feb 25;219(4587):983-5.

14. Ferrara N, Henzel WJ. Pituitary follicular cells secrete a novel heparinbinding growth factor specific for vascular endothelial cells. Biochem Biophys Res Commun. 1989 Jun 15;161(2):851-8.

15. Byrne AM, Bouchier-Hayes DJ, Harmey JH. Angiogenic and cell survival functions of vascular endothelial growth factor (VEGF). J Cell Mol Med. 2005 Oct-Dec;9(4):777-94.

16. Yamazaki $\mathrm{Y}$, Morita T. Molecular and functional diversity of vascular endothelial growth factors. Mol Divers. 2006 Nov;10(4):515-27.

17. Ferrara N, Gerber HP, LeCouter J. The biology of VEGF and its receptors. Nat Med. 2003 Jun;9(6):669-76.

18. Camargo RS, Maeda MYS, di Loreto C, Shirata NK, Garcia EA, Longatto Filho A. Is AgNOR and DNA ploidy analysis useful for evaluating thyroid neoplasms? Analytical and Quantitative Cytology and Histology 2005;27(3):157-61. 
19. Lin JD, Chao TC. Vascular endothelial growth factor in thyroid cancers. Cancer Biother Radiopharm. 2005 Dec;20(6):648-61.

20. Klein M, Vignaud JM, Hennequin V, Toussaint B, Bresler L, Plenat F, et al. Increased expression of the vascular endothelial growth factor is a pejorative prognosis marker in papillary thyroid carcinoma. J Clin Endocrinol Metab. 2001 Feb;86(2):656-8.

21. de la Torre NG, Buley I, Wass JA, Turner HE. Angiogenesis and lymphangiogenesis in thyroid proliferative lesions: relationship to type and tumour behaviour. Endocr Relat Cancer. 2006 Sep;13(3):931-44.

22. Tanaka K, Kurebayashi J, Sonoo H, Otsuki T, Yamamoto Y, Ohkubo S, et al. Expression of vascular endothelial growth factor family messenger RNA in diseased thyroid tissues. Surg Today. 2002;32(9):761-8.

23. Jussila L, Alitalo K. Vascular growth factors and lymphangiogenesis. Physiol Rev. 2002 Jul;82(3):673-700.

24. Dadras SS, Detmar M. Angiogenesis and lymphangiogenesis of skin cancers. Hematol Oncol Clin North Am. 2004 Oct;18(5):1059-70, viii.

25. Bono P, Wasenius VM, Heikkilä $P$, Lundin J, Jackson DG, Joensuu $H$. High LYVE-1-positive lymphatic vessel numbers are associated with poor outcome in breast cancer. Clin Cancer Res. 2004;10:7144-9.

26. Jia YT, Li ZX, He YT, Liang W, Yang HC, Ma HJ. Expression of vascular endothelial growth factor- $C$ and the relationship between lymphangiogenesis and lymphatic metastasis in colorectal cancer. World J Gastroenterol. 2004 Nov 15;10(22):3261-3.

27. Kawakami M, Yanai Y, Hata F, Hirata K. Vascular endothelial growth factor $\mathrm{C}$ promotes lymph node metastasis in a rectal cancer orthotopic model. Surg Today. 2005;35(2):131-8. 
28. Shimizu K, Kubo H, Yamaguchi K, Kawashima K, Ueda Y, Matsuo K, et al. Suppression of VEGFR-3 signaling inhibits lymph node metastasis in gastric cancer. Cancer Sci. 2004 Apr;95(4):328-33.

29. He $\mathrm{Y}$, Karpanen T, Alitalo K. Role of lymphangiogenic factors in tumor metastasis. Biochim Biophys Acta. 2004 Mar 4;1654(1):3-12.

30. Duff SE, Li C, Jeziorska M, Kumar S, Saunders MP, Sherlock D, et al. Vascular endothelial growth factors $C$ and $D$ and lymphangiogenesis in gastrointestinal tract malignancy. Br J Cancer. 2003 Aug 4;89(3):426-30.

31. Hung CJ, Ginzinger DG, Zarnegar R, Kanauchi H, Wong MG, Kebebew $E$, et al. Expression of vascular endothelial growth factor- $C$ in benign and malignant thyroid tumors. J Clin Endocrinol Metab. 2003 Aug;88(8):3694-9.

32. Yasuoka H, Nakamura $Y$, Zuo $H$, Tang W, Takamura $Y$, Miyauchi $A$, et al. VEGF-D expression and lymph vessels play an important role for lymph node metastasis in papillary thyroid carcinoma. Mod Pathol. 2005 Aug;18(8):1127-33.

33. Camargo RS. Cirurgia da glândula tireóide. In: Goffi. Técnica Cirúrgica - bases anatômicas, fisiopatológicas e técnica cirúrgica. 4 ed. São Paulo: Atheneu; 1996.

34. Carvalho HF, Buzato CBC. Células - Uma abordagem multidisciplinar. 1 ed. Barueri: Manole; 2004.

35. Camargo RS. Anatomia Cirúrgica da Tireóide. In: Petroianu, A. (Org.). Anatomia Cirúrgica 1ed. Horizonte UFdB, editor. Rio de Janeiro: Guanabara Koogan; 1999.

36. Sherman SI. Thyroid carcinoma. Lancet. 2003 Feb 8;361(9356):501-11. 
37. Guyton AC, Hall JE. Textbook of medical physiology. 11th ed. ed: Elsevier, 2006.

38. Yen PM. Physiological and molecular basis of thyroid hormone action. Physiol Rev. 2001 Jul;81(3):1097-142.

39. Gharib H, Papini E, Valcavi R, Baskin HJ, Crescenzi A, Dottorini ME, et al. American Association of Clinical Endocrinologists and Associazione Medici Endocrinologi medical guidelines for clinical practice for the diagnosis and management of thyroid nodules. Endocr Pract. 2006 JanFeb;12(1):63-102.

40. Stang MT, Carty SE. Recent developments in predicting thyroid malignancy. Curr Opin Oncol. 2009 Jan;21(1):11-7.

41. Hegedus L. Clinical practice. The thyroid nodule. N Engl J Med. 2004 Oct 21;351(17):1764-71.

42. Camargo RS, Shirata NK, di Loreto C, Garcia EA, Castelo A, Longatto Filho A. Significance of AgNOR measurement in thyroid lesions. Anal Quant Cytol Histol. 2006 Aug;28(4):188-92.

43. Nikiforov YE. Thyroid carcinoma: molecular pathways and therapeutic targets. Mod Pathol. 2008 May;21 Suppl 2:S37-43.

44. Institute. NC. Estimated new cases and deaths from thyroid cancer in the United States in 20092009 [cited 201014 march 2010]; Available from: http://www.cancer.gov/cancertopics/types/thyroid.

45. Todd WUt, Wenig BM. Thyroid follicular epithelial cell-derived carcinomas: an overview of the pathology of primary and recurrent disease. Otolaryngol Clin North Am. 2008 Dec;41(6):1079-94, vii-viii. 
46. Maia AL, Ward LS, Carvalho GA, Graf H, Maciel RMB, Maciel LMZ, et al. Nódulos de tireóide e câncer diferenciado de tireóide: Consenso brasileiro. Arq Bras Endocrinol Metab. 2007;51(5):867-93.

47. Brown RL. Standard and emerging therapeutic approaches for thyroid malignancies. Semin Oncol. 2008 Jun;35(3):298-308.

48. Matsuo ES, Martins L, Leoni SG, Hajjar D, Ricart-Filho JCM, Ebina KN, et al. Marcadores biológicos de tumores tiroidianos. Arq Bras Endocrinol Metab. 2004;48(1):114-25.

49. Kumar V, Abbas AK, Fausto N, Aster J. Robbins and Cotran Pathologic Basis of Disease. 8th ed: Elsevier, 2010.

50. Begum A, Bari S, Ayaz KFM, Yasmin R, Rajib NC, Rashid MA, et al. Thyroiditis. J Medicine. 2006;7:58-63.

51. Schlumberger MJ. Papillary and follicular thyroid carcinoma. N Engl J Med. 1998 Jan 29;338(5):297-306.

52. Rubin R, Strayer DS. Rubin's pathology: Clinicopathologic foundations of medicine. 5th ed: Lippincott Williams \& Wilkins; 2008.

53. Utiger RD. The multiplicity of thyroid nodules and carcinomas. $N$ Engl J Med. 2005 Jun 9;352(23):2376-8.

54. Ward LS, Assumpção LVM. Câncer diferenciado da tiróide: fatores prognósticos e tratamento. Arq Bras Endocrinol Metab. 2004;48(1):126-36.

55. Lang BH, Lo CY, Chan WF, Lam KY, Wan KY. Prognostic factors in papillary and follicular thyroid carcinoma: their implications for cancer staging. Ann Surg Oncol. 2007 Feb;14(2):730-8. 
56. Weber T, Schilling T, Buchler MW. Thyroid carcinoma. Curr Opin Oncol. 2006 Jan;18(1):30-5.

57. Roskoski R, Jr. Vascular endothelial growth factor (VEGF) signaling in tumor progression. Crit Rev Oncol Hematol. 2007 Jun;62(3):179-213.

58. Carmeliet P. Angiogenesis in life, disease and medicine. Nature. 2005 Dec 15;438(7070):932-6.

59. Hillen F, Griffioen AW. Tumour vascularization: sprouting angiogenesis and beyond. Cancer Metastasis Rev. 2007 Dec;26(3-4):489-502.

60. Lohela M, Bry M, Tammela T, Alitalo K. VEGFs and receptors involved in angiogenesis versus lymphangiogenesis. Curr Opin Cell Biol. 2009 Apr;21(2):154-65.

61. Sabin FR. On the origin of the lymphatic system from the veins, and the development of the lymph hearts and thoracic duct in the pig. Am J Anat. 1902;3:183-95.

62. Hong YK, Detmar M. Prox1, master regulator of the lymphatic vasculature phenotype. Cell Tissue Res. 2003 Oct;314(1):85-92.

63. Oliver G. Lymphatic vasculature development. Nat Rev Immunol. 2004 Jan;4(1):35-45.

64. Schneider M, Othman-Hassan K, Christ B, Wilting J. Lymphangioblasts in the avian wing bud. Dev Dyn. 1999 Dec;216(4-5):311-9.

65. Rodriguez-Niedenfuhr $\mathrm{M}$, Papoutsi $\mathrm{M}$, Christ $\mathrm{B}$, Nicolaides $\mathrm{KH}$, von Kaisenberg CS, Tomarev SI, et al. Prox1 is a marker of ectodermal placodes, endodermal compartments, lymphatic endothelium and lymphangioblasts. Anat Embryol (Berl). 2001 Nov;204(5):399-406. 
66. Andrade M. Lymphangiogenesis and genetics in lymphedemas: a review of the literature. J Vasc Bras. 2008;7(3):256-61.

67. Reis-Filho JS, Schmitt FC. Lymphangiogenesis in tumors: what do we know? Microsc Res Tech. 2003 Feb 1;60(2):171-80.

68. Harper SJ, Bates DO. VEGF-A splicing: the key to anti-angiogenic therapeutics? Nat Rev Cancer. 2008 Nov;8(11):880-7.

69. Takahashi H, Shibuya M. The vascular endothelial growth factor (VEGF)/VEGF receptor system and its role under physiological and pathological conditions. Clin Sci (Lond). 2005 Sep;109(3):227-41.

70. Zhang F, Tang Z, Hou X, Lennartsson J, Li Y, Koch AW, et al. VEGF-B is dispensable for blood vessel growth but critical for their survival, and VEGF-B targeting inhibits pathological angiogenesis. Proc Natl Acad Sci U S A. 2009 Apr 14;106(15):6152-7.

71. Roskoski R, Jr. VEGF receptor protein-tyrosine kinases: structure and regulation. Biochem Biophys Res Commun. 2008 Oct 24;375(3):287-91.

72. Underiner TL, Ruggeri B, Gingrich DE. Development of vascular endothelial growth factor receptor (VEGFR) kinase inhibitors as antiangiogenic agents in cancer therapy. Curr Med Chem. 2004 Mar;11(6):731-45.

73. Camargo RS, Scafuri AG, de Tolosa EM, Ferreira EA. DNA image cytometric analysis of differentiated thyroid adenocarcinoma specimens. Am J Surg. 1992 Dec;164(6):640-5.

74. Camargo RS, Longatto Filho A, di Loreto C, Kanamura CT, Garcia EA. Clinicopathologic evaluation of thyroid tumors through p53 protein 
accumulation and proliferative activity measured using Ki-67 and PCNA monoclonal antibodies. A Folha Médica. 2002;121 (4):221-6.

75. Garcia EA, Simões K, Wakamatsu A, Ressio RA, Alves VA, LongattoFilho $A$, et al. Lymphatic vessel density and VEGF-C expression are significantly different among benign and malignant thyroid lesions. Endocr Pathol. 2010;21(2):101-7.

76. Toledo AC, . Cirurgia da glândula tireóide. In: Goffi, F. Técnica cirúrgica: bases anatômicas, fisiopatológicas e técnicas da cirurgia. Rio de Janeiro: Livraria Atheneu 1978.

77. DeLellis RA, Vlloyd R, Heitz PU, Eng C. World Health Organization classification of tumours pathology and genetics of tumours of endocrine organs. 2004.

78. Kononen J, Bubendorf L, Kallioniemi A, Barlund M, Schraml P, Leighton $\mathrm{S}$. Tissue microarrays for high-throughput molecular profiling of tumor specimens. Nat Med. 1998;4(7):844-7.

79. Weidner N. Current pathologic methods for measuring intratumoral microvessel density within breast carcinoma and other solid tumors. Breast Cancer Res Treat. 1995;36(2):169-80.

80. Longatto Filho A, Pinheiro C, Perreira SMM, Etlinger D, Moreira MAR, Jubé LF, et al. Lymphatic vessel density and ephitelial D2-40 immunoreactivity in pre-invasive lesions of the uterine cervix. Gynecologic Oncology. 2007;107(1):45-51.

81. Klein M, Picard E, Vignaud JM, Marie B, Bresler L, Toussaint B, et al. Vascular endothelial growth factor gene and protein: Strong expression in thyroiditis and thyroid carcinoma. Journal of Endocrinology. 1999;161:41-9. 
82. Ferrara N, Davis-Smyth $\mathrm{T}$. The biology of vascular endothelial growth factor. Endocrine Reviews. 1997;18(1):4-25.

83. Jebreel A, England J, Bedford K, Murphy J, Karsai L, Atkin S. Vascular endothelial growth factor (VEGF), VEGF receptors expression and microvascular density in benign and malignant thyroid diseases. Int $J$ Exp Pathol. 2007;88(4):271-7.

84. Ramsden JD. Angiogenesis in the thyroid gland. $J$ Endocrinol. 2000;166(3):475-80.

85. Klein M, Catargi B. VEGF in physiological process and thyroid disease. Ann Endocrinol. 2007;68(6):438-48.

86. Klein M, Brunaud L, Muresan M, Barbé F, Marie B, Sapin R, et al. Recombinant human thyrotropin stimulates thyroid angiogenesis in vivo. Thyroid. 2006;16(6):531-6.

87. Cohen T, Nahari D, Cerem LW, Neufeld G, Levi BZ. Interleukin 6 induces the expression of vascular endothelial growth factor. $J \mathrm{Biol}$ Chem. 1996;271(2):736-41.

88. Nisato RE, Tille JC, Pepper MS. Lymphangiogenesis and tumor metastasis. Thromb Haemost. 2003;90(4):591-7.

89. Longatto-Filho A, Pinheiro C, Ferreira L, Scapulatempo C, Alves VA, Baltazar F, et al. Peritumoural, but not intratumoural, lymphatic vessel density and invasion correlate with colorectal carcinoma poor-outcome markers. Virchows Arch. 2008;452(2):133-8.

90. Stacker SA, Caesar C, Baldwin ME, Thornton GE, Williams RA, Prevo $\mathrm{R}$, et al. VEGF-D promotes the metastatic spread of tumor cells via the lymphatics. Nat Med. 2001;7(2):186-91. 
91. Vieira JM, Santos SC, Espadinha C, Correia I, Vag T, Casalou C, et al. Expression of vascular endothelial growth factor (VEGF) and its receptors in thyroid carcinomas of follicular origin: a potential autocrine loop. Eur J Endocrinol. 2005;153(5):701-9.

92. Heloterä H, Alitalo K. The VEGF family, the inside story. Cell. 2007;24(4):591-2.

93. Carrillo SPE, Arias FC, Caso PE, Molina MGM, Hernández SI, Trueba $\mathrm{MI}$, et al. Prognostic significance of the expression of vascular endothelial growth factors $A, B, C$, and D and their receptors $R 1, R 2$, and R3 in patients with nonsmall cell lung cancer. Cancer. 2009;115(8):1701-12.

94. Bunone G, Vigneri P, Mariani L, Butó S, Collini P, Pilotti S, et al. Expression of angiogenesis stimulators and inhibitors in human thyroid tumors and correlation with clinical pathological features. Am J Pathol. 1999;155(6):1967-76.

95. Fenton C, Patel A, Dinauer C, Robie DK, Tuttle RM, Francis GL. The expression of vascular endothelial growth factor and the type 1 vascular endothelial growth factor receptor correlate with the size of papillary thyroid carcinoma in children and young adults. Thyroid. 2000;10(4):349-57.

96. Kilicarslan AB, Ogus M, Arici C, Pestereli HE, Cakir M, Karpuzoglu G. Clinical importance of vascular endothelial growth factor (VEGF) for papillary thyroid carcinomas. APMIS. 2003;111(3):439-43.

97. Lennard CM, Patel A, Wilson J, Reinhardt B, Tuman C, Fenton C, et al. Intensity of vascular endothelial growth factor expression is associated with increased risk of recurrence and decreased disease-free survival in papillary thyroid cancer. Surgery. 2001;129(5):552-8. 
98. Huang SM, Lee JC, Wu TJ, Chow NH. Clinical relevance of vascular endothelial growth factor for thyroid neoplasms. World $J$ Surg. 2001;25(3):302-6.

99. Salven $P$, Lymboussaki $A$, Heikkilä $P$, Jääskela-Saari $H$, Enholm $B$, Aase K, et al. Vascular endothelial growth factors VEGF-B and VEGF-C are expressed in human tumors. Am J Pathol. 1998;153(1):103-8.

100. Ivy SP, Wick JY, Kaufman BM. An overview of small-molecule inhibitors of VEGFR signaling. Nat Rev Clin Oncol. 2009;6(10):569-79.

101. Deshpande HA, Gettinger S, Sosa JA. Axitinib: The evidence of its potential in the treatment of advanced thyroid cancer. Core Evid. 2010;15(4):43-8.

102. Sherman SI. Tyrosine kinase inhibitors and the thyroid. Best Pract Res Clin Endocrinol Metab. 2009;23(6):731-22.

103. Turner HE, Harris AL, Melmed S, Wass JA. Angiogenesis in endocrine tumors. Endocr Rev. 2003;24(5):600-32.

104. Soh EY, Duh QY, Sobhi SA, Young DM, Epstein HD, Wong MG, et al. Vascular endothelial growth factor expression is higher in differentiated thyroid cancer than in normal or benign thyroid. $J$ Clin Endocrinol Metab. 1997;82(11):3741-7.

105. Koehne P, Willam C, Strauss E, Schindler R, Eckardt KU, Bührer C. Lack of hypoxic stimulation of VEGF secretion from neutrophils and platelets. Am J Physiol Heart Circ Physiol. 2000;279(2):817-24.

106. Giorgadze TA, Baloch ZW, Pasha T, Zhang PJ, Livolsi VA. Lymphatic and blood vessel density in the follicular patterned lesions of thyroid. Mod Pathol. 2005;18(11):1424-31. 
107. Segal K, Shpitzer T, Feinmesser M, Stern $Y$, Feinmesser R. Angiogenesis in follicular tumors of the thyroid. $J$ Surg Oncol. 1996;63:95-8.

108. Akslen LA, Livolsi VA. Increased angiogenesis in papillary thyroid carcinoma but lack of prognostic importance. Hum Pathol. 2000;31(4):439-42.

109. Xie K, Wei D, Shi Q, Huang S. Constitutive and inducible expression and regulation of vascular endothelial growth factor. Cytokine \& Growth Factor Reviews. 2004;15 297-324. 
APÊNDICE 
ISSN 1046-3976, Volume 21, Number 2

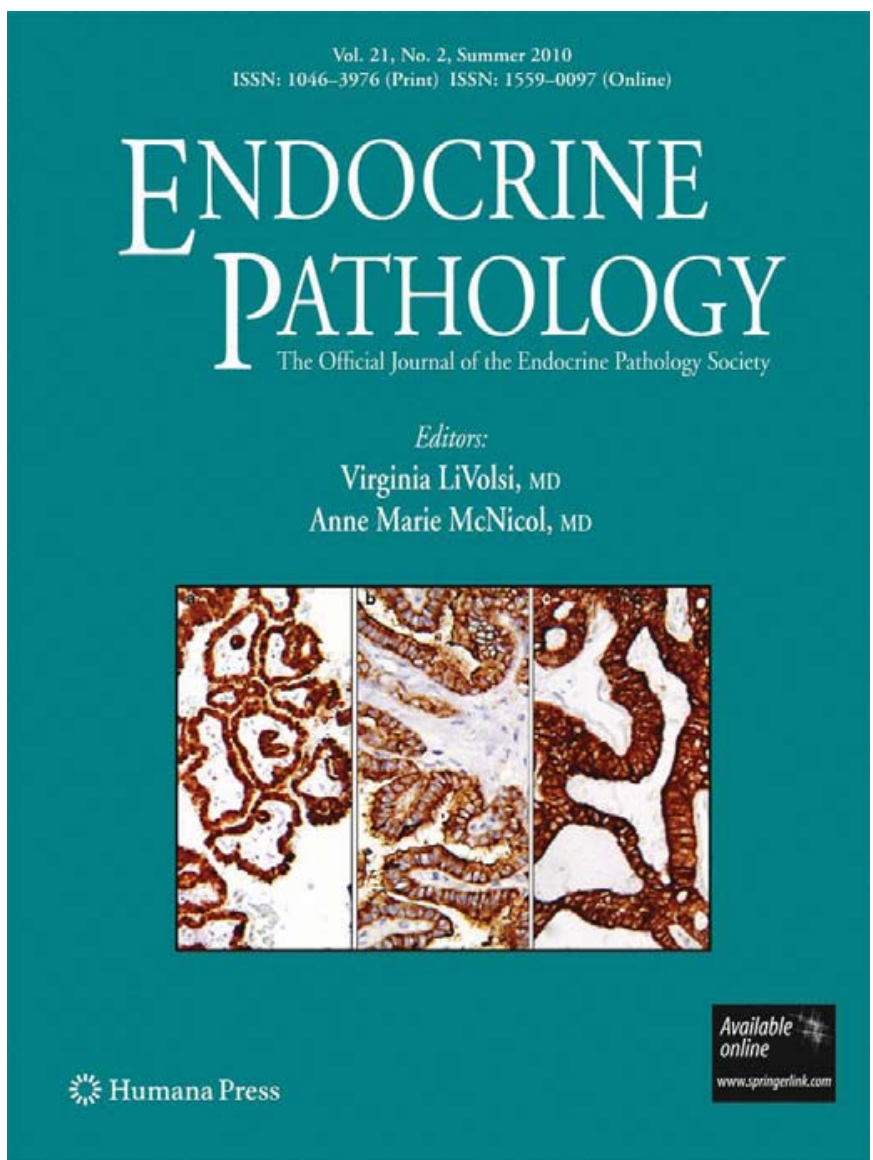

This article was published in the above mentioned Springer issue. The material, including all portions thereof, is protected by copyright; all rights are held exclusively by Springer Science + Business Media.

The material is for personal use only; commercial use is not permitted.

Unauthorized reproduction, transfer and/or use may be a violation of criminal as well as civil law. 


\title{
Lymphatic Vessel Density and VEGF-C Expression are Significantly Different Among Benign and Malignant Thyroid Lesions
}

\author{
Eduardo Anselmo Garcia • Kleber Simões • Alda Wakamatsu • \\ Rodrigo Albergaria Ressio • Venâncio Avancini Ferreira Alves • \\ Adhemar Longatto-Filho • Roberto Souza Camargo
}

Published online: 23 March 2010

(C) Springer Science+Business Media, LLC 2010

\begin{abstract}
Thyroid cancer is the most frequent endocrine neoplasia worldwide. The route for metastasis and locoregional invasion preferentially occurs by lymphatic vessels. For this reason, the assessment of lymphatic vessel density (LVD) is supposed to represent both a prognostic parameter and also a potential therapeutic target. In order to evaluate the value of LVD in benign and malignant thyroid
\end{abstract}

\section{E. A. Garcia}

Medical Research Laboratory LIM26,

Experimental Pathophysiology Program, School of Medicine,

University of São Paulo,

São Paulo, Brazil

e-mail: eduardoag@usp.br

\section{K. Simões}

Department of Pathology, School of Medicine,

University of São Paulo,

São Paulo, Brazil

A. Wakamatsu $\cdot$ R. A. Ressio $\cdot$ A. Longatto-Filho

Medical Research Laboratory LIM14, School of Medicine,

University of São Paulo,

São Paulo, Brazil

\section{A. F. Alves}

Medical Research Laboratory LIM14, Department of Pathology, School of Medicine, University of São Paulo,

São Paulo, Brazil

\section{A. Longatto-Filho}

Life and Health Sciences Research Institute (ICVS),

School of Health Sciences, University of Minho,

Braga, Portugal

R. S. Camargo $(\bowtie)$

Medical Research Laboratory LIM26, Department of Surgery,

School of Medicine, University of São Paulo,

Dr. Arnaldo Avenue, 455 ,

1246-903 São Paulo, Brazil

e-mail: robcamar@terra.com.br lesions, we analyzed 110 thyroidectomy specimens using D240, a specific marker for lymphatic vessels and vascular endothelial growth factor C (VEGF-C), the most potent molecule of lymphatic proliferation. LVD was significantly different between papillary and follicular carcinomas in total $(p=0.045)$ and peritumoral area $(p=0.042)$. Follicular adenoma and follicular carcinoma showed an important difference of intra- $(p=0.019)$ and peritumoral $(p=0.033)$ LVD. VEGF-C was more markedly expressed in malignancies than in benignant lesions $(p=0.0001)$. Almost all cancers with high positive VEGF-C expression also exhibited increased peritumoral LVD $(p=0.049)$ when compared with the benignant lesions. Indeed, the high peritumoral LVD of malignant thyroid lesions is an important finding for surgery planning and supports the practice of total thyroidectomy in malignant thyroid neoplasm's since the lymphatic peritumoral vessels definitely are an escape path for tumor cells.

Keywords Lymphatic vessel density · VEGF-C · Thyroid . Thyroid cancer - Vascular endothelial growth factor. Tumor lymphangiogenesis

\section{Introduction}

Several mechanisms can mediate tumor cell dissemination, including hematogenous or lymphatic spread, local invasion, and direct seeding of body cavities or surfaces [1]. Increased lymphatic vessel density (LVD) is commonly associated with more aggressive behavior of malignant neoplasias which commonly escape from the primary site preferentially through lymphatic vessels due to its structural features without cohesive pericytes and thin endothelial wall [2]. Evaluation of lymphangiogenesis in cancer is relatively recent when compared to angiogenesis, mainly due to the lack of specific 
markers to identify lymphatic endothelial cells. D2-40 monoclonal antibody $[3,4]$ proved to be a selective marker for lymphatic endothelium, allowing identification of lymphatic vessels in formalin-fixed paraffin-embedded tissue, and consequently facilitating the studies of LVD in solid tumors [4, 5]. This is important because identification of lymphatic vessels on morphological basis alone is not consistent due to overlap with blood vessels capillaries [6-8]. Furthermore, adequate distinction between these two types of vessels is crucial for understanding the biology of interaction between tumors and neoformed vascular structures, potentially contributing to the specific tailoring of therapeutical strategies in the future. This approach highlights the important differences between blood and lymphatic vessels regarding their receptors, with potential effects on diagnostic evaluation as well as prognostication [2].

In recent years, a number of evidences provided better understanding of the role and the molecular mechanisms related to development and maintenance of lymphatic vessels and also their role in different pathologic conditions $[1,9]$. The vascular endothelial growth factor C (VEGF-C) is involved in proliferation and migration of endothelial cells, increased vascular permeability and lymphangiogenesis [10, 11]. VEGF-C and its receptor VEGFR-3 were shown to be essential to lymphatic vessels development in embryos [12] and in the maintenance of lymphatic endothelial cells in adults [13]. Some reports showed VEGF-C expression in several types of human tumors and a correlation between VEGF-C expression in primary tumors and nodal metastasis $[8,14,15]$.

Thyroid carcinomas are the most frequent endocrine malignancy, mainly affecting women, with an estimated 37,200 new cases and 1,630 deaths due to the thyroid cancer in United State of America in 2009 [16]. Most thyroid tumors follow an indolent clinical course with favorable prognosis [17-20]. Although it has been already well characterized that metastatic dissemination differs between papillary and follicular carcinoma [18, 21], studies on differential distribution of these two types of vascular structures in common benign and malignant thyroid lesions are relatively scant in literature. LVD and expression of VEGF-C in malignant and benign thyroid lesions are poorly studied and are still far to be fully understood [21]. In addition, intra- and peritumoral LVD show different patterns and prognostic significance related to the tumor behavior in different types of tumors [22]. However, few data are available regarding LVD and VEGF-C expression in thyroid lesions, and for the majority of them, the results are conflicting [21,23].

The objective of the present study was to determine the LVD pattern assessed by D2-40 antibody in malignant and benignant thyroid lesions, exploring potential differences between LVD distributions among the different types of thyroid lesions and correlated them with VEGF-C expression and clinicopathological features.

\section{Materials and Methods}

The casuistic comprised a series of formalin-fixed, paraffinembedded tissues from 110 patients submitted to thyroidectomy. The frequency of different thyroid lesions was: 34 $(30.9 \%)$ goiters, $17(15.5 \%)$ thyroiditis, six $(5.5 \%)$ follicular adenomas, $49(44.5 \%)$ papillary carcinomas, and four (3.6\%) follicular carcinomas (none of them were classified as minimally invasive). The papillary carcinoma samples comprised 33 samples of papillary carcinoma of conventional form, 11 samples of follicular variant of papillary carcinoma, one sample of tall cell variant of papillary carcinoma and four samples of papillary microcarcinoma. For statistical purposes, all papillary carcinomas were grouped as a single type. All patients were submitted to surgical resection by the same surgeon (RSC) and the diagnoses were categorized according World Health Organization classification [24] by one of the authors (KSES).

Pathological features herein evaluated included macroscopic presentation, principal site of the tumor, histological type, status of resection margins, and lymph node status.

\section{Immunohistochemistry}

Thyroid tissue samples were analyzed for D2-40 immunohistochemical expression using monoclonal D2-40 clone (DAKO Corporation, Carpinteria, CA, USA) specific antibody. Comparisons of D2-40 expression in intra- and peritumoral neoplastic areas were quantified. Also, D2-40LVD from benign lesions as adenoma, goiter, and thyroiditis were evaluated.

The lymphatic molecular player VEGF-C was analyzed in all non-malignant and malignant cases with rabbit polyclonal anti-VEGF-C antibody (Zymed Laboratories, San Francisco, CA, USA). Slides from all 110 specimens were reviewed and mapped, and tissue microarrays were building using manual tissue arrayer (MTA-1 Beecher Instrument, Silver Spring, MD, USA). Representative areas of the thyroid lesions were selected and cores of $1.0 \mathrm{~mm}$ in diameter were twice sampled and arranged at $0.3 \mathrm{~mm}$, one from each other, in the recipient paraffin block. A database was build for every block produced, including the coordinates of each core and case of origin. The positive expressions of VEGF-C were semi-quantitatively assessed.

\section{D2-40 and VEGF-C Immunohistochemistry}

D2-40 and VEGF-C protocol followed Longatto-Filho et al. [25] recommendations with slight modifications. Brief- 
ly, deparaffinized and rehydrated sections were immersed in $0.01 \mathrm{M}$ citrate buffer $(\mathrm{pH} 6.0)$ and heated at $98^{\circ} \mathrm{C}$ for $20 \mathrm{~min}$ for epitope-antigen retrieval. Subsequently, endogenous peroxidase was blocked with $0.3 \%$ hydrogen peroxide in methanol. Primary antibody incubation step was done with 1:200 dilution for D2-40 and VEGF-C, overnight at $4^{\circ} \mathrm{C}$. The amplification method used was Novolink system (Novocastra Laboratories Ltd, Newcastle Upon Tyne, UK). Visualization was developed with 3,3'-diamino-benzidine (DAKO Corporation, Carpinteria, CA, USA) and counterstaining with Harris' hematoxylin (Merck, Dermstadt, Germany). Negative controls were obtained by omitting the primary antibody incubation step; and tonsil was used as positive controls.

\section{Immunohistochemical Evaluation}

Immunohistochemical reaction for D2-40 was considered positive when the staining decorated the cytoplasm of lymphatic endothelial cells. The evaluation was performed blindly and LVD was assessed as postulated by Weidner et al. [26] with slight modifications. LVD was defined as a single endothelial cell or a cluster of endothelial cells positive for D2-40, sitting around a visible lumen clearly separate from adjacent microvessels and from other connective tissue components. Additionally, as lymphatic vessels could generally appear as distorted and overlapped structures in cancer setting, the packed vessels were assumed as one lymphatic unit. Number of vessels was determined at $200 \times$ magnification, with the mean and median for ten fields calculated and defined as LVD.

Expression of VEGF-C by neoplastic and non-neoplastic samples was semi-quantified under $200 \times$ magnification, considering membrane and/or cytoplasmic staining of normal, follicular, or malignant thyroid cells. The evaluation was performed blindly and the tissue microarray spot of each sample were fully analyzed. The following grading system was used: negative (0) absence of expression, + positive staining with expression in up to $10 \%$ of cells, ++ positive expression in over $10 \%$ up to $25 \%$ of cells, +++ positive expression in over $25 \%$ up to $50 \%$ of cells, and ++++ positive expression in over $50 \%$ of cells. For statistical analyses purposes, VEGF-C expression was dichotomized in two categories: negative ( 0 to up $10 \%$ of positivity) and positive (over $10 \%$ of positive reaction).

\section{Statistic Analysis}

The data were obtained from the available information on patient's files and tissue samples revised. Accordingly, the statistics were based on these variables.

The relationship between D2-40 expression, VEGF-C, and clinicopathologic features were examined using Pearson's chi-square $\left(\chi^{2}\right)$ test or Fisher's exact test when appropriate and considered significant when $p<0.05$. The Mann-Whitney test was used for continuous variables.
Table 1 Summary of clinicopathologic features

\begin{tabular}{llll}
\hline & & Frequencies & Percent \\
\hline Gender $(n=110)$ & $\mathrm{M}$ & 23 & $21 \%$ \\
& $\mathrm{~F}$ & 87 & $79 \%$ \\
Age (years, $n=104)$ & $<45$ & 55 & $52.9 \%$ \\
& $\geq 45$ & 49 & $47.1 \%$ \\
Mean age $( \pm \mathrm{SD}, n=104)$ & & $45.9+14.9$ & \\
Diagnosis $(n=110)$ & Goiter & 34 & $30.9 \%$ \\
& Thyroiditis & 17 & $15.5 \%$ \\
& Follicular adenoma & 6 & $5.5 \%$ \\
& Papillary thyroid carcinoma & 49 & $44.5 \%$ \\
Capsular invasion $(n=35)$ & Follicular carcinoma & 4 & $3.6 \%$ \\
Vascular invasion $(n=44)$ & Present & 16 & $45.7 \%$ \\
Peri-thyroidal soft tissue compromise $(n=34)$ & Non-detected & 19 & $54.3 \%$ \\
& Present & 12 & $27.30 \%$ \\
Lymph node status $(n=35)$ & Non-detected & 32 & $72.70 \%$ \\
& Present & 6 & $17.6 \%$ \\
& Non-detected & 28 & $82.4 \%$ \\
& Negative & 21 & $60 \%$ \\
& Positive & 14 & $40 \%$ \\
\hline
\end{tabular}


Data were analyzed with Statistical Package of Social Sciences software, version 13.0.

\section{Results}

A total of 110 thyroidectomy specimens were evaluated. Women were 3.7-fold more likely to be affected than men (87 female and 23 male patients) and the mean age was
45.9 years old. Capsular invasion were present in 16 $(45.7 \%)$ and not detected in 19 (54.3\%) samples; vascular invasion were present in $12(27.3 \%)$ and not detected in 32 $(72.7 \%)$ samples; peri-thyroidal soft tissue compromise were present in six (17.6\%) and non-detected in $28(82.4 \%)$ samples; and lymph node status were positive in $14(40 \%)$ and negative $21(60 \%)$ samples (Table 1). The tumors were predominantly found in the right or in the left lobe, each one of them with similar frequencies: $32.7 \%$ and $30.8 \%$,

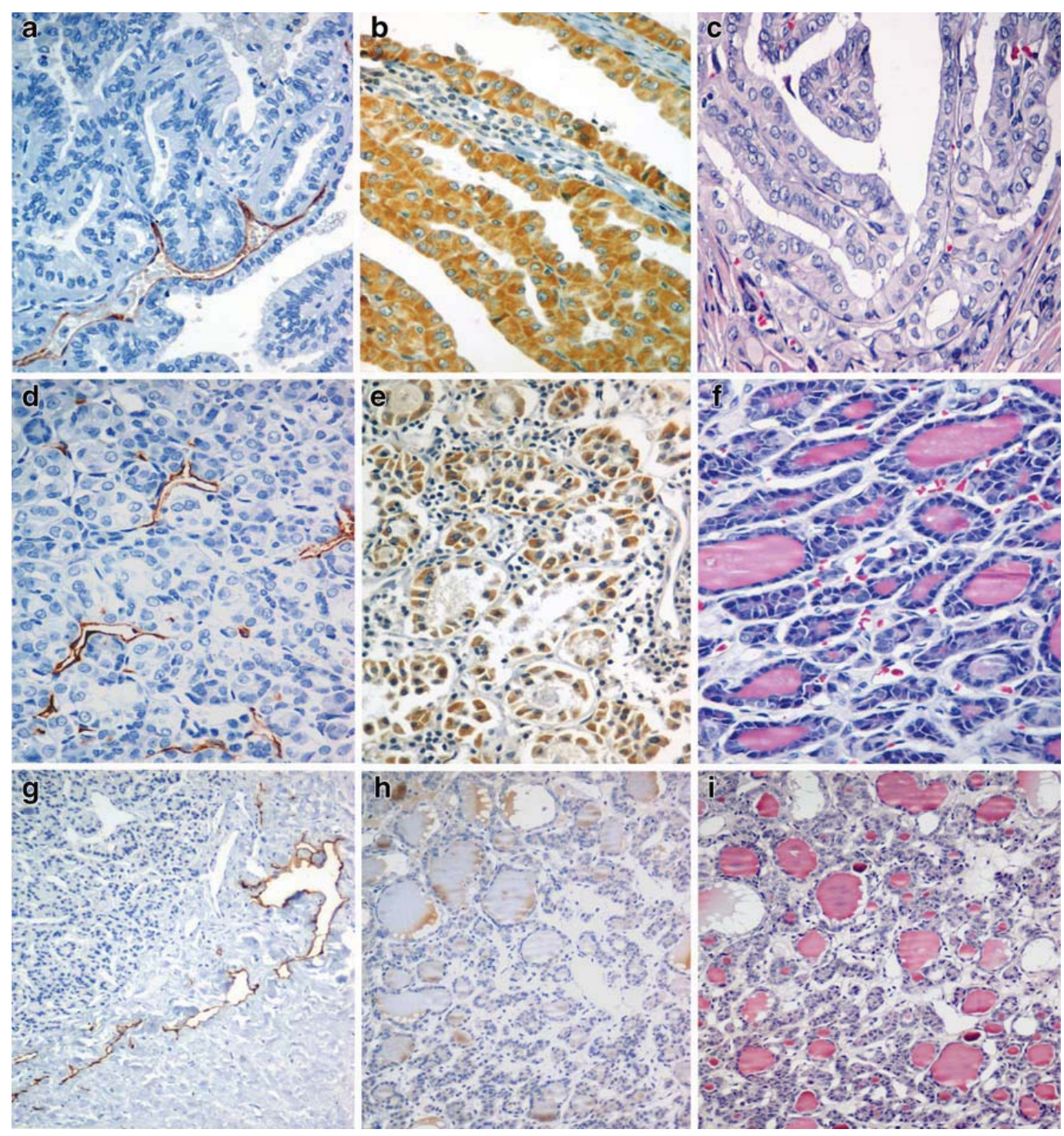

Fig. 1 The D2-40 antibody stains specifically intratumoral lymphatic endothelial cells in papillary carcinoma (a) $40 \times$ and follicular carcinoma (d) $40 \times$. The D2-40 antibody stains specifically peritumoral lymphatic endothelial cells in follicular carcinoma (g) 20×. The VEGF-C antibody strongly $(++++)$ and specifically stains tumoral cells in papillary carcinoma (b) $40 \times$ and follicular carcinoma (e) $40 \times$. VEGF-C antibody specifically weak (+) stain in goiter (h) $20 \times$. Hematoxylin and eosin (HE) staining of papillary carcinoma (c) 40X, follicular carcinoma (f) $40 \times$ and goiter (i) $20 \times$. These HE images are from the same samples represented in $\mathbf{b}$, $\mathbf{e}$, and $\mathbf{h}$, respectively 
Table 2 Total, intra- and peritumoral lymphatic vessel density

\begin{tabular}{lrcr}
\hline & $\begin{array}{l}\text { Total } \\
\text { mean } \pm \text { SD }\end{array}$ & $\begin{array}{l}\text { Intratumoral } \\
\text { mean } \pm \text { SD }\end{array}$ & $\begin{array}{r}\text { Peritumoral } \\
\text { mean } \pm \text { SD }\end{array}$ \\
\hline Goiter & $11.2 \pm 4.2$ & - & - \\
Thyroiditis & $10.3 \pm 5.2$ & - & - \\
Follicular adenoma & $6.8 \pm 2.8$ & $5.3 \pm 2.1$ & $8.0 \pm 3.5$ \\
Papillary thyroid carcinoma & $8.4 \pm 2.7$ & $7.0 \pm 3.0$ & $9.0 \pm 3.8$ \\
Follicular carcinoma & $12.2 \pm 4.1$ & $11.3 \pm 5.9$ & $12.3 \pm 1.9$ \\
\hline
\end{tabular}

respectively. The other cases affected right lobe, isthmus, and left lobe in different combinations, but none of these combinations were greater than $10 \%$.

The immunohistochemical expression of D2-40 and VEGF-C in thyroid lesions was analyzed in all samples as exemplified in Fig. 1.

Different lesions showed different LVD patterns as summarized in Table 2. Among neoplasm's, peritumoral LVDs mean were always higher when compared with the intratumoral LVD in the same group. When analyzed in peers, LVD showed significant differences between papillary and follicular carcinomas in total $(p=0.045)$ and peritumoral LVD $(p=0.042)$. Follicular adenoma and follicular carcinoma showed an important difference of intra $(p=0.019)$ and peritumoral $(p=0.033)$ LVD (Table 3).

Total, intratumoral or peritumoral LVDs did not differ according to the gender, age, vascular invasion, or lymph node status of patients, although the capsular invasion correlate with peritumoral LVD $(p=0.045)$.

The VEGF-C show different patterns of immunoreactivity in all samples and was markedly expressed in both papillary ( $80.9 \%$ positive) and follicular carcinoma (100\% positive) when compared to goiter ( $41.2 \%$ positive), thyroiditis $(62.5 \%$ positive), and follicular adenoma ( $16.7 \%$ positive, $p=0.0001$; Table 4). The more aggressive tumor subtypes, like the tall cell variant of papillary carcinoma, and almost all samples with high positive VEGF-C expression exhibit increased LVD when compared with the negative cases. However, statistical significance was found only when comparing VEGF-C expression with peritumoral LVD ( $p=0.049$, Table 5$)$. VEGF-C immunoreactivity did not differ according to the gender, age, vascular invasion, capsular invasion, or lymph node status.

\section{Discussion}

Thyroid cancer usually follows an indolent clinical course and is associated with good prognosis, with few examples emerging as aggressive tumors as anaplastic or medullary carcinomas [17-19]. Papillary carcinomas generally shows good prognosis whereas follicular and some papillary subtypes have more aggressive behavior [27]. Increased lymphatic vessel density is assumed as one of the most important parameters associated to the aggressive behavior of malignant tumors [22]. Nevertheless, we failed to corroborate this rationale because papillary carcinoma and benign lesions showed similar LVD, comparatively. However, the overall findings clearly demonstrated that thyroid lesions have different LVDs, which opens a new exciting view to explore the differences between them based on specific lymphatic vessels development. Remarkably, we identified a significant difference in LVD between follicular adenoma and follicular carcinoma. This is important because it is well-known that this discrimination is difficult to be assessed by morphological criteria, the carcinoma diagnosis is only confirmed if truly capsular invasion is observed [28, 29]. Our results are confirmed, in part, by those reported by Giorgadze and colleagues that showed that LVD determination can be a valuable tool to discriminate follicular lesions of thyroid gland [21]. Of note, we have to stress that peritumoral and intratumoral LVD were significantly different between these neoplasms ( $p=0.033$ and 0.019 , respectively), but not the total LVD ( $p=$ 0.054 ), probably due to the very limited number of cases.

Additionally, we also investigated the expression of VEGF-C, one of the major players in lymphatic vessel
Table 3 Total, intra- and peritumoral LVD comparison by diagnosis

\begin{tabular}{|c|c|c|c|c|c|c|}
\hline & \multicolumn{2}{|l|}{ LVD total } & \multicolumn{2}{|l|}{ LVD intra } & \multicolumn{2}{|l|}{ LVD peri } \\
\hline & Mean \pm SD & $P$ value & Mean \pm SD & $P$ value & Mean \pm SD & $P$ value \\
\hline \multirow[t]{2}{*}{ Papillary thyroid carcinoma } & $8.4 \pm 2.7$ & & $7.0 \pm 3.0$ & & $9.0 \pm 3.8$ & \\
\hline & & $0.045^{*}$ & & 0.083 & & $0.042 *$ \\
\hline Follicular carcinoma & $12.2 \pm 4.1$ & & $11.3 \pm 5.9$ & & $12.3 \pm 1.9$ & \\
\hline \multirow[t]{2}{*}{ Follicular adenoma } & $6.8 \pm 2.8$ & & $5.3 \pm 2.1$ & & $8.0 \pm 3.5$ & \\
\hline & & 0.054 & & $0.019^{*}$ & & $0.033 *$ \\
\hline Follicular carcinoma & $12.2 \pm 4.1$ & & $11.3 \pm 5.9$ & & $12.3 \pm 1.9$ & \\
\hline
\end{tabular}


Table 4 VEGF-C expression in different thyroid lesions

\begin{tabular}{lccc}
\hline & \multicolumn{2}{l}{ VEGF-C } & \\
\cline { 2 - 4 } & Negative $(<10 \%)$ & Positive $(>10 \%)$ & $P$ value \\
\hline Goiter $(n=34)$ & $58.8 \%$ & $41.2 \%$ & $0.0001 *$ \\
Thyroiditis $(n=16)$ & $37.5 \%$ & $62.5 \%$ & $16.7 \%$ \\
Follicular adenoma & $83.3 \%$ & & \\
$(n=6)$ & & $80.9 \%$ & $100.0 \%$ \\
Papillary thyroid carcinoma $(n=47)$ & $19.1 \%$ & & \\
Follicular carcinoma $(n=4)$ & $0.0 \%$ & & \\
\hline
\end{tabular}

sprout, to verify some particular differences among the thyroid lesions we studied. Of interest, we also hypothesized that the well recognized more aggressive behavior of thyroid tumors in males could be attributed to the enhanced LVD stimulated by augmented VEGF-C expression in these patients; however, this was not supported by our results since LVD and VEGF-C expression for both genders had similar values.

Peritumoral LVDs did not correlate with vascular invasion or other clinicopathological features indicative of aggressiveness such as lymph node metastases, which is believed to be associated to the good prognoses in general imputed for thyroid cancer [23]. However, we observed that capsular invasion was related to higher peritumoral LVD $(p=0.045)$. This result endorses previous reports with solid tumors where peritumoral, but not intratumoral LVD is associated with more aggressive cancer behavior [4, 7]. Additionally, intratumoral lymphangiogenesis is presumed to form large, weak, and distorted new vessels, implicating a new formed fragile vascular network. Thus, it is reasonable to assume that peritumoral LVD is more tailored to provide competent routes for malignant cells escape. Functional lymphatics at the tumor margin is believed to be sufficient for promoting metastasis by offering a large area for tumor cell escape [4].This fact was clearly evidenced by Padera and colleagues which studied the influence of tumoral pressure in intratumoral lymphatic vessels, showing that these vessels were collapsed and unable to support the malignant cells spread [30].

Our results showed that peritumoral LVD was significantly higher in follicular carcinoma than in papillary carcinoma $(p=0.042)$, but no other conjecture could be extract of this limited observation.

The significance of VEGF-C expression in the thyroid neoplasms is contentious [23]. Despite that, we found some interesting correlations which indicate VEGF-C as an important feature contributing to thyroid neoplasm development. Notably, VEGF-C was markedly expressed in both papillary and follicular carcinoma, which significantly separated malignant from benign lesions. Parallel to this statement, it was also important to highlight that follicular carcinoma importantly expressed more VEGF-C than its benign counterpart, follicular adenoma. The majority of malignant cases with increased LVD also exhibited high VEGF-C expression, with statistical significance in peritumoral LVD $(p=0.049)$. A higher VEGF-C immunoreactivity at the tumor borders have been demonstrated in several types of cancers [4, 31, 32]. This finding suggests that VEGF-C expressed by thyroid tumor cells at the invasive front can directly drive peritumoral lymphangiogenesis [7]. This assumption, however, was not ratified in the present work. Additional data with whole tumor samples of more robust casuistic of thyroid lesions would clarify this interesting point. The contradicting data about LVD and thyroid carcinomas maybe due to differences samples selection and LVD quantification methodology. Also, these contentious results might be related to the inherent complex mechanisms of lymphangiogenesis and metastatic spread. Further studies evaluating the molecular biology involved with lymphatic vascularization network in thyroid tumors progression should be conducted in order to clarify the differences herein observed.

Table 5 Comparison between VEGF-C expression and LVD

\begin{tabular}{|c|c|c|c|c|c|c|}
\hline \multirow[t]{2}{*}{ VEGF-C } & \multicolumn{2}{|l|}{ LVD total } & \multicolumn{2}{|l|}{ LVD intra } & \multicolumn{2}{|l|}{ LVD peri } \\
\hline & Mean \pm SD & $P$ value & Mean \pm SD & $P$ value & Mean \pm SD & $P$ value \\
\hline Negative $(<10 \%)$ & $90.9 \pm 439.2(n=40)$ & 0.246 & $61.6 \pm 289.0(n=14)$ & 0.303 & $75.4+414.6(n=14)$ & $0.049^{*}$ \\
\hline Positive $(>10 \%)$ & $99.5 \pm 361.5(n=67)$ & & $73.9 \pm 356.0 \quad(n=43)$ & & $97.2 \pm 297.5(n=43)$ & \\
\hline
\end{tabular}


Acknowledgments We thank the supply of the histological samples by the histopathology laboratories of Sírio Libanês Hospital, Oswaldo Cruz Hospital CICAP, and Diagnóstika Laboratory and the technical support of the Medical Research Laboratories 14 (LIM-14) and 26 (LIM-26) of Faculty of Medicine of São Paulo University.

Conflict of interest The authors declare that there is no conflict of interest that would prejudice the impartiality of this scientific work.

\section{References}

1. Stacker SA, Achen MG, Jussila L, Baldwin ME, Alitalo K Lymphangiogenesis and cancer metastasis. Nat Rev Cancer 2:573-83, 2002.

2. Reis-Fillho JS, Schmitt FC. Lymphangiogenesis in tumors: what do we know? Microsc Res Techn 60:171-80, 2003.

3. Schacht V, Dadras SS, Johnson LA, Jackson DG, Hong YK, Detmar M. Up-regulation of the lymphatic marker podoplanin, a mucin-type transmembrane glycoprotein, in human squamous cell carcinomas and germ cell tumors. Am J Pathol 166:913-21, 2005.

4. Gombos Z, Xiamowei X, Chu CS, Zhang PJ, Acs G. Peritumoral lymphatic vessel density and vascular endothelial growth factor $\mathrm{C}$ expression in early-stage squamous cell carcinoma of the uterine cervix. Clin Cancer Res 11:8364-71, 2005.

5. Kahn HJ, Marks A. A new monoclonal antibody, D2- 40, for detection of lymphatic invasion in primary tumors. Lab Invest 82:1255-7, 2002

6. Van der Auwera I, Cao Y, Tille JC, et al. First international consensus on the methodology of lymphangiogenesis quantification in solid human tumours. Br J Cancer 95:1611-25, 2006.

7. Afonso J, Santos LL, Amaro T, Lobo F, Longatto-Filho A. The aggressiveness of urothelial carcinoma depends to a large extent on lymphovascular invasion. Histopathology 55:514-24, 2009

8. Beasley NJ, Prevo R, Banerji S, et al. Intratumoral lymphangiogenesis and lymph node metastasis in head and neck cancer Cancer Res 62:1315-20, 2002.

9. Alitalo K, Carmeliet P. Molecular mechanisms of lymphangiogenesis in health and disease. Cancer Cell 1:219-27, 2002.

10. Byrne AM, Bouchier-Hayes DJ, Harmey JH. Angiogenic and cell survival functions of vascular endothelial growth factor (VEGF). J Cell Mol Med 9(4): 777-94, 2005.

11. Yamazaki Y, Morita T. Molecular and functional diversity of vascular endothelial growth factors. Mol Divers. 10(4):515-27, 2006.

12. Karkkainen MJ, Haiko $P$, Sainio $K$, et al. Vascular endothelial growth factor $\mathrm{C}$ is required for sprouting of the first lymphatic vessels from embryonic veins. Nat Immunol 5:74-80, 2004.

13. Roskoski, R.J. Vascular endothelial growth factor (VEGF) signaling in tumor progression. Critical Reviews in Oncology Hematology 62:179-213, 2007.

14. Duff SE, Li C, Jeziorska M, Kumar S, Saunders MP, Sherlock D, O'Dwyer ST, Jayson GC. Vascular endothelial growth factors C and $\mathrm{D}$ and lymphangiogenesis in gastrointestinal tract malignancy. Br J Cancer 89:426-30, 2003.

15. Jussila L, Alitalo K. Vascular growth factors and lymphangiogenesis. Physiol Rev 82:673-700, 2002.
16. (http://www.cancer.gov/cancertopics/types/thyroid assessed 12 September, 2009).

17. Camargo RS, Maeda MYS, DI Loreto C, Shirata NK, Garcia EA, Longatto Filho A. Is AgNOR and DNA ploidy analysis useful for evaluating thyroid neoplasms? Analytical and Quantitative Cytology and Histology 27, 2005.

18. Kondo T, Ezzat S, Asa SL. Pathogenetic mechanisms in thyroid follicular-cell neoplasias. Nature Reviews Cancer 6:292-306, 2006

19. Lang BHH, Lo CY, Chan WF, Lam KY, Wan KY. prognostic factors in papillary and follicular thyroid carcinoma: their implications for cancer staging. Annals of Surgical Oncology 14:730-38, 2007.

20. Camargo RS, Scafuri AG, de Tolosa EM, Ferreira EA. DNA image cytometric analysis of differentiated thyroid adenocarcinoma specimens. Am J Surg 164(6): 640-5, 1992.

21. Giorgadze TA, Baloch ZW, Pasha T, Zhang PJ, LiVolsi VA: Lymphatic and blood vessel density in the follicular patterned lesions of thyroid. Modern Pathology 18:1424-31, 2005.

22. Longatto-Filho A, Pinheiro C, Ferreira L, Scapulatempo C, Alves VA, Baltazar F, Schmitt F. Peritumoural, but not intratumoural, lymphatic vessel density and invasion correlate with colorectal carcinoma poor-outcome markers. Virchows Arch 452(2):133-8, 2008

23. Torre GNL, Buley I, Wass JAH, Turner HE. Angiogenesis and lymphangiogenesis in thyroid proliferative lesions: relationship to type and tumor behavior. Endocrine-Related Cancer 13:931-44, 2006.

24. IARC WHO Classification of Tumours. Pathology and Genetics of Tumours of Endocrine Organs 3ed 8:8, 2004.

25. Longatto-Filho A, Pinheiro C, Pereira SM, Etlinger D, Moreira MA, Jubé LF, Queiroz GS, Baltazar F, Schmitt FC. Lymphatic vessel density and epithelial D2-40 immunoreactivity in preinvasive and invasive lesions of the uterine cervix. Gynecol Oncol 107(1):45-51, 2007

26. Weidner N, Semple JP, Welch WR, Folkman J. Tumor angiogenesis and metastasis - correlation in invasive breast carcinoma. $\mathrm{N}$ Engl J Med 324:1-8, 1991.

27. Fassnacht M, Kreissl MC, Weismann D, Allolio B. New targets and therapeutic approaches for endocrine malignancies. Pharmacol Ther 123:117-41, 2009

28. Camargo RS Cirurgia da glândula tireóide. In: Goffi. Técnica Cirúrgica - bases anatômicas, fisiopatológicas e técnica cirúrgica. 4ed. São Paulo Atheneu, pp 297-305, 1996.

29. Schlumberger MJ. Papillary and follicular thyroid carcinoma. New England Journal of Medicine 29:297-306, 1998.

30. Padera TP, Kadambi A, di Tomaso E, Carreira CM, Brown EB, Boucher Y, Choi NC, Mathisen D, Wain J, Mark EJ, Munn LL, Jain RK. Lymphatic metastasis in the absence of functional intratumor lymphatics. Science 7:296:1883-6, 2002.

31. Kurahara H,Takao S,Maemura K,Shinchi H,Natsugoe S, Aikou T. Impact of vascular endothelial growth factor-C and -D expression in human pancreatic cancer: its relationship to lymph node metastasis. Clin Cancer Res 10:8413-20, 2004.

32. Bono P, Wasenius VM, Heikkila P, Lundin J, Jackson DG, Joensuu H. High LYVE-1-positive lymphatic vessel numbers are associated with poor outcome in breast cancer. Clin Cancer Res 10:7144-9, 2004. 